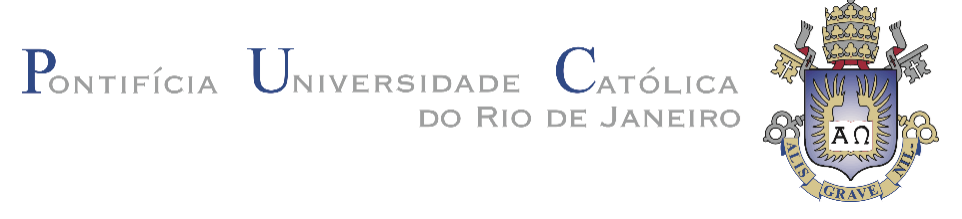

Rodrigo Araújo Gonçalves

\title{
Estudo da variação temporal e espacial de metais tóxicos em sedimentos da Baía de Sepetiba, RJ, Brasil
}

Tese de Doutorado

Tese apresentada ao Programa de Pós-graduação em Química da PUC-Rio como requisito parcial para obtenção do grau de Doutor em Química.

Orientador: Prof. José Marcus de Oliveira Godoy

Rio de Janeiro 
Estudo da variação temporal e espacial de metais tóxicos em sedimentos da Baía de Sepetiba, RJ, Brasil.

Tese apresentada como requisito parcial para obtenção do grau de Doutor pelo Programa de PósGraduação em Química da PUC-Rio. Aprovada pela Comissão Examinadora abaixo assinada.

Prof. José Marcus de Oliveira Godoy

Orientador

Departamento de Química - PUC-Rio

Prof. Luiz Drude de Lacerda

UFC

Prof. Carlos Eduardo de Rezende

UENF

Prof. Sergio Felipe Jerez Veguería

UFF

Prof. a Tatiana Dillenburg Saint'Pierre

Departamento de Química - PUC-Rio

Prof. Carlos German Massone Departamento de Química - PUC-Rio

Prof. Márcio da Silveira Carvalho Coordenador Setorial do Centro Técnico Científico - PUC-Rio

Rio de janeiro, 31 de outubro de 2018 
Todos os direitos reservados. É proibida a reprodução total ou parcial do trabalho sem a autorização da universidade, do autor e do orientador.

\section{Rodrigo Araújo Gonçalves}

Graduou-se em Engenharia Química pela Universidade do Estado do Rio de Janeiro (UERJ) em 2007. Atualmente é químico na Central Analítica Padre Leopoldo Hainberger (CAPLH) da Pontifícia Universidade Católica do Rio de Janeiro (PUC-Rio), atuando intensamente na pesquisa e desenvolvimento em química analítica e em análises químicas.

Ficha Catalográfica

Gonçalves, Rodrigo Araújo

Estudo da variação temporal e espacial de metais tóxicos em sedimentos da Baía de Sepetiba, RJ, Brasil / Rodrigo Araújo Gonçalves; orientador: José Marcus de Oliveira Godoy. -2018.

211 f. : il. color. ; $30 \mathrm{~cm}$

Tese (doutorado) - Pontifícia Universidade Católica do Rio de Janeiro, Departamento de Química, 2018.

Inclui bibliografia

1. Química - Teses. 2. Metais tóxicos. 3. Sedimentos. 4. Baía de Sepetiba. 5. Datação com 210Pb. I. Godoy, José Marcus de Oliveira. II. Pontifícia Universidade Católica do Rio de Janeiro. Departamento de Química. III. Título. 
Aos meus amados pais Mariza e Rocir (in memorian) que nunca pouparam esforços na educação dos filhos. À minha esposa Sabrina e meus filhos Pedro Enrique e Ana Beatriz que, com muito amor e carinho, souberam me apoiar nesta etapa da vida. 


\section{Agradecimentos}

Primeiramente agradeço ao Professor José Marcus de Oliveira Godoy pela orientação, confiança e apoio.

Agradeço a minha esposa Sabrina pelo apoio e conforto nos momentos difícies, sempre disposta a ajudar dando força e incentivo nesta caminhada, muito obrigado meu amor.

Agradeço aos meus filhos, Pedro Enrique e Ana Beatriz, pela compreensão em muitos momentos em que lhes faltava um pouco de atenção e pela torcida que fizeram para "papai terminar de escrever o livro".

Faltam palavras para agradecer suficientemente ao meu pai Rocir, sempre atencioso e rigoroso com os estudos, e a minha mãe, Mariza, uma mulher batalhadora que, após a perda do marido, seguiu firme com os filhos, fazendo o melhor que podia, sempre muito atenta e carinhosa, apoiando incondicionalmete todas as minhas escolhas até chegar neste momento.

Agradeço ao amigo Douglas pela imensurável ajuda na realização deste trabalho e pelo apoio, incondicional, nos momentos difíceis.

Não posso deixar de agradecer à amiga Fátima, por toda boa vontade e por estar sempre pronta a ajudar.

Agradeço ao Professor Carlos Eduardo de Rezende, o Carlão, e a equipe do Laboratório de Ciências Ambientais da UENF, pela ajuda nas determinações isotópicas.

Agradeço ao Phelipe Almeida e à Aline Almeida, da empresa Ph Mar Consultoria Ambienal pela enorme colaboração nas campanhas de amostragem. Possuem uma equipe de trabalho sensacional, que não pouparam esforços e sempre estiveram disponíveis para ajudar, quaisquer que fossem os desafios.

Agradeço, de forma muito sincera, a colaboração e apoio dos queridos amigos Maurício, Alvaro, Pedro Henrique, Jefferson, Claudia Vega, Thiago e Jarol. Me desculpo com os que não estão aqui citados nominalmente, mas também fundamentais nessa jornada.

Agradeço ainda à PUC-Rio pela bolsa de isenção e aos professores do programa de pós graduação em química, que contribuiram para minha formação. 


\section{Resumo}

Gonçalves, Rodrigo Araújo; Godoy, José Marcus de Oliveira. Estudo da variação temporal e espacial de metais tóxicos em sedimentos da Baía de Sepetiba, RJ, Brasil. Rio de Janeiro, 2018. 211p. Tese de Doutorado Departamento de Química, Pontifícia Universidade Católica do Rio de Janeiro.

A Baía de Sepetiba localiza-se a $60 \mathrm{~km}$ da região metropolitana do Rio de Janeiro e proporciona, há séculos, a base econômica de divesas comunidades residentes ao longo de suas margens e ilhas. Seu pescado, além da subsistência, já foi amplamente usado para abastecimento de diversos mercados da região metropolitana. No entanto, nas últimas décadas a baía sofre com um intenso desenvolvimento industrial, com a instalação de várias grandes indústrias em seus arredores, como duas siderúrgicas, terminais navais para conteiners e, também, terminais de carga e descarga de minério de ferro e carvão, entre outros. Pode-se acrescentar a este cenário, um rápido adensamento demográfico, que se intensificou na década de 60 em consequência do estabelecimento de tais indústrias. A ausência de sistema de saneamento básico e infraestrutura para suprir a demanda populacional só tende a agravar as condições ambientais do sistema costeiro. Este trabalho teve como objetivo avaliar a qualidade do sedimento da Baía de Sepetiba, utilizando valores-guia de qualidade como parâmetros de comparação, verificar correlações entre os metais potencialmente tóxicos com outros parâmetros indicativos de qualidade, avaliar a variação nas taxas de sedimentação em diferentes pontos da baía e levantar um histórico de contaminação da região através de testemunhos datados com ${ }^{210} \mathrm{~Pb}$. Foram amostrados, entre junho e setembro de 2016, 38 pontos de sedimento superficial ao longo de toda a área da baía e 9 testemunhos sedimentares de até $90 \mathrm{~cm}$ de profundidade. As variáveis analisadas foram: carbono orgânico total (COT), nitrogênio total, $\delta^{13} \mathrm{C}, \delta^{15} \mathrm{~N}$, granulometria, metais tóxicos $(\mathrm{Zn}, \mathrm{Cd}, \mathrm{Pb}, \mathrm{Ni}, \mathrm{Cu}, \mathrm{Cr}$ e $\mathrm{Hg}$ ) e sulfetos ácidos voláteis / metais simultaneamente extraídos (AVS/SEM). A relação molar ( $[$ [SEM] - [AVS])/COT, que é o critério adotado pela USEPA como valor-guia de qualidade do AVS, apontou que o sedimento de fundo não apresenta toxicidade provável à organismos bentônicos. As concentrações de sulfetos e matéria orgânica encontrados nos sedimentos, juntamente às frações silte e argila, mostraram-se como importantes 
fases imobilizadoras dos metais. A concentração dos metais foi determinada pela técnica da Espectrometria de Massa com Fonte de Plasma Indutivamente Acoplado (ICP-MS). Aos resultados obtidos, aplicou-se a análise hierárquica de clusters (AHC), a fim de obter informações que descrevessem melhor a região estudada. Foi possível realizar a subdivisão da Baía de Sepetiba em 4 áreas e, também, observar hotspots, onde a concentração de um ou mais parâmetros se eleva substancialmente, destacando-se na área amostrada. Com relação aos valores-guia de qualidade de sedimento (ERL - "Effects Range-Low" e ERM - "Effects Range-Median") estabelecidos pela Administração Oceânica e Atmosférica Nacional (NOAA), órgão americano, a grande maioria dos pontos de amostragem apresentaram concentrações de $\mathrm{Zn}$ acima do ERM, numa faixa onde a probabilidade da ocorrência de efeitos adversos à vida marinha é maior do que $70 \%$. Foram observadas, em alguns pontos, concentrações de Cd entre o ERL e o ERM, onde a probabilidade de efeitos adversos é próxima de $36 \%$. Todos os demais metais determinados neste estudo apresentaram valores abaixo do ERL, com pouca probabilidade de serem tóxicos à vida marinha. As taxas de sedimentação foram determinadas a partir do método da datação com ${ }^{210} \mathrm{~Pb}$. Foram aplicados os modelos $\mathrm{CF}: \mathrm{CR}$ (constant flux:constant rate) e CRS (constant rate of supply), e os resultados da datação foram validados com base na variação da concentração de $\mathrm{Zn}$ e $\mathrm{Cd}$ ao longo dos testemunhos. Com base nos resultados obtidos, foi possível sugerir uma nova malha amostral a ser empregada no programa de monitoramento ambiental desenvolvido pelo Instituto Estadual do Ambiente (INEA). Essa nova malha proposta possui 19 pontos de amostragem, reduzindo pela metade a original utilizada pelo órgão ambiental.

\section{Palavras chave}

Metais tóxicos; Sedimentos; Baía de Sepetiba; Datação ${ }^{210} \mathrm{~Pb}$. 


\section{Abstract}

Gonçalves, Rodrigo Araújo; Godoy, José Marcus de Oliveira (Advisor). Study of temporal and spatial variation of toxic metals in sediments at Sepetiba Bay, RJ, Brazil. Rio de Janeiro, 2018. 211p. Tese de Doutorado Departamento de Química, Pontifícia Universidade Católica do Rio de Janeiro.

Sepetiba Bay is located $60 \mathrm{~km}$ from the metropolitan area of Rio de Janeiro and has for centuries provided the economic base of living communities along its banks and islands. Its fish, besides subsistence, has already been widely used to supply several markets in the metropolitan region. However, in the last decades it suffers with an intense industrial development, with the installation of many large industries in its surroundings, as two steel mills, naval terminals for containers and also terminals for loading and unloading iron ore and coal. It can be added to this scenario a rapid population density, which intensified in the 1960's as a result of the establishment of such industries. The absence of a basic sanitation system and infrastructure to supply the population demand only tends to aggravate the environmental conditions of the coastal system. The objective of this study was to evaluate the quality of Sepetiba Bay's sediments using quality guideline as comparison parameters, to verify correlations between potentially toxic metals with others parameters indicative of quality, to evaluate the variation in sedimentation rates at different points in the bay and raise a history of contamination of the region through the dated sediment core samples with ${ }^{210} \mathrm{~Pb}$. Between June and September of 2016, 38 points of superficial sediments were sampled along the entire bay area and 9 sediment core samples up to $90 \mathrm{~cm}$ depth. The analyzed variables were: total organic carbon (TOC), total nitrogen, $\delta 13 \mathrm{C}, \delta 15 \mathrm{~N}$, granulometry, toxic metals (Zn, $\mathrm{Cd}, \mathrm{Pb}, \mathrm{Ni}, \mathrm{Cu}, \mathrm{Cr}$ and $\mathrm{Hg}$ ) and acid volatile sulfides / simultaneously extracted metals (AVS/SEM). The molar ratio $\left(\sum[\mathrm{SEM}]-[\mathrm{AVS}]\right) / \mathrm{TOC}$, which is the criterion adopted by USEPA as a quality guideline for AVS, indicated that the bottom sediment does not present a probable toxicity to benthic organisms. The sulfides and organic matter concentrations found in the sediments together with the silt and clay fractions showed to be important immobilizing phases of the metals. The concentration of the metals was determined by the Inductively Coupled Plasma Mass Spectrometry (ICP-MS) technique. To the results obtained, the hierarchical 
cluster analysis (AHC) was applied, in order to obtain information that better described the studied region. It was possible to subdivide the Sepetiba Bay into 4 areas and also to observe hotspots where the concentration of one or more parameters increases substantially, standing out in the sampled area. In respect to sediment quality guidelines (ERL - "Effects Range-Low" e ERM - "Effects RangeMedian") established by the US National Oceanic and Atmospheric Administration (NOAA), the vast majority of sampling points showed concentrations of Zinc above the ERM, in a range where the probability of the occurrence of adverse effects to marine life is greater than 70\%. Cadmium concentrations between ERL and ERM were observed at some points, where the probability of adverse effects is close to $36 \%$. All other metals determined in this study presented values below the ERL, with low probability of being toxic to marine life. Sedimentation rates were determined by the $210 \mathrm{~Pb}$ dating method. The $\mathrm{CF}: \mathrm{CR}$ (constant flux:constant rate) and CRS (constant rate of supply) models were applied and the dating results were validated based on the $\mathrm{Zn}$ and $\mathrm{Cd}$ concentration variation throughout the sediment core. Based on the results obtained it was possible to suggest a new sampling grid to be used in the environmental monitoring program developed by the Instituto Estadual do Ambiente (INEA). The proposed grid has 18 sampling points, reducing by half the original used by the environmental agency.

\section{Keywords}

Toxic Metals; Sediments; Sepetiba Bay; ${ }^{210} \mathrm{~Pb}$ Dating. 


\section{Sumário}

1 Introdução 22

1.1 Contextualização 22

1.2 Objetivos 24

1.2.1 Objetivo Geral 24

1.2.2 Objetivos Específicos 24

2 Fundamentação Teórica 25

2.1 Área de Estudo - Baía de Sepetiba 25

2.2 Características ambientais de um estuário 26

2.3 Circulação das águas na Baía de Sepetiba 26

2.4 A natureza do problema da Baía de Sepetiba 28

2.5 Principais empreendimentos no entorno da Baía de Sepetiba 29

2.5.1 Porto de Itaguaí 29

2.5.2 Porto Sudeste 30

2.5.3 Base Militar para Construção de Submarinos 31

2.5.4 Companhia Mercantil Industrial Ingá 32

2.5.5 Ternium Brasil 34

2.6 Técnicas Analíticas Utilizadas 36

2.6.1 Espectrometria de Massas com Plasma Indutivamente Acoplado (ICP-MS) 36

2.6.2 Espectrometria de Absorção Atômica com Geração de Vapor Frio - Determinação de Mercúrio 38

2.6.3 Datação por ${ }^{210} \mathrm{~Pb} \quad 39$

2.6.4 Granulometria dos sedimentos 42

2.6.5 Sulfetos volatilizados por acidificação / Metais extraídos simultaneamente 45

2.6.6 Determinação Elementar e Isotópica de carbono e nitrogênio 46

2.7 Valores-Guia de Qualidade de Sedimentos de Ambientes Aquáticos (VGQS) 48 
2.7.1 VGQS de Partição 48

2.7.2 VGQS Empíricos $\quad 50$

2.7.3 Valores-Guia adotados no Brasil 51

3 Materiais e Métodos 53

3.1 Coleta de amostras 53

3.1.1 Amostragem de sedimento superficial 53

3.1.2 Amostragem de testemunhos sedimentares 56

3.2 Teor de Umidade no Sedimento 57

3.3 Determinação de Metais 58

3.4 Determinação de Mercúrio 60

3.5 Determinação de sulfetos ácidos voláteis / metais simultaneamente extraídos (AVS/SEM) 61

3.6 Datação das camadas sedimentares por ${ }^{210} \mathrm{~Pb} \quad 64$

3.7 Determinação granulométrica 66

3.8 Determinação elementar e isotópica de carbono e nitrogênio 67

4 Resultados e Discussão 68

4.1 Sedimentos Superficiais $\quad 68$

4.1.1 Determinação de Umidade 68

4.1.2 Análise Granulométrica 69

4.1.3 Determinação de carbono orgânico, carbono e nitrogênio totais e suas composições isotópicas 70

4.1.4 Sulfetos ácidos voláteis / metais simultaneamente extraídos (AVS/SEM) 73

4.1.5 Determinação de Metais Totais $\quad 75$

4.1.6 Integração dos Resultados (Sedimentos Superficiais) 81

4.1.6.1 Relação entre mercúrio, cobre e sulfeto (AVS) 83

4.1.6.2 Variação temporal das concentrações de mercúrio, zinco e cádmio 85

4.1.6.3 Análise de Cluster - Método de Ligação de Ward 88

4.2 Testemunhos Sedimentares 94

4.2.1 Avaliação Preliminar dos Testemunhos 94

4.2.1.1 Determinação de umidade 95 
4.2.1.2 Determinação de Metais Totais 96

4.2.1.3 Concentração de Zn e Cd nos perfis sedimentares 97

4.2.2 Datação de sedimentos com ${ }^{210} \mathrm{~Pb} \quad 101$

$\begin{array}{ll}\text { 4.2.2.1 Testemunho T-8 } & 101\end{array}$

4.2.2.2 Testemunho T-13 102

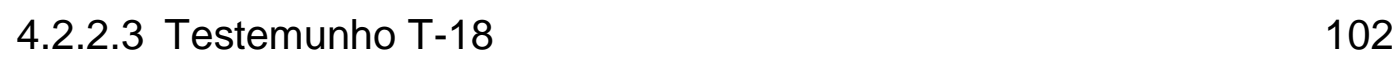

4.2.2.4 Testemunho T-19 103

$\begin{array}{ll}\text { 4.2.2.5 Testemunho T-26 } & 104\end{array}$

$\begin{array}{ll}\text { 4.2.2.6 Testemunho T-28 } & 105\end{array}$

4.2.3 Validação da datação com ${ }^{210} \mathrm{~Pb} \quad 106$

$\begin{array}{ll}\text { 4.2.4 Concentração de Mercúrio } & 110\end{array}$

5 Conclusão 112

6 Referências bibliográficas $\quad 115$

$\begin{array}{lr}\text { ANEXO A - Umidade } & 125\end{array}$

ANEXO B - Granulometria $\quad 127$

$\begin{array}{ll}\text { ANEXO C - Carbono e Nitrogênio } & 165\end{array}$

$\begin{array}{ll}\text { ANEXO D - AVS / SEM } & 166\end{array}$

$\begin{array}{lr}\text { ANEXO E - Metais Totais } & 168\end{array}$

ANEXO F - Datação com ${ }^{210} \mathrm{~Pb} \quad 201$

$\begin{array}{ll}\text { ANEXO G - Perfis Sedimentares } & 207\end{array}$ 


\section{Lista de figuras}

Figura 1: Imagem de satélite da baía de Sepetiba, Google Earth

Figura 2: Pluma formada pelo aporte de sedimentos finos na Baía de Sepetiba oriunda da bacia hidrográfica do entorno

Figura 3: Porto de Itaguaí

29

Figura 4: Píer do Porto Sudeste

Figura 5: Rejeitos de metalurgia abandonados pela Ingá Mercantil

Figura 6: Esquema estrutural de um espectrômetro de massa com fonte de plasma indutivamente acoplado (ICP-MS)

Figura 7: Série do ${ }^{238} \mathrm{U}$ : do ${ }^{226} \mathrm{Ra}$ ao ${ }^{210} \mathrm{~Pb}$. São indicadas as meiasvidas dos radionuclídeos (Argollo, 2001).

Figura 8: Dinâmica do ${ }^{210} \mathrm{~Pb}$ no meio ambiente (Lima, 1996).

Figura 9: Distribuição geográfica dos pontos de amostragem de sedimento superficial ao longo da Baía de Sepetiba.

Figura 10: Draga Petersen utilizada na coleta dos sedimentos

Figura 11: Distribuição dos pontos de amostragem de testemunhos sedimentares ao longo da Baía de Sepetiba.

Figura 12: Amostrador gravitacional de testemunhos e acessório para subdivisão das camadas

Figura 13: Aparato utilizado para a geração/adsorção do $\mathrm{H}_{2} \mathrm{~S}$

Figura 15: Teores de umidade nos pontos de amostragem de sedimento superficial

Figura 16: Características granulométricas \% de Argila, Silte e Areia na Baía de Sepetiba 
Figura 17: Superfície de resposta para a composição granulométrica \% de silte+argila

Figura 18: Teor de carbono orgânico (\%) em sedimentos superficiais da Baía de Sepetiba

Figura 19: COT, $\delta^{13} \mathrm{C}$, razão $\mathrm{C} / \mathrm{N}$, e $\delta^{15} \mathrm{~N}$ em função do ponto de amostragem.

Figura 20: Superfície de resposta obtida para concentração molar de sulfetos volatilizáveis por acidificação.

Figura 21: Superfície de resposta obtida para o somatório das concentrações molares de SEM

Figura 22: Superfície de resposta obtida para relação $\Sigma$ SEM/AVS na baía de Sepetiba.

Figura 23: Superfície de resposta para concentrações de Zn na baía de Sepetiba

Figura 24: Superfície de resposta para concentrações de $\mathrm{Pb}$ na baía de Sepetiba

Figura 25: Superfície de resposta para concentrações de Cu na baía de Sepetiba

Figura 26: Superfície de resposta para concentrações de Cd na baía de Sepetiba

Figura 27: Superfície de resposta para concentrações de Cr na baía de Sepetiba

Figura 28: Superfície de resposta para concentrações de Ni na baía de Sepetiba

Figura 29: Superfície de resposta para concentrações de $\mathrm{Hg}$ na baía de Sepetiba

Figura 30: Correlação entre $\mathrm{Hg}(\mathrm{a})$ / Cu (b) e sulfetos volatilizáveis por acidificação (AVS) em sedimentos superficiais da Baía de Sepetiba. 
Figura 31: Variação percentual da concentração atual de $\mathrm{Hg}$ em sedimento superficial da baía de Sepetiba, escala relativa à concentração obtida em 2001.

Figura 32: Variação percentual da concentração atual de $\mathrm{Zn}$ em sedimento superficial da baía de Sepetiba, escala relativa à concentração obtida em 2001.

Figura 33: Variação percentual da concentração atual de Cd em sedimento superficial da baía de Sepetiba, escala relativa à concentração obtida em 2001.

Figura 34: Dendrograma da análise de cluster pelo método de ligação de Ward

Figura 35: Grupos formados após a seleção do nível 3 do dendrograma como distância de corte

Figura 36: Malha amostral proposta para monitoramento ambiental da Baía de Sepetiba

Figura 37: Diagramas de caixa (box-plot), metais $\mathrm{Zn}, \mathrm{Cd}, \mathrm{Cr}, \mathrm{Ni}, \mathrm{Pb}$, $\mathrm{Cu}$ e $\mathrm{Hg}$ organizados em 4 grupos de similaridade. Faixas azul e vermelha - níveis 1 e 2 do CONAMA 454/12 respectivamente.

Figura 38: Teor de água nas camadas oriundas do fatiamento dos testemunhos sedimentares

Figura 39: Perfis de concentração de $\mathrm{Zn}$ versus profundidade em diferentes pontos da Baía de Sepetiba, a faixa vermelha indica o nível $2\left(410 \mathrm{mg} \mathrm{kg}^{-1}\right)$ da resolução CONAMA 454/12

Figura 40: Perfis de concentração de Cd versus profundidade em diferentes pontos da Baía de Sepetiba, a faixa vermelha indica o nível $1\left(1,2 \mathrm{mg} \mathrm{kg}^{-1}\right)$ da resolução CONAMA 454/12

Figura 41: Testemunho T-13 - ${ }^{210} \mathrm{~Pb}_{\text {exc }}$ versus massa acumulada

Figura 42: Testemunho T-18 - ${ }^{210} \mathrm{~Pb}$ exc versus massa acumulada 
Figura 44: Testemunho T-26 - profundidade média versus calendário anual 104

Figura 45: Testemunho T-28 $-{ }^{210} \mathrm{Pbexc}$ versus massa acumulada 106

Figura 46: Idade versus concentrações de $\mathrm{Zn}$ e $\mathrm{Cd}$ para os testemunhos T-13, T-18, T-19, T-26 e T-28 108

Figura 47: Variação temporal de Hg nos testemunhos T-13, T-18 110

Figura 48: Idade versus concentração de níquel, chumbo, cobre e cromo, testemunho T-13

Figura 49: Idade versus concentração de níquel, chumbo, cobre e cromo, testemunho T-18

Figura 50: Idade versus concentração de níquel, chumbo, cobre e cromo, testemunho T-19

Figura 51 Idade versus concentração de níquel, chumbo, cobre e cromo, testemunho T-28

Figura 52: Idade versus concentração de níquel, chumbo e cromo, testemunho T-26 


\section{Lista de tabelas}

Tabela 1: Classificação Granulométrica, adaptada de ABNT NBR $6502 / 95$

Tabela 2: Níveis de classificação de metais em sedimentos, CONAMA $454 / 12$

Tabela 3: Coordenadas geográficas das estações de amostragem de sedimentos superficiais.

Tabela 4: Coordenadas geográficas das estações de amostragem de testemunhos sedimentares

Tabela 5: Limites de detecção obtidos para SEM

Tabela 6: Limites de detecção obtidos

Tabela 7: Concentrações de metais encontradas no MRC MESS-3 e cálculo de recuperação.

Tabela 8: Concentrações médias de metais no sedimento superficial e valores-guia CONAMA 454/12

Tabela 9: Coeficientes de correlação de Pearson

Tabela 10: Concentrações máximas de Zn e Cd em testemunhos e data em que estes valores foram alcançados

Tabela 11: \% de umidade em sedimentos superficiais da Baía de Sepetiba

Tabela 12: \% de umidade em camadas de testemunhos sedimentares da Baía de Sepetiba

Tabela 13: Determinação Granulométrica, SP-101.

Tabela 14: Determinação granulométrica, SP-102.

Tabela 15: Determinação granulométrica, SP-103. 
Tabela 16: Determinação granulométrica, SP-106.

Tabela 17: Determinação granulométrica, SP-105.

Tabela 18: Determinação granulométrica, SP-106.

Tabela 19: Determinação granulométrica, SP-107. 133

Tabela 20: Determinação granulométrica, SP-108. 134

Tabela 21: Determinação granulométrica, SP-109. 135

Tabela 22: Determinação granulométrica, SP-110. 136

Tabela 23: Determinação granulométrica, SP-111.

Tabela 24: Determinação granulométrica, SP-112.

Tabela 25: Determinação granulométrica, SP-113. 139

Tabela 26: Determinação granulométrica, SP-114. 140

Tabela 27: Determinação granulométrica, SP-115. 141

Tabela 28: Determinação granulométrica, SP-116. 142

Tabela 29: Determinação granulométrica, SP-117. 143

Tabela 30: Determinação granulométrica, SP-118. 144

Tabela 31: Determinação granulométrica, SP-119. 145

Tabela 32: Determinação granulométrica, SP-120. 146

Tabela 33: Determinação granulométrica, SP-121. 147

Tabela 34: Determinação granulométrica, SP-122. 148

Tabela 35: Determinação granulométrica, SP-123. 149

Tabela 36: Determinação granulométrica, SP-124. 150

Tabela 37: Determinação granulométrica, SP-125. 151

Tabela 38: Determinação granulométrica, SP-126. 152

Tabela 39: Determinação granulométrica, SP-130. 
Tabela 40: Determinação granulométrica, SP-131.

Tabela 41: Determinação granulométrica, SP-132.

Tabela 42: Determinação granulométrica, SP-133.

Tabela 43: Determinação granulométrica, SP-134.

Tabela 44: Determinação granulométrica, SP-135.

158

Tabela 45: Determinação granulométrica, SP-136.

Tabela 46: Determinação granulométrica, SP-137.

160

Tabela 47: Determinação granulométrica, SP-138.

Tabela 48: Determinação granulométrica, SP-139.

162

Tabela 49: Determinação granulométrica, SP-140.

163

Tabela 50: Determinação granulométrica, SP-141.

Tabela 51: Determinação elementar e isotópica de carbono e nitrogênio

Tabela 52: Concentração de SEM e AVS, ¿SEM e razão ¿SEM/AVS

Tabela 53: Determinação de $\mathrm{Zn}, \mathrm{Cd}, \mathrm{Cr}, \mathrm{Pb}, \mathrm{Ni}, \mathrm{Cu}$ e $\mathrm{Hg}$ em sedimentos superficiais da Baía de Sepetiba

Tabela 54: Determinação de $\mathrm{Cr}, \mathrm{Ni}, \mathrm{Cu}, \mathrm{Zn}, \mathrm{Cd}$ e Pb em testemunho sedimentar, T-3.

Tabela 55: Determinação de $\mathrm{Cr}, \mathrm{Ni}, \mathrm{Cu}, \mathrm{Zn}, \mathrm{Cd}$ e Pb em testemunho sedimentar, T-8.

Tabela 56: Determinação de $\mathrm{Cr}, \mathrm{Ni}, \mathrm{Cu}, \mathrm{Zn}, \mathrm{Cd}$ e Pb em testemunho sedimentar, T-13.

Tabela 57: Determinação de $\mathrm{Cr}, \mathrm{Ni}, \mathrm{Cu}, \mathrm{Zn}, \mathrm{Cd}$ e Pb em testemunho sedimentar, T-18.

Tabela 58: Determinação de $\mathrm{Cr}, \mathrm{Ni}, \mathrm{Cu}, \mathrm{Zn}, \mathrm{Cd}$ e Pb em testemunho sedimentar, T-19. 
Tabela 59: Determinação de $\mathrm{Cr}, \mathrm{Ni}, \mathrm{Cu}, \mathrm{Zn}, \mathrm{Cd}$ e Pb em testemunho sedimentar, T-20.

Tabela 60: Determinação de $\mathrm{Cr}, \mathrm{Ni}, \mathrm{Cu}, \mathrm{Zn}, \mathrm{Cd}$ e Pb em testemunho sedimentar, T-26.

Tabela 61: Determinação de $\mathrm{Cr}, \mathrm{Ni}, \mathrm{Cu}, \mathrm{Zn}, \mathrm{Cd}$ e Pb em testemunho sedimentar, T-28.

Tabela 62: Determinação de $\mathrm{Cr}, \mathrm{Ni}, \mathrm{Cu}, \mathrm{Zn}, \mathrm{Cd}$ e Pb em testemunho sedimentar, T-31. 
O tamanho dos seus sonhos deve sempre exceder a sua capacidade de alcançá-los.

Se os seus sonhos não te assustam, eles não são grandes o suficiente.

Ellen Johnson Sirleaf 


\section{1 \\ Introdução}

1.1

Contextualização

Nossa sociedade vem em um acentuado processo evolutivo, em especial no último século, o que proporcionou grandes alterações no nosso meio ambiente. Para tanto, foi necessário um aumento significativo dos processos industriais e, consequentemente, um expressivo crescimento urbano para suprir a necessidade dessa industrialização em expansão.

Todo esse avanço desenfreado teve como consequência a degradação ambiental, com o esgotamento dos solos, desmatamentos e contaminação dos recursos hídricos, tendo como principal consequência a extinção de espécies animais e vegetais.

Segundo Pinto (2005) o processo de conscientização acerca deste problema foi melhor percebido após a II Guerra Mundial, quando os efeitos da bomba atômica alertaram sobre a possibilidade de destruição do mundo pelo homem. Na década de 1950 dava-se muita ênfase aos perigos do uso intensivo de pesticidas sintéticos. Nos anos 60, o movimento de conscientização ambiental aumentou ainda mais, sendo o excesso de nutrientes dispensados em rios e lagoas, oriundos principalmente dos detergentes com fósforo, o principal vilão responsável pelo fenômeno de eutrofização. Pinto (2005) cita, ainda, que a era da eutrofização foi substituída, já nos anos 70, pela contaminação com metais pesados e pela chuva ácida, constituindo-se em período marcante para a regulamentação da atividade industrial.

No Brasil, existem casos documentados de contaminação de grandes áreas em função da atividade industrial, gerando um passivo ambiental que, não raramente, fica sem solução ou sem tratamento adequado. Este é o resultado de muitos anos de produção desprovida de preocupações com o meio ambiente e, principalmente, com o descarte de resíduos tóxicos

No litoral do Rio de Janeiro, a Baía de Sepetiba vem sendo, há décadas, alvo de profundas mudanças ambientais com a construção de grandes complexos 
industriais e de terminais marítimos, mudanças estas que vêm se acentuando nos últimos anos com a implantação da Companhia Siderúrgica do Atlântico (CSA), do terminal do Porto Sudeste e da base militar de submarinos. Interessante também notar que, neste mesmo período, ocorreu o descomissionamento da antiga Companhia Industrial Ingá, que foi por muitos anos uma fonte de contaminação significativa de Zn e Cd para a baía, e foi a principal responsável por um passivo ambiental que perdurou por dez anos sem solução até a compra do terreno pela Usinas Siderúrgicas de Minas Gerais (USIMINAS) e início da descontaminação.

No período entre 2000 e 2005, o Instituto Estadual do Ambiente (INEA) realizou um diagnóstico ambiental, envolvendo qualidade de água e de sedimento superficial, abrangendo 12 estações de sedimento superficial das 38 estações existentes no levantamento realizado pelo INEA, dentro do projeto de cooperação técnica entre a Fundação Estadual de Engenharia do Meio Ambiente (FEEMA) e a Sociedade Alemã de Cooperação Técnica (GTZ - Deutsche Gesellschaft für Technische Zusammenarbeit), na década de 1990 (FEEMA, 2006). De acordo com este diagnóstico, a contaminação do sedimento superficial com metais decresceu ao longo deste período, 2000-2005, exceto o mercúrio que apresentou um aumento nos níveis observados.

Neste trabalho foi reproduzida a malha de 38 estações de sedimento superficial utilizada no projeto de cooperação técnica FEEMA/GTZ, para avaliação do atual estado de contaminação e potencial tóxico do sedimento da Baía de Sepetiba. Para uma avaliação temporal da contaminação e melhor compreensão do que ocorreu durante as últimas décadas, com respeito à contaminação indicada pelo relatório da FEEMA, foram amostrados 9 testemunhos sedimentares, que foram fatiados em camadas de dois centímetros, para quantificação dos metais tóxicos e datação com ${ }^{210} \mathrm{~Pb}$.

Existem diversos métodos analíticos capazes de determinar o potencial tóxico de determinada região. Os dados absolutos das concentrações dos metais não são suficientes para afirmar ou descartar a toxicidade de determinada região, os valores obtidos devem ser comparados com outros parâmetros, como matéria orgânica ou teor de sulfetos voláteis. Além disso, órgãos ambientais como a Agência de Proteção Ambiental dos Estados Unidos da América (USEPA) e, no Brasil, o Conselho Nacional do Meio Ambiente (CONAMA), utilizam Valores-Guia de Qualidade de Sedimentos de Ambientes Aquáticos (VGQS), que foram derivados 
de forma empírica e apontam com boa precisão para o potencial tóxico de determinado contaminante em sedimento aquático.

\section{2 \\ Objetivos}

\subsection{1}

\section{Objetivo Geral}

Estudar a contaminação atual do sedimento de fundo da Baía de Sepetiba por metais potencialmente tóxicos.

\section{2 .2 \\ Objetivos Específicos}

Estudar a correlação existente entre metais e outros parâmetros indicativos de qualidade do sedimento (granulometria, carbono orgânico total, sulfetos, nitrogênio total).

Avaliar o potencial tóxico de $\mathrm{Zn}, \mathrm{Cd}, \mathrm{Pb}, \mathrm{Cr}, \mathrm{Cu}, \mathrm{Ni}$ e $\mathrm{Hg}$ nos sedimentos superficiais da Baía de Sepetiba.

Levantar o histórico da contaminação através de testemunhos sedimentares datados $\operatorname{com}^{210} \mathrm{~Pb}$.

Avaliar a variação nas taxas de sedimentação em diferentes setores da Baía de Sepetiba nas últimas décadas.

Com base nos resultados obtidos, avaliar a abrangência dos programas de monitoramento ambiental. 


\section{2 \\ Fundamentação Teórica}

\section{1 Área de Estudo - Baía de Sepetiba}

A baía de Sepetiba possui aproximadamente $305 \mathrm{~km}^{2}$ de área, encontra-se limitada a nordeste pela Serra do Mar, a norte pela serra de Madureira, a sudeste pelo maciço da Pedra Branca e a sul pela restinga da Marambaia.

É um corpo de águas salinas e salobras, comunicando-se com o oceano Atlântico por meio de duas passagens, na parte oeste, entre os cordões de ilhas que limitam com a ponta da restinga e, na porção leste, pelo canal que deságua na Barra de Guaratiba, o que lhe confere uma configuração quase elíptica. Seu perímetro é de aproximadamente $130 \mathrm{~km}$.

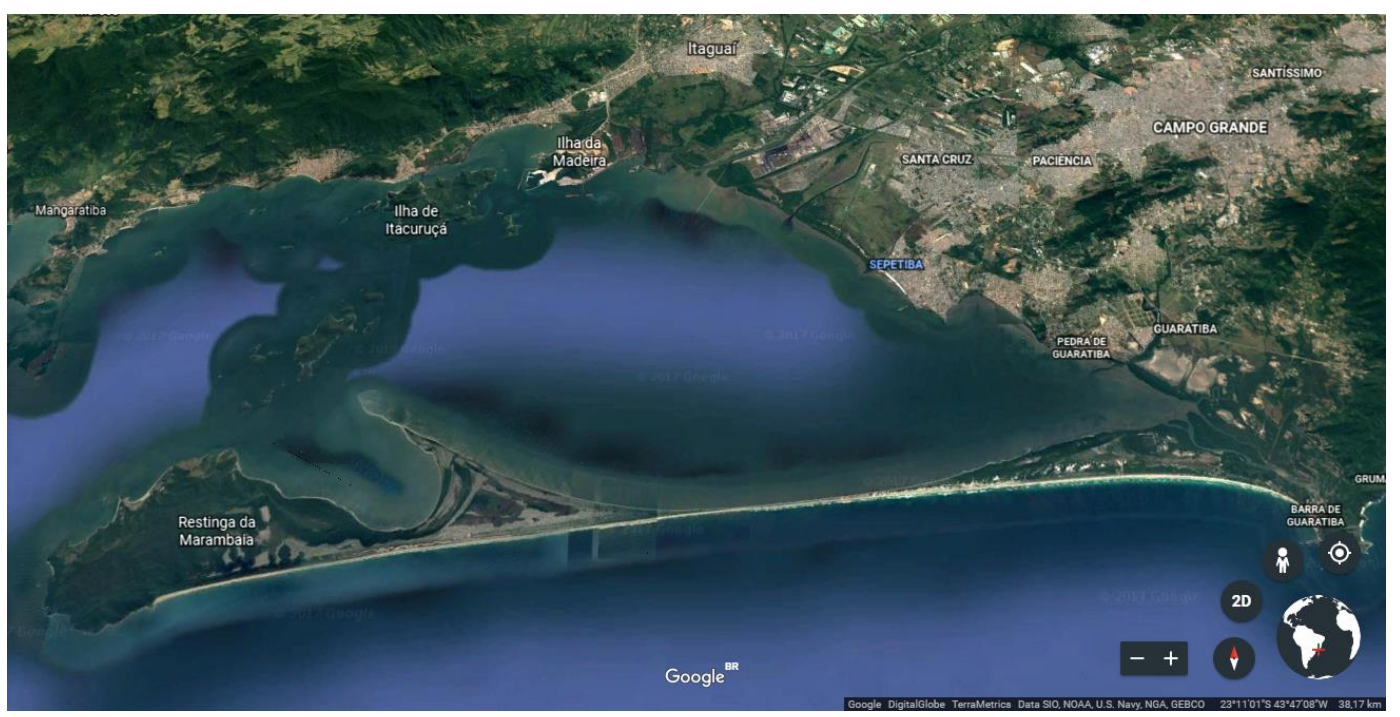

Figura 1: Imagem de satélite da baía de Sepetiba, Google Earth

A baía de Sepetiba, com suas áreas de mangue e zonas estuarinas é um criadouro natural para diversas espécies de camarões, crustáceos e peixes, sendo a atividade pesqueira uma das principais atividades econômicas para a população que vive em seu entorno (FEEMA, 2006).

A região tem como áreas típicas de turismo as ilhas da Madeira, Martins, Jaguanum e Itacuruçá, além de três cachoeiras, Mazomba, Itimirim e Bicão. Os 
municípios de Itaguaí, Mangaratiba, Sepetiba e o distrito de Itacuruçá, localizados no entorno da baía possuem praias e pequenas ilhas de grande beleza, e grande potencial para o turismo e lazer.

A sul da baía destaca-se a restinga da Marambaia, que se constitui como uma imensa barragem de areia, que, embora, possua poucos metros acima do nível do mar, funciona como um dique, isolando as águas da baía de Sepetiba e do Oceano Atlântico. A restinga possui aproximadamente $79 \mathrm{~km}^{2}$, estende-se de Barra de Guaratiba, a leste, até a ilha da Marambaia, a oeste, chegando a distar aproximadamente $18 \mathrm{~km}$ do bordo continental (FEEMA, 2006).

\section{2 \\ Características ambientais de um estuário}

Estuário é um ambiente transicional localizado entre o continente e o oceano. Existem várias definições para um estuário, conforme descrito por Perillo (1995). Na oceanografia, a proposta de Pritchard (1967), embora muito antiga, ainda é uma das mais adotadas e diz que: "Estuário é um corpo d’água costeiro semifechado, com livre ligação com o oceano aberto, no interior do qual a água do mar é mensuravelmente diluída pela água doce oriunda da drenagem continental”.

Presentes em todo o mundo, os estuários são frequentemente encontrados em planícies costeiras das médias latitudes, constituindo ambientes com idades inferiores a 5.000 anos, originados por variações do nível do mar de naturezas eustáticas e isostáticas, bem como por processos de origem tectônica que ocorreram em épocas geológicas recentes. Estes ambientes apresentam tempo de vida relativamente curto, visto que tendem a ser colmatados por sedimentos oriundos da drenagem continental, segundo Fonseca e Guerra (2011).

\section{3}

\section{Circulação das águas na Baía de Sepetiba}

Os fatores determinantes do padrão de circulação de águas existente na baía de Sepetiba são a amplitude da maré, morfologia costeira, batimetria, regime dos 
ventos e o aporte de água doce proveniente das bacias hidrográficas (FEEMA, 2006).

Tem sido demonstrado que há um semi-confinamento da porção leste da baía e já é destacado de forma bem relevante a baixa movimentação de fundo da baía e a diminuição gradual de seu espelho d'água. Sendo assim, pode-se inferir que vem acontecendo um processo gradativo de assoreamento, em função da significativa contribuição do aporte fluvial/terrígeno (Borges e Nittrouer, 2016). Esse fenômeno é natural e ocorre de forma contínua, como já descrido por Fonseca e Guerra (2011) para ambientes estuarinos.

Essa contribuição fluvial é confirmada pelas imagens de satélite, que mostram claramente a movimentação de sedimentos oriundos dos rios da Guarda e Piraquê. Destaca-se também o canal de São Francisco que forma uma extensa pluma de material em suspensão (Figura 2), que se dirige com notável inflexão para sudeste, ao fundo da baía, auxiliada ainda pela corrente de fundo, que atua lateralmente à linha costeira, no sentido leste.

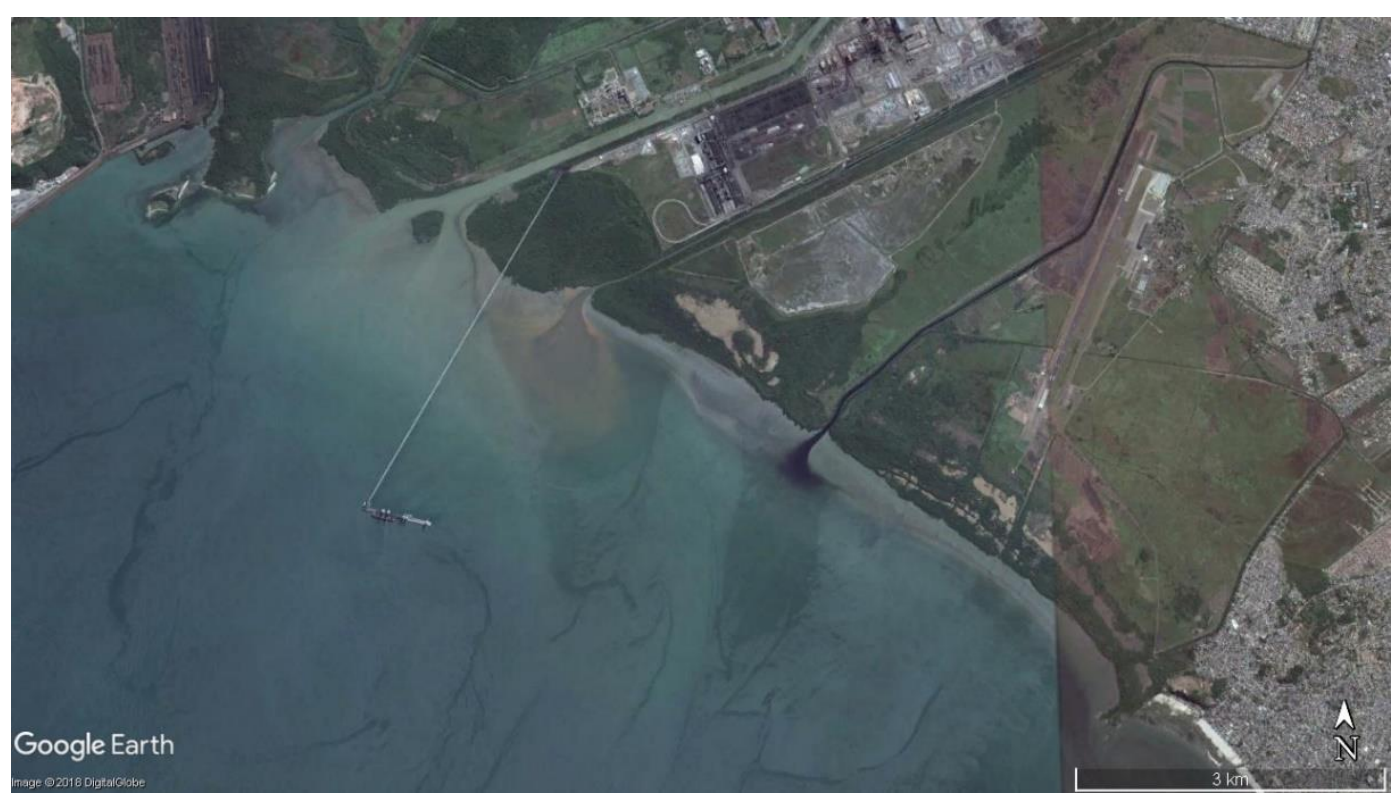

Figura 2: Pluma formada pelo aporte de sedimentos finos na Baía de Sepetiba oriunda da bacia hidrográfica do entorno

Outra peculiaridade da baía de Sepetiba é o estreitamento de sua largura nas proximidades da ilha da Guaíba, causando assim uma diminuição na área de passagem das águas. Esta situação promove um aumento de velocidade nas correntes até a área próxima à ilha de Jaguanum, havendo uma gradual diminuição 
das correntes, que se tornam fracas a partir deste ponto, em direção ao fundo da baía (FEEMA, 2006).

Segundo Cunha et al. (2006), o escoamento da baía é praticamente todo induzido para a parte central, onde há um canal natural de maior batimetria, gerando nesta região, correntes mais intensas. Na parte mais interna da baía há uma perda progressiva de carga na circulação acarretando uma mistura das águas oceânicas e interiores.

\section{4}

\section{A natureza do problema da Baía de Sepetiba}

A baía de Sepetiba caracterizava-se pela pesca e turismo até início dos anos 60, quando começou a sofrer as consequências da expansão da região metropolitana do Rio de Janeiro, resultando em grandes modificações em suas estruturas espaciais, socioeconômicas e ecológicas.

O desenvolvimento da região com o processo de industrialização tornou-se uma fonte de renda, gerando ciclos migracionais e potenciais riscos de poluição, na medida em que a atividade industrial foi responsável pelo lançamento de vários resíduos potencialmente tóxicos para a baía, com destaque especial para os metais (FEEMA, 2006)

O órgão competente pela fiscalização e regulação da atividade industrial era a Fundação Estadual de Engenharia do Meio Ambiente (FEEMA), criado em março de 1975, quase duas décadas após o início da industrialização da região. Este órgão era responsável pelo exercício de ações efetivas de controle industrial, visando manter as atividades dentro do que era estabelecido pela legislação vigente, a NT 202, que foi publicada no Diário Oficial do Estado do Rio de Janeiro somente em 1986.

Em janeiro de 2009 foi criado o Instituto Estadual do Ambiente (INEA). Este unificou as ações da FEEMA, da Superintendência Estadual de Rios e Lagos (SERLA) e do Instituto Estadual de Florestas (IEF). Atualmente, o INEA monitora as atividades industriais, no contexto ambiental, seguindo os padrões recomendados pelo Conselho Nacional do Meio Ambiente, por meio da resolução CONAMA 430, de 13 de maio de 2011. 
Por outro lado, e de modo geral, nos últimos 30 anos os serviços de infraestrutura de saneamento e drenagem não acompanharam o crescimento e adensamento populacional nas bacias hidrográficas do Rio de Janeiro. O desenvolvimento da região do entorno da Baía de Sepetiba aumentou a migração populacional, resultando em questões de ordem física, como a destruição de ecossistemas, aterros e uso desordenado do solo, causando efeitos impactantes em termos de assoreamento de corpos d'água e aumento das taxas de sedimentação.

Sérios problemas de saúde pública assolam a região, devido à presença de esgotos sanitários sem tratamento adequado e diversos resíduos sólidos urbanos que são lançados diretamente nos rios e canais da região (PACS, 2015)

\section{5 \\ Principais empreendimentos no entorno da Baía de Sepetiba}

\subsection{1 \\ Porto de Itaguaí}

O Porto de Itaguaí (Figura 3), anteriormente denominado Porto de Sepetiba, é um porto localizado na cidade de Itaguaí, a 80 quilômetros da capital fluminense. Foi inaugurado em 7 de maio de 1982, e sua operação, à época, era dedicada à descarga de carvão para a Companhia Siderúrgica Nacional (CSN) e alumina para a Valesul (SINDARIO, 2018).

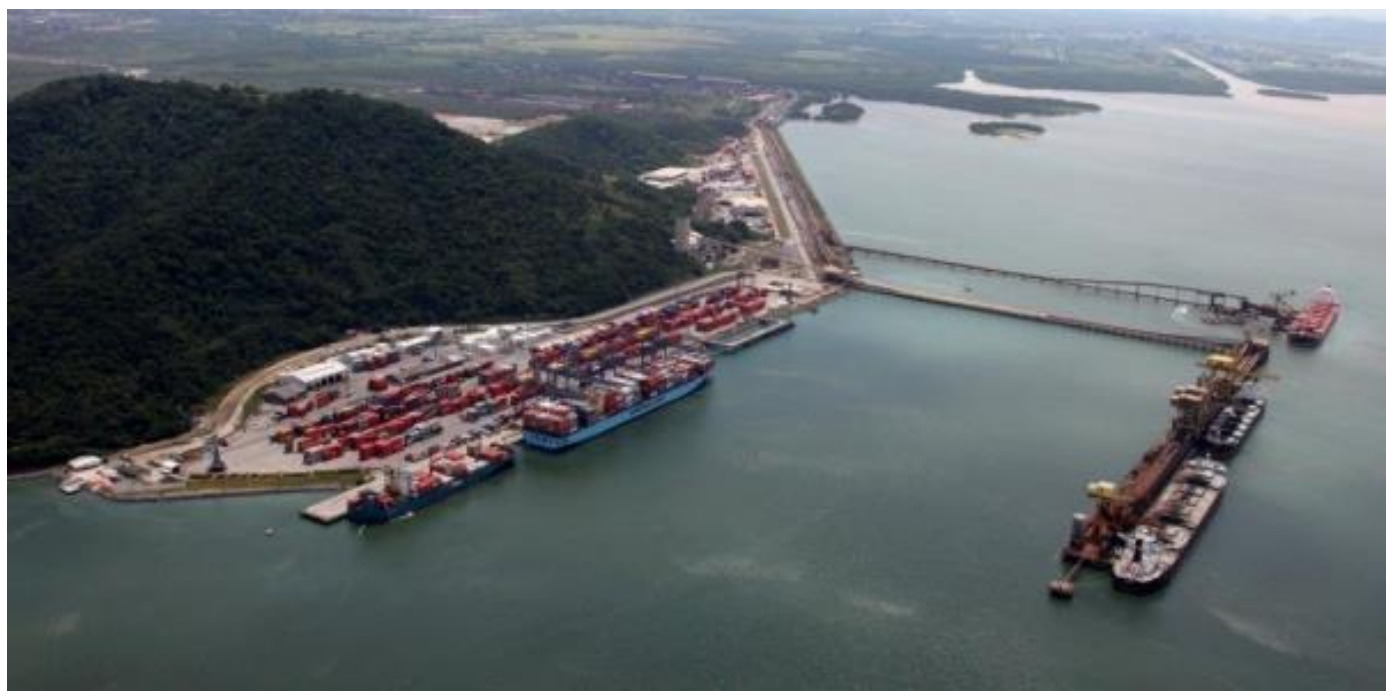

Figura 3: Porto de Itaguaí 
Os estudos para a implantação do porto foram realizados no ano de 1973, objetivando atender principalmente ao complexo industrial de Santa Cruz, situado na zona oeste do Rio de Janeiro. Em 1976, foram iniciadas as obras de acesso e o píer de Carvão, em paralelo, começaram as atividades de dragagem do canal de acesso com cerca de $22 \mathrm{~km}$ de extensão, $200 \mathrm{~m}$ de largura e profundidade oficial de 17,10 m. A barra do canal localiza-se entre a Ponta dos Castelhanos, na ilha Grande, e a Ponta Grossa da Restinga da Marambaia, oferecendo $12 \mathrm{~km}$ de largura e profundidade de $19 \mathrm{~m}$.

Atualmente, o porto é administrado pela Companhia Docas do Rio de Janeiro (CDRJ) e é um dos maiores e mais modernos portos da América Latina. O cais de uso público está dividido em trechos arrendados: cais de carga geral, píer de carvão, píer de minérios, terminal de alumina com dois silos para estocagem de até $30 \mathrm{t}$, cinco pátios de carvão com capacidade de estocagem total de 750.000 t, 4 pátios de minério que comportam até 1.500 .000 t, o pátio de carga geral que é uma área pavimentada com $200.000 \mathrm{~m}^{2}$ e armazéns cobertos para consolidação de carga e produtos de siderurgia.

Arrendam atualmente os terminais de carvão a Companhia Siderúrgica Nacional (CSN), o terminal de contêineres é administrado pela SEPETIBA TECON, o terminal de minérios é arrendado pela Companhia Portuária Baía de Sepetiba S/A (CPBS) e o terminal de Alumina é controlado pela VALESUL Alumínio S/A.

\subsection{2}

\section{Porto Sudeste}

A construção da Porto Sudeste foi iniciada em junho de 2010, com a escavação de um túnel que faz a ligação entre a estrutura principal e as estruturas marítimas do empreendimento. As operações foram iniciadas em setembro de 2015 e, em fevereiro do ano seguinte, foram atracados ao píer dois grandes navios cargueiros. 


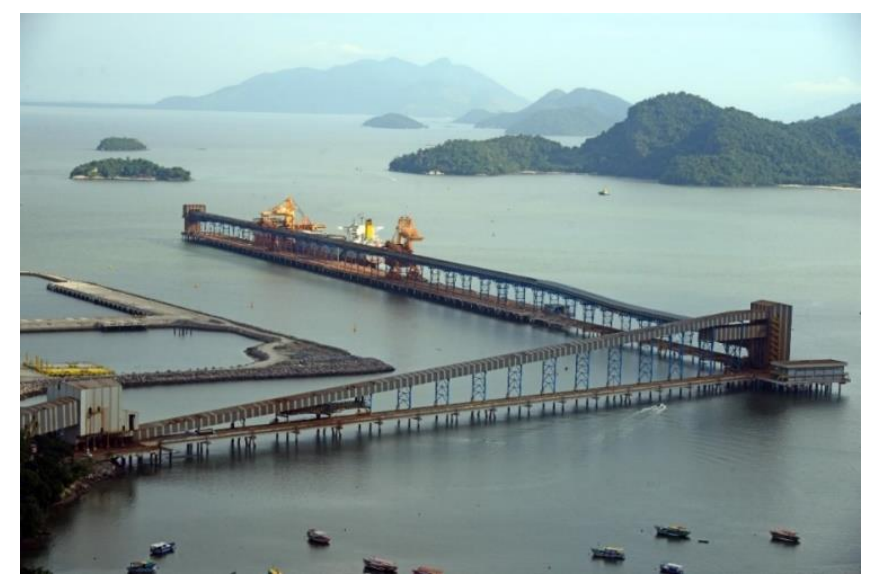

Figura 4: Píer do Porto Sudeste

O píer da Porto Sudeste ( Figura 4) possui 765 m de extensão e é ligado ao continente através de uma ponte de acesso com $647 \mathrm{~m}$ de comprimento. Para a conclusão de todo projeto, foi necessária a cravação de 635 estacas de concreto de $90 \mathrm{~cm}$ cada. ("Grupo ARG | Porto Sudeste”). O porto possui uma profundidade de $21 \mathrm{~m}$ para receber navios Capesize para embarque de minério de ferro. Para a manutenção desta profundidade no porto e no canal de navegação são realizadas dragagens anuais destes locais e o sedimento retirado é lançado fora da Baía de Sepetiba.

A capacidade de armazenagem de minério é de 2,5 $10^{6} \mathrm{t}$, as esteiras e berços para o transporte do minério até o porão dos navios são capazes de escoar 12 mil granéis sólidos por hora. No primeiro ano de operação, a movimentação do terminal foi de 6,31 milhões de toneladas e em 2017 a movimentação já era de 9,45 milhões de toneladas, segundo o Sistema Público de Informações Gerenciais da Agencia Nacional de Transportes Aquaviários (ANTAG), consultado em 08 de outubro de 2018.

\subsection{3}

\section{Base Militar para Construção de Submarinos}

Segundo o Ministério da Defesa, a base submarina do "PROSUB” (programa de construção de submarinos da Marinha do Brasil) está sendo construída em parceria com o governo francês e o contrato prevê transferência de tecnologia entre 
os dois países. As obras para a construção do estaleiro e da base naval foram iniciadas em 2010.

A base naval é dividida em duas áreas, norte e sul, interligadas por um túnel com 703 metros de comprimento e 14 metros de diâmetro. Na área sul estão localizados dois grandes estaleiros e o complexo radiológico, são $487 \mathrm{mil} \mathrm{m}^{2}$ que, no final da construção, contarão com dois píeres e duas docas, todos com 140 m, além de oficinas, 13 cais e um elevador de submarinos com capacidade de até 8 mil toneladas.

O complexo radiológico, onde serão feitas as trocas do combustível nuclear, possui altura de um prédio de 16 andares e possuirá uma unidade móvel, feita em estrutura metálica e totalmente blindada, para acesso ao reator instalado dentro do submarino.

O cronograma já sofreu vários adiamentos, na última atualização, em 2017, a Marinha informou que o lançamento do primeiro submarino convencional está previsto para dezembro de 2018 e mais outros 3 submarinos serão lançados ao mar entre 2020 e 2022. Não há previsão para o lançamento do submarino nuclear.

\subsection{4 \\ Companhia Mercantil Industrial Ingá}

A companhia Mercantil e Industrial Ingá era beneficiadora de minério de zinco para exportação, instalou-se na Ilha da Madeira em 1962 e encerrou as atividades no final dos anos 1990, quando entrou em processo de falência (Ferreira, 2010). Durante os anos de operação, a Ingá gerou um enorme passivo ambiental para a localidade e seu entorno, pois o processo de produção de zinco usava como matéria prima o minério Calamina $\left(\mathrm{Zn}_{2} \mathrm{SiO}_{3}(\mathrm{OH})_{2}\right)$ proveniente de Minas Gerais (Barcellos, 1995) ou Willemita $\left(\mathrm{Zn}_{2} \mathrm{SiO}_{4}\right)$ (Magalhães \& Pfeiffer, 1995), e gera como subprodutos o próprio zinco, além de cádmio principalmente.

Os efluentes líquidos eram lançados diretamente na Baía de Sepetiba, numa área de manguezal próximo ao Saco do Engenho. Os resíduos sólidos eram acumulados no pátio da empresa, formando montanhas de material tóxico a céu aberto. Em 1984 a empresa construiu um dique argiloso no perímetro da área de 
deposição dos resíduos, e, para a contenção dos resíduos sólidos e líquidos, a empresa instalou tanques de acumulação de águas e uma estação de tratamento de resíduos e águas residuárias e outros sistemas de controle (Bredariol, 2004).

Tais medidas deveriam minimizar o despejo de resíduos tóxicos na baía, mas sondagens geotécnicas realizadas no local revelaram que a construção do dique havia sido malfeita, ficando muito próxima ao mar e num terreno baixo, deixandoo vulnerável a rompimentos (Viégas, 2006).

Em 1996, a Cia. Ingá Mercantil era uma das três maiores produtoras de zinco do Brasil, sua capacidade total instalada representava, naquela época, $30 \%$ do mercado brasileiro. Em fevereiro deste mesmo ano, em decorrência das fortes chuvas, o dique de contenção se rompeu, causando um dos maiores desastres ambientais do Rio de Janeiro, contaminando a Baía de Sepetiba com metais tóxicos (Pinto, 2005).

Após a falência da Companhia Mercantil e Industrial Ingá em 1998, 390 mil $\mathrm{m}^{3}$ de efluentes foram abandonados formando uma pilha de aproximadamente $45 \mathrm{~m}$ de altura (Figura 5), composta principalmente por rejeitos metalúrgicos ricos em $\mathrm{Zn}$ e $\mathrm{Cd}$, além de outros metais tóxicos, classificados como rejeitos de Classe 1, como As, $\mathrm{Pb}, \mathrm{Cu}, \mathrm{Ni}, \mathrm{Co}, \mathrm{Fe}$ e Mn. (Barcellos et al., 1991; Lacerda \& Molisani, 2006; Ferreira; 2010).

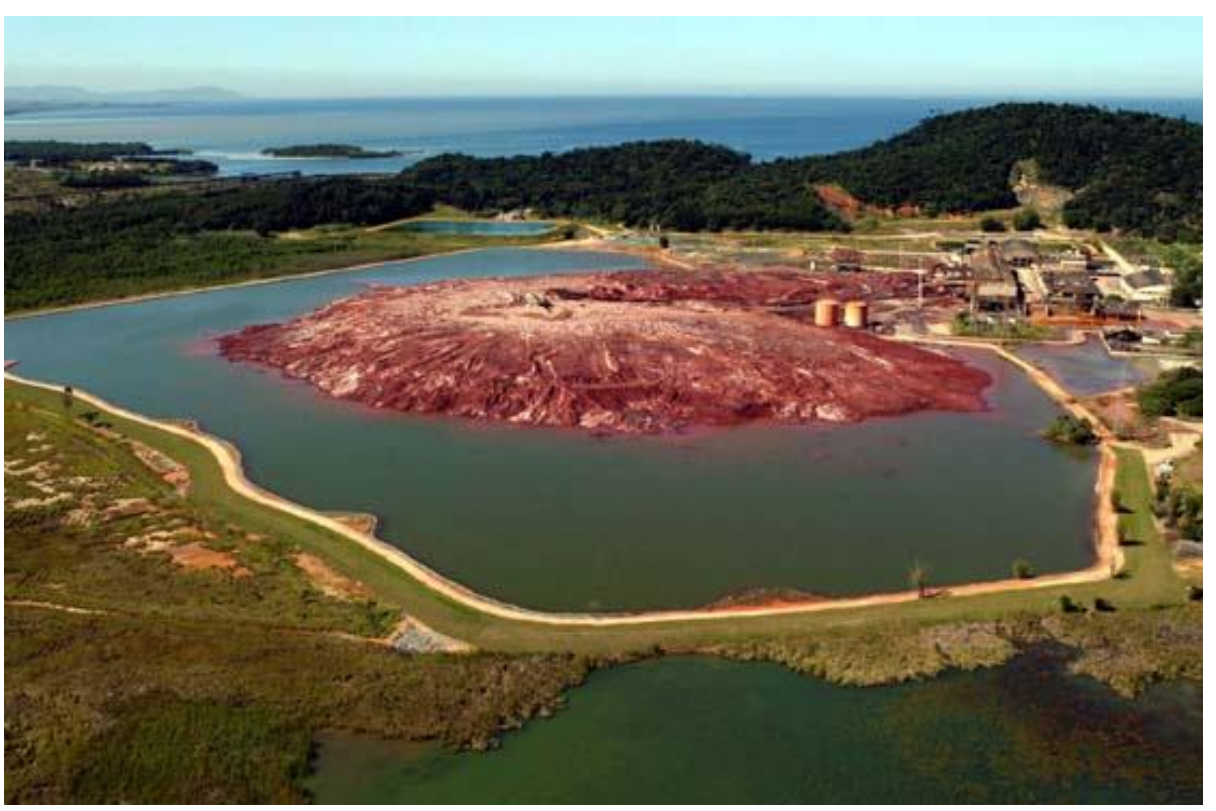

Figura 5: Rejeitos de metalurgia abandonados pela Ingá Mercantil 
Em 2002 parte deste material vazou para a Baía de Sepetiba, nada foi feito para a recuperação do dique e um novo vazamento ocorreu em 2003, repetindo o desastre ecológico de 1996, quando cerca de $6000 \mathrm{~m}^{2}$ de manguezal foram soterrados (Viégas, 2006).

Em junho de 2008, o terreno foi arrematado, em leilão, pela Usinas Siderúrgicas de Minas Gerais S.A. (USIMINAS) com a promessa de descontaminação do terreno (USIMINAS, 2011) e recuperação total da área contaminada.

\subsection{5 \\ Ternium Brasil}

A Ternium Brasil, inicialmente conhecida como Companhia Siderúrgica do Atlântico (CSA), é uma das maiores siderúrgicas do Brasil e da América Latina. O conglomerado industrial, siderúrgico e portuário era uma Joint Venture formada pela Vale (27\%) e Thyssen Krupp (73\%) e contou com amplo apoio dos governos municipal, estadual e federal por meio de financiamento direto de quase $\mathrm{R} \$ 1,5$ bilhão do Banco Nacional de Desenvolvimento Econômico e Social (BNDES) e importantes isenções fiscais (PACS, 2012).

O conglomerado é composto pela usina siderúrgica, com capacidade para produção de 10 milhões de toneladas por ano; usina termoelétrica, para a geração de 490 MW de energia elétrica alimentada por 4 milhões de toneladas de carvão mineral proveniente da Colômbia; e um porto com dois terminais compostos por um píer de $700 \mathrm{~m}$ e uma ponte de acesso de $4 \mathrm{~km}$ que atravessa uma área de manguezal. (ECOLOGUS, 2005)

O lançamento da pedra fundamental da siderúrgica foi em 29 de setembro de 2006, neste mesmo ano se iniciaram as obras para implantação do polo, com a dragagem para ampliação do Canal de São Francisco.

Segundo publicação do Instituto Políticas Alternativas para o Cone Sul PACS (2012), a empresa retirou cerca de 21.810.000 $\mathrm{m}^{3}$ de lama do fundo da Baía e do Canal São Francisco com o objetivo de aumentar a sua profundidade e permitir o acesso aos navios. Parte deste material está no canteiro de obras da empresa para o aterro do terreno onde se ergueu a usina. Estas obras sempre foram cercadas de 
denúncias de irregularidades, falhas no licenciamento e descaso com o meio ambiente.

A planta entrou em operação em 18 de junho de 2010 com o acionamento do primeiro alto-forno. Nos dias subsequentes, a incapacidade da CSA de garantir as condições operacionais adequadas desencadeou uma série de eventos de poluição atmosférica aguda, que ficou conhecida pela população como "chuva de prata", desencadeando problemas respiratórios e dermatológicos que afetaram principalmente os idosos e as crianças, segundo a organização não governamental PareTKCSA (2018)

Os efluentes líquidos da siderúrgica são resultantes do sistema de resfriamento e de tratamento dos gases da fabricação do coque e apresentam níveis elevados de amônia, benzeno e outros. O tratamento deste material requereu a construção de estações de tratamento dos efluentes líquidos, reservando grande cautela para o destino do lodo dessas estações, que possuem altas concentrações de metais tóxicos. Utiliza-se água do canal de São Francisco para o resfriamento, esta é filtrada e bombeada para o sistema e após a troca de calor é dispensada no rio Guandu (PACS, 2015).

Depois de uma série de embargos na construção, inúmeras multas pelos órgãos ambientais, várias ações em diferentes esferas jurídicas e uma dívida de 300 milhões de Euros com o BNDES, associado à desvalorização do Real frente ao Dólar e uma forte queda do preço do aço no mercado internacional, a CSA começou a operar de forma deficitária. A ThyssenKrupp então resolve mudar a estratégia internacional e anuncia a venda da siderúrgica, que demorou cinco anos para se concretizar.

No dia 7 de setembro de 2017, a Ternium anunciou em seu site a aquisição por 1,4 bilhão de Euros da Companhia Siderúrgica do Atlântico (CSA), que passou a ser Ternium Brasil. A usina agora é integrada ao sistema industrial e à cadeia de abastecimento da Ternium, que produz 12,4 milhões de toneladas de aço por ano e conta com 20 mil funcionários (Cavalcanti, 2017). 


\section{6 \\ Técnicas Analíticas Utilizadas}

\subsection{1 \\ Espectrometria de Massas com Plasma Indutivamente Acoplado (ICP-MS)}

A espectrometria de massas com plasma indutivamente acoplado (ICP-MS) é amplamente utilizada para determinar a concentração e composição isotópica de grande parte dos elementos da tabela periódica. Embora seja possível trabalhar-se com amostras sólidas, através da técnica de ablação a laser, bastante empregada na geologia, pode-se dizer que, na análise de amostras ambientais, faz-se necessária uma etapa prévia de solubilização do material. As amostras devem ser apresentadas ao equipamento como uma solução líquida, sem material em suspensão, sendo imprescindível o preparo de qualquer outro tipo de amostra que não tenha esta característica (Giné-Rosias, 1999). A solução passa por processo de nebulização, atomização e ionização ao longo de seu tempo de residência no plasma de argônio de alta temperatura, e a fração dos íons que penetram no espectrômetro de massa são então separados e quantificados. Como existe uma relação entre a quantidade de analito em soluções padrão e o sinal produzido, uma função de calibração pode ser estabelecida e a quantificação destes analitos pode ser realizada nas amostras com exatidão (Thomas, 2001).

Na Figura 6 observa-se a estrutura de um ICP-MS. Este equipamento possui um sistema de introdução de amostra (Figura 6-1), responsável pela admissão de uma quantidade suficiente de solução e formação da névoa com características necessárias para a posterior atomização/ionização eficiente sem alterar as características do plasma. O plasma de argônio é iniciado com uma descarga tesla através do fluxo de argônio, esta descarga retira elétrons de alguns átomos de argônio. Um campo magnético oscilante gerado por uma bobina acoplada a um gerador de radiofrequência estabiliza os elétrons retirados, assim como os cátions de argônio, dando início a uma reação em cadeia nesta região formando o plasma, que alcança temperaturas que podem variar entre 6000 e $10000 \mathrm{~K}$ (Figura 6-2). Desta forma, praticamente todas as moléculas que chegam ao plasma são dissociadas e, posteriormente, os elementos são ionizados, o que torna o ICP uma 
fonte de íons muito abundante e adequada para a determinação de mais de $70 \%$ dos elementos da tabela periódica (Agilent Technologies, 2005).

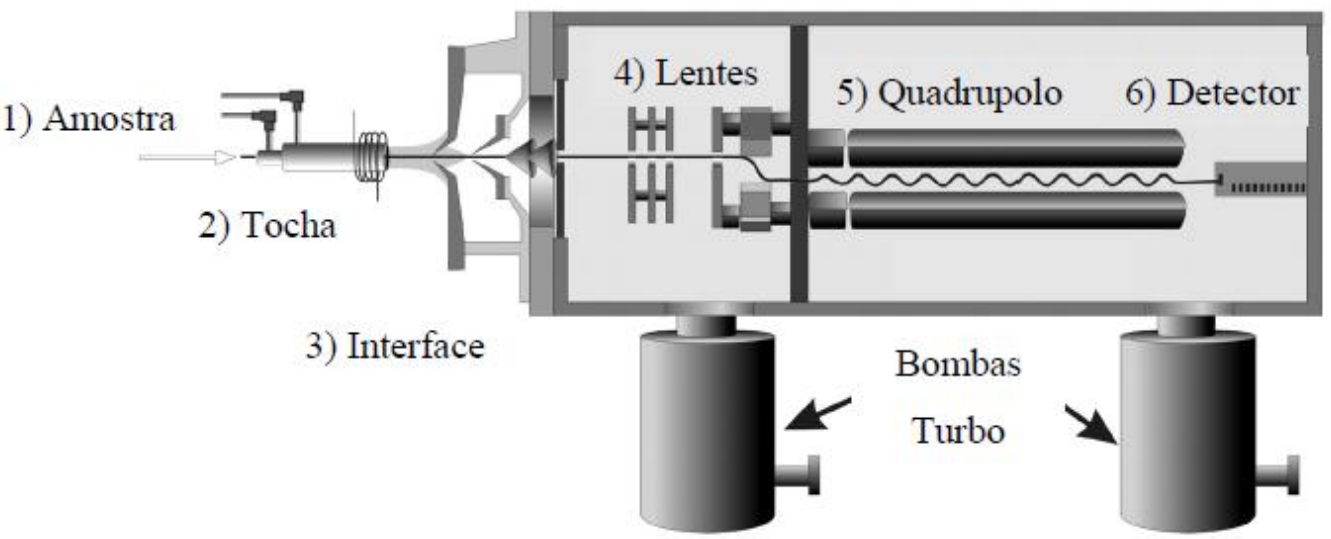

Figura 6: Esquema estrutural de um espectrômetro de massa com fonte de plasma indutivamente acoplado $(I C P-M S)$

Entre o plasma de argônio, que é a unidade geradora de íons e opera à pressão atmosférica, e o analisador de massa, que opera em alto vácuo, existe uma interface (Figura 6-3) de pressão intermediária. Essa interface é responsável pela extração dos íons do plasma e direcionamento para o espectrômetro, a diferença de pressão acelera os íons a velocidades ultrassônicas, este serão posteriormente colimados e terão suas energias cinéticas ajustadas por um conjunto de lentes iônicas (Figura $6-4)$.

Segundo Giné-Rosias (1999), alguns elementos sofrem interferência de isóbaros, de íons poliatômicos, ou até mesmo de íons com carga diferente de +1 que também podem ser produzidos pelas condições de operação do plasma. No caso das interferências isobáricas ou poliatômicas, deve-se escolher um isótopo do elemento de interesse livre de interferência ou, caso não seja possível, deve-se utilizar células de reação/colisão que eliminam as espécies poliatômicas do feixe de íons a caminho do espectrômetro de massa.

O princípio de funcionamento destes sistemas consiste na passagem dos íons através de uma região que contém um gás de reação/colisão que irá atuar na dissociação destes interferentes poliatômicos ou apenas irá desestabilizar estas espécies retirando-as do feixe iônico (Agilent Technologies, 2005).

O feixe iônico é então direcionado para o analisador de massa do tipo quadrupolo (Figura 6-5), que opera variando continuamente a magnitude de um 
campo elétrico e também alternando, em frequências bem definidas, a polaridade deste campo. Desta maneira, num curto intervalo de tempo, apenas íons que possuem uma razão massa/carga bem definida terão sua trajetória estabilizada e encaminhada até o detector (Figura 6-6), todas as outras espécies serão desestabilizadas e desviadas do fluxo de íons, sendo assim, em intervalos de tempo bem determinados apenas uma espécie iônica será capaz de atingir o detector, que converte a energia de colisão dos íons em sinal elétrico que é posteriormente amplificado e registrado (Agilent Technologies, 2005).

Giné-Rosias (1999) afirma que as determinações por ICP-MS são extremamente sensíveis e permitem a detecção de metais em níveis extremamente baixos $\left(\mathrm{ng} \mathrm{L}^{-1}\right)$. Além da boa sensibilidade, esta técnica também apresenta como característica principal a análise multielementar em tempo extremamente reduzido, o que a torna uma ferramenta extremamente poderosa e útil na determinação da concentração total de metais em amostras ambientais.

\subsection{2 \\ Espectrometria de Absorção Atômica com Geração de Vapor Frio - Determinação de Mercúrio}

A absorção de energia por átomos livres, gasosos e no estado fundamental é a base de espectrometria de absorção atômica. Quando uma radiação de um determinado comprimento de onda passa através de algum sistema que contenha vapor de átomos no estado fundamental, parte desta radiação pode ser absorvida de acordo com o processo $M+h v \rightarrow M^{*}$, onde $M$ é o átomo no estado fundamental e $M^{*}$ é o átomo no estado excitado. O que define a especificidade para a absorção de radiação por átomos diferentes é a relação entre a frequência da radiação incidente $(v)$ e a diferença de energia entre os estados fundamental $(E)$ e excitado $\left(E^{*}\right)$. Se $E^{*}-E=h v$, onde $h$ é a constante de Planck, o processo de absorção pode ocorrer (Welz, 1999).

A espectrometria de absorção atômica com geração de vapor frio (CV-AAS) é atualmente o método analítico mais utilizado para a determinação de mercúrio em concentrações muito baixas e em uma grande variedade de matrizes (Srogi, 2008). Esta técnica é específica para a quantificação de mercúrio, pois este é o único 
elemento metálico, que em sua forma atômica $\left(\mathrm{Hg}^{0}\right)$ encontra-se presente na forma de vapor à temperatura ambiente.

$\mathrm{O}$ método baseia-se na redução do íon mercuroso $\mathrm{Hg}_{2}{ }^{2+}$ a $\mathrm{Hg}^{0}$ em solução aquosa pela adição de um agente fortemente redutor, sendo comumente utilizadas soluções de cloreto estanoso $\left(\mathrm{SnCl}_{2}\right)$ ou borohidreto de sódio $\left(\mathrm{NaBH}_{4}\right) . \mathrm{O} \mathrm{Hg}^{0}$ é então liberado completamente da solução por meio de forte agitação ou borbulhamento com um gás inerte, geralmente nitrogênio $\left(\mathrm{N}_{2}\right)$ ou argônio (Ar), que também serve como gás de arraste e conduz $\mathrm{o} \mathrm{Hg}^{0}$ até a célula de absorção, um tubo cilíndrico de vidro com janelas de quartzo, localizado no caminho ótico do equipamento de absorção atômica, de forma longitudinal. Segundo Welz (1999), essa técnica recebe o nome de "vapor frio" exatamente pelo fato de que o elemento químico em questão chega à célula de absorção já na forma atômica e sem a necessidade de aquecimento.

\subsection{3 \\ Datação por ${ }^{210} \mathrm{~Pb}$}

$\mathrm{O}{ }^{210} \mathrm{~Pb}\left(\mathrm{t}_{1 / 2}=22,26\right.$ anos $)$ é um dos radioisótopos produto do decaimento da série natural do ${ }^{238} \mathrm{U}$.

O desequilíbrio entre o $210 \mathrm{~Pb}$ e o $226 \mathrm{Ra}(\mathrm{t} 1 / 2=1602$ anos) ocorre devido a presença do $222 \mathrm{Rn}$ ( $\mathrm{t} 1 / 2=3,82$ dias) na atmosfera. Esse $222 \mathrm{Rn}$ formado a partir do decaimento 226Ra, por ser um gás, desprende-se do solo e difunde-se pela atmosfera, onde, decai formando uma sequência de vários nuclídeos de meia-vida curta, até a formação do $210 \mathrm{~Pb}$ (Figura 7) que, denomina-se ${ }^{210} \mathrm{~Pb}$ exc, por estar em excesso e em desequilíbrio com o ${ }^{226} \mathrm{Ra}$ (Mozeto et al., 2006).

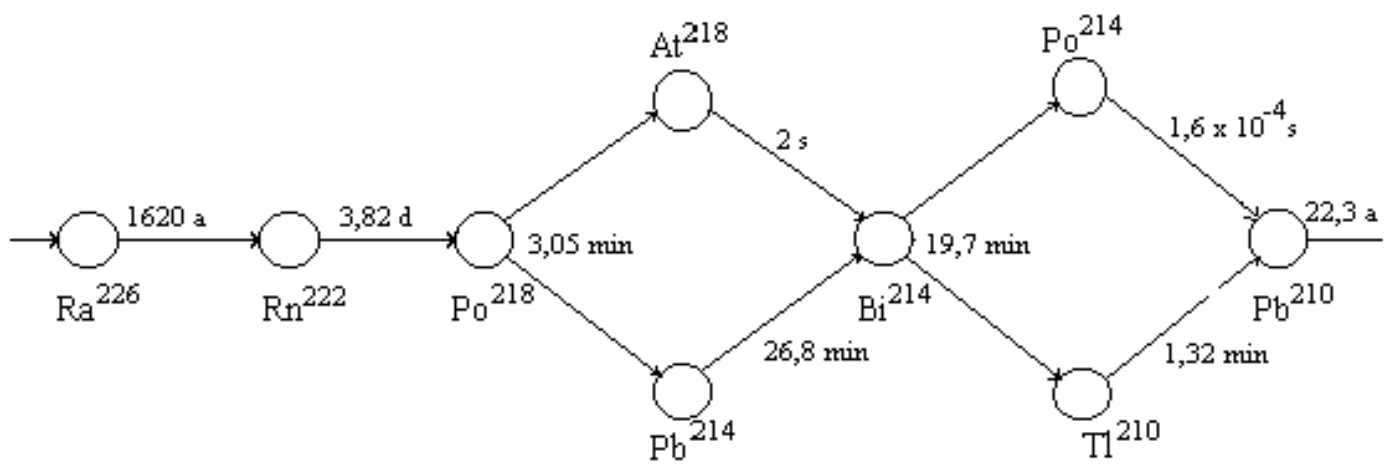

Figura 7: Série do ${ }^{238} \mathrm{U}$ : do ${ }^{226} \mathrm{Ra}$ ao ${ }^{210} \mathrm{~Pb}$. São indicadas as meias-vidas dos radionuclídeos (Argollo, 2001). 
$\mathrm{O}{ }^{210} \mathrm{~Pb}_{\text {exc }}$ é removido da atmosfera por precipitação úmida ou seca. Esta precipitação é considerada constante por unidade de área para uma mesma região e depende de uma série de fatores relacionados com as características do solo, ventilação e índice pluviométrico (Lima, 1996; Mozeto et al., 2006).

$\mathrm{O}{ }^{210} \mathrm{~Pb}_{\text {exc }}$ se deposita nas superfícies dos lagos e oceanos e, com o tempo, acumula-se no fundo com o sedimento. (Lima, 1996; Mozeto et al., 2006).

A fração de ${ }^{210} \mathrm{~Pb}_{\text {sup }}$ que se mantém no sedimento, em equilíbrio com o ${ }^{222} \mathrm{Rn}$, que não emanou para a atmosfera, e que, consequentemente, está em equilíbrio com o ${ }^{226} \mathrm{Ra}$, é denominada "suportada radiologicamente"; essa fração, por estar em equilíbrio com o ${ }^{226} \mathrm{Ra}$ pode ser obtida pela medida da atividade do mesmo. (Mozeto et al., 2006).

$\mathrm{O}{ }^{210} \mathrm{~Pb}_{\text {Total }}$ presente no sedimento é uma soma das frações de ${ }^{210} \mathrm{~Pb}_{\text {exc }}$ (não suportado radiologicamente) e do ${ }^{210} \mathrm{~Pb}_{\text {sup }}$ (Figura 8) que está em equilíbrio com o ${ }^{226} \mathrm{Ra}$ (Mozeto et al., 2006).

$$
{ }^{210}{ }_{\mathrm{Pb}_{\text {Total }}}={ }^{210} \mathrm{~Pb}_{\text {sup }}+{ }^{210} \mathrm{~Pb}_{\text {exc }}
$$

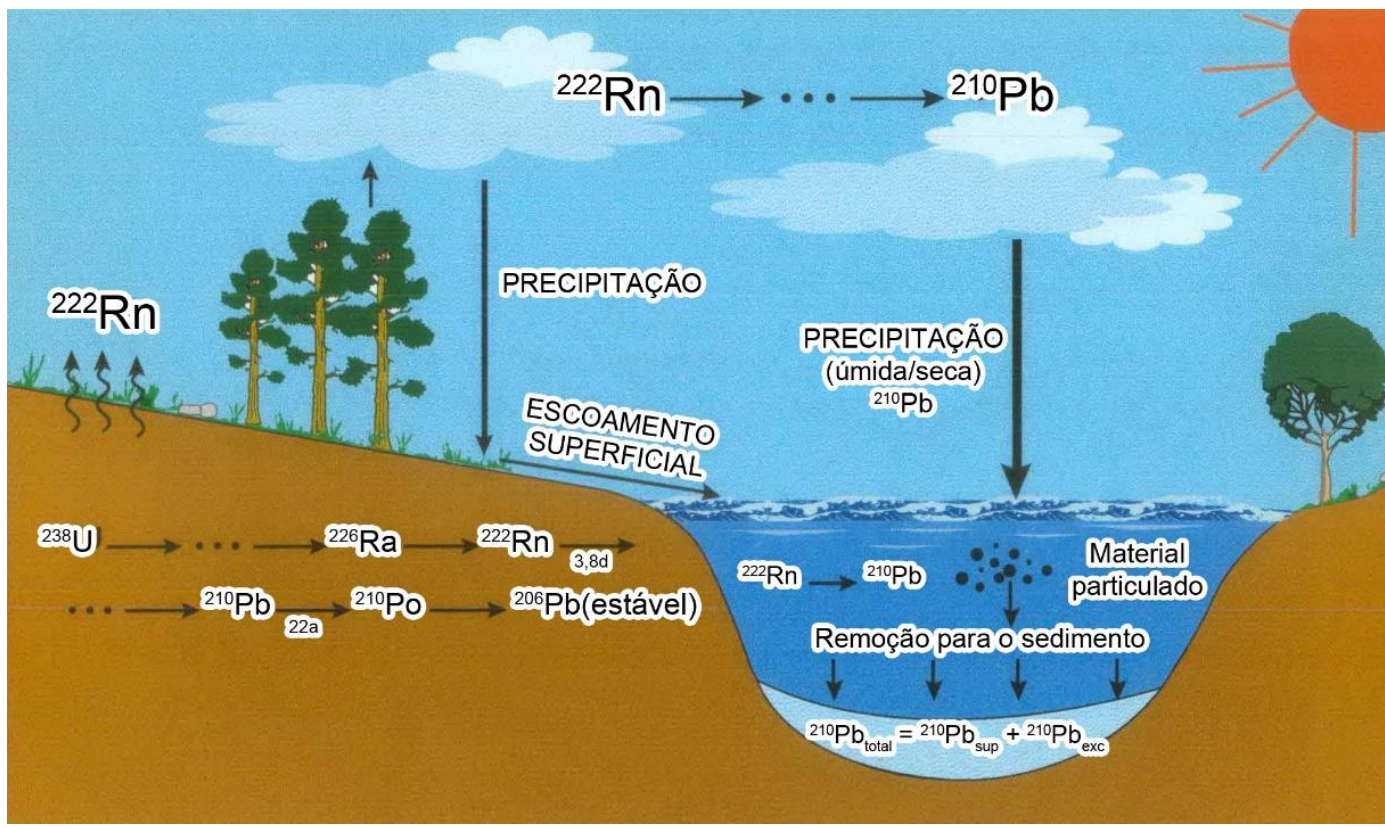

Figura 8: Dinâmica do ${ }^{210} \mathrm{~Pb}$ no meio ambiente (Lima, 1996).

A correção da concentração de ${ }^{210} \mathrm{~Pb}_{\text {exc }}$ é garantida a partir da concentração 
$\mathrm{de}^{210} \mathrm{~Pb}_{\text {sup }}$ encontrada nas camadas sedimentares mais profundas. Sabe-se que, com o aumento da profundidade, a concentração de ${ }^{210} \mathrm{~Pb}_{\text {exc }}$ tende a zero, alcançando-se, assim, um valor constante para ${ }^{210} \mathrm{~Pb}$ total, visto que este seria a própria concentração de ${ }^{210} \mathrm{~Pb}_{\text {sup. }}$ Este seria subtraído da concentração de ${ }^{210} \mathrm{~Pb}_{\text {total das demais camadas }}$ acima da referencial. Isto corrigiria a concentração de ${ }^{210} \mathrm{~Pb}_{\text {exc }}$, que é utilizada para avaliação da taxa de sedimentação (Mozeto et al., 2006).

Segundo Godoy et al. (1998), em áreas costeiras, onde as taxas de sedimentação são elevadas (> $1 \mathrm{~cm}$ ano ${ }^{-1}$ ), a determinação radiométrica de ${ }^{210} \mathrm{~Pb}$ apresenta-se como a técnica mais indicada devido ao período de aplicação (até 100 anos).

Segundo Wanderley (1995), existem dois modelos matemáticos que se aplicam à interpretação dos perfis sedimentares, o modelo CF:CR (Constant Flux : Constant Rate) e o modelo CRS (Constant Rate of Supply).

\section{- Modelo CF:CR (Constant Flux : Constant Rate)}

Neste modelo, supõe-se que a área estudada é estável, sem mudanças na taxa de sedimentação e a incorporação de ${ }^{210} \mathrm{~Pb}_{\text {exc }}$, ocorre a um fluxo constante, portanto, a concentração inicial de ${ }^{210} \mathrm{~Pb}_{\text {exc é considerada constante. }}$

A concentração de ${ }^{210} \mathrm{~Pb}_{\text {exc }}$ irá apresentar um decaimento exponencial em relação à profundidade representada pela massa acumulada de sedimento $\left(\mathrm{g} \mathrm{cm}^{-2}\right)$. $\mathrm{O}$ gráfico da concentração de ${ }^{210} \mathrm{~Pb}_{\text {exc }}$ versus a massa acumulada irá apresentar uma variação que segue a equação da lei do decaimento radiotivo:

$$
\begin{gathered}
C(x)=C_{0} \cdot e^{-\lambda \cdot t} \\
\text { ou } \\
C(x)=C_{0} \cdot e^{-\lambda \cdot \frac{x}{w}}
\end{gathered}
$$

Onde:

$C(x)=$ atividade do ${ }^{210} \mathrm{~Pb}_{\text {exc }}\left(\mathrm{mBq} \mathrm{g}^{-1}\right)$ a uma profundidade $x$

$C_{0}=$ atividade inicial do ${ }^{210} \mathrm{~Pb}_{\text {exc }}\left(\mathrm{mBq} \mathrm{g}^{-1}\right)$

$\lambda=$ constante de decaimento do ${ }^{210} \mathrm{~Pb}\left(0,03114 \mathrm{ano}^{-1}\right)$

$t=$ idade da camada de sedimento (anos)

$x=$ profundidade expressa pela massa acumulada $\left(\mathrm{g} \mathrm{cm}^{-2}\right)$

$w=$ taxa de sedimentação $\left(\mathrm{g} \mathrm{cm}^{-2} \mathrm{ano}^{-1}\right)$ 


\section{- Modelo CRS (Constant Rate of Supply)}

Este modelo é aplicado quando o fluxo de ${ }^{210} \mathrm{~Pb}_{\text {exc }}$ é uma constante, mas a taxa de sedimentação não é constante (Wanderley, 1995).

A diferença entre esses modelos é que o primeiro assume que as velocidades de sedimentação são constantes durante o período em que se é possível mensurar o ${ }^{210} \mathrm{~Pb}_{\text {exc }}$, enquanto o segundo modelo considera qualquer variação na velocidade (Shukla e Joshi, 1989 apud Wanderley, 1995).

Para regiões que sofrem grandes modificações antropogênicas, o modelo CRS mostra-se mais adequado devido à grande variação na velocidade de sedimentação (Wanderley, 1995).

A partir dos valores da atividade de ${ }^{210} \mathrm{~Pb}$ em cada fatia do sedimento, é possível calcular a idade dessas fatias aplicando-se a integração dos valores das atividades de acordo com a seguinte equação:

$$
\mathrm{t}=\lambda^{-1} \cdot \ln \left[\mathrm{A}_{\infty} / \mathrm{A}_{\mathrm{x}}\right]
$$

onde:

$\mathrm{t}=$ Idade (anos) de uma determinada fatia

$\lambda=$ Constante de decaimento do ${ }^{210} \mathrm{~Pb}=0,0311 \mathrm{ano}^{-1}$

$\mathrm{A}_{\infty}=\sum \mathrm{A}_{0 \rightarrow \infty}$ Atividade integrada $\left(\mathrm{mBq} \mathrm{cm}^{-2}\right)$ da superfície até $\mathrm{A}=0$

$\mathrm{A}_{\mathrm{x}}=\sum \mathrm{A}_{0 \rightarrow \mathrm{x}}$ Atividade integrada $\left(\mathrm{mBq} \mathrm{cm}^{-2}\right)$ até a seção em questão

\subsection{4}

\section{Granulometria dos sedimentos}

A descrição quantitativa da textura de solo ou sedimento marinho é realizada por meio de uma análise granulométrica, um ensaio em que se obtém informações a respeito das dimensões dos grãos e da distribuição percentual, em peso, em intervalos de dimensões arbitradas por métodos de classificação de solos e sedimentos. Esses intervalos são também conhecidos como frações do solo ou sedimento e recebem designações específicas, para permitir a descrição do material segundo, exclusivamente, a sua granulometria (Folk, 1966). 
A análise granulométrica pode ser realizada por peneiramento do material seco, por sedimentação, por difração de laser ou por análise de imagem fotográfica com o auxílio de softwares específicos para tal finalidade (Rząsa \& Owczarzak, 2013)

No Brasil, segundo a ABNT NBR 6502 (1995), é adotada a seguinte classificação granulométrica:

Tabela 1: Classificação Granulométrica, adaptada de ABNT NBR 6502/95

\begin{tabular}{cc}
\hline Classificação & Diâmetro dos Grãos $(\boldsymbol{\varnothing , \mathbf { m m } )}$ \\
\hline Bloco de Rocha & $\varnothing>1000$ \\
Matacão & $200<\varnothing \leq 1000$ \\
Seixo & $60<\varnothing \leq 200$ \\
Grânulo & $2<\varnothing \leq 60$ \\
Areia Grossa & $0,6<\varnothing \leq 2$ \\
Areia Média & $0,2<\varnothing \leq 0,6$ \\
Areia Fina & $0,06<\varnothing \leq 0,2$ \\
Silte & $0,002<\varnothing \leq 0,06$ \\
Argila & $\varnothing \leq 0,002$
\end{tabular}

O cascalho (bloco de rocha, matacão, seixo e grânulo) é o sedimento mais grosso e consiste de uma acumulação não consolidada de fragmentos arredondados de minerais e/ou rochas de granulação maior que areia.

A areia (grossa, média e fina) é um sedimento sem coesão em que os grãos são constituídos predominantemente de quartzo, que é formado por sílica ( $\mathrm{SiO} 2)$ em estado cristalino. As partículas mais finas englobam os siltes e as argilas. Acredita-se que mais de 50\% dos minerais em rochas sedimentares são constituídos por minerais de argila que são bons captadores de metais (Suguio, 1980).

Em amostras de sedimento marinho o conhecimento da distribuição granulométrica permite uma melhor interpretação dos dados obtidos, principalmente no que diz respeito à disponibilidade e mobilidade dos metais. É sabido que a presença de metais em sedimento depende fortemente do tamanho das partículas e do teor de matéria orgânica (Fernandes et al., 2011).

No ambiente aquático, as espécies metálicas podem se concentrar na água, nos sedimentos e na biota. Como os sedimentos constituem uma mistura 
heterogênea de partículas (quartzo, minerais argilosos, carbonatos e sólidos orgânicos), predominantemente, a distribuição dos contaminantes, sejam íons metálicos ou contaminantes apolares, dá-se na superfície das partículas da fase sólida, sejam eles particulados suspensos, em deposição ou já depositados no fundo do ambiente aquático (Silvério et al., 2005). Segundo Moore et al. (1989), isto ocorre pois as partículas orgânicas são mais finas e apresentam elevada área superficial que favorece a retenção dos metais.

Conforme descrito por McBride (1989) os metais encontram-se associados às partículas dos sedimentos sob diversos mecanismos de ligação:

$\checkmark \quad$ Adsorvidos em sítios de trocas catiônicas;

$\checkmark$ Co-precipitados com oxi-hidróxidos de ferro-manganês, carbonatos e sulfetos;

$\checkmark$ Complexados com matéria orgânica e

$\checkmark$ Incorporados à rede cristalina de minerais detríticos.

Mestrinho (1998) estudou o comportamento de metais em uma região estuarina e afirma que estes depositam-se em função da predisposição na adsorção e modificação dos mesmos no material sedimentar particulado. O tempo de residência dos metais nos sedimentos dependerá de vários processos no meio aquático, além da adsorção, coprecipitação/floculação e complexação, verifica-se que modificação de $\mathrm{pH}$ e a salinidade poderão promover a fixação ou a dessorção parcial ou liberação total das frações metálicas, associadas aos substratos sedimentares.

A capacidade de troca ou habilidade de adsorver íons, varia amplamente de acordo com o tamanho do grão e a natureza das partículas envolvidas. Botelho et al. (1999) mostraram que a adsorção é importante na fração de tamanho reduzido, pois o grão fino apresenta elevada área especifica. As argilas apresentam a tendência de se associar à matéria orgânica, óxidos e hidróxidos de ferro e manganês e possuem uma alta capacidade de troca catiônica (CTC), ou seja, facilidade em adsorver cátions metálicos. 


\subsection{5 Sulfetos volatilizados por acidificação / Metais extraídos simultaneamente}

Por definição, os sulfetos volatilizados por acidificação (acid volatile sulfides, AVS) são aqueles sulfetos capazes de se transformar em ácido sulfídrico $\left(\mathrm{H}_{2} \mathrm{~S}\right)$ e serem liberados do sedimento na forma gasosa, mediante acidificação a frio com ácido clorídrico $(\mathrm{HCl}) 1 \mathrm{~mol} \mathrm{~L}^{-1}$, sob agitação leve e purga de gás inerte (Allen et $a l .$, 1993). Para este mesmo autor, na fase líquida desta extração estão os metais extraídos simultaneamente (simultaneously extracted metals, SEM), acredita-se que os metais ligados aos sulfetos, assim como os adsorvidos em óxido de ferro ou em carbono orgânico particulado são completamente extraídos durante a acidificação. (Allen et al. (1993); Ankley et al. (1993); Di Toro et al. (1996)).

Larner et al. (2008) afirma que essa extração mais branda não é capaz de recuperar os metais ligados às estruturas de silício e às formas geoquímicas ou minerais mais recalcitrantes da matriz, por isso pode ser considerada uma boa indicação da biodisponibilidade destes metais às populações bentônicas.

Diversos estudos têm mostrado que o AVS é a principal fase controladora da partição de alguns cátions metálicos bivalentes nos sedimentos, principalmente em sedimentos anóxidos, controlando desta forma a biodisponibilidade e toxicidade destes cátions. Metais como chumbo, cádmio, cobre, níquel e zinco são tóxicos a várias formas de vida, principalmente, quando estes se encontram dissolvidos em água, em sua forma iônica. Estes metais são normalmente encontrados em águas superficiais como resultados de processos naturais, como o intemperismo que pode afetar rochas que contêm estes metais ou, principalmente, devido à atividade humana, como mineração, fundição ou outros processos industriais que gerem resíduos tóxicos.

Em ambientes marinhos não contaminados o AVS é composto basicamente de sulfetos amorfos de ferro. Na presença de cátions metálicos bivalentes, como $\mathrm{Pb}^{2+}, \mathrm{Cd}^{2+}, \mathrm{Cu}^{2+}, \mathrm{Ni}^{2+}$ e $\mathrm{Zn}^{2+}$, que formam sulfetos menos solúveis que o sulfeto ferroso, ocorre o deslocamento do ferro no $\mathrm{FeS}_{(\mathrm{s})}$, conforme a reação:

$$
\mathrm{Me}^{2+}+\mathrm{FeS}_{(\mathrm{s})} \rightarrow \mathrm{MeS}_{(\mathrm{s})}+\mathrm{Fe}^{2+}
$$


Desta mesma forma, um íon metálico mais solúvel será preferencialmente substituído por outro íon que forme um sulfeto menos solúvel.

A partir de década de 1990, muitos estudos começaram a ser conduzidos, tendo como objetivo a avaliação da toxicidade de substâncias orgânicas não iônicas nos sedimentos (Di Toro et al., 1990), além da função dos sulfetos na imobilização ou biodisponibilização de metais tóxicos neste mesmo compartimento (Di Toro et al., 1991; Ankley et al., 1993). Estes estudos demonstraram que a toxicidade dos íons metálicos supracitados não é manifestada quando a concentração molar de AVS excede a soma molar da concentração iônica.

\subsection{6 \\ Determinação Elementar e Isotópica de carbono e nitrogênio}

A composição elementar e isotópica de sedimentos costeiros tem potencial para permitir identificação das fontes de matéria orgânica neste ambiente, possibilitando uma avaliação da influência fluvio-marinha a que o ambiente estuarino está sujeito.

A razão isotópica de carbono permite distinguir entre fontes marinhas e continentais de matéria orgânica, bem como identificar diferentes tipos de plantas, dado que estas podem ter diferentes processos bioquímicos de incorporação do carbono, segundo Jorge e Portela (2013). A maioria das plantas fotossintéticas utiliza o mecanismo de Calvin (C3), mecanismo este que produz um composto com 3 átomos de carbono após a reação de fixação do dióxido de carbono. Por outro lado, as plantas C4 favorecem o mecanismo de Slack, que produz ácido málico ou aspartato, compostos com 4 átomos de carbono.

Meyers (1994) determinou os valores de $\delta^{13} \mathrm{C}$ para plantas $\mathrm{C} 3$, obtendo valores na ordem de $-27 \%$ enquanto para as plantas $\mathrm{C} 4$, o valor obtido estava em torno de $-14 \%$. Nos dois casos, a fonte de $\mathrm{CO}_{2}$ é a atmosfera, onde o valor $\delta^{13} \mathrm{C}$ fica em torno de $-7 \%$. Segundo Meyers (1994) as algas marinhas possuem uma assinatura isotópica distinta das de água doce, permitindo a sua diferenciação por meio da determinação do $\delta^{13} \mathrm{C}$ em sedimentos marinhos. As algas marinhas apresentam valores de $\delta^{13} \mathrm{C}$ entre $20-23 \%$, enquanto as algas de água doce apresentam valores entre 27-29\%. Essa diferença ocorre, pois, as algas de água 
doce utilizam em seu metabolismo $\mathrm{CO}_{2}$ dissolvido, que normalmente está em equilíbrio isotópico com o $\mathrm{CO}_{2}$ atmosférico, enquanto a fonte de carbono inorgânico para as algas marinhas é o bicarbonato dissolvido, que apresenta valores de $\delta^{13} \mathrm{C}$ próximos a $0 \%$.

Quando determinada a composição isotópica de um sedimento que acumula matéria orgânica de diversas fontes, esta irá sempre refletir uma mistura dessas fontes, sendo necessário analisar vários parâmetros para uma melhor diferenciação. O cálculo da razão entre a composição elementar em carbono e nitrogênio $(\mathrm{C} / \mathrm{N})$ e a sua correlação com os correspondentes valores de $\delta^{13} \mathrm{C}$ melhora a identificação das fontes com maior influência no fornecimento da matéria orgânica (Meyers, 1994).

Rezende et al. (2010) determinaram a razão $\mathrm{C} / \mathrm{N}$ e $\delta^{13} \mathrm{C}$ e concluíram que o sedimento da Baía de Sepetiba apresenta uma mistura equilibrada de matéria orgânica oriunda de plantas superiores $(48 \%$ ) e de material planctônico (46\%), com uma pequena contribuição de vegetação do tipo gramínea (6\%), com valor médio para a razão $\mathrm{C} / \mathrm{N}$ de $7,48(11,1$ a 15,3$)$ e de $-23,9 \%$ o $(-21,8$ a $25,2 \%$ ) para $\delta^{13} \mathrm{C}$.

Assim como os valores de $\delta^{13} \mathrm{C}$, também os valores de $\delta^{15} \mathrm{~N}$ têm sido empregados em regiões estuarinas, como uma ferramenta auxiliar na determinação da origem da matéria orgânica. Matéria orgânica de origem marinha possui $\delta^{15} \mathrm{~N}$ entre 3-12\%, com uma média de 5-7\%o para fito plâncton que usam nitrato dissolvido. A matéria orgânica de plantas terrestres fixadoras de nitrogênio tem $\delta^{15} \mathrm{~N}$ próximo de zero, enquanto aquelas que usam fertilizantes minerais apresentam $\delta^{15} \mathrm{~N}$ positivo. Adicionalmente, nitrogênio derivado de esgoto é bastante enriquecido em ${ }^{15} \mathrm{~N}$, apresentando $\delta^{15} \mathrm{~N}$ entre $10-22 \%$ (Gao et al., 2012).

É importante, também ressaltar que as características do $\delta^{15} \mathrm{~N}$ em sedimentos podem ser modificadas tendendo refletir mais a diagênese da matéria orgânica do que a sua origem em si (Thornton e McManus, 1994; Xu et al., 2017). 


\section{7 Valores-Guia de Qualidade de Sedimentos de Ambientes Aquáticos (VGQS)}

A avaliação da qualidade de sedimentos foi, por muito tempo, realizada somente por meio da determinação das concentrações das espécies químicas individuais. Muitas vezes, esses valores eram comparados apenas com referências, que geralmente eram valores de "background" e que não permitiam, evidentemente, um estudo aprofundado sobre o verdadeiro impacto dos contaminantes no meio ambiente. Nas últimas décadas, conforme apontado por Burton (2002), tem sido desenvolvido um grande número de guias de qualidade de sedimentos para avaliação e manejo de sedimentos contaminados.

Das várias abordagens que aparecem na literatura especializada empregadas na avaliação da qualidade e manejo de sedimentos contaminados, muitas fazem uso de valores e critérios, mais apropriadamente falando, de guias numéricos de qualidade para diversas espécies químicas. Estes guias são referidos como valoresguia de qualidade de sedimento, ou apenas VGQS. (Mozeto et al., 2006).

\subsection{1 \\ VGQS de Partição}

Os VGQS de partição, também descritos como VGQS do AVS ou VGQS da fase sólida, apoiam-se, teoricamente, no equilíbrio de partição de contaminantes para metais e sulfetos volatilizáveis por acidificação. Este valor é calculado a partir da diferença entre o $\sum[\mathrm{SEM}]$ e $[\mathrm{AVS}]$, onde $\sum[\mathrm{SEM}]$ é igual ao somatório da concentração molar de metais extraídos simultaneamente ( $\mathrm{Pb}, \mathrm{Cd}, \mathrm{Cu}, \mathrm{Ni}$ e $\mathrm{Zn})$ e [AVS] é a concentração molar de sulfetos volatilizáveis por acidificação nos sedimentos (Ankley et al., 1996; Simpson et al., 2005; Di Toro et al., 1990)

Se o resultado da diferença $\sum[\mathrm{SEM}]$ - [AVS] for menor ou igual a zero, ou seja, não há excesso de SEM em relação ao AVS, a concentração da mistura destes metais não deve causar impactos sobre organismos bentônicos, conforme descrito por Mozeto et al. (2006). Porém é importante ressaltar que este VGQS apenas prevê a não toxicidade dos sedimentos para estes parâmetros, quando o valor da diferença $\sum[\mathrm{SEM}]$ - [AVS] for maior do que zero, os sedimentos não necessariamente 
apresentarão toxicidade, uma vez que pode haver o controle da biodisponibilidade e toxicidade por outra fase que não o sulfeto, como por exemplo, o carbono orgânico total (COT) dos sedimentos. (Ankley et al., 1996; USEPA, 2000).

Para Fagnani et al. (2011), expressar a relação entre SEM e AVS apresenta duas desvantagens, a primeira diz respeito ao fato de que quando valores muito baixos de sulfeto são comparados com valores relativamente altos de metais, o número resultante é extremamente alto e não se pode afirmar nada sobre a quantidade de metais que estaria biodisponível. Em segundo lugar, refinamentos do cálculo levando em conta outras fases ligantes são difíceis de serem realizados.

Quando o somatório das concentrações molares dos metais for maior do que a concentração molar de sulfeto, os metais poderão apresentar riscos significativos para a biota caso não exista outra fase ligante controlando a biodisponibilidade destes. Fagnani et al. (2011) acrescenta que os óxidos e hidróxidos de ferro e manganês dificilmente existem em ambientes anaeróbicos e sulfídricos, limitando a importância destas espécies químicas às primeiras camadas do sedimento. Neste contexto, a matéria orgânica passa a ter alta relevância, já que ela é a principal fase ligante de metais depois dos sulfetos, estando presente mesmo em ambientes anaeróbicos.

Por esta razão, nos casos em que $\sum[\mathrm{SEM}]>$ [AVS], adiciona-se uma variável à expressão, tornado-a:

$$
\frac{\sum[\mathrm{SEM}]-[\mathrm{AVS}]}{f_{\mathrm{OC}}}
$$

Sendo foc a fração em massa de carbono orgânico presente no sedimento.

Baseada neste conceito, a Agência de Proteção Ambiental dos Estados Unidos da América (USEPA), utilizando um banco de dados com aproximadamente quatrocentos resultados de diversos estudos de toxicidade à biota, derivou quatro faixas de valores-guia de qualidade do sedimento com base nos resultados de AVS, SEM e $f_{\text {OC }}$ (Hansen et al., 2005). Resumidamente, encontram-se a seguir as faixas com os VGQS. 


\section{$1-\left(\sum[\mathrm{SEM}]-[\mathrm{AVS}]\right) /$ foc $<130 \mu \mathrm{mol} \mathrm{goc}^{-1}$}

Baixo risco de efeitos biológicos adversos devido ao $\mathrm{Cd}, \mathrm{Cu}, \mathrm{Pb}, \mathrm{Ni}$ e $\mathrm{Zn}$.

\section{$2-130 \mu \mathrm{mol} \mathrm{goc}^{-1}<\left(\sum[\mathrm{SEM}]-[\mathrm{AVS}]\right) /$ foc $<3000 \mu \mathrm{mol} \mathrm{goc}{ }^{-1}$}

Podem haver efeitos biológicos adversos devido ao $\mathrm{Cd}, \mathrm{Cu}, \mathrm{Pb}, \mathrm{Ni}$ e $\mathrm{Zn}$.

\section{$3-\left(\sum[\mathrm{SEM}]-[\mathrm{AVS}]\right) /$ foc $>\mathbf{3 0 0 0} \boldsymbol{\mu m o l ~ \mathrm { goc } ^ { - 1 }}$}

São esperados efeitos biológicos adversos devido ao $\mathrm{Cd}, \mathrm{Cu}, \mathrm{Pb}$, Ni e $\mathrm{Zn}$.

\section{$4-\sum[\mathrm{SEM}]-[\mathrm{AVS}] \leq \mathbf{0}$}

Não são esperados efeitos biológicos adversos devido ao $\mathrm{Cd}, \mathrm{Cu}, \mathrm{Pb}$, Ni e Zn.

\subsection{2}

\section{VGQS Empíricos}

Os VGQS empíricos são aqueles que se apoiam, empiricamente, em dados emparelhados de concentração química dos contaminantes individuais e efeitos biológicos observados, ou seja, aqueles derivados de informações da comunidade bentônica ou de testes de toxicidade realizados em laboratório com sedimentos fortificados ou não (Mozeto et al., 2006).

Diferente do VGQS de partição, que possuem faixas bem definidas e utilizadas amplamente pela comunidade científica, Burton (2002) aponta a existência de numerosos modelos para os VGQS empíricos, todos derivados de maneira bastante similar e que, em alguns casos, apresentam valores próximos, mas possuem denominações diferentes, como por exemplo:

a) 'TEL' e 'PEL', do inglês Threshold Effect Level e Probable Effect Level, ou seja, nível limiar de efeitos e nível provável de efeitos (Long \& Morgan, 1990)

b) 'ERL' e 'ERM', do inglês Effect Range-Low e Effect Range-Median, intervalo de efeito baixo e intervalo de efeito médio, respectivamente. (Macdonald et al., 1996)

c) 'TEC', 'MEC' e 'EEC, do inglês Threshold Effect Concentration, Medium Effect Concentration e Extreme Effect Concentration, ou seja, concentração limiar de efeito, concentração de médio efeito e concentração de efeitos extremos. (Swartz, 1999) 
Estes VGQS foram derivados a partir de um amplo banco de dados, no qual o peso estatístico é bastante significativo para a definição dos valores numéricos em questão, válidos para contaminantes individuais. Segundo o modelo da curva de resposta biológica apresentada por vários organismos bentônicos, VGQS do tipo limiar de efeitos preveem toxicidade para menos de $5 \%$ da fauna e os VGQS de efeitos prováveis preveem toxicidade para quantidades iguais ou maiores do que $50 \%$ da fauna dos sedimentos (Mozeto et al., 2006). Evidentemente, entre os níveis inferiores e superiores há uma zona de transição, em que a toxicidade varia significativamente à medida que a concentração do contaminante aumenta.

Para Burton (2002), esses VGQS apontam para uma situação de contaminação, ou não, do sedimento marinho, mas não consideram a variação da biodisponibilidade dos contaminantes nos sedimentos, razão pela qual não são capazes de prever inequivocamente a toxicidade dos sedimentos. Os contaminantes dos sedimentos não agem individualmente sobre os organismos, efeitos tóxicos são causados por misturas complexas de contaminantes, além disso, os diferentes organismos bentônicos não respondem da mesma forma, quando expostos aos contaminantes. Burton (2002) cita ainda que, apesar do amplo banco de dados a disposição da comunidade científica para a derivação de VGQS, há de se considerar a natureza altamente dinâmica dos sedimentos nos ambientes aquáticos, por isso se faz necessário uma abordagem integrada para a avaliação da qualidade e manejo de sedimentos marinhos.

\subsection{3}

\section{Valores-Guia adotados no Brasil}

No Brasil não há uma legislação vigente em todo território nacional que utilize os VGQS empíricos como referência, sendo adotados os valores de 'TEL' e 'PEL' para águas doces e os valores de 'ERL' e 'ERM' para águas salinas e salobras.

No âmbito federal, o Conselho Nacional do Meio Ambiente (CONAMA), que é um órgão colegiado ligado ao Ministério do Meio Ambiente, é competente para o estabelecimento de normas e critérios para o licenciamento ambiental, como 
também, para o estabelecimento de padrões de controle da poluição ambiental, atribuições que são exercidas por meio de atos administrativos normativos chamados de resoluções.

No que diz respeito aos sedimentos, pode-se citar a resolução CONAMA 454 (2012) que estabelece as diretrizes gerais e os procedimentos referenciais para o gerenciamento do material a ser dragado em águas sob jurisdição nacional. A Tabela 2 apresenta os níveis de classificação apontados pela resolução, estão contemplados nesta tabela apenas os metais determinados neste estudo.

$\mathrm{Na}$ ausência de uma resolução específica sobre qualidade de sedimentos, a resolução CONAMA 454 (2012) tem sido amplamente utilizada, em particular, pelo fato dos valores guia adotados terem sido originados das normas canadense e americana de qualidade de sedimentos.

Tabela 2: Níveis de classificação de metais em sedimentos, CONAMA 454/12

Níveis de Classificação em

Unidade de Material Seco $\left(\mathrm{mg} \mathrm{kg}^{-1}\right)$

Metais

Nível 2 (ERM)

\begin{tabular}{ccc}
\hline cádmio $(\mathrm{Cd})$ & 1,2 & 7,2 \\
chumbo $(\mathrm{Pb})$ & 46,7 & 218 \\
cobre $(\mathrm{Cu})$ & 34 & 270 \\
cromo $(\mathrm{Cr})$ & 81 & 370 \\
mercúrio $(\mathrm{Hg})$ & 0,3 & 1,0 \\
níquel $(\mathrm{Ni})$ & 20,9 & 51,6 \\
zinco $(\mathrm{Zn})$ & 150 & 410 \\
\hline
\end{tabular}




\section{3 \\ Materiais e Métodos}

\section{1}

\section{Coleta de amostras}

\subsection{1}

\section{Amostragem de sedimento superficial}

Foram coletados sedimentos em 38 estações ao longo da Baía de Sepetiba, entre julho e outubro de 2016, e o critério adotado para selecionar esses pontos de amostragem foi o estudo realizado pelo INEA na década de 1990 dentro do projeto de cooperação técnica FEEMA/GTZ, no qual as mesmas estações foram amostradas e avaliadas. A distribuição das estações na região da baía pode ser vista na Figura 9 e as coordenadas encontram-se na Tabela 3.

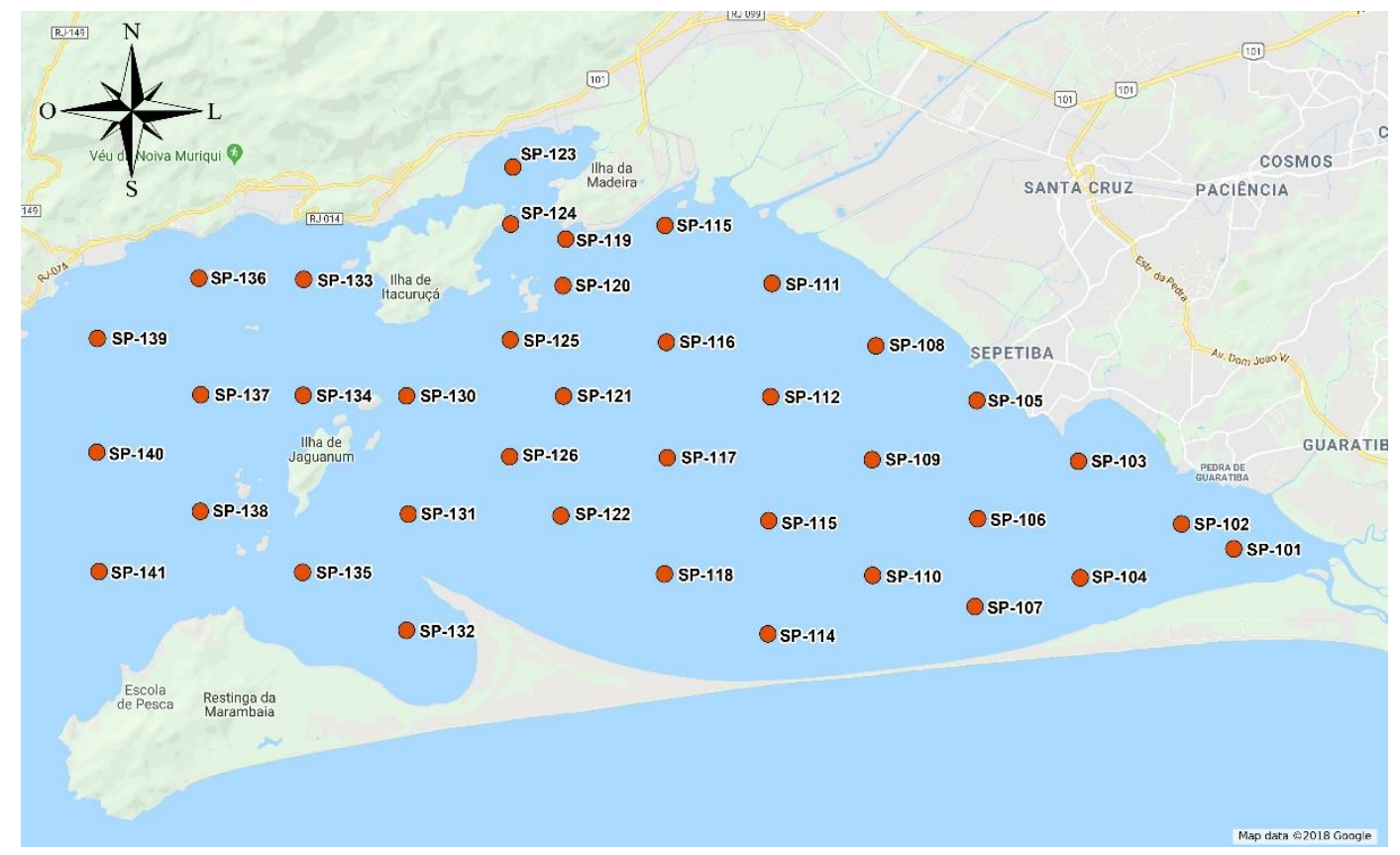

Figura 9: Distribuição geográfica dos pontos de amostragem de sedimento superficial ao longo da Baía de Sepetiba. 
Tabela 3: Coordenadas geográficas das estações de amostragem de sedimentos superficiais.

\begin{tabular}{|c|c|c|c|c|}
\hline \multirow{2}{*}{$\begin{array}{l}\text { Estações de } \\
\text { amostragem }\end{array}$} & \multicolumn{2}{|c|}{ Coordenadas Geográficas (GMS) } & \multicolumn{2}{|c|}{ UTM-23S / Datum WGS 84} \\
\hline & Latitude & Longitude & $\mathrm{X}$ & $\mathrm{Y}$ \\
\hline SP-101 & $23^{\circ} 01^{\prime} 26.35^{\prime \prime} \mathrm{S}$ & $43^{\circ} 38^{\prime} 04.66^{\prime \prime O}$ & 639910 & 7453173 \\
\hline SP-102 & $23^{\circ} 01^{\prime} 00.36^{\prime \prime} \mathrm{S}$ & $43^{\circ} 39^{\prime} 04.85^{\prime \prime O}$ & 638204 & 7453988 \\
\hline SP-103 & $22^{\circ} 59^{\prime} 55.18^{\prime \prime S}$ & $43^{\circ} 41^{\prime} 03.92^{\prime \prime O}$ & 634832 & 7456023 \\
\hline SP-104 & $23^{\circ} 01^{\prime} 56.49^{\prime \prime} \mathrm{S}$ & $43^{\circ} 41^{\prime} 01.72^{\prime \prime O}$ & 634854 & 7452292 \\
\hline SP-105 & $22^{\circ} 58^{\prime} 52.17 " \mathrm{~S}$ & $43^{\circ} 43^{\prime} 00.98^{\prime \prime O}$ & 631516 & 7457991 \\
\hline SP-106 & $23^{\circ} 00^{\prime} 55.13^{\prime \prime S}$ & $43^{\circ} 42^{\prime} 59.96 " \mathrm{O}$ & 631512 & 7454209 \\
\hline SP-107 & $23^{\circ} 02^{\prime} 26.30^{\prime \prime} \mathrm{S}$ & $43^{\circ} 43^{\prime} 02.92^{\prime \prime O}$ & 631403 & 7451406 \\
\hline SP-108 & $22^{\circ} 57^{\prime} 55.39 " \mathrm{~S}$ & $43^{\circ} 44^{\prime} 57.29 " \mathrm{O}$ & 628219 & 7459766 \\
\hline SP-109 & $22^{\circ} 59^{\prime} 53.45^{\prime \prime} \mathrm{S}$ & $43^{\circ} 45^{\prime} 01.61^{\prime \prime O}$ & 628065 & 7456136 \\
\hline SP-110 & $23^{\circ} 01^{\prime} 53.98 " \mathrm{~S}$ & $43^{\circ} 45^{\prime} 01.02^{\prime \prime O}$ & 628050 & 7452429 \\
\hline SP-111 & $22^{\circ} 56^{\prime} 50.34^{\prime \prime} \mathrm{S}$ & $43^{\circ} 46^{\prime} 57.29^{\prime \prime} \mathrm{O}$ & 624818 & 7461795 \\
\hline SP-112 & $22^{\circ} 58^{\prime} 48.16^{\prime \prime S}$ & $43^{\circ} 46^{\prime} 58.94^{\prime \prime O}$ & 624741 & 7458172 \\
\hline SP-113 & $23^{\circ} 00^{\prime} 57.10^{\prime \prime} \mathrm{S}$ & $43^{\circ} 47^{\prime} 00.87^{\prime \prime O}$ & 624653 & 7454207 \\
\hline SP-114 & $23^{\circ} 02^{\prime} 54.68 " \mathrm{~S}$ & $43^{\circ} 47^{\prime} 01.78^{\prime \prime O}$ & 624597 & 7450591 \\
\hline SP-115 & $22^{\circ} 55^{\prime} 50.05^{\prime \prime} \mathrm{S}$ & $43^{\circ} 49^{\prime} 00.66^{\prime \prime O}$ & 621319 & 7463678 \\
\hline SP-116 & $22^{\circ} 57^{\prime} 51.62^{\prime \prime S}$ & $43^{\circ} 48^{\prime} 59.14^{\prime \prime O}$ & 621332 & 7459939 \\
\hline SP-117 & $22^{\circ} 59^{\prime} 51.59^{\prime \prime} \mathrm{S}$ & $43^{\circ} 48^{\prime} 58.20^{\prime \prime O}$ & 621329 & 7456249 \\
\hline SP-118 & $23^{\circ} 01^{\prime} 52.51^{\prime \prime S}$ & $43^{\circ} 49^{\prime} 01.23^{\prime \prime O}$ & 621213 & 7452531 \\
\hline SP-119 & $22^{\circ} 56^{\prime} 04.39^{\prime \prime} \mathrm{S}$ & $43^{\circ} 50^{\prime} 55.23^{\prime \prime O}$ & 618052 & 7463263 \\
\hline SP-120 & $22^{\circ} 56^{\prime} 52.63^{\prime \prime S}$ & $43^{\circ} 50^{\prime} 58.33^{\prime \prime O}$ & 617952 & 7461780 \\
\hline SP-121 & $22^{\circ} 58^{\prime} 47.54^{\prime \prime S}$ & $43^{\circ} 50^{\prime} 57.57^{\prime \prime O}$ & 617946 & 7458246 \\
\hline SP-122 & $23^{\circ} 00^{\prime} 52.03^{\prime \prime S}$ & $43^{\circ} 51^{\prime} 00.62^{\prime \prime O}$ & 617829 & 7454418 \\
\hline SP-123 & $22^{\circ} 54^{\prime} 49.45^{\prime \prime S}$ & $43^{\circ} 51^{\prime} 55.99^{\prime \prime O}$ & 616339 & 7465581 \\
\hline SP-124 & $22^{\circ} 55^{\prime} 48.52^{\prime \prime} \mathrm{S}$ & $43^{\circ} 51^{\prime} 58.48^{\prime \prime O}$ & 616254 & 7463765 \\
\hline SP-125 & $22^{\circ} 57^{\prime} 49.11 " \mathrm{~S}$ & $43^{\circ} 51^{\prime} 59.07^{\prime \prime O}$ & 616279 & 7460056 \\
\hline SP-126 & $22^{\circ} 59^{\prime} 50.55^{\prime \prime S}$ & $43^{\circ} 51^{\prime} 59.66^{\prime \prime O}$ & 616163 & 7456322 \\
\hline SP-130 & $22^{\circ} 58^{\prime} 47.33^{\prime \prime S}$ & $43^{\circ} 53^{\prime} 58.61 " \mathrm{O}$ & 612791 & 7458292 \\
\hline SP-131 & $23^{\circ} 00^{\prime} 50.23^{\prime \prime S}$ & $43^{\circ} 53^{\prime} 56.66^{\prime \prime O}$ & 612818 & 7454512 \\
\hline SP-132 & $23^{\circ} 02^{\prime} 51.17^{\prime \prime S}$ & $43^{\circ} 53^{\prime} 58.63^{\prime \prime O}$ & 612734 & 7450793 \\
\hline SP-133 & $22^{\circ} 56^{\prime} 46.24^{\prime \prime S}$ & $43^{\circ} 55^{\prime} 57.41^{\prime \prime O}$ & 609435 & 7462041 \\
\hline SP-134 & $22^{\circ} 58^{\prime} 46.62^{\prime \prime S}$ & $43^{\circ} 55^{\prime} 57.91 " \mathrm{O}$ & 609394 & 7458339 \\
\hline SP-135 & $23^{\circ} 01^{\prime} 50.83^{\prime \prime S}$ & $43^{\circ} 55^{\prime} 58.71 " \mathrm{O}$ & 609330 & 7452674 \\
\hline SP-136 & $22^{\circ} 56^{\prime} 44.96 " \mathrm{~S}$ & $43^{\circ} 57^{\prime} 58.13^{\prime \prime O}$ & 605997 & 7462105 \\
\hline SP-137 & $22^{\circ} 58^{\prime} 46.23^{\prime \prime S}$ & $43^{\circ} 57^{\prime} 56.12^{\prime \prime O}$ & 606028 & 7458375 \\
\hline SP-138 & $23^{\circ} 00^{\prime} 47.33^{\prime \prime S}$ & $43^{\circ} 57^{\prime} 56.74 " \mathrm{O}$ & 605984 & 7454651 \\
\hline SP-139 & $22^{\circ} 57^{\prime} 47.46^{\prime \prime S}$ & $43^{\circ} 59^{\prime} 55.33^{\prime \prime O}$ & 602646 & 7460206 \\
\hline SP-140 & $22^{\circ} 59^{\prime} 46.05^{\prime \prime S}$ & $43^{\circ} 59^{\prime} 55.82^{\prime \prime O}$ & 602607 & 7456559 \\
\hline SP-141 & $23^{\circ} 01^{\prime} 49.99^{\prime \prime S}$ & $43^{\circ} 59^{\prime} 53.36^{\prime \prime O}$ & 602651 & 7452747 \\
\hline
\end{tabular}


Os sedimentos superficiais foram coletados com o auxílio de uma draga Petersen (Figura 10) e, em seguida, 3 alíquotas das amostras foram separadas e acondicionadas em recipientes e temperatura adequados para a preservação necessária a cada ensaio que viria a ser realizado no laboratório.

Para a determinação de sulfetos ácidos voláteis e metais simultaneamente extraídos utilizou-se frascos de vidro limpos e descontaminados por meio de imersão em solução de $\mathrm{HNO}_{3} 10 \%$ m/v por, pelo menos $24 \mathrm{~h}$, seguido por uma lavagem com água ultrapura (Master System MS2000, GEHAKA, Brasil).

Os recipientes foram preenchidos completamente para prevenir as perdas de sulfeto por volatilização ou por oxidação, que seria causada por exposição ao ar (Fagnani et al., 2011). Os frascos foram imediatamente refrigerados a, pelo menos, $4{ }^{\circ} \mathrm{C}$ para prevenir a ação biológica neste material até o momento das análises, que foram realizadas o mais rápido possível, dentro do prazo máximo de 2 semanas, conforme recomendado por Allen et al. (1991). Estes frascos receberam, além da identificação do ponto amostral, a letra "S".

Para a determinação de mercúrio $(\mathrm{Hg})$ as amostras foram acondicionadas em tubos tipo falcon de $50 \mathrm{~mL}$ (Sarstedt AG \& Co, Germany), identificados com "Hg", congeladas imediatamente e mantidas desta forma até a extração do Hg total e determinação instrumental.

Uma terceira alíquota da mesma amostra, utilizada para os demais ensaios, foi acondicionada em frascos plásticos de polietileno novos e mantidas sob refrigeração a pelo menos $4{ }^{\circ} \mathrm{C}$, estes recipientes receberam a letra " $\mathrm{M}$ " como identificação adicional.

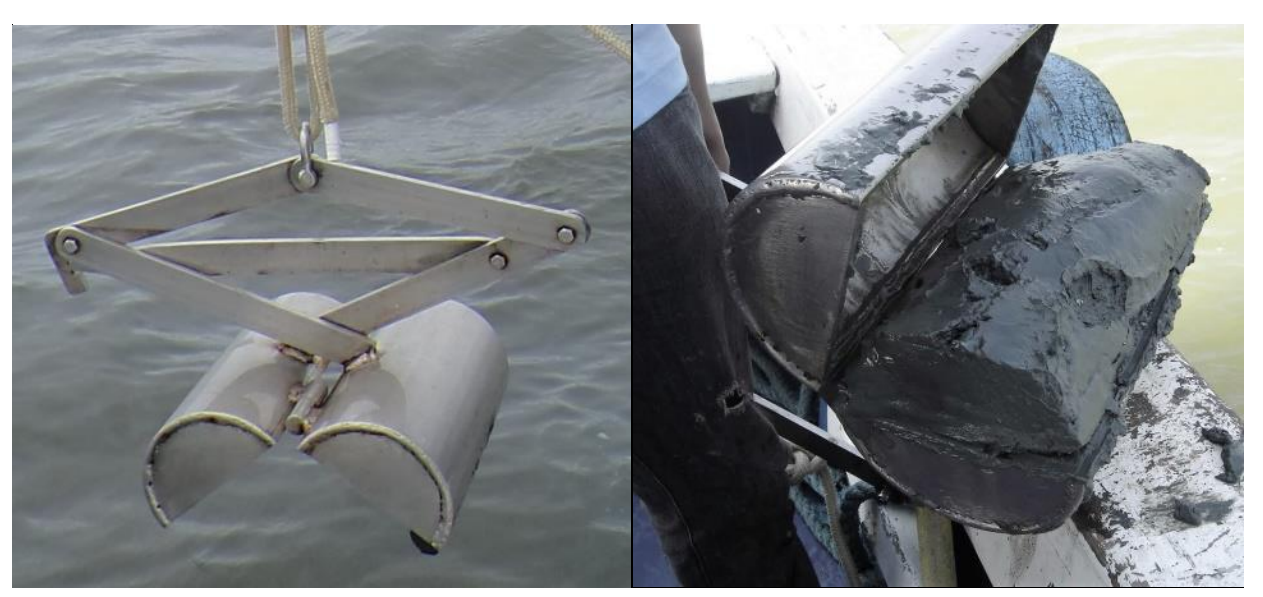

Figura 10: Draga Petersen utilizada na coleta dos sedimentos 


\subsection{2}

\section{Amostragem de testemunhos sedimentares}

Foram coletados 9 testemunhos sedimentares em diferentes regiões da Baía de Sepetiba. Para a escolha dos pontos de amostragem foram definidos como critérios, a distância dos mesmos com relação aos principais rios e canais que desaguam na baía; e o sentido de circulação das águas na maré enchente, uma vez que o sedimento oriundo dos rios e canais é naturalmente conduzido para a parte leste da baía, conforme descrito por Fonseca (2011). A distribuição dos pontos de amostragem pode ser observada na Figura 11 e as coordenadas geográficas encontram-se na Tabela 4.

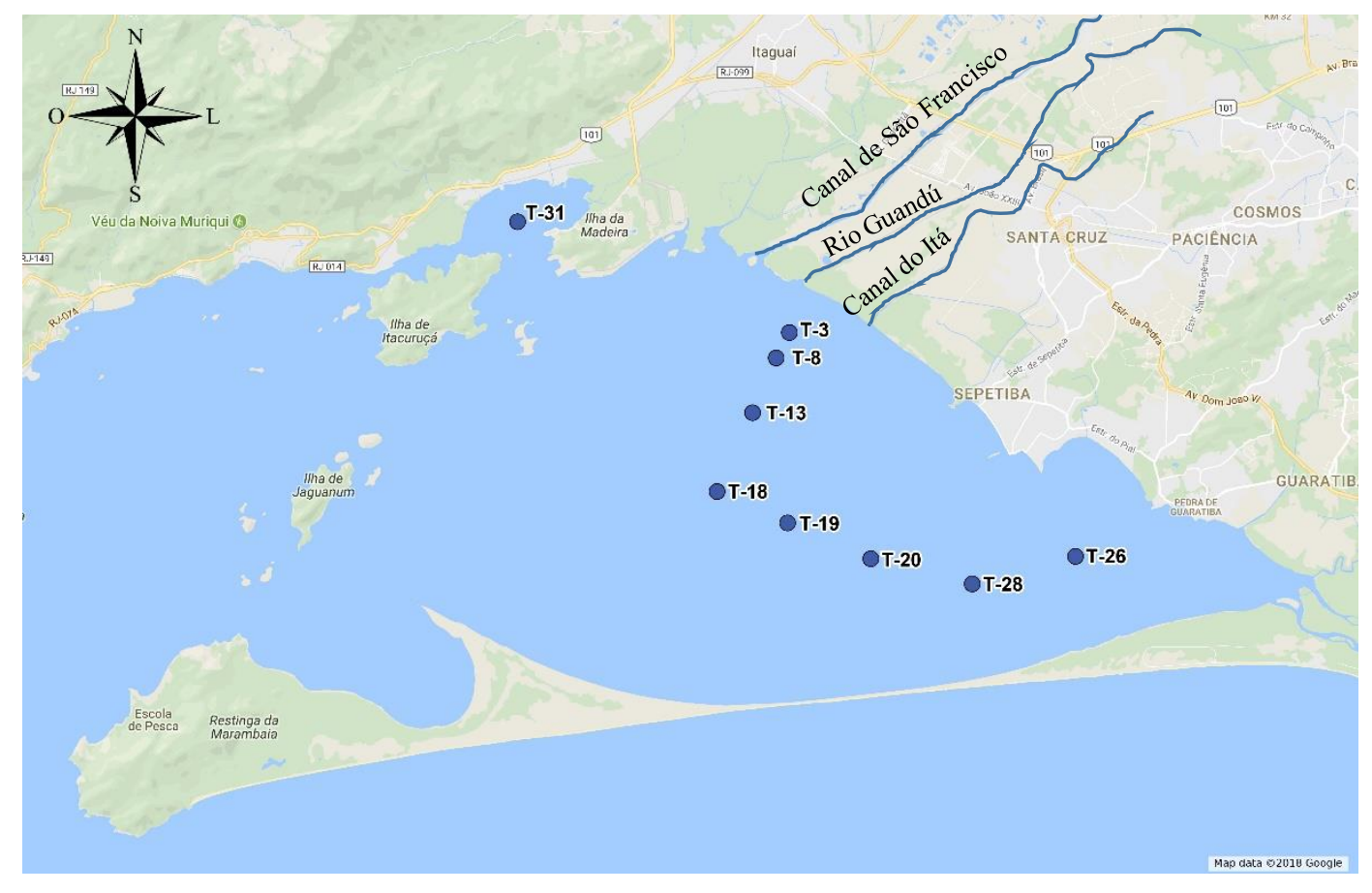

Figura 11: Distribuição dos pontos de amostragem de testemunhos sedimentares ao longo da Baía de Sepetiba.

Tabela 4: Coordenadas geográficas das estações de amostragem de testemunhos sedimentares

\begin{tabular}{|c|c|c|c|c|}
\hline \multirow{2}{*}{$\begin{array}{l}\text { Estações de } \\
\text { amostragem }\end{array}$} & \multicolumn{2}{|c|}{ Coordenadas Geográficas (GMS) } & \multicolumn{2}{|c|}{ UTM-23S / Datum WGS 84} \\
\hline & Latitude & Longitude & $X$ & Y \\
\hline $\mathrm{T}-3$ & $22^{\circ} 56^{\prime} 55.5^{\prime \prime S}$ & $43^{\circ} 46^{\prime} 22.2^{\prime \prime O}$ & 625816 & 7461627 \\
\hline $\mathrm{T}-8$ & $22^{\circ} 57^{\prime} 23.4^{\prime \prime S}$ & $43^{\circ} 46^{\prime} 37.9^{\prime \prime O}$ & 625363 & 7460773 \\
\hline $\mathrm{T}-13$ & $22^{\circ} 58^{\prime} 23.4^{\prime \prime S}$ & $43^{\circ} 47^{\prime} 05.8^{\prime \prime O}$ & 624551 & 7458935 \\
\hline $\mathrm{T}-18$ & $22^{\circ} 59^{\prime} 50.0^{\prime \prime S}$ & $43^{\circ} 47^{\prime} 48.2^{\prime \prime O}$ & 623323 & 7456283 \\
\hline $\mathrm{T}-19$ & $23^{\circ} 00^{\prime} 24.3^{\prime \prime S}$ & $43^{\circ} 46^{\prime} 24.2^{\prime \prime O}$ & 625707 & 7455208 \\
\hline $\mathrm{T}-20$ & $23^{\circ} 01^{\prime} 03.6^{\prime \prime S}$ & $43^{\circ} 44^{\prime} 45.0^{\prime \prime O}$ & 628519 & 7453976 \\
\hline $\mathrm{T}-26$ & $23^{\circ} 01^{\prime} 01.1^{\prime \prime S}$ & $43^{\circ} 40^{\prime} 41.3^{\prime \prime O}$ & 635458 & 7453991 \\
\hline $\mathrm{T}-28$ & $23^{\circ} 01^{\prime} 31.1^{\prime \prime S}$ & $43^{\circ} 42^{\prime} 44.2^{\prime \prime} \mathrm{O}$ & 631950 & 7453100 \\
\hline $\mathrm{T}-31$ & $22^{\circ} 54^{\prime} 53.9^{\prime \prime} \mathrm{S}$ & $43^{\circ} 51^{\prime} 46.0^{\prime \prime O}$ & 616624 & 7465442 \\
\hline
\end{tabular}


A amostragem foi realizada com o auxílio de um amostrador gravitacional de testemunhos (Figura 12) equipado com tubos de PVC de $120 \mathrm{~cm}$ e diâmetro de $6 \mathrm{~cm}$, fornecido pela empresa austríaca Uwitec.

Os testemunhos amostrados foram subdivididos imediatamente após a coleta em camadas de $2 \mathrm{~cm}$ que foram pesadas e refrigeradas a pelo menos $4{ }^{\circ} \mathrm{C}$ para posterior tratamento laboratorial.
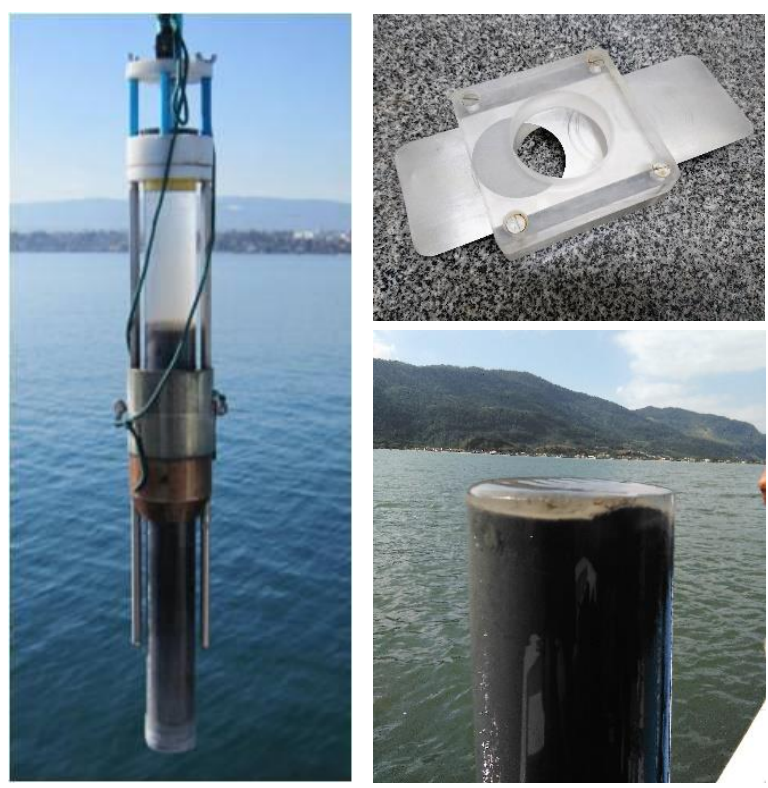

Figura 12: Amostrador gravitacional de testemunhos e acessório para subdivisão das camadas

\section{2}

\section{Teor de Umidade no Sedimento}

A determinação de umidade dos sedimentos é necessária para a normalização dos dados e comparação com normas vigentes para cada tipo de sedimento.

Os ensaios foram realizados logo após a coleta, de modo a minimizar ao máximo a perda por evaporação.

Para a determinação do teor de umidade nas amostras de sedimento superficial foram pesados cerca de $100 \mathrm{~g}$ de amostra em recipientes de vidro limpos, que foram levados a estufa por $48 \mathrm{~h}$ a aproximadamente $110^{\circ} \mathrm{C}$, e após este tempo de secagem as amostras foram resfriadas em dessecador e pesadas. $\mathrm{O}$ processo de secagem foi então repetido por mais $12 \mathrm{~h}$ e as amostras foram pesadas novamente, observando-se a massa constante, indicativo de que toda a água havia sido retirada 
do sedimento. $\mathrm{O}$ teor de umidade foi determinado pela diferença entre as massas úmida e seca de cada amostra.

Para a determinação do teor de umidade nas camadas obtidas pelo fatiamento dos testemunhos seguiu-se o mesmo procedimento de secagem utilizado nos sedimentos superficiais, mas nesse caso a massa inicial úmida era correspondente a massa de toda camada.

\section{3 \\ Determinação de Metais}

A metodologia utilizada para a determinação dos metais em sedimento total foi adaptada de USEPA 3050B (1996). Em um primeiro momento, foram pesados, em tubos novos, tipo falcon, de $50 \mathrm{~mL}$ (Sarstedt AG \& Co, Germany), cerca de 0,2 $\mathrm{g}$ dos sedimentos previamente secos e pulverizados em moinho de almofariz de ágata, modelo RM-200 (Retsh GmbH, Germany); cada um destes foi pesado em triplicata de modo a garantir a reprodutibilidade do método. Em seguida, às amostras, foi acrescentado $10 \mathrm{~mL}$ de $\mathrm{HNO}_{3}$ ultrapuro (Merck KGaA, Germany) e deixadas em repouso por 12 horas.

Posteriormente, procedeu-se ao aquecimento a $80{ }^{\circ} \mathrm{C}$ em bloco digestor modelo DigiPrep (SCP Science, Canadá), por 5 horas. Após a digestão ácida, foi adicionado $1 \mathrm{~mL}$ de $\mathrm{H}_{2} \mathrm{O}_{2}$ (Merck $\mathrm{KGaA}$, Germany) e as amostras foram deixadas em repouso por 1 hora. Após esse período, as mesmas foram levadas a um banho de ultrassom Ultra Cleaner USC-3300 (Unique, Brasil), por 1 hora, e, então, aquecidas novamente a $80{ }^{\circ} \mathrm{C}$, por igual tempo e, em seguida, deixadas em repouso por 12 horas. Após este período, as amostras foram centrifugadas por 3 minutos, a $3.000 \mathrm{rpm}$ e o sobrenadante separado em um segundo tubo tipo falcon de $50 \mathrm{~mL}$. Ao resíduo, foi acrescentado $10 \mathrm{~mL}$ de água ultrapura (Master System MS2000, Gehaka, Brasil), homogeneizada a mistura e levada novamente à centrifugação, nas mesmas condições. Ao término desta etapa o sobrenadante foi adicionado ao extrato previamente separado no tubo tipo falcon de $50 \mathrm{~mL}$, e, finalmente, o extrato foi avolumado a $40 \mathrm{~mL}$ com água ultrapura para posterior quantificação dos metais por ICP-MS. 
O preparo dos extratos e as determinações instrumentais foram acompanhadas, em paralelo, por soluções "branco" contendo todos os reagentes utilizados e também por material de referência certificado MESS-3 (Marine Sediment Reference Materials for Trace Metals and other Constituents) fornecido pelo Conselho Nacional de Pesquisa no Canadá (NRC) para garantir a qualidade dos resultados obtidos e verificação da metodologia utilizada.

Foram determinadas as concentrações de zinco, cádmio, cromo, chumbo, cobre e níquel por ICP-MS e, utilizou-se os isótopos ${ }^{66} \mathrm{Zn},{ }^{111} \mathrm{Cd},{ }^{53} \mathrm{Cr},{ }^{206} \mathrm{~Pb},{ }^{63} \mathrm{Cu}$ e ${ }^{60} \mathrm{Ni}$ para as medições. Optou-se por trabalhar com o isótopo ${ }^{53} \mathrm{Cr}$ pois o isótopo mais abundante deste elemento ${ }^{52} \mathrm{Cr}$ sofre forte interferência da espécie biatômica ${ }^{40} \mathrm{Ar}^{12} \mathrm{C}$ que se forma no plasma quando se tem carbono em solução. Esta interferência pode causar um incremento significativo no sinal de ${ }^{52} \mathrm{Cr}$, resultando em concentrações equivocadamente elevadas deste elemento. Embora o isótopo ${ }^{53} \mathrm{Cr}$ possua abundância relativa de apenas $9,5 \%$, as concentrações nas soluções de leitura eram suficientemente elevadas para possibilitar a quantificação de cromo.

Godoy et al. (2007) demonstrou que na determinação de ${ }^{208} \mathrm{~Pb}$, em soluções

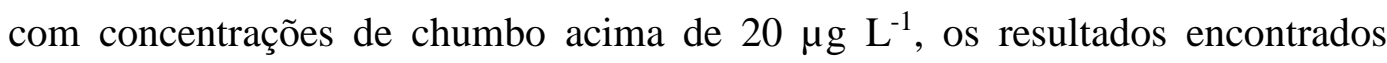
tendem a ser menores que os esperados devido ao efeito de tempo morto, por isso optou-se pelo ${ }^{206} \mathrm{~Pb}$ para a quantificação deste elemento.

$\mathrm{Na}$ determinação da concentração dos metais, foram preparadas curvas de calibração em matriz que pudesse simular os reagentes utilizados, com treze pontos de concentrações variando entre 0,1 e $1000 \mu \mathrm{g} \mathrm{L}^{-1}$ dos respectivos analitos, além de um branco desta curva. Os extratos foram diluídos mais 100X para a determinação de $\mathrm{Zn}$ e 25X para a determinação de $\mathrm{Pb}, \mathrm{Cd}, \mathrm{Cu}, \mathrm{Cr}$ e Ni, e Ródio foi utilizado como padrão interno, sendo adicionado em todos os pontos da curva de calibração e amostras na mesma concentração. A partir dos dados de preparo, teor de umidade e diluição adicional para leitura das amostras, calculou-se suas concentrações em $\mathrm{mg} \mathrm{kg}{ }^{-1}$.

Todas as determinações foram realizadas em um ICP-MS 7500CX (Agilent Technologies, Japão), e os parâmetros pertinentes ao ensaio eram otimizados a cada dia de trabalho, precedendo o início das determinações. 


\section{4 Determinação de Mercúrio}

$\mathrm{Na}$ determinação de $\mathrm{Hg}$, foram pesados, em tubos tipo falcon de $50 \mathrm{~mL}$ (Sarstedt AG \& Co, Germany), cerca de 1,0 g dos sedimentos úmidos, em duplicata, e adicionou-se $10 \mathrm{~mL}$ de solução sulfonítrica $\left(0,1 \% \mathrm{~m} \mathrm{~m}^{-1}\right.$ de $\mathrm{V}_{2} \mathrm{O}_{5}$ em mistura de $\mathrm{HNO}_{3}$ e $\mathrm{H}_{2} \mathrm{SO}_{4}$ 1:1) para dissolução parcial do material. Posteriormente, as amostras foram aquecidas a $90^{\circ} \mathrm{C}$, em bloco digestor modelo DigiPrep (SCP Science, Canadá), por 1 hora. Após resfriamento à temperatura ambiente, as amostras foram centrifugadas por 3 minutos, a $3000 \mathrm{rpm}$, e o sobrenadante separado em um segundo tubo tipo falcon de $50 \mathrm{~mL}$. Ao resíduo, foi acrescentado $10 \mathrm{~mL}$ de água ultrapura (Master System MS2000, GEHAKA, Brasil), homogeneizada a mistura e levada novamente a centrifugação, nas mesmas condições. Ao término desta etapa o sobrenadante foi adicionado ao extrato previamente separado no tubo tipo falcon de $50 \mathrm{~mL}$, e à solução resultante foi pipetado um excesso de solução de $\mathrm{KMnO}_{4}$ (Vetec Ltda, Brasil) $5 \%$ m/v até a manutenção da sua forma oxidada indicada pela coloração violeta na solução final (Limaverde \& Campos, 1999), que podem ser armazenadas por até 5 dias em freezer com temperatura abaixo de $0{ }^{\circ} \mathrm{C}$ (Campos, 1980).

Para garantir a qualidade dos resultados obtidos, todas as bateladas de preparo das amostras foram acompanhadas por uma triplicata de material de referência certificado MESS-3 (Marine Sediment Reference Materials for Trace Metals and other Constituents) e três brancos de preparo contendo todos os reagentes utilizados e seguindo o mesmo processo adotado para as amostras.

O procedimento para a determinação da concentração de $\mathrm{Hg}$ nas soluções foi adaptado de Campos (1980), e consiste, resumidamente, em adicionar no momento da determinação instrumental volume suficiente de uma solução de cloridrato de hidroxilamina (Vetec Ltda, Brasil) $10 \%$ m/v apenas para a redução do excesso de $\mathrm{KMnO}_{4}$, indicado pelo descoramento da solução; então as soluções foram avolumadas a $50 \mathrm{~mL}$, homogeneizadas, e foram retiradas 3 alíquotas de $10 \mathrm{~mL}$ para o frasco de geração de vapor frio de mercúrio.

A redução do íon mercuroso $\left(\mathrm{Hg}_{2}{ }^{2+}\right)$ a mercúrio elementar $\left(\mathrm{Hg}^{0}\right)$ foi realizada com a adição de $1,0 \mathrm{~mL}$ de solução de cloreto estanoso $20 \%$ m/v. A vigorosa agitação da solução promoveu a liberação do vapor frio de mercúrio e a posterior 
condução deste vapor para a célula de absorção com o auxílio de ar comprimido como gás de arraste, permitiu a determinação do metal

As determinações foram realizadas em um espectrômetro de absorção atômica modelo RA-915 equipado com gerador de vapor frio modelo RP-91 (LUMEX, Rússia). A análise das soluções de calibração e das amostras preparadas foi realizada em triplicata, determinando as suas concentrações em $\mu \mathrm{g} \mathrm{L}^{-1}$. A partir dos dados de preparo das amostras e teor de umidade nos sedimentos, calculou-se suas concentrações em $\mu \mathrm{g} \mathrm{kg}^{-1}$. O limite de detecção obtido foi $0,002 \mu \mathrm{g} \mathrm{kg}^{-1}$

\section{5 \\ Determinação de sulfetos ácidos voláteis / metais simultaneamente extraídos (AVS/SEM)}

A extração ácida dos metais e volatilização dos sulfetos para a determinação do SEM e AVS, respectivamente, foi baseada na metodologia adotada pela USEPA (Allen et al., 1991). Neste procedimento os sulfetos presentes no sedimento são convertidos em sulfeto de hidrogênio $\left(\mathrm{H}_{2} \mathrm{~S}\right)$ pela acidificação da amostra com ácido clorídrico $(\mathrm{HCl})$ e adsorvidos em solução de hidróxido de sódio $(\mathrm{NaOH})$ para posterior quantificação. Paralelamente, são feitas quantificações gravimétricas do teor de umidade de cada amostra de modo a permitir a apresentação dos resultados em base seca.

O aparato para a geração e adsorção dos sulfetos voláteis está apresentado na Figura 13. Para a conversão dos sulfetos em $\mathrm{H}_{2} \mathrm{~S}$ utilizou-se uma solução $1 \mathrm{~mol} \mathrm{~L}{ }^{-1}$ $\mathrm{HCl}$ (Merck KGaA, Germany), nitrogênio 3.0 (Linde Gases, Brasil) foi utilizado como gás de arraste e a adsorção do sulfeto gerado ocorreu em uma solução $0,5 \mathrm{~mol} \mathrm{~L}^{-1}$ de $\mathrm{NaOH}$ (Merck KGaA, Germany). Todas as soluções utilizadas foram preparadas com água ultrapura (Master System MS2000, GEHAKA, Brasil) e foram desaeradas por pelo menos 20 minutos com o borbulhamento de nitrogênio

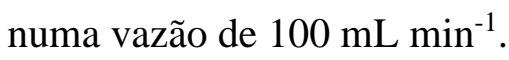




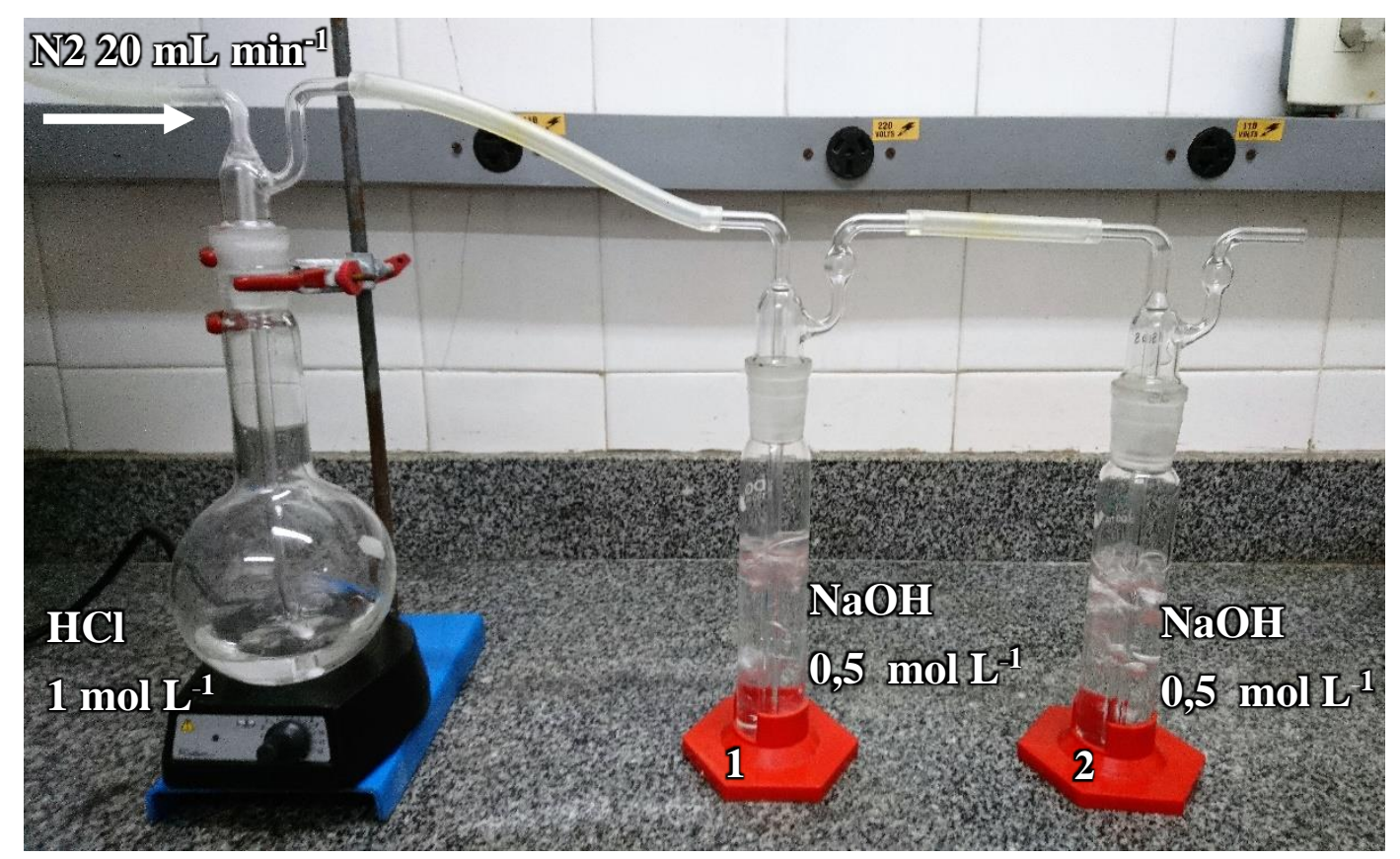

Figura 13: Aparato utilizado para a geração/adsorção do $\mathrm{H}_{2} \mathrm{~S}$

Foram utilizados cerca de $5 \mathrm{~g}$ de amostra úmida para a geração de $\mathrm{H}_{2} \mathrm{~S}$. A cada amostra foram adicionados $100 \mathrm{~mL}$ de água ultrapura e $20 \mathrm{~mL}$ de $\mathrm{HCl}$ $6 \mathrm{~mol} \mathrm{~L}^{-1}$ para a obtenção de uma solução final de $1 \mathrm{~mol} \mathrm{~L}^{-1} \mathrm{HCl}$. A solução resultante foi borbulhada com nitrogênio $\left(20 \mathrm{~mL} \mathrm{~min}^{-1}\right)$ por uma hora e um agitador magnético foi utilizado para evitar a deposição do sedimento no fundo do frasco e contribuir para a homogeneização do sistema.

A solução de $\mathrm{HCl}$ com o sedimento foi filtrada em filtro com porosidade de $45 \mu \mathrm{m}$ (Macherey-Nagel GmbH, Germany) e armazenada em tubos tipo falcon de $50 \mathrm{~mL}$ (Sarstedt AG \& Co, Germany) sob refrigeração a $4{ }^{\circ} \mathrm{C}$ para posterior determinação dos metais simultaneamente extraídos (SEM) por ICP-MS.

A quantificação do sulfeto retido na solução absorvedora foi realizada por espectrofotometria molecular na faixa do visível, no espectrofotômetro Spectroquant ${ }^{\circledR}$ Nova 60 (Merck KGaA, Germany). Este equipamento opera com kits fornecidos pela própria empresa, possui calibração interna e o procedimento para a determinação colorimétrica é análogo a USEPA 376.2 (1978) e APHA 4500$\mathrm{S}^{2-}$. Este método está baseado no princípio de que, em soluções aquosas contendo sulfetos, existe um equilíbrio dependente do $\mathrm{pH}$ entre sulfeto de hidrogênio $\left(\mathrm{H}_{2} \mathrm{~S}\right)$ dissolvido, íons hidrogenosulfeto $\left(\mathrm{HS}^{-}\right)$e íons sulfeto $\left(\mathrm{S}^{2-}\right)$. Em $\mathrm{pH}$ ácido praticamente só existe o sulfeto de hidrogênio e este pode reagir com dimetil-p- 
fenilenodiamina na presença de íons $\mathrm{Fe}^{3+}$ para produzir azul de metileno, que pode ser quantificado no comprimento de onda máximo $625 \mathrm{~nm}$.

Para a determinação da concentração dos metais simultaneamente extraídos por ICP-MS, foi preparada a curva de calibração em matriz que pudesse simular os reagentes utilizados, com treze pontos de concentrações variando entre 0,1 a $1000 \mu \mathrm{g} \mathrm{L}^{-1}$ dos respectivos analitos, além de um branco desta curva. As soluções armazenadas foram diluídas adequadamente para a determinação de $\mathrm{Zn}, \mathrm{Pb}, \mathrm{Cd}, \mathrm{Cu}$ e Ni, e Rh foi utilizado como padrão interno, sendo adicionado em todos os pontos da curva de calibração e amostras na mesma concentração. A partir dos dados de preparo e diluições adicionais para leitura das amostras, calculou-se suas concentrações em $\mathrm{mg} \mathrm{kg}^{-1}$.

Para garantir a qualidade dos resultados obtidos dos metais simultaneamente extraídos, todas as bateladas das amostras foram acompanhadas por uma triplicata de material de referência certificado MESS-3 (Marine Sediment Reference Materials for Trace Metals and other Constituents) e três brancos de preparo contendo todos os reagentes utilizados e seguindo o mesmo processo adotado para as amostras.

Todas as determinações foram realizadas em um ICP-MS 7500CX (Agilent Technologies, Japão), e os parâmetros pertinentes ao ensaio eram otimizados a cada dia de trabalho, precedendo o início das determinações. Os limites de detecção obtidos na determinação do SEM podem ser observados na Tabela 5, abaixo.

Tabela 5: Limites de detecção obtidos para SEM

\begin{tabular}{cc}
\hline Elemento & LOD $\left(\mathbf{m g ~ k g}^{\mathbf{- 1}}\right)$ \\
\hline $\mathrm{Cd}$ & 0,2 \\
$\mathrm{Cu}$ & 0,1 \\
$\mathrm{Ni}$ & 0,6 \\
$\mathrm{~Pb}$ & 1,0 \\
$\mathrm{Zn}$ & 0,2 \\
\hline
\end{tabular}




\section{6 Datação das camadas sedimentares por ${ }^{210} \mathrm{~Pb}$}

Para a determinação radioquímica de ${ }^{210} \mathrm{~Pb}$ seguiu-se o método proposto por Godoy et al. (1998), no qual, inicialmente, é necessário realizar o ataque ácido das frações dos testemunhos. Para tanto, adicionou-se $40 \mathrm{~mL}$ de solução $0,5 \mathrm{~mol} \mathrm{~L}^{-1} \mathrm{de}$ $\mathrm{HBr}$ (Vetec Ltda, Brasil) a aproximadamente $3 \mathrm{~g}$ de cada uma das amostras secas. Essa mistura foi levada a aquecimento a $80^{\circ} \mathrm{C}$ por 3 horas, e ao fim, centrifugada a 3000 RPM por 2 minutos. O sobrenadante obtido após centrifugação foi reservado em um bécher e ao sólido repetiu-se o processo de lixiviação com $\mathrm{HBr}$, adicionando-se à mistura $1 \mathrm{~g}$ de cloridrato de hidroxilamina (Vetec Ltda, Brasil). A solução obtida na segunda lixiviação foi então transferida para o bécher contendo a fração anteriormente reservada.

A lixiviação com $\mathrm{HBr}$ permite a formação de bromo-complexos aniônicos solúveis com o $\mathrm{Pb}$ em sua forma iônica $\left[\mathrm{PbBr}_{3}\right]^{-}$, o que faz com que o íon $\mathrm{Pb}^{2+}$ seja retido em resina aniônica, separando-o de alguns interferentes, principalmente, ${ }^{137} \mathrm{Cs}, \mathrm{U}, \mathrm{Th},{ }^{226} \mathrm{Ra},{ }^{228} \mathrm{Ra} \mathrm{e}{ }^{210} \mathrm{Po}$, além de $\mathrm{Al}$ e Fe que são macro constituintes em amostras de sedimentos. Já o cloridrato de hidroxilamina é adicionado à solução para reduzir o $\mathrm{Fe}^{+3}$ a $\mathrm{Fe}^{+2}$ e minimizar a adsorção de ferro na coluna.

Mediu-se o volume recuperado nas duas etapas de lixiviação e adicionou-se ao extrato obtido $20 \mathrm{mg}$ de uma solução padrão de $\mathrm{Pb}$ que é utilizado na quantificação do rendimento químico final.

Passou-se, então, à separação do $\mathrm{Pb}$ por meio de uma coluna contendo aproximadamente $5 \mathrm{~mL}$ de resina Dowex $1 \mathrm{X} 8$, aniônica e fortemente alcalina. Essa coluna foi, primeiramente, condicionada com $50 \mathrm{~mL}$ da solução $0,5 \mathrm{~mol} \mathrm{~L}^{-1} \mathrm{de} \mathrm{HBr}$, em seguida, a alimentação é realizada a uma vazão de $1 \mathrm{~mL} \mathrm{~min}{ }^{-1}$ de forma a reter o complexo $\left[\mathrm{PbBr}_{3}\right]^{-}$, após, a coluna foi lavada por duas vezes com $25 \mathrm{~mL}$ de 0,5 mol L ${ }^{-1}$ de $\mathrm{HBr}$ e $1 \mathrm{~g}$ de cloridrato de hidroxilamina, e, por fim, o $\mathrm{Pb}$ foi recuperado em solução com $100 \mathrm{~mL}$ de $\mathrm{HNO}_{3} 1 \mathrm{~mol} \mathrm{~L}^{-1} \mathrm{em}$ um bécher. A coluna foi regenerada com $20 \mathrm{~mL}$ de água deionizada e reservada para um novo extrato.

Evaporou-se a solução até quase a secura e adicionou-se $100 \mathrm{~mL}$ de água deionizada. O pH dessa solução foi ajustado com Acetato de Amônio (Vetec Ltda, Brasil), de modo a obter um valor entre 5 e 6, condição necessária para a formação do precipitado. Passada essa etapa, pipetou-se $2 \mathrm{~mL}$ de $\mathrm{K}_{2} \mathrm{CrO}_{4}$ a $5 \%$ m/v (Vetec 
Ltda, Brasil) à solução promovendo a precipitação do $\mathrm{PbCrO}_{4}$, a data e hora da precipitação foram anotadas para posteriormente serem utilizadas nos cálculos. A solução foi aquecida novamente com o objetivo de se obter um precipitado de separação mais fácil para a filtração.

Pesou-se um papel de filtro (faixa branca com 2,5 cm de diâmetro) e filtrouse o precipitado utilizando um sistema de filtração tipo Milipore apropriado. $\mathrm{O}$ precipitado foi lavado com Etanol 80\% v/v (Vetec Ltda, Brasil), e posteriormente seco em estufa até obtenção de peso constante, para, por fim, ser embalado, identificado e armazenado adequadamente até o dia da determinação da atividade.

Após 10 dias, determina-se a atividade beta em contador proporcional de baixa contagem de fundo, modelo LB-770 (Berthold Technologies GmbH \& Co). Esta contagem refere-se à radiação do ${ }^{210} \mathrm{Bi}\left(\mathrm{t}_{1 / 2}=5\right.$ dias $)$ que é de $1,17 \mathrm{MeV}$ e, que corresponde a uma medida indireta do ${ }^{210} \mathrm{~Pb}$, possibilitando a datação das frações dos testemunhos.

A atividade do ${ }^{210} \mathrm{~Pb}$ em cada fatia é calculada pela equação:

$$
A_{P b}^{210}=\frac{C_{a m}-C_{b}}{R Q \cdot m \cdot E_{\beta} \cdot\left(1-e^{-\lambda(B i 210) \cdot t}\right)}
$$

Onde:

$\mathrm{A}_{\mathrm{Pb}}{ }^{210}=$ Atividade radiométrica do ${ }^{210} \mathrm{~Pb}\left(\mathrm{~Bq} \mathrm{~kg}^{-1}\right) ;$

$\mathrm{C}_{\mathrm{am}}=$ Contagem da amostra $(\mathrm{Bq})$;

$\mathrm{C}_{\mathrm{b}}=$ Contagem do background $(\mathrm{Bq})$;

$\mathrm{RQ}=$ Rendimento químico, obtido a partir de análises químicas de $\mathrm{Pb}$;

$\mathrm{m}=$ Massa da amostra $(\mathrm{kg})$

$\mathrm{E}_{\beta}=$ Eficiência final de contagem beta do ${ }^{210} \mathrm{Bi}$;

$\lambda\left({ }^{210} \mathrm{Bi}\right)=$ Constante de desintegração do ${ }^{210} \mathrm{Bi}=0,1383 \mathrm{~d}^{-1} ;$

$\mathrm{t}=$ Tempo, em dias, transcorrido entre a precipitação do $\mathrm{PbCrO}_{4}$ e a contagem. 


\section{7 Determinação granulométrica}

A granulometria foi realizada em colaboração com Departamento de Engenharia Civil da PUC-Rio, empregando-se o analisador de partículas Cilas 1190 Particle Size Analyzer ( Figura 14). Este equipamento é configurado com três lasers e detector do tipo dispositivo de carga acoplada (CCD) que, combinados, permitem de uma só vez a medida de partículas com tamanhos que variam entre 0,04 e $2500 \mu \mathrm{m}$. As partículas mais finas são medidas pelo padrão de difração usando a teoria de Fraunhofer e as maiores são obtidas usando transformada de Fourrier em tempo real da imagem obtida pelo CCD.

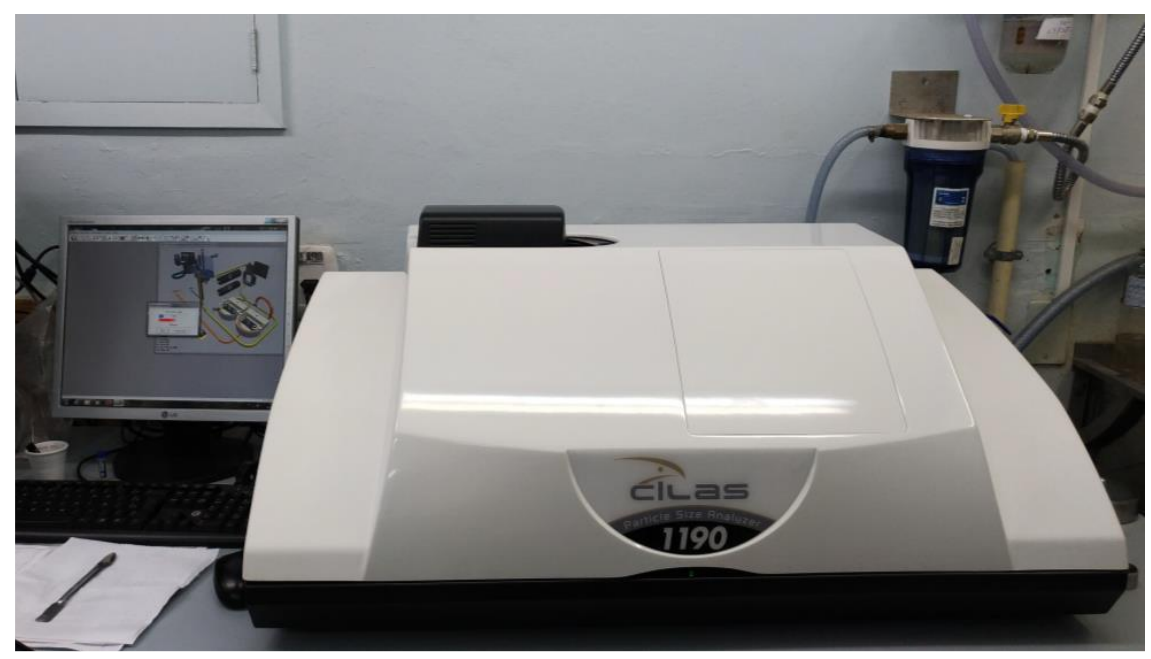

Figura 14: Cilas Particle Size Analyzer 1190

As amostras secas foram previamente peneiradas $(2 \mathrm{~mm})$, de modo a retirar a fração de cascalho, e em seguida foram analisadas no equipamento seguindo a metodologia descrita pelo fabricante para este tipo de material. 


\section{8 Determinação elementar e isotópica de carbono e nitrogênio}

Os ensaios foram realizados em parceria com o Laboratório de Ciências Ambientais da Universidade Estadual do Norte Fluminense (UENF), empregandose um analisador elementar hifenado a um espectrômetro de massa.

Preparo das amostras para determinação de carbono e nitrogênio totais $\underline{\left(\mathrm{C}_{\mathrm{T}} \text { e } \mathrm{N}_{\mathrm{T}}\right)}$ :

Aproximadamente $8 \mathrm{mg}$ do sedimento previamente seco e homogeneizado foram pesados em cápsulas de estanho para determinação de $\mathrm{C}_{\mathrm{T}}$ e $\mathrm{N}_{\mathrm{T}}$, além da composição isotópica de nitrogênio.

Preparo das amostras para determinação de carbono orgânico ( $\left.\mathrm{C}_{0}\right)$ :

Aproximadamente $8 \mathrm{mg}$ do mesmo material foram acondicionados em cápsulas de prata e foram adicionados lentamente três porções de $25 \mu \mathrm{L}$ de $\mathrm{HCl}$ 2,0 mol L ${ }^{-1}$, até o fim da reação de eliminação do carbono inorgânico, caracterizada pelo término da evolução de gases da mistura. Após, as cápsulas foram secas em estufa a $110^{\circ} \mathrm{C}$ (temperatura de ebulição) por 24 horas e as mesmas foram utilizadas na determinação da quantidade de $C_{0}$ e sua composição isotópica.

Determinação instrumental:

As amostras contidas nas cápsulas foram queimadas em um Analisador Elementar com fluxo contínuo (Flash 2000 Organic Elemental Analyzer), que determinou as concentrações elementares de carbono e nitrogênio; acoplado a um espectrômetro de massa (IRMS Delta V Advantage Thermo Scientific, Alemanha), no qual foi determinada a composição isotópica de carbono e nitrogênio.

Pee Dee Belemnite (PDB) e nitrogênio atmosférico foram utilizados como padrões para as análises de carbono e nitrogênio, respectivamente. A incerteza foi de $\pm 0,1 \%$ para $\delta^{13} \mathrm{C}$ e $\pm 0,2 \%$ para $\delta^{15} \mathrm{~N}$ e a exatidão para as composições isotópicas e elementares foi comprovada pelas determinações destes parâmetros em material de referência certificado (Protein OAS/Isotope Cert. 114859; Elemental Microanalises). 


\section{Resultados e Discussão}

\section{1 Sedimentos Superficiais}

\subsection{1}

\section{Determinação de Umidade}

Os valores de umidade variaram de 15 a $81 \%$, com um valor mediano de $62 \%$. Essa variação já era esperada uma vez que algumas estações estão localizadas em áreas onde o sedimento era muito arenoso, com baixa umidade, e outras onde os sedimentos eram mais finos, com alta predominância de silte e argila, e alta umidade. Os resultados encontram-se no Anexo A, Tabela 11.

Pode-se observar na Figura 15 que os pontos onde o teor de umidade está mais baixo localizam-se na parte externa da baía, enquanto que os pontos na parte interna da baía apresentaram valores acima de $40 \%$ de umidade, com exceção para os pontos SP-125 e SP-130, pois estes estão localizados próximo ao canal central de entrada e escoamento de água da Baía de Sepetiba, onde a profundidade e as velocidades das correntes são mais elevadas, como consequência disso há um grande arraste de material mais fino e o teor de umidade do sedimento é menor.

\section{Umidade em Sedimentos (\%)}

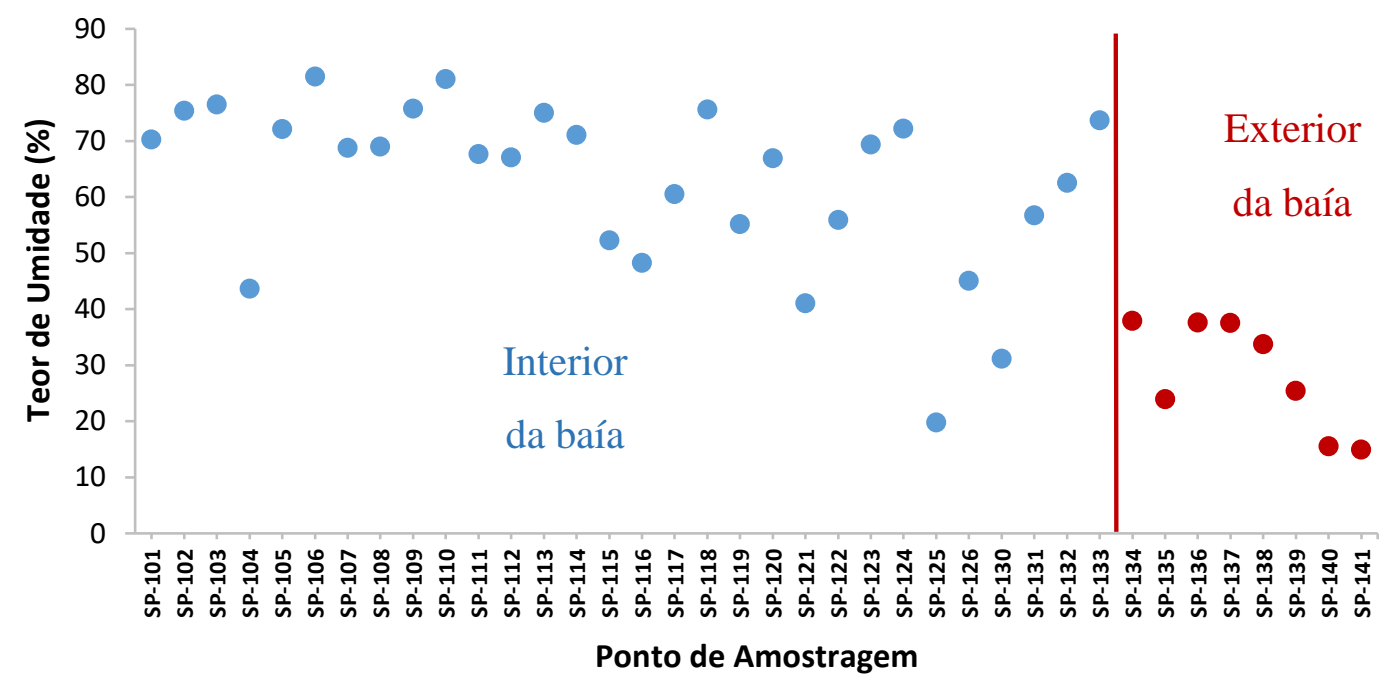

Figura 15: Teores de umidade nos pontos de amostragem de sedimento superficial 


\subsection{2}

\section{Análise Granulométrica}

Os resultados da determinação granulométrica do sedimento superficial da baía de Sepetiba encontram-se no Anexo B, Tabela 13 a 50.

Os resultados foram organizados em 3 grupos, de acordo com o tamanho do grão: argila $(\varnothing \leq 0,02 \mathrm{~mm})$, silte $(0,02<\varnothing \leq 0,06 \mathrm{~mm})$ e areia + cascalho $(\varnothing \geq 0,06$ mm). A relação percentual destas faixas pode ser observada na Figura 16.

\section{Granulometria do Sedimento Superficial}

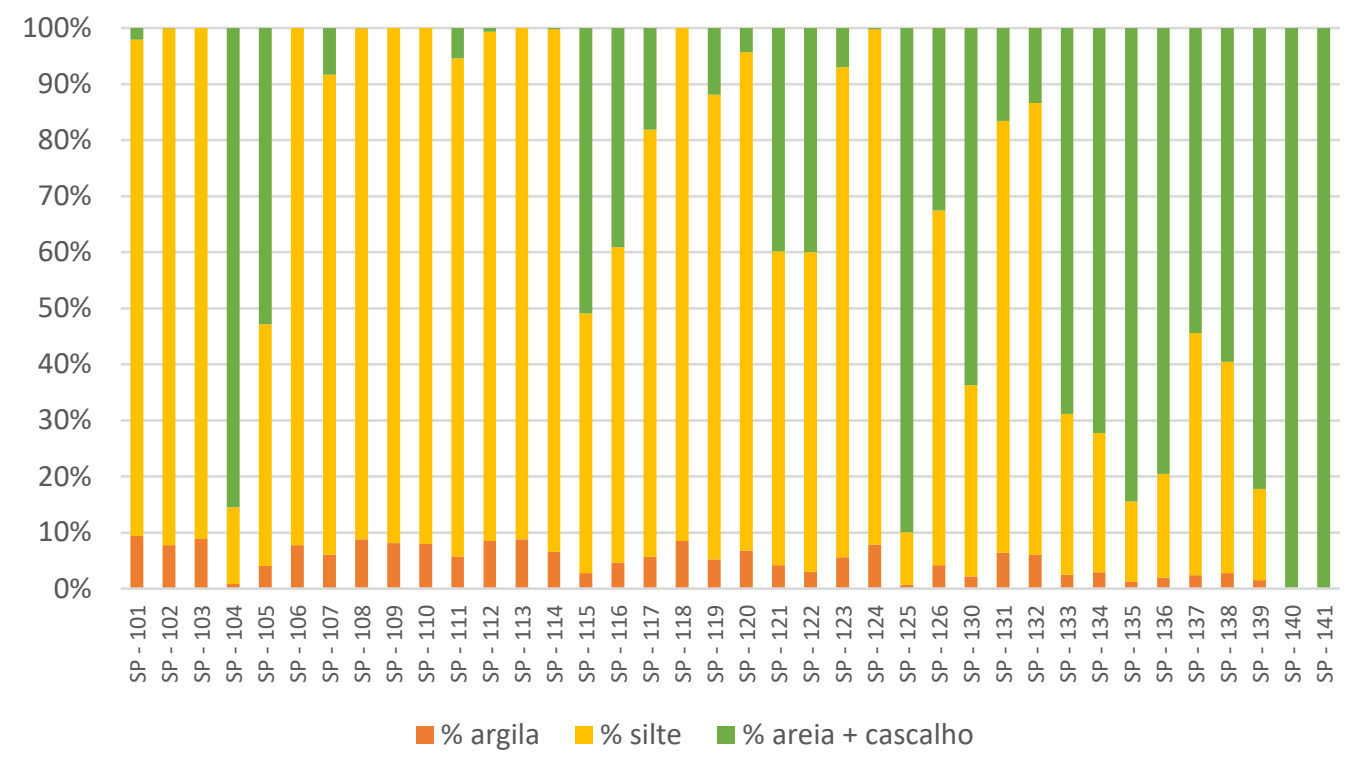

Figura 16: Características granulométricas \% de Argila, Silte e Areia na Baía de Sepetiba

As regiões com menores frações de material mais fino estão localizadas na parte externa da baía, que compreendem os pontos SP-133 a SP-141; os pontos SP125 e SP-130 estão localizados próximo ao canal de navegação, na região central de entrada de água na baía, consequentemente onde se encontram correntes marinhas com maiores velocidades; e os pontos SP-104 e SP-115 estão localizados em áreas rasas, com pouca influência das correntes.

Considerando que os metais estão preferencialmente ligados às frações mais finas de sedimentos, argila e silte, pode-se somar as respectivas frações destes grupos granulométricos e, desta forma, com o auxílio do software Ocean Data View, versão 4.7.8, construir uma superfície de resposta (Figura 17) com a composição percentual deste grupo combinado, com $\emptyset \leq 0,06 \mathrm{~mm}$. 


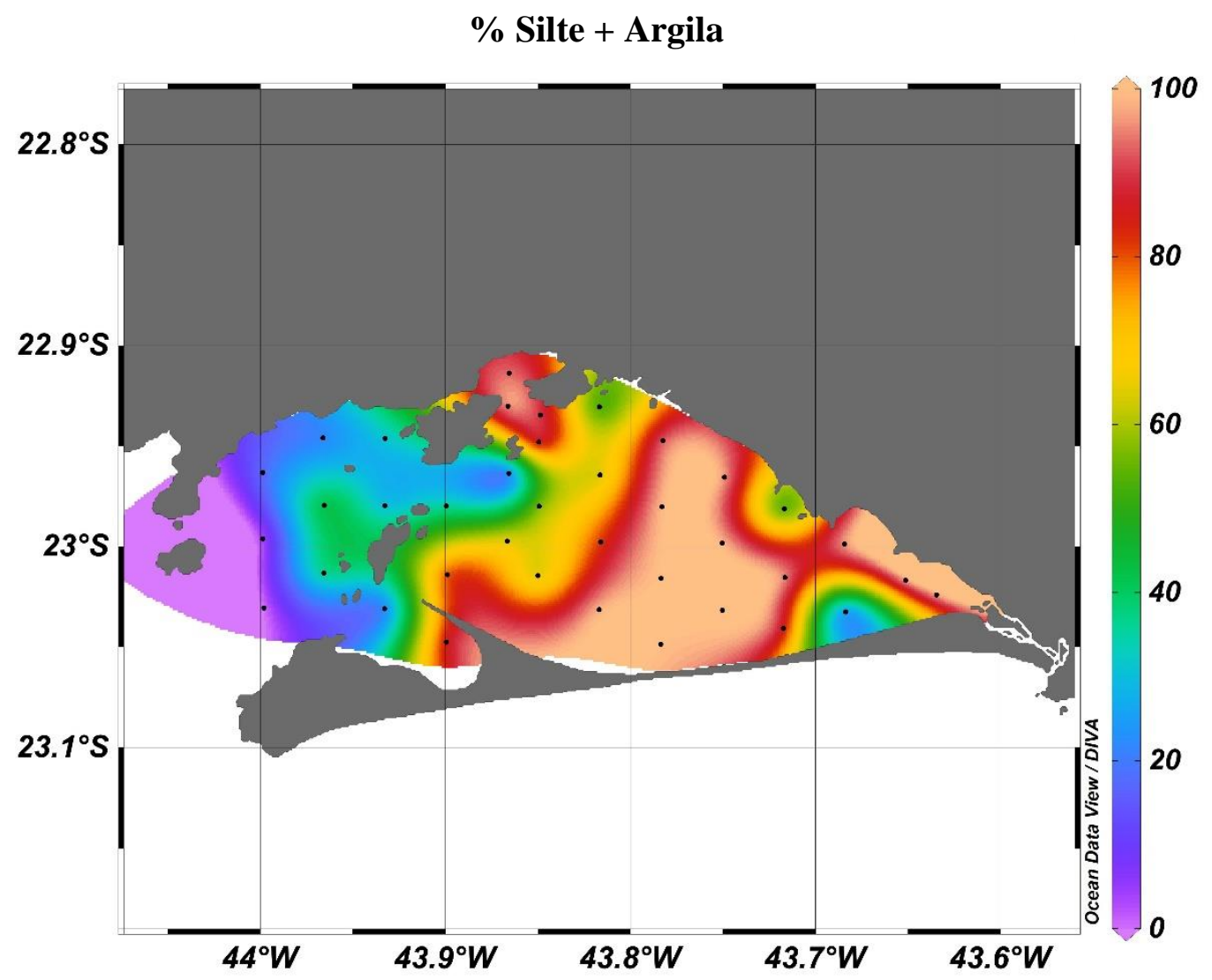

Figura 17: Superfície de resposta para a composição granulométrica \% de silte+argila

Fica evidenciado na superfície apresentada na Figura 17, que a região central da baía e uma parte da porção leste, próxima à região de Pedra de Guaratiba, apresentam praticamente $100 \%$ de sedimento superficial fino, enquanto a parte externa da baía e a entrada do canal de navegação possui, em média, menos de $20 \%$ de material com granulometria abaixo de $0,06 \mathrm{~mm}$.

\subsection{3 \\ Determinação de carbono orgânico, carbono e nitrogênio totais e suas composições isotópicas}

Todos os resultados obtidos nas respectivas determinações estão tabelados no Anexo C, Tabela 51.

A partir da análise da superfície de resposta obtida para o carbono orgânico na Figura 18, observa-se a presença de dois pontos principais com elevadas concentrações de carbono orgânico, o primeiro localiza-se entre o continente e a Ilha de Itacuruçá, região com alta densidade de casas de veraneio, o que pode 
influenciar diretamente nos dados encontrados; o segundo ponto com concentração de carbono orgânico também elevada é a praia de Sepetiba, reconhecida por ser imprópria para banho por causa do despejo direto de esgoto não tratado da comunidade de Sepetiba.

Carbono Orgânico, \% (m/m)

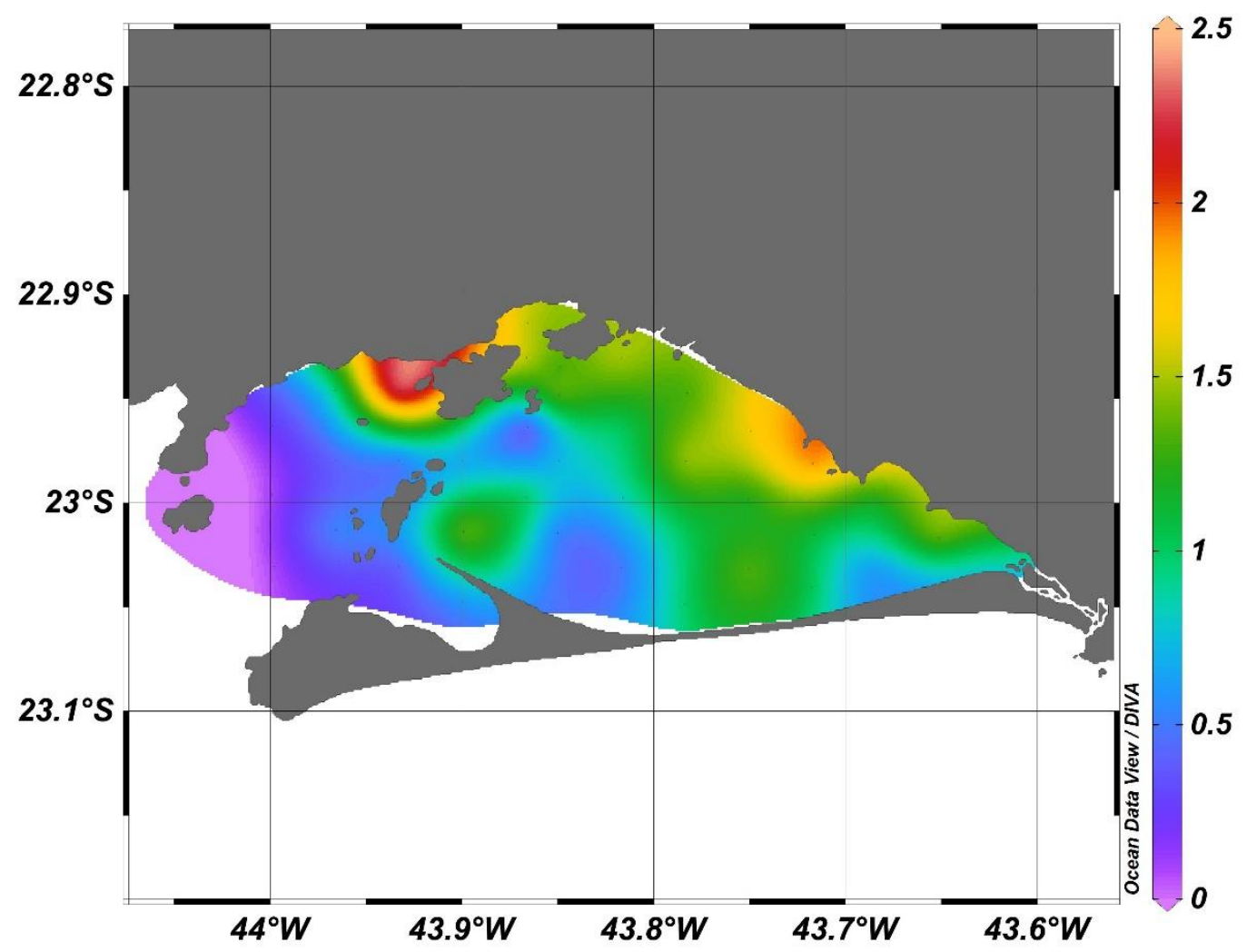

Figura 18: Teor de carbono orgânico (\%) em sedimentos superficiais da Baía de Sepetiba

Esta região também foi estudada por Rezende et al. (2010) que apresentaram resultados de matéria orgânica semelhantes aos encontrados neste trabalho. De acordo com esse mesmo autor, os constituintes da matéria orgânica eram basicamente folhas e plâncton, com aproximadamente 50\% de cada um. Como há uma diferença maior na razão $\mathrm{C} / \mathrm{N}$ do que no valor $\delta\left({ }^{13} \mathrm{C}\right)$ para os marcadores de folhas e plâncton, a contribuição deles para o carbono orgânico na Baía de Sepetiba foi calculada utilizando a razão $\mathrm{C} / \mathrm{N}$ e a contribuição planctônica variou entre $75 \%$ e $100 \%$, observando-se uma menor contribuição ao longo da linha costeira entre os pontos 123 e 103, onde estão presentes manguezais e foz dos rios afluentes.

O teor percentual de matéria orgânica foi calculado segundo a equação apresentada abaixo e os resultados podem ser observados na Tabela 51, Anexo C. $\% M O_{\text {terrestre }}=\frac{(C / N)_{\text {folhas }}-(C / N)_{\text {amostra }}}{(C / N)_{\text {folhas }}-(C / N)_{\text {plancton }}} \times 100=\frac{28,1-(C / N)_{\text {amostra }}}{20,4} \times 100$ 
As Figura 19 a-d apresentam a variação de carbono orgânico total (COT), $\delta^{13} \mathrm{C}$, razão $\mathrm{C} / \mathrm{N}$, e $\delta^{15} \mathrm{~N}$ em função do ponto de amostragem, destacando as regiões interna, em preto, e externa, em vermelho, da Baía de Sepetiba.

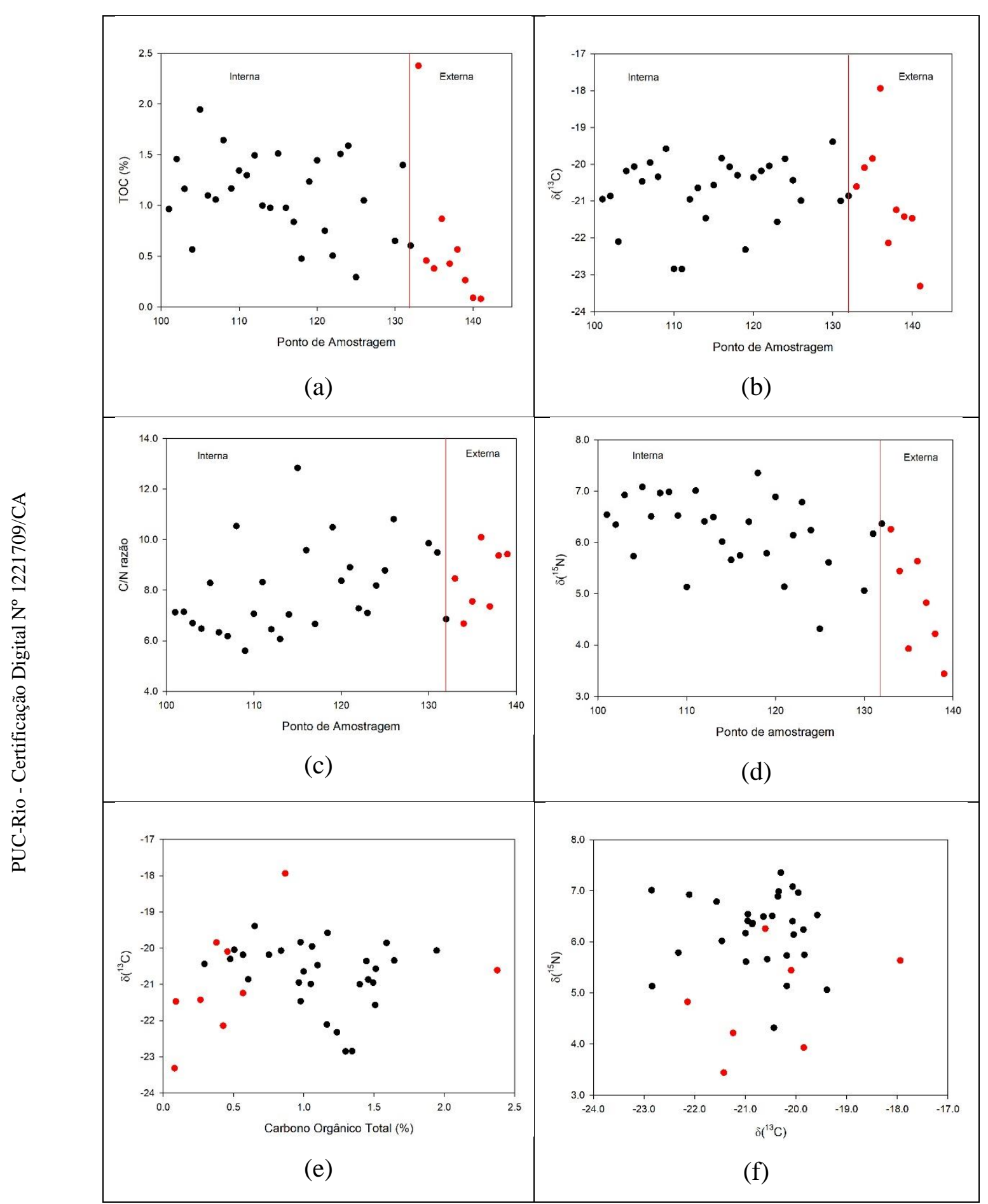

Figura 19: $C O T, \delta^{13} \mathrm{C}$, razão $\mathrm{C} / \mathrm{N}$, e $\delta^{15} \mathrm{~N}$ em função do ponto de amostragem.

A Figura 19a espelha o já observado na Figura 18, na Figura 19b chama a atenção o $\delta^{13} \mathrm{C}$ relacionado ao ponto 136 , o qual mostra uma certa influência de planta C3. 
Na Figura 19c é possível observar que o ponto 115 apresentou a maior razão $\mathrm{C} / \mathrm{N}$ entre os pontos da região interna da baía, este valor pode estar diretamente relacionado com a foz do canal de São Francisco e com o rio Guandú.

Assim como relatado por $\mathrm{Xu}$ et al. (2017), a tendência observada para $\delta^{15} \mathrm{~N}$ (Figura 19) é inversa a esperada, com matéria orgânica de origem terrestre com um menor $\delta^{15} \mathrm{~N}$ e o componente marinho com um maior $\delta^{15} \mathrm{~N}$, sendo essa tendência inversa fruto de uma transformação da matéria orgânica.

As Figura $19 \mathrm{e}-\mathrm{f}$ mostram a relação do $\delta^{13} \mathrm{C}$ com o COT e com o $\delta^{15} \mathrm{~N}$, não sendo possível observar qualquer tendência entre eles.

\subsection{4 \\ Sulfetos ácidos voláteis / metais simultaneamente extraídos (AVS/SEM)}

Foram detectados sulfetos volatilizáveis por acidificação (AVS) em 36 das 38 estações de trabalho e as concentrações variaram de 0,01 a $30,4 \mu \mathrm{mol} \mathrm{g} \mathrm{g}^{-1}$ com os valores mais altos localizados ao longo da linha costeira entre os pontos SP-115 e SP-102 (Figura 20), e os menores valores localizados na parte externa da baía e em estações próximas ao canal de navegação onde há a predominância de sedimentos mais arenosos e com menores teores de matéria orgânica.

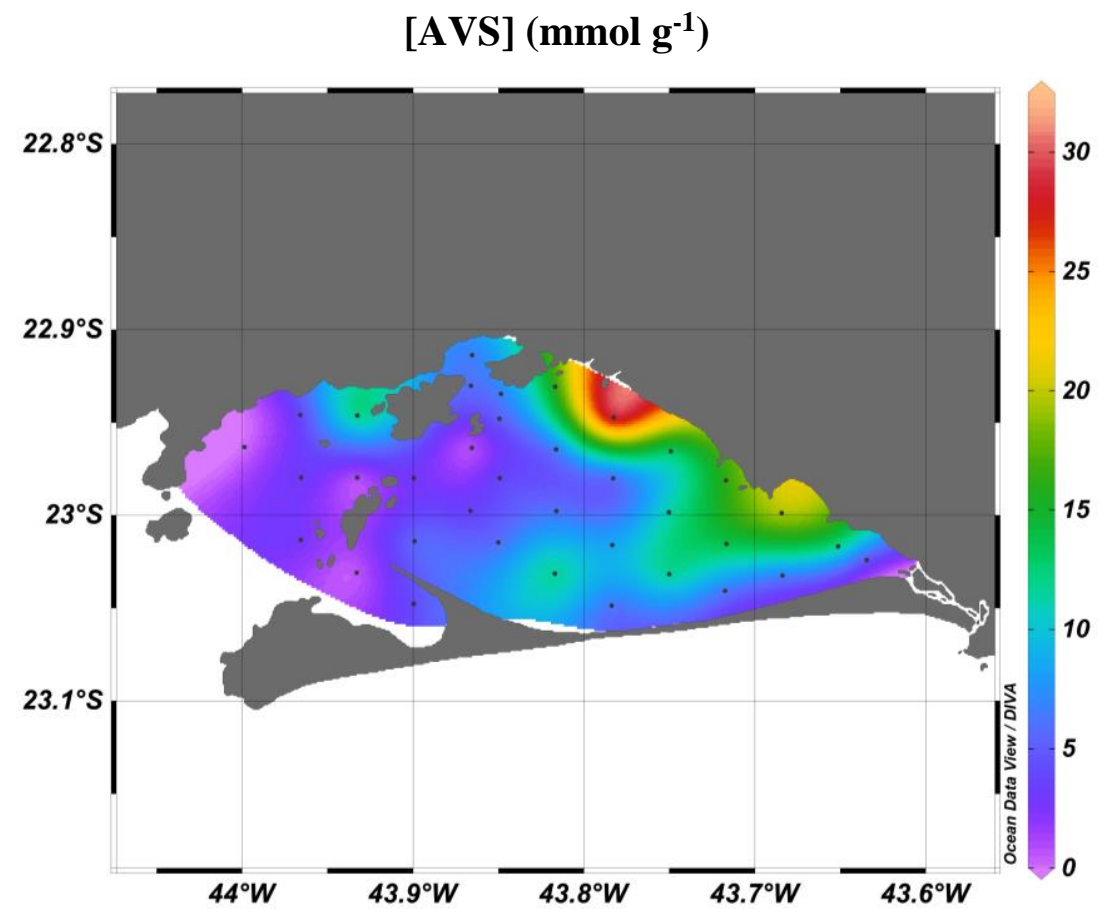

Figura 20: Superfície de resposta obtida para concentração molar de sulfetos volatilizáveis por acidificação. 
O somatório molar das concentrações dos metais simultaneamente extraídos (SEM) variou entre 0,02 e 4,67 $\mu \mathrm{mol} \mathrm{g}^{-1}$, com valores mais elevados entre os pontos SP-115 e SP-105, localizados ao longo da linha costeira (Figura 21).

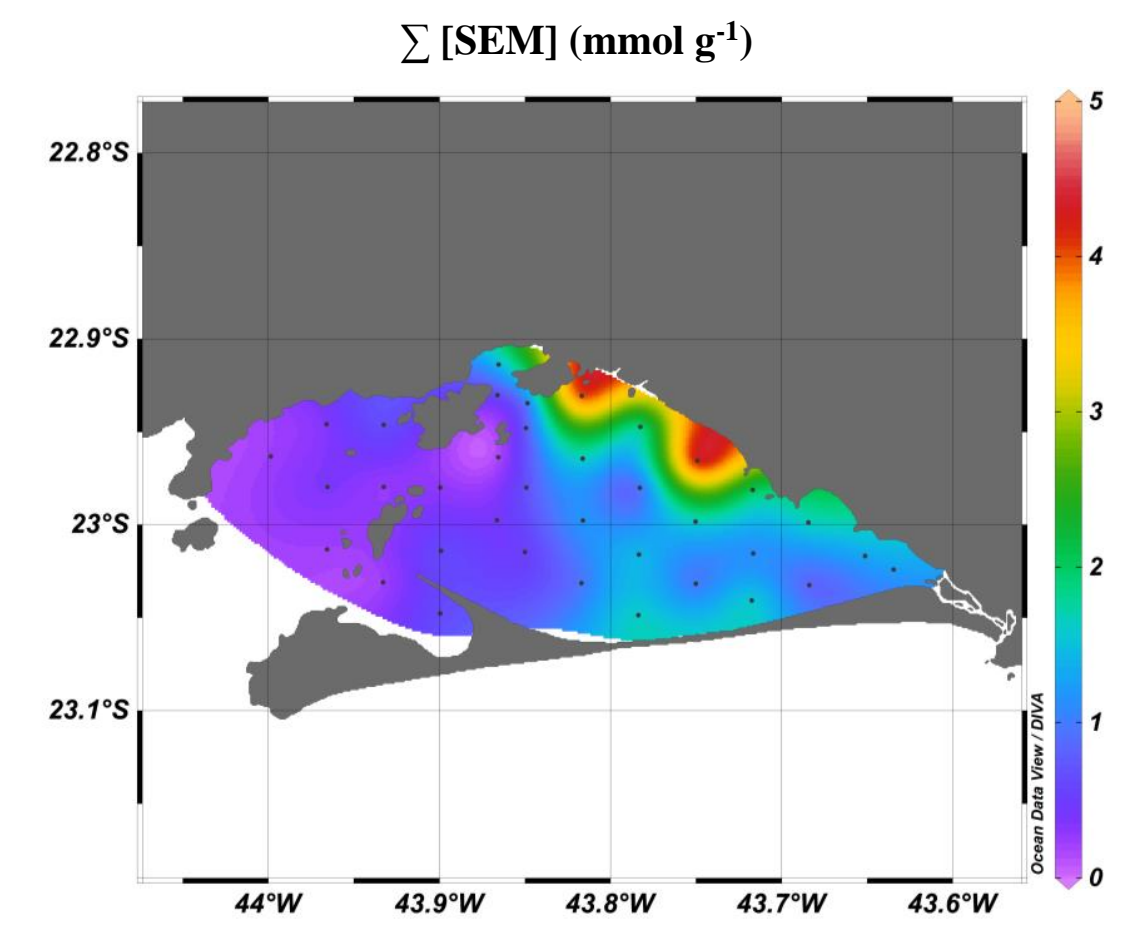

Figura 21: Superfície de resposta obtida para o somatório das concentrações molares de SEM

O cálculo da razão $\sum[\mathrm{SEM}] /[\mathrm{AVS}]$ foi precedido por uma avaliação criteriosa dos dados obtidos. Para Fagnani et al. (2011), expressar a relação entre SEM e AVS é desvantajosa quando se tem valores extremamente baixos de AVS comparados com valores mais altos de SEM, neste caso a razão $\sum[\mathrm{SEM}] /[\mathrm{AVS}]$ resulta em um número extremamente alto e nada se pode afirmar sobre a quantidade de metais que estaria biodisponível. Desta forma foram excluídos da avaliação os pontos 125, 134, 135 e 139, que apresentaram concentrações de AVS menores que $0,21 \mu \mathrm{mol} \mathrm{g}^{-1} \mathrm{e}$ concentrações de SEM abaixo de 0,24 $\mu \mathrm{mol} \mathrm{g}^{-1}$.

Com os demais dados, foi possível a construção da superfície de resposta da razão $\sum[\mathrm{SEM}] /[\mathrm{AVS}]$ (Figura 22). Observa-se claramente que todos as estações de amostragem apresentaram razões menores do que 1, sugerindo uma não toxicidade destes sedimentos, uma vez que os metais chumbo, cádmio, cobre, níquel e zinco estariam imobilizados na forma de sulfetos insolúveis e, consequentemente, não biodisponíveis para a população bentônica local (Di Toro et al., 1991) 


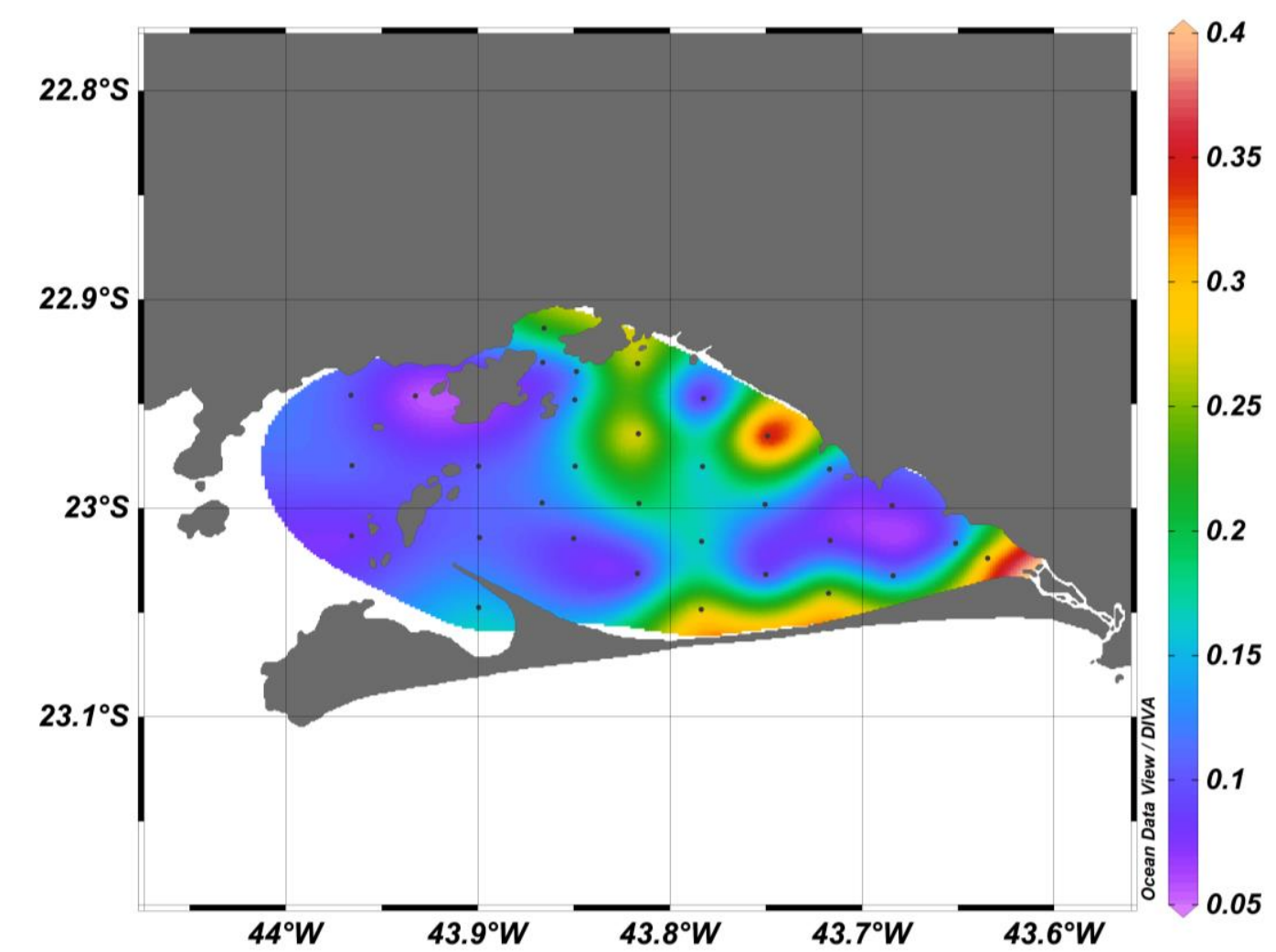

Figura 22: Superfície de resposta obtida para relação ¿SEM/AVS na baía de Sepetiba.

A tabela completa, contendo os resultados individuais de AVS e SEM, assim como a razão $\sum$ SEM/AVS calculada para cada estação de amostragem está disponível no Anexo D.

\subsection{5 \\ Determinação de Metais Totais}

As extrações dos metais foram realizadas em triplicata e as determinações instrumentais foram efetuadas com 5 leituras por elemento, conforme metodologia descrita em 3.3. A determinação de mercúrio foi realizada por CVAAS em triplicada, conforme descrito em 3.4.

Os limites de detecção obtidos para os metais determinados nas amostras estão apresentados na Tabela 6. 
Tabela 6: Limites de detecção obtidos

\begin{tabular}{cc}
\hline Elemento & LOD $\left(\mathrm{mg} \mathrm{kg}^{-1}\right)$ \\
\hline $\mathrm{Cd}$ & 0,2 \\
$\mathrm{Cr}$ & 1,0 \\
$\mathrm{Cu}$ & 0,2 \\
$\mathrm{Ni}$ & 0,5 \\
$\mathrm{~Pb}$ & 1,0 \\
$\mathrm{Zn}$ & 0,5 \\
\hline
\end{tabular}

As concentrações encontradas no material de referência certificado $(n=3)$, assim como os valores de recuperação calculados encontram-se na Tabela 7.

Tabela 7: Concentrações de metais encontradas no MRC MESS-3 e cálculo de recuperação.

\begin{tabular}{cccc}
\hline Metais & medido $\left(\mathrm{mg} \mathrm{kg}^{-1}\right)$ & certificado $\left(\mathrm{mg} \mathrm{kg}^{-1}\right)$ & Recuperação (\%) \\
\hline $\mathrm{Zn}$ & $162 \pm 1,9$ & $159 \pm 8$ & $101,9 \%$ \\
$\mathrm{~Pb}$ & $19,8 \pm 0,5$ & $21,1 \pm 0,7$ & $93,8 \%$ \\
$\mathrm{Cu}$ & $32,5 \pm 0,4$ & $33,9 \pm 1,6$ & $95,9 \%$ \\
$\mathrm{Cd}$ & $0,23 \pm 0,01$ & $0,24 \pm 0,01$ & $95,8 \%$ \\
$\mathrm{Cr}$ & $58,1 \pm 0,5$ & $105 \pm 4$ & $55,3 \%$ \\
$\mathrm{Ni}$ & $46,6 \pm 0,97$ & $46,9 \pm 2,2$ & $99,4 \%$ \\
$\mathrm{Hg}$ & $0,083 \pm 0,006$ & $0,091 \pm 0,009$ & $91,2 \%$ \\
\hline
\end{tabular}

Excetuando-se o Cromo, todos os demais elementos determinados no material de referência certificado apresentaram boa recuperação. Este comportamento do cromo já era esperado, pois, quando não há uma decomposição completa do material por meio de ácido fluorídrico (HF), não é possível uma extração completa deste elemento para a solução (Oliveira, 2009). Assumindo que o método de extração adotado neste trabalho não foi suficiente para lixiviar todo Cromo nos sedimentos, optou-se por trabalhar com um fator de correção baseado na concentração esperada e na concentração encontrada no material de referência certificado, conforme especificado a seguir:

$$
\text { fator }=\frac{\text { Concentração Esperada }(M R C)}{\text { Concentração Encontrada }}
$$

O fator de correção calculado, utilizado para corrigir todos os resultados obtidos de Cromo, foi 1,81 . 
A Tabela 8 apresenta os valores médio, máximo e mínimo das concentrações encontradas nos sedimentos analisados e os valores-guia indicados pelo CONAMA 454 (2012).

Tabela 8: Concentrações médias de metais no sedimento superficial e valores-guia CONAMA 454/12

\begin{tabular}{cccccc}
\hline $\begin{array}{c}\text { Metais } \\
\left(\mathrm{mg} \mathrm{kg}^{-1}\right)\end{array}$ & Média & $\begin{array}{c}\text { Este Trabalho } \\
\text { Max. }\end{array}$ & Mín. & Nível 1 & Nível 2 \\
\hline $\mathrm{Zn}$ & 295 & 1116 & 29,7 & 150 & 410 \\
$\mathrm{~Pb}$ & 13,9 & 25,7 & 2,2 & 46,7 & 218 \\
$\mathrm{Cu}$ & 8,4 & 24,6 & 0,3 & 34,0 & 270 \\
$\mathrm{Cd}$ & 1,6 & 4,6 & 0,4 & 1,2 & 7,2 \\
$\mathrm{Cr}$ & 79,7 & 145 & 1,5 & 81 & 370 \\
$\mathrm{Ni}$ & 9,9 & 15,5 & 0,8 & 20,9 & 51,6 \\
$\mathrm{Hg}$ & 0,057 & 0,291 & $<0,002$ & 0,3 & 1,0 \\
\hline
\end{tabular}

Pode-se observar na Tabela 8 que os níveis encontrados para Chumbo, Cobre, Níquel e Mercúrio estão abaixo do Nível 1 recomendado pelo CONAMA 454 (2012), ou seja, valores abaixo do ERL (Effect Range-Low) e, portanto, probabilidade de se encontrar efeitos adversos à biota é baixo. No caso do Cádmio e Cromo, foram encontrados alguns pontos com concentrações entre os Níveis 1 e 2, onde a probabilidade de efeitos adversos é considerada média, estando estes valores dentro da ERM (Effect Range-Median). Já para o Zinco, a maioria dos pontos de amostragem apresentaram concentrações acima do nível 1, e, na parte interior da baía, principalmente na faixa costeira, foram encontradas concentrações acima do nível 2, sendo que alguns dos pontos estão com quase o triplo da concentração indicada, sugerindo uma alta probabilidade de efeitos adversos à vida marinha.

É importante ressaltar que, embora alguns valores de concentração de Cádmio estejam entre os níveis 1 e 2, o Artigo 12 do CONAMA 454 (2012) enfatiza que deverão ser realizados ensaios de ecotoxicidade do sedimento caso este venha a ser manipulado, numa situação de dragagem, por exemplo.

O tratamento dos dados com o software Ocean Data View, versão 4.7.8, permitiu a construção de superfícies de resposta para cada um dos metais avaliados neste trabalho, que podem ser observadas nas Figura 23 a 29. 


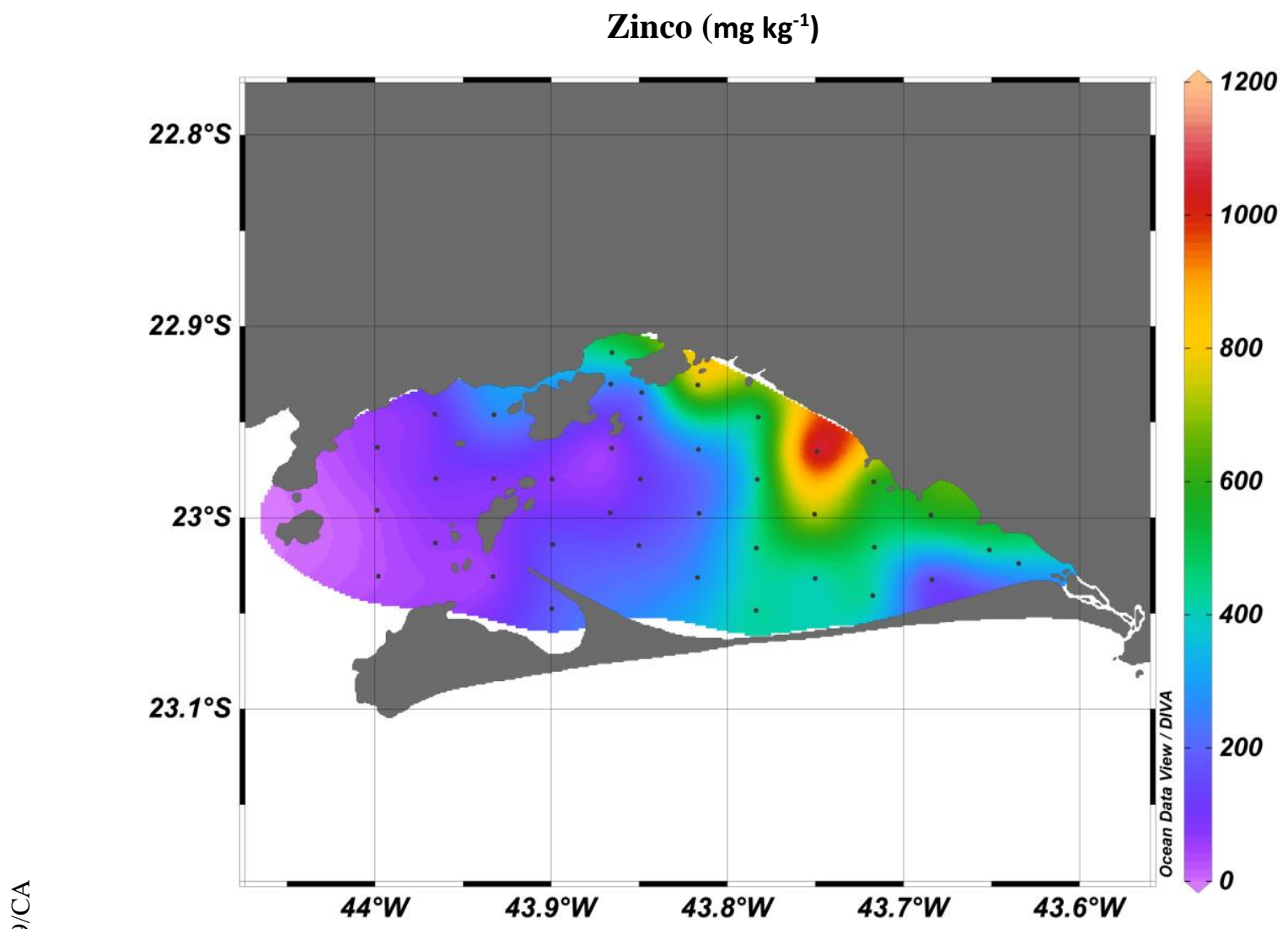

Figura 23: Superfície de resposta para concentrações de Zn na baía de Sepetiba

Chumbo (mg kg-1)

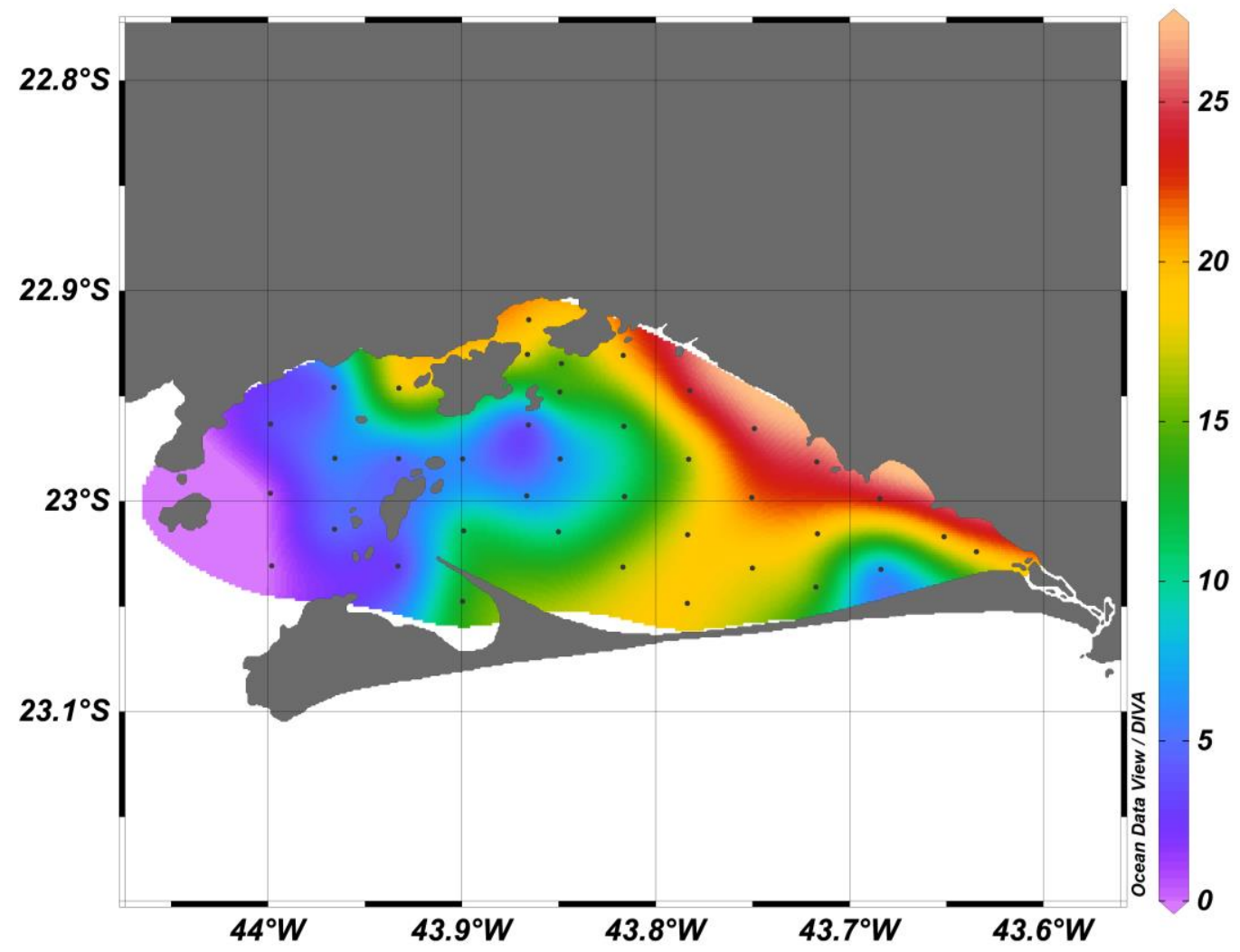

Figura 24: Superfície de resposta para concentrações de Pb na baía de Sepetiba 


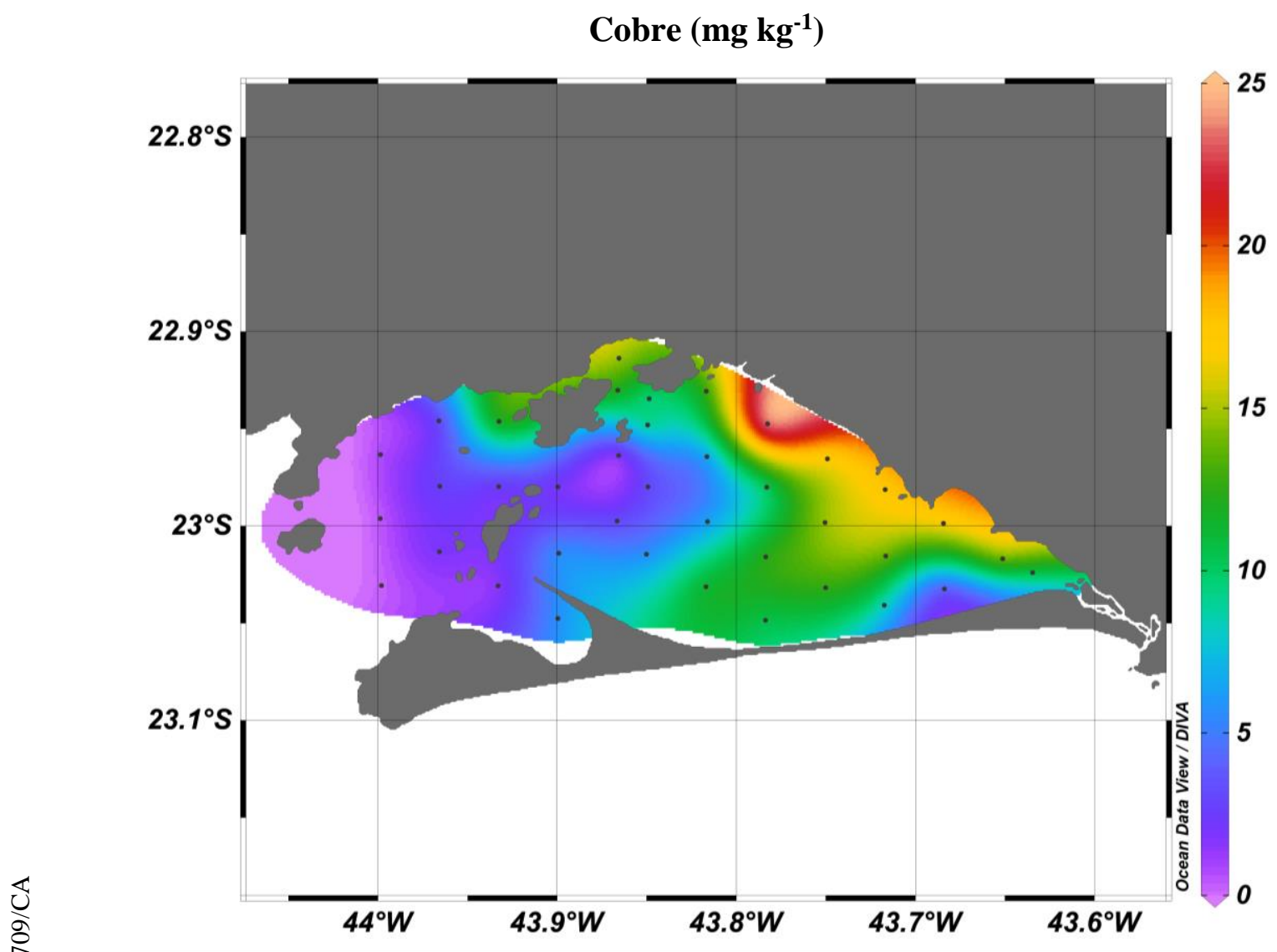

Figura 25: Superfície de resposta para concentrações de Cu na baía de Sepetiba

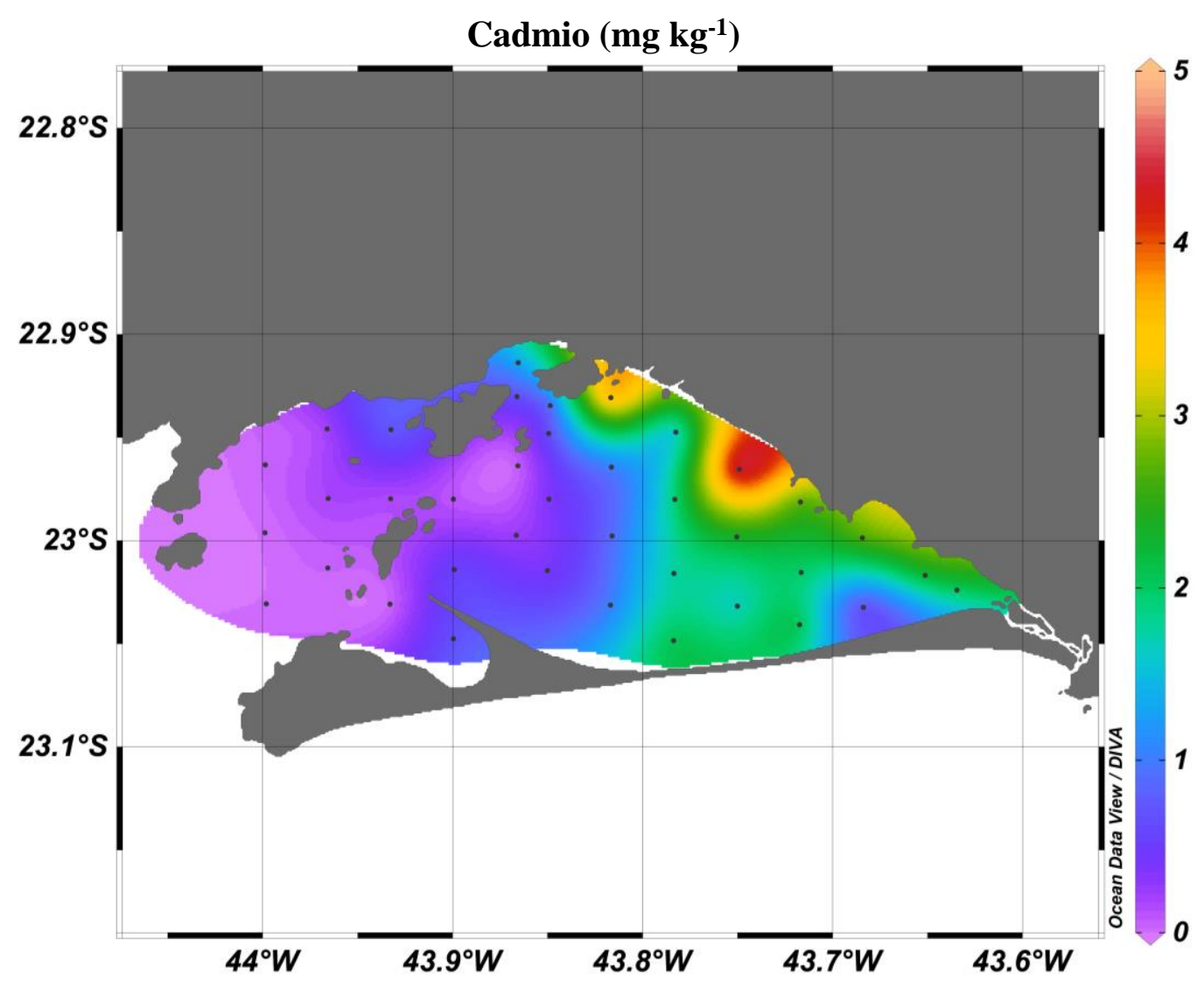

Figura 26: Superfície de resposta para concentrações de Cd na baía de Sepetiba 


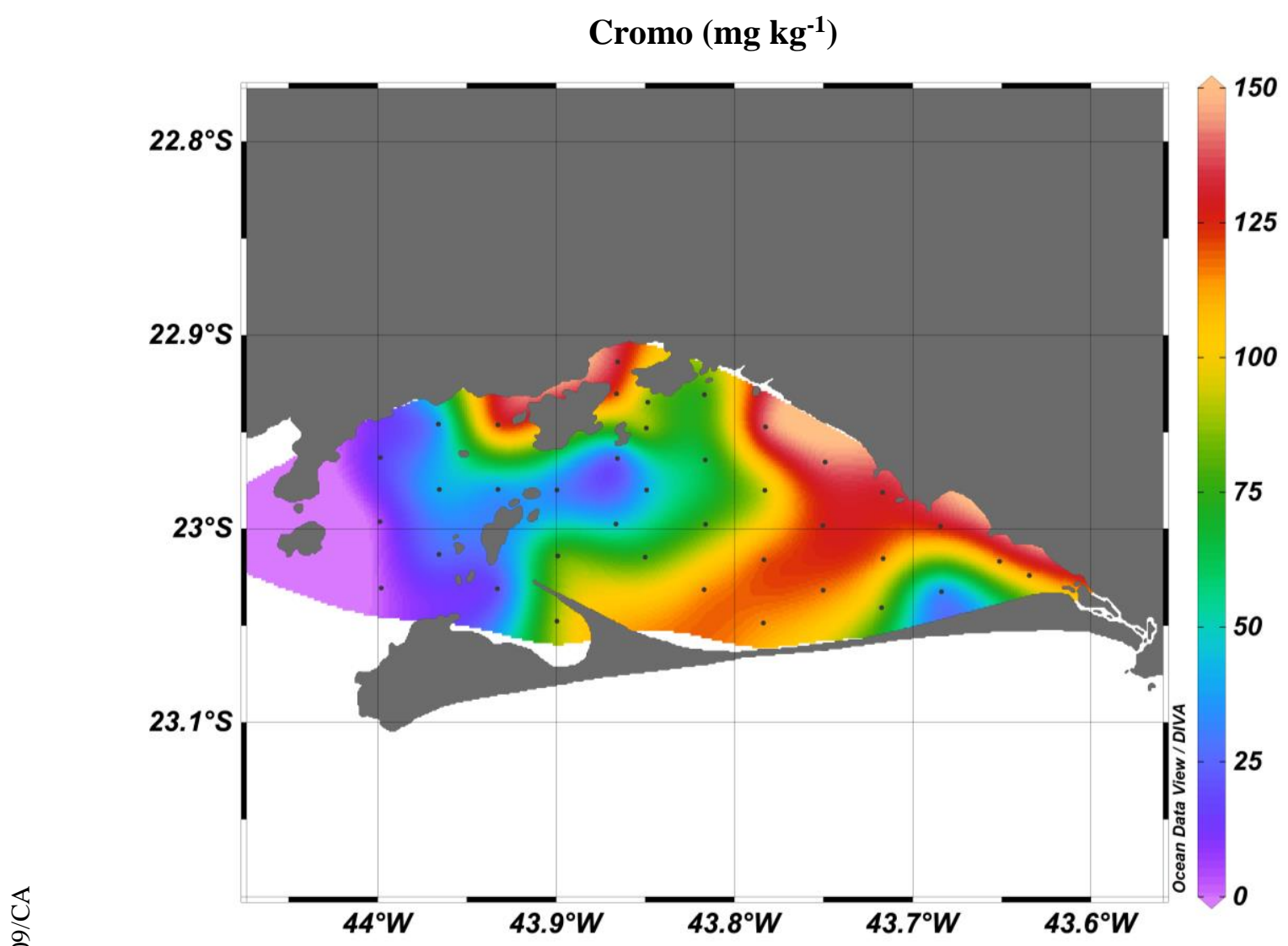

Figura 27: Superfície de resposta para concentrações de Cr na baía de Sepetiba

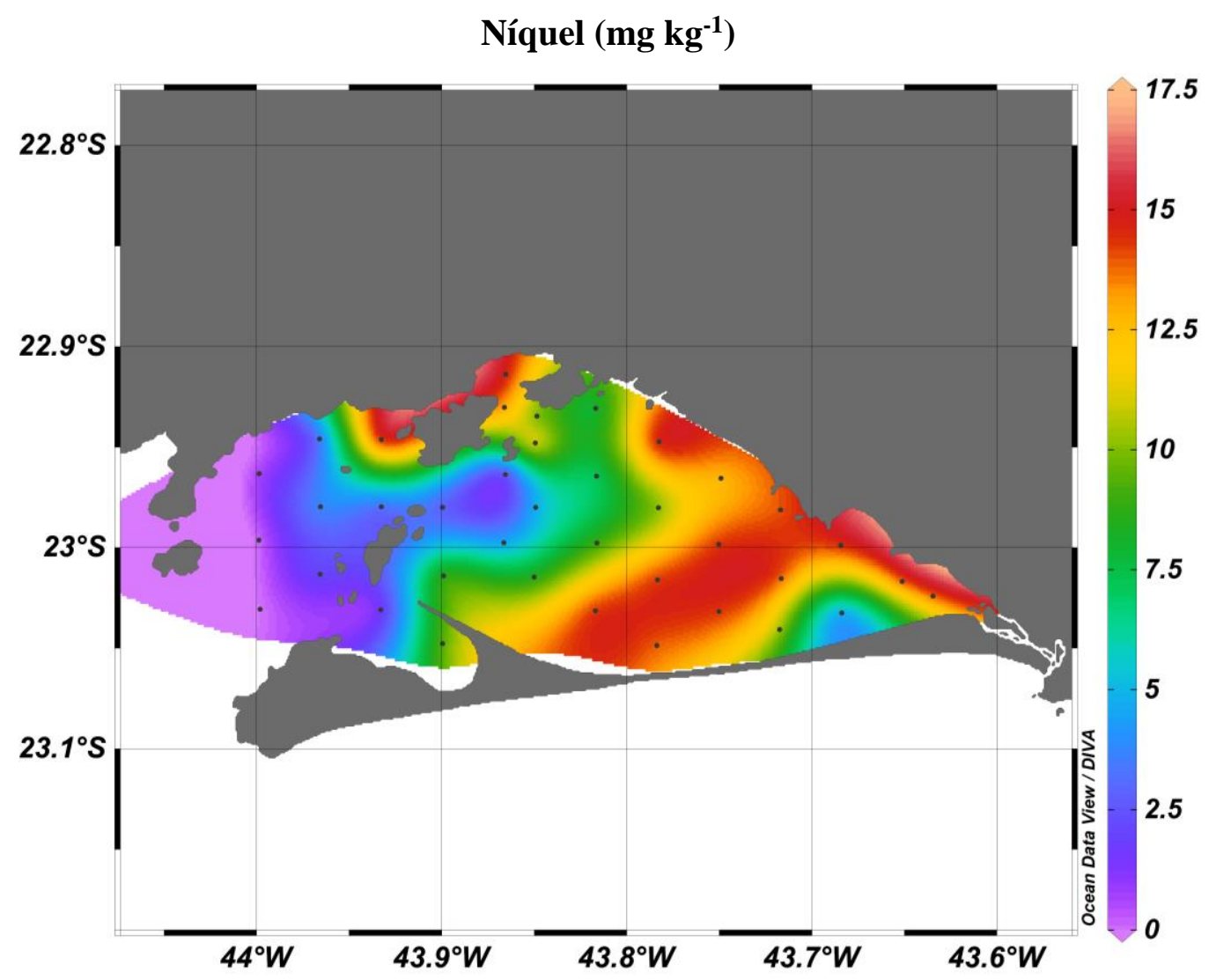

Figura 28: Superfície de resposta para concentrações de Ni na baía de Sepetiba 


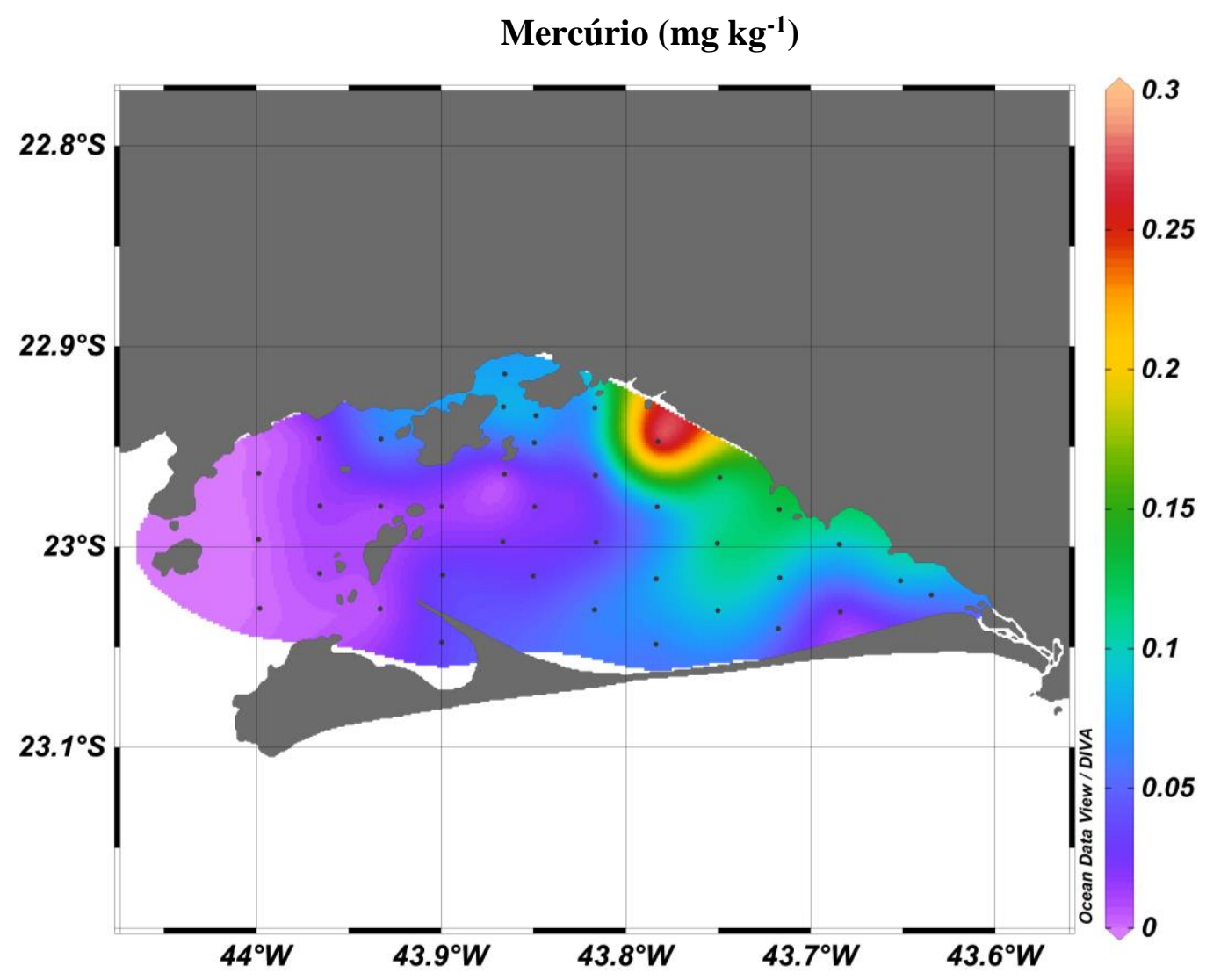

Figura 29: Superfície de resposta para concentrações de Hg na baía de Sepetiba

\subsection{6 \\ Integração dos Resultados (Sedimentos Superficiais)}

Observando as superfícies apresentadas nas Figura 23, e comparando-as com a distribuição do sedimento com granulometria menor do que 0,06 mm (Figura 17), pode-se notar a movimentação do sedimento superficial não consolidado de forma análoga ao regime da hidrodinâmica da baía de Sepetiba e consequentemente a distribuição de sedimentos contaminados com metais ao longo de toda a área interna da baía, com incidência de concentrações mais elevadas em pontos onde ocorrem deposições de matéria fina em taxas mais elevadas. De modo geral, as regiões norte e leste da baía são as regiões que apresentam os maiores níveis de contaminação por estes metais.

Nota-se também, que em todas as superfícies de resposta, a região de maior concentração de metais totais localiza-se ao longo da linha costeira da baía de Sepetiba próxima aos principais rios afluentes, o Rio Guandú e o Canal de São Francisco, entre os pontos SP-123 (Coroa Grande) e SP-103 (Sepetiba). Alguns 
metais destacam-se por apresentarem pontos com elevada concentração, destoando um pouco da superfície apresentada, entre eles $\mathrm{Zn}, \mathrm{Cd}$ e Hg.

O zinco e o cádmio apresentam as maiores concentrações nos pontos SP-108 e SP-115, enquanto a maior concentração de mercúrio foi encontrada no ponto SP111. Em comum, estes três pontos são os mais próximos aos rios tributários e que recebem boa parte da carga de esgoto dos bairros do entorno da baía, além de rejeitos industriais. Paraquetti et al. (2004) estudou os principais rios e canais da região e constatou que, de fato esta região é a principal responsável pelo aporte de Hg na baía. Segundo Paraquetti et al. (2004), o rio Guandú apresenta uma concentração de mercúrio total de $188 \mathrm{ng} \mathrm{L}^{-1}$.

Gomes et al. (2009) e Rodrigues et al. (2017) determinaram a concentração de $\mathrm{Zn}$ e $\mathrm{Cd}$, além de outros metais, nesta mesma região situada ao longo da linha costeira, encontrando concentrações compatíveis com as observadas neste estudo.

As superfícies de resposta apresentadas nas Figura 23 a 29 são visualmente muito similares, indicando que podem haver correlações significativas entre $\mathrm{Zn}, \mathrm{Pb}$, $\mathrm{Cu}, \mathrm{Cd}, \mathrm{Cr}, \mathrm{Ni}$ e Hg. Esta hipótese se confirma quando são calculados os valores de correlação entre todos os metais e também entre os resultados de Corg, AVS, e \% de sedimentos finos (silte+argila), que possuem influência direta nos mecanismos de transporte, deposição e imobilização dos metais no sedimento.

Tabela 9: Coeficientes de correlação de Pearson

\begin{tabular}{c|cccccccccc}
\hline--- & Zinco & Chumbo & Cobre & Cádmio & Cromo & Níquel & Mercúrio & Corg & AVS & Finos \\
\hline Zinco & 1 & & & & & & & & & \\
Chumbo & $\mathbf{0 , 8 4 7}$ & 1 & & & & & & & & \\
Cobre & $\mathbf{0 , 7 9 3}$ & $\mathbf{0 , 9 5 7}$ & 1 & & & & & & & \\
Cádmio & $\mathbf{0 , 9 5 4}$ & $\mathbf{0 , 7 3 4}$ & 0,557 & 1 & & & & & & \\
Cromo & $\mathbf{0 , 7 4 1}$ & $\mathbf{0 , 9 5 6}$ & $\mathbf{0 , 9 3 2}$ & 0,430 & 1 & & & & & \\
Níquel & $\mathbf{0 , 6 7}$ & $\mathbf{0 , 9 1 3}$ & $\mathbf{0 , 8 8 1}$ & 0,313 & $\mathbf{0 , 9 7 8}$ & 1 & & & & \\
Mercúrio & $\mathbf{0 , 6 1 2}$ & $\mathbf{0 , 8 0 1}$ & $\mathbf{0 , 9 1 8}$ & 0,346 & $\mathbf{0 , 7 7 1}$ & $\mathbf{0 , 7 0 3}$ & 1 & & & \\
Corg & 0,589 & $\mathbf{0 , 7 4 2}$ & $\mathbf{0 , 7 0 7}$ & 0,560 & $\mathbf{0 , 7 1 8}$ & 0,690 & 0,566 & 1 & & \\
AVS & 0,619 & $\mathbf{0 , 7 7 3}$ & $\mathbf{0 , 8 7 7}$ & 0,591 & $\mathbf{0 , 7 0 5}$ & 0,679 & $\mathbf{0 , 8 7 9}$ & 0,547 & 1 & \\
Finos & 0,553 & $\mathbf{0 , 7 4 5}$ & 0,683 & 0,535 & $\mathbf{0 , 8 0 5}$ & $\mathbf{0 , 8 1 7}$ & 0,574 & 0,421 & 0,436 & 1 \\
\hline
\end{tabular}

Embora os níveis de concentração encontrados para cada um dos metais sejam bem diferentes, os coeficientes de correlação apresentados na

Tabela 9 demonstram que há correlações significativas entre quase todos eles, variando entre correlações positivas moderadas a muito forte. 
Esperava-se uma correlação dos metais em geral com a percentagem de finos, no entanto, esta correlação só foi observada para $\mathrm{Pb}, \mathrm{Cr}$ e Ni. Para os demais metais, esta ausência de correlação com os finos pode estar relacionada diretamente com o fato de que a distância dos pontos com a fonte de contaminação possa ser o fator preponderante para a sua distribuição.

A forte correlação observada entre $\mathrm{Zn}$ e Cd não surpreende, uma vez que o cádmio é o principal subproduto do beneficiamento do minério Calamina $\left(\mathrm{Zn}_{2} \mathrm{SiO}_{3}(\mathrm{OH})_{2}\right)$ na produção de zinco puro e os resíduos da produção deste metal foram, durante muitos anos, descartados diretamente na baía de Sepetiba e, além disso, acidentes como o rompimento do dique de contenção da companhia Mercantil e Industrial Ingá em 1996 liberaram milhares de metros cúbicos de resíduos contaminados diretamente neste estuário.

Em relação aos demais metais, uma correlação significativa é verificada para o $\mathrm{Cu}$ e o $\mathrm{Hg}$ em relação ao AVS, já observada na semelhança da sua distribuição nos sedimentos superficiais (Figura 20, Figura 25 e Figura 29), com a região de máxima concentração na margem norte da baía, próximo à desembocadura do canal de São Francisco e do rio Guandú.

Observa-se também uma forte correlação entre cromo e níquel, levando a crer na possibilidade de uma fonte comum de ambos. A concomitante correlação destes com o percentual de finos e, também, a faixa de concentração observada ser compatível com aquela existente na Baía da Ribeira (Gomes et al., 2009) faz supor que a origem de ambos seja comum e natural. Essa hipótese é, também, corroborada pelo perfil homogêneo de $\mathrm{Cr}$ e $\mathrm{Ni}$ ao longo dos testemunhos sedimentares (Anexo G).

\subsubsection{1 \\ Relação entre mercúrio, cobre e sulfeto (AVS)}

As mais altas concentrações de sulfetos foram observadas na área da margem continental da baía de Sepetiba próxima aos rios afluentes que, segundo Cunha et al. (2006), contribuem com a carga principal da demanda bioquímica de oxigênio (DBO) para a baía. 
É importante observar que a superfícies de resposta para as concentrações de mercúrio (Figura 29) e cobre (Figura 25) são muito semelhantes à do sulfeto (Figura 20), assim como o ponto de concentração máximo na estação SP-111, com concentrações de $0,291 \mathrm{mg} \mathrm{kg}^{-1}$ e $25 \mathrm{mg} \mathrm{kg}^{-1}$ para mercúrio e cobre, respectivamente. A estação SP-111 fica localizada próximo aos principais rios afluentes da baía de Sepetiba, entre eles o Rio Guandú e o Canal de São Francisco. Esta distribuição espacial do mercúrio, com pontos de máxima concentração próximo aos principais rios tributários também já foi observado por Paraquetti et al. (2004) e Molisani et al. (2004).

Para avaliar a correlação entre estes contaminantes, foi construído o gráfico de concentração de mercúrio versus concentração de sulfetos (AVS) (Figura 30-a) e cobre (Figura 30-b).

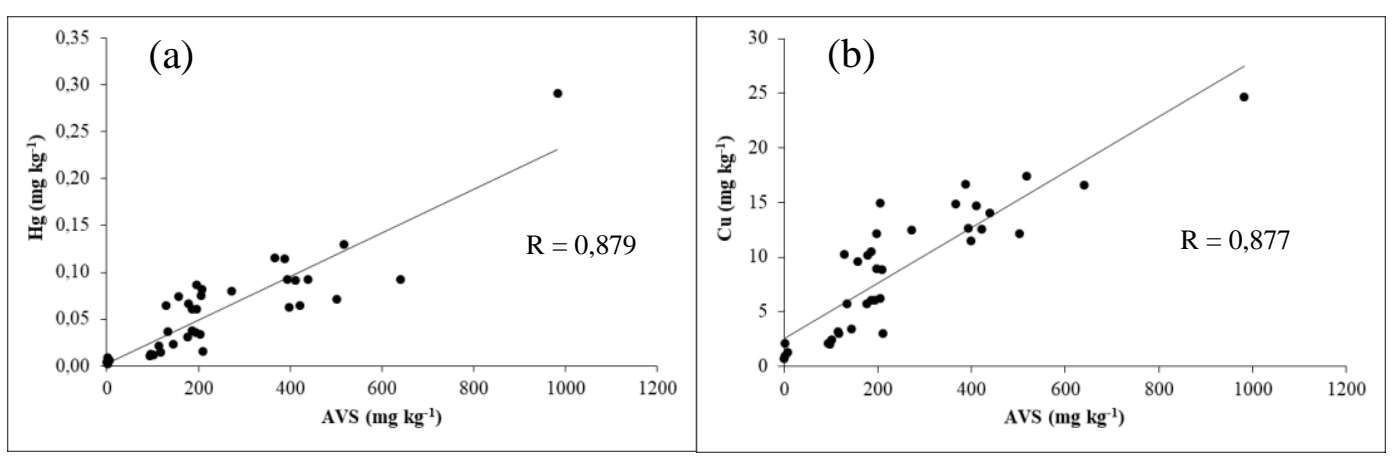

Figura 30: Correlação entre $\mathrm{Hg}(a)$ / Cu (b) e sulfetos volatilizáveis por acidificação (AVS) em sedimentos superficiais da Baía de Sepetiba.

Essa correlação entre estes metais e sulfetos, explica-se principalmente pela baixa solubilidade do $\mathrm{HgS}\left(\mathrm{K}_{\mathrm{ps}}=1,6 \times 10^{-54}\right)$ e $\mathrm{CuS}\left(\mathrm{K}_{\mathrm{ps}}=8,0 \times 10^{-37}\right)$, segundo Fagnani et al. (2011), em ambientes onde a concentração de sulfetos é elevada, a formação destas espécies insolúveis é favorecida e consequentemente encontramse imobilizadas no sedimento.

A afinidade do $\mathrm{Hg}$ pelo $\mathrm{S}$ de fato, já está muito bem documentada e, até mesmo a correlação entre o $\mathrm{Hg}$ e a matéria orgânica é atribuída a alguns grupos funcionais contendo enxofre (Schartup et al., 2014). O teor de metil-mercúrio nestes sedimentos foi muito baixo, não passando de $0,1 \%$ da concentração de mercúrio total. Segundo Schartup et al. (2014) e Bratkič et al. (2013), a metilação de mercúrio em sedimentos anóxidos e ricos em sulfetos é quase inexistente.

Com relação ao cobre, Casas e Crecelius (1994) também observaram a forte interação com sulfeto, estando completamente imobilizado na forma de $\mathrm{CuS}$ no 
sedimento. De acordo com estes mesmos autores, na coluna d'água o cobre só é detectado quando sua concentração é superior à concentração de AVS. Nos pontos amostrados na área externa da Baía de Sepetiba, em regiões onde o sedimento é basicamente arenoso (areia/cascalho > $70 \%$ ), as concentrações de cobre e sulfetos determinadas foram muito baixas, inviabilizando a comparação entre estes dois parâmetros, através da razão entre eles, mas em todos os demais pontos a concentração de sulfeto é aproximadamente entre 150 e 700 vezes maior do que a concentração de cobre.

\subsubsection{2}

\section{Variação temporal das concentrações de mercúrio, zinco e cádmio}

A variação temporal das concentrações de mercúrio no sedimento superficial pode ser obtida por meio da simples comparação entre os dados obtidos em 2001 por FEEMA (2006) e os dados atuais, obtidos neste trabalho. Utilizando o software Ocean Data View, versão 4.7.8 e uma escala de variação relativa, foi possível a construção da superfície de resposta apresentada na Figura 31.

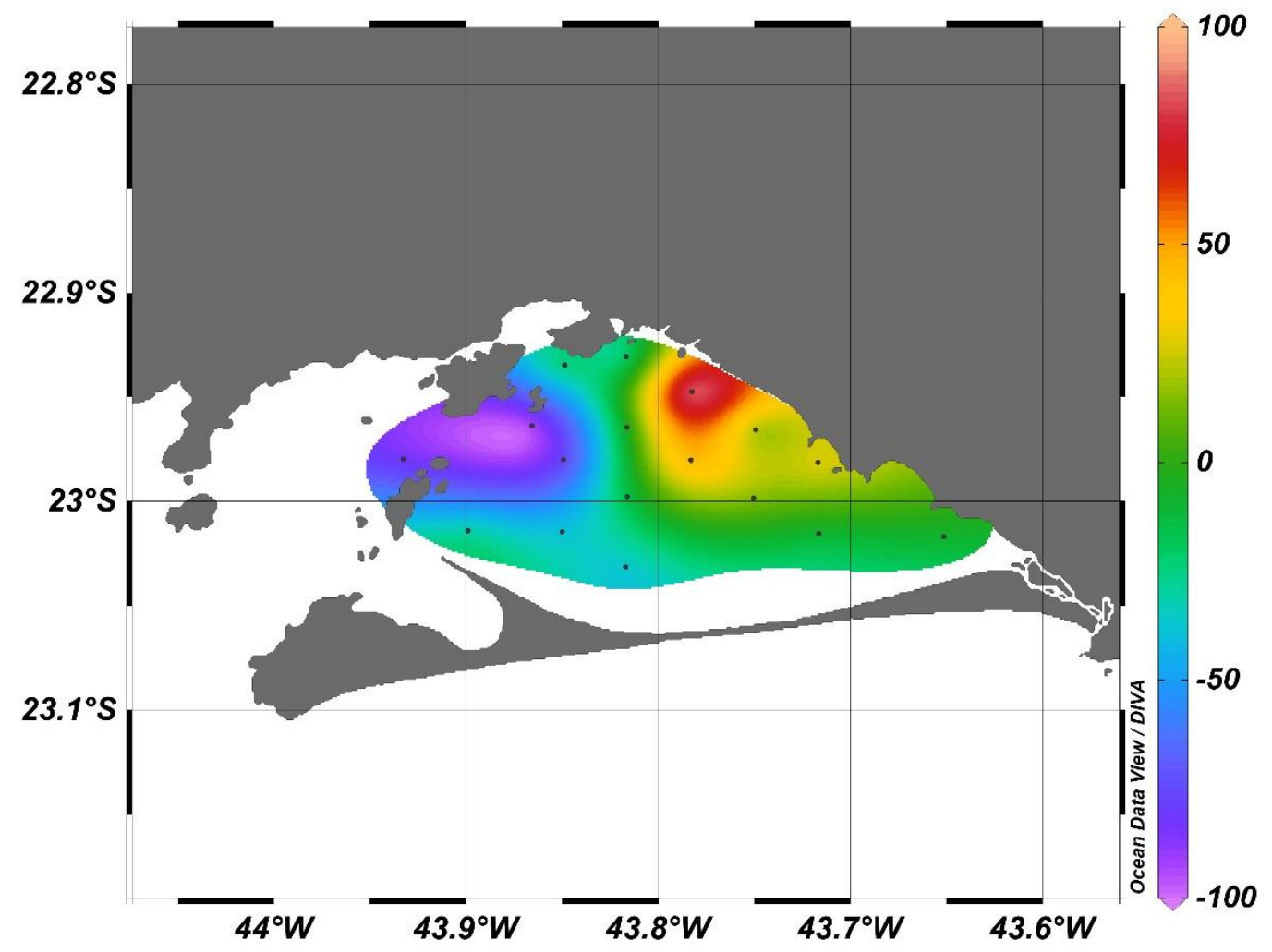

Figura 31: Variação percentual da concentração atual de Hg em sedimento superficial da baía de Sepetiba, escala relativa à concentração obtida em 2001. 
Observa-se um aumento de $100 \%$ na estação SP-111, que fica próxima às principais fontes de mercúrio para a baía, o rio Guandú e o canal de São Francisco. Segundo Marins et al. (2004) estes dois rios são responsáveis por $95 \%$ de todo aporte de mercúrio na baía de Sepetiba e sua influência na distribuição deste metal no sedimento de fundo já havia sido relatada anteriormente por Marins et al. (1998). Por outro lado, nota-se um decréscimo de quase 100 \% em outra área da baía, que corresponde ao canal principal de navegação que liga a área externa ao porto de Sepetiba, essa redução, provavelmente, é resultado de dragagens periódicas que ocorrem para manter a profundidade do canal. O material dragado desta região é descartado em área oceânica, fora da baía de Sepetiba.

Assim como foi feito com o $\mathrm{Hg}$, as variações temporais das concentrações de $\mathrm{Zn}$ e Cd no sedimento superficial foi obtida por meio da comparação entre os dados atuais e os obtidos em 2001 por FEEMA (2006). Utilizando uma escala de variação relativa foi possível a construção das superfícies de resposta apresentadas nas Figura 32 e 33.

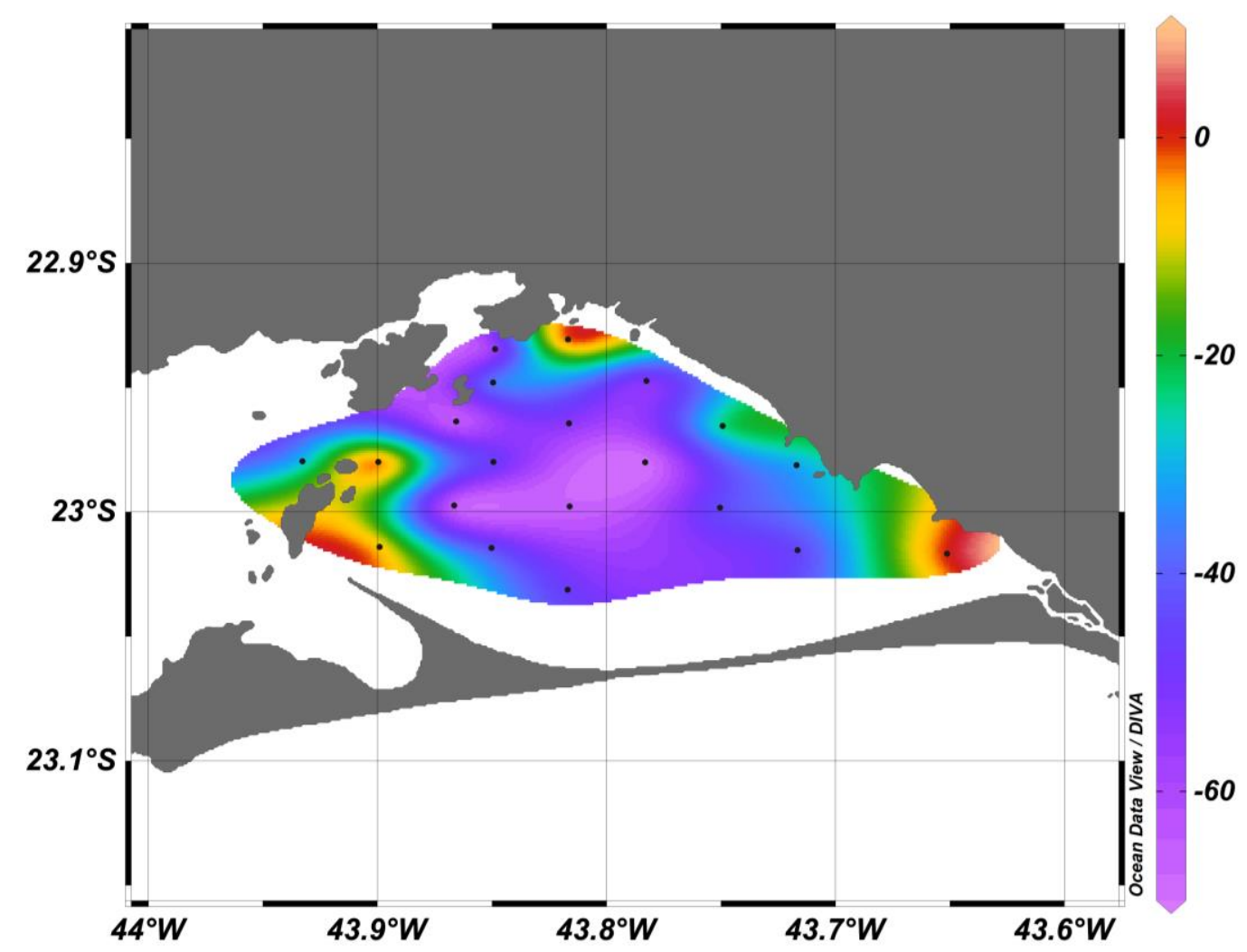

Figura 32: Variação percentual da concentração atual de Zn em sedimento superficial da baía de Sepetiba, escala relativa à concentração obtida em 2001. 


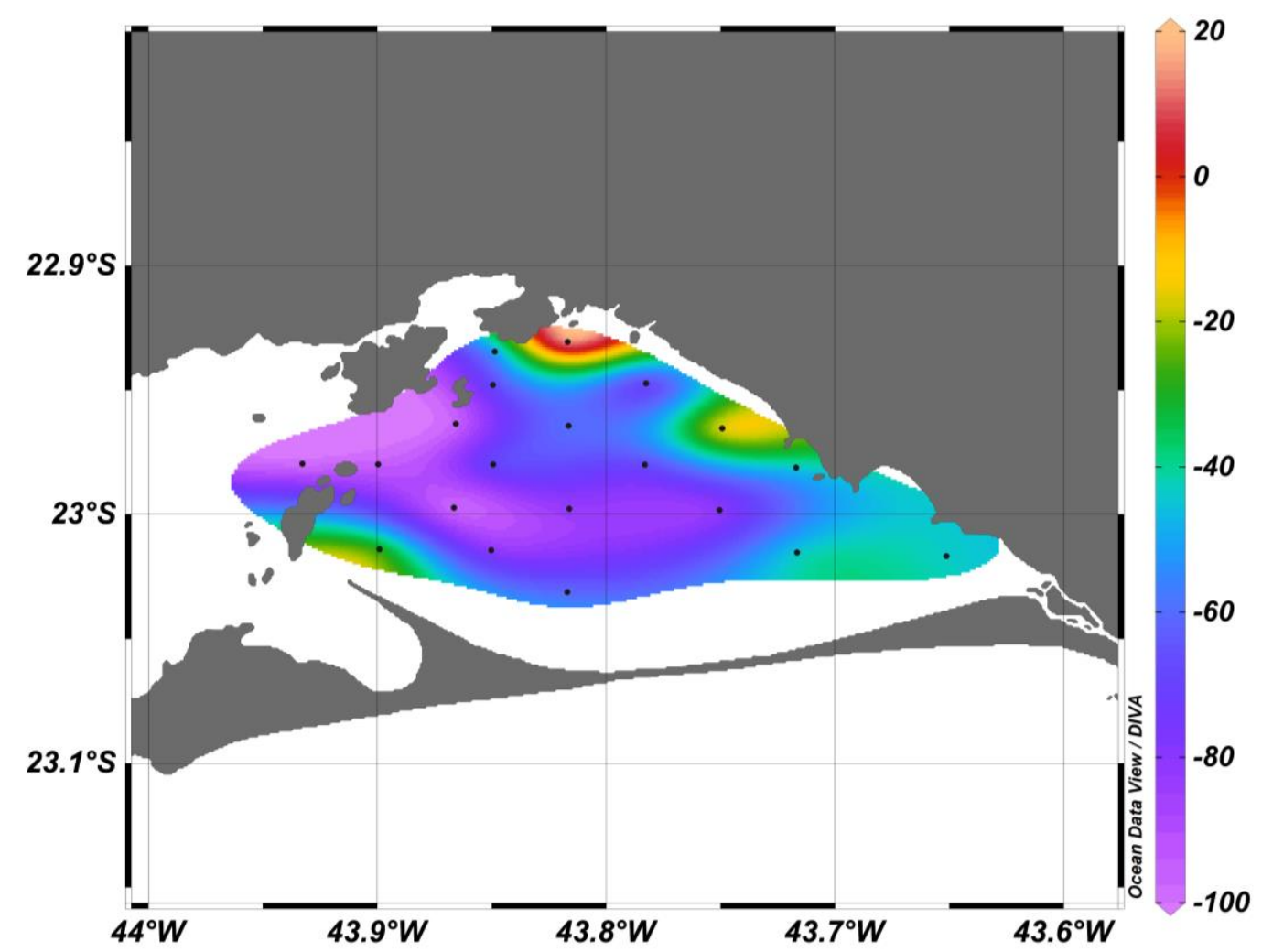

Figura 33: Variação percentual da concentração atual de Cd em sedimento superficial da baía de Sepetiba, escala relativa à concentração obtida em 2001.

Observa-se que houve grande redução nas concentrações de zinco e cadmio com diferenças relativas de até $-71 \%$ e $-98 \%$ respectivamente. Entretanto, alguns pontos próximos ao principais rios afluentes apresentaram concentrações bem próximas às relatadas por FEEMA (2006) sugerindo que podem haver fontes contribuindo para a não redução dos níveis de concentração de $\mathrm{Zn}$ e $\mathrm{Cd}$, ou até mesmo aumentando estes níveis. O ponto SP-115, próximo à ilha da madeira e ao saco do engenho foi o que apresentou a maior variação relativa, com 3,1 \% para $\mathrm{Zn}$ e $19,8 \%$ para Cd.

A concentração de Zn e Cd nesta região foi avaliada por Gomes et al. (2009) e, mais recentemente, por Rodrigues et al. (2017), que encontraram concentrações destes metais similares a este trabalho, Barcellos e Lacerda (1994) e Molisani et al. (2004) afirmam que os rios afluentes são, também, uma importante fonte de Zn e Cd para a Baía pois foram encontradas altas concentrações no material particulado.

Gomes et al. (2009) sugere que outra possível fonte de Zn seja a COSIGUA, uma indústria siderúrgica, pertencente ao grupo Gerdau S.A., instalada às margens do canal de São Francisco, distando apenas 5 km da baía. 


\subsubsection{3}

\section{Análise de Cluster - Método de Ligação de Ward}

A análise de cluster é um método de partição de uma população heterogênea em vários subgrupos mais homogêneos. No agrupamento não há classes prédefinidas, os elementos são agrupados de acordo com a semelhança, neste caso, os elementos a serem comparados são as estações de coleta e o agrupamento é baseado na similaridade entre os resultados encontrados em cada determinação analítica.

Geralmente, os critérios adotados agrupam os elementos de forma a se obter homogeneidade dentro dos grupos e heterogeneidade entre eles. Os métodos aglomerativos caracterizam-se pelo fato de que inicialmente cada elemento representa um grupo e, a cada passo de aglomeração, um elemento (ou grupo) é ligado a outro de acordo com sua similaridade, até o último passo em que se tem um único grupo com todos os elementos.

Os grupos são geralmente representados por um diagrama bi-dimensional chamado de dendrograma, deve-se determinar uma distância de corte para definir quais são os grupos formados, essa decisão é subjetiva e foi realizada de acordo com o objetivo desta análise.

Existem vários métodos aglomerativos, que são caracterizados de acordo com o critério que se utilizam para definir as distâncias entre grupos. Utilizando o método de ligação de Ward, ou método da soma de erros quadráticos, obteve-se o dendrograma apresentado na Figura 34. 


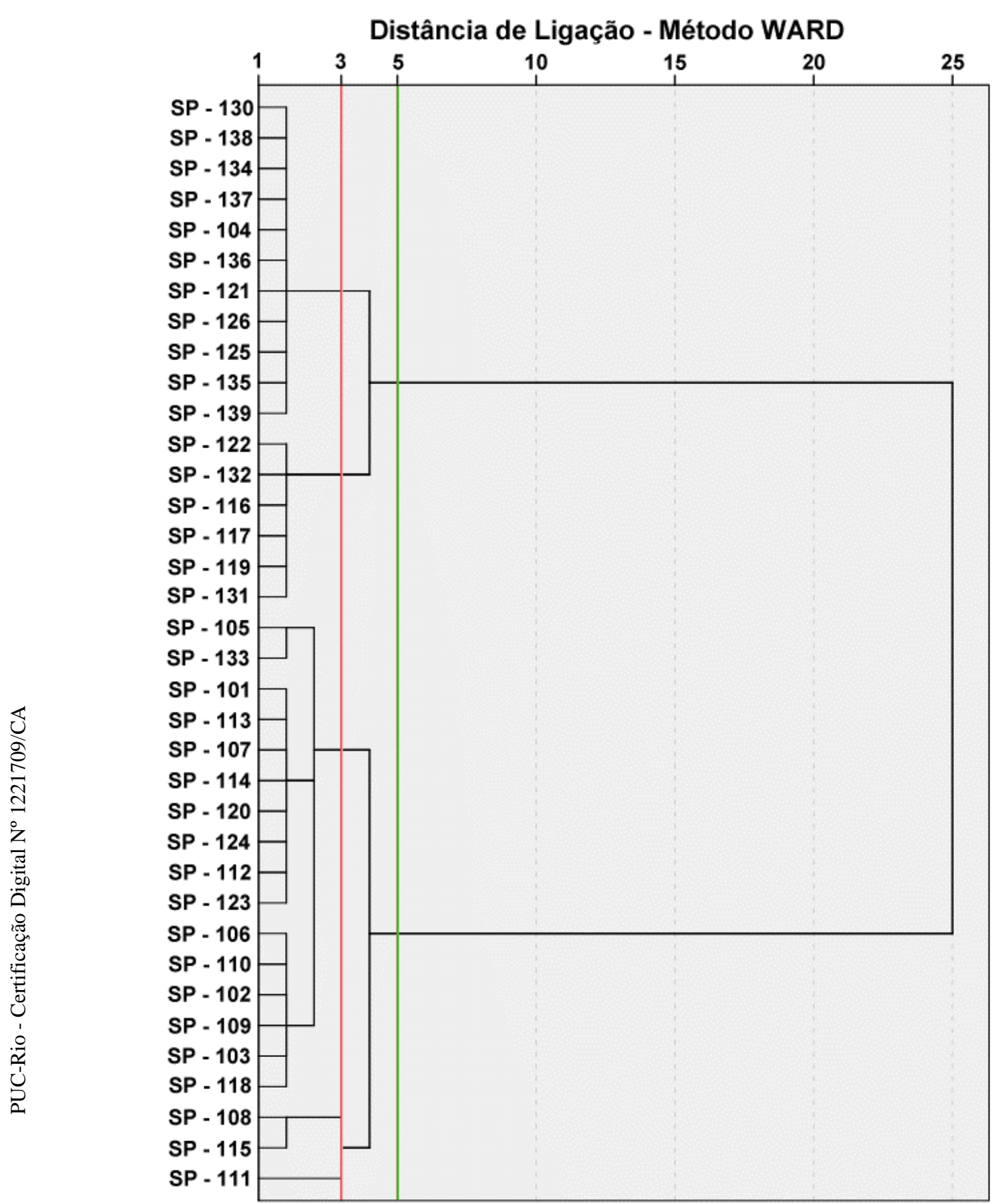

Figura 34: Dendrograma da análise de cluster pelo método de ligação de Ward

Pode-se observar no dendrograma apresentado na Figura 34 que várias estações de amostragem apresentam alta similaridade, concatenando-os em grandes grupos que chegam a conter até 11 estações de amostragem. Seguindo o método aglomerativo, logo se percebe a formação de dois grandes grupos que possuem baixa similaridade entre si, ou seja, são dois grandes aglomerados que possuem características muito distintas e apontam para uma divisão da Baía de Sepetiba em duas grandes regiões com características muito diferentes. 
A distância de ligação entre os grupos que mais se adequou aos dados observados neste trabalho e que foi utilizada como corte para a definição dos grupos foi a distância euclidiana 3. Neste caso, foi possível a observação de 4 grupos com boa similaridade entre as estações de coleta dentro de cada grupo e características distintas entre os grupos. Vale ressaltar que, mesmo fazendo parte de algum grupo formado na condição de corte escolhida, cinco pontos possuem características bem distintas dos demais em pelo menos um dos parâmetros utilizados na elaboração do dendrograma, são eles:

O ponto SP-111 apresenta-se isolado dos demais em função do elevado valor de AVS, bem superior aos demais, apresentando uma concentração 50\% maior do que o segundo ponto mais alto, além de também representar a maior concentração de $\mathrm{Hg}$ observada.

Os pontos SP-108 e SP-115 representam os dois pontos com as maiores concentrações de zinco, $1116 \mathrm{mg} \mathrm{kg}^{-1}$ e $799 \mathrm{mg} \mathrm{kg}^{-1}$, respectivamente, bem acima do nível dois (410 $\mathrm{mg} \mathrm{kg}^{-1}$ ) recomendado pela resolução CONAMA 454 (2012), apresentado na Tabela 2.

Os pontos SP-105 e SP-133 associam simultaneamente elevada concentração de carbono orgânico total e uma baixa percentagem de sedimentos finos.

A Figura 35 apresenta a distribuição espacial dos grupos ao longo de toda a área de amostragem, as estações estão divididas em cores diferentes, representando o grupo ao qual pertencem.

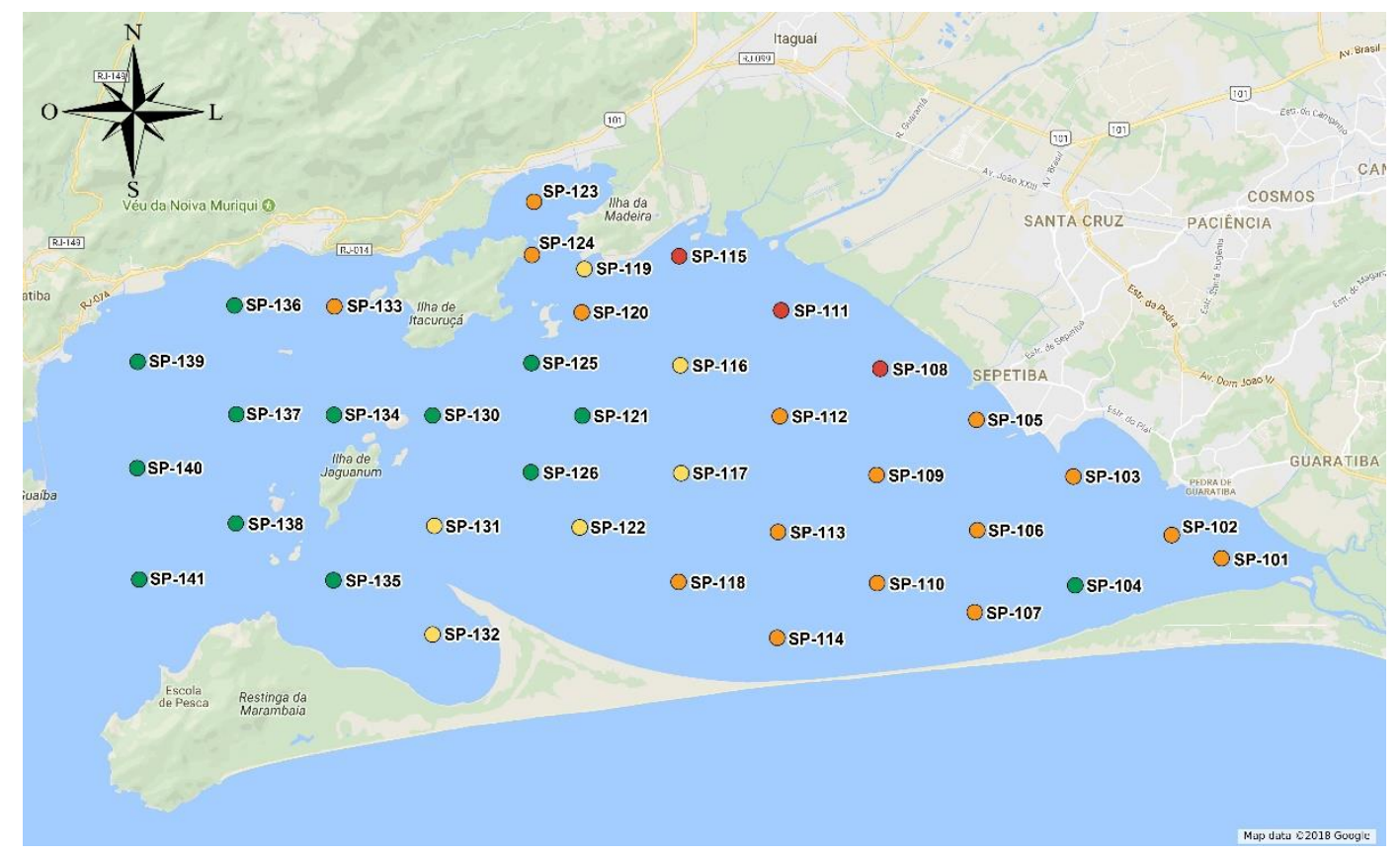

Figura 35: Grupos formados após a seleção do nível 3 do dendrograma como distância de corte 
Fica evidente a divisão da Baía de Sepetiba em duas grandes regiões, a área externa da baía, é representada em verde no mapa e apresenta características bem distintas da área interna da baía, representada em laranja no mapa. Entre as áreas externa e interna há uma faixa, representada em amarelo, é uma zona de transição onde as concentrações determinadas para os contaminantes analisados apresentaram valores intermediários às duas grandes regiões da baía.

Neste mapa destaca-se uma região que se inicia na parte leste da Ilha da Madeira e percorre a costa interna da baía na direção sudeste até a praia de Sepetiba. Nesta área, representada em vermelho, estão localizados todos os rios e canais que sofrem com o descarte de resíduos industriais e também esgoto sanitário e, por isso, foram encontradas as maiores concentrações de todos os metais determinados neste trabalho (Figura 23), além dos valores também mais elevados de AVS e $\sum$ SEM (Figura 20).

Com base no diagrama apresentado na Figura 34 e nas evidências observadas para cada ponto amostral, individualmente ou em grupos, pode-se sugerir uma malha amostral dos sedimentos superficiais simplificada, mas representativa, que possa ser empregada no monitoramento ambiental da Baía de Sepetiba, desenvolvido pelo Instituto Estadual do Ambiente (INEA), representando uma redução de $50 \%$ dos pontos originais.

- Pontos SP-105, SP-108, SP-111, SP-115 e SP-133

- Pontos SP-125, SP-137 e SP-130

- Pontos SP-101, SP-103, SP-107, SP-109, SP-112, SP-120 e SP-124

- Pontos SP-116, SP-122 e SP-131

- Ponto SP-123 (Coroa Grande)

A malha amostral proposta (Figura 36) cobre toda a costa interna da baía, onde se observam as maiores concentrações dos parâmetros analisados, além de pontos representativos da área central da baía, onde foram observadas concentrações intermediárias de metais tóxicos à vida marinha, destacando-se o zinco, com os maiores valores, e cádmio e cromo com concentrações intermediárias, acima do nível 1 recomendado pela resolução CONAMA 454 (2012). Acrescenta-se também na proposta de malha amostral alguns pontos na região externa da baía e também próximos ao canal principal de navegação. 


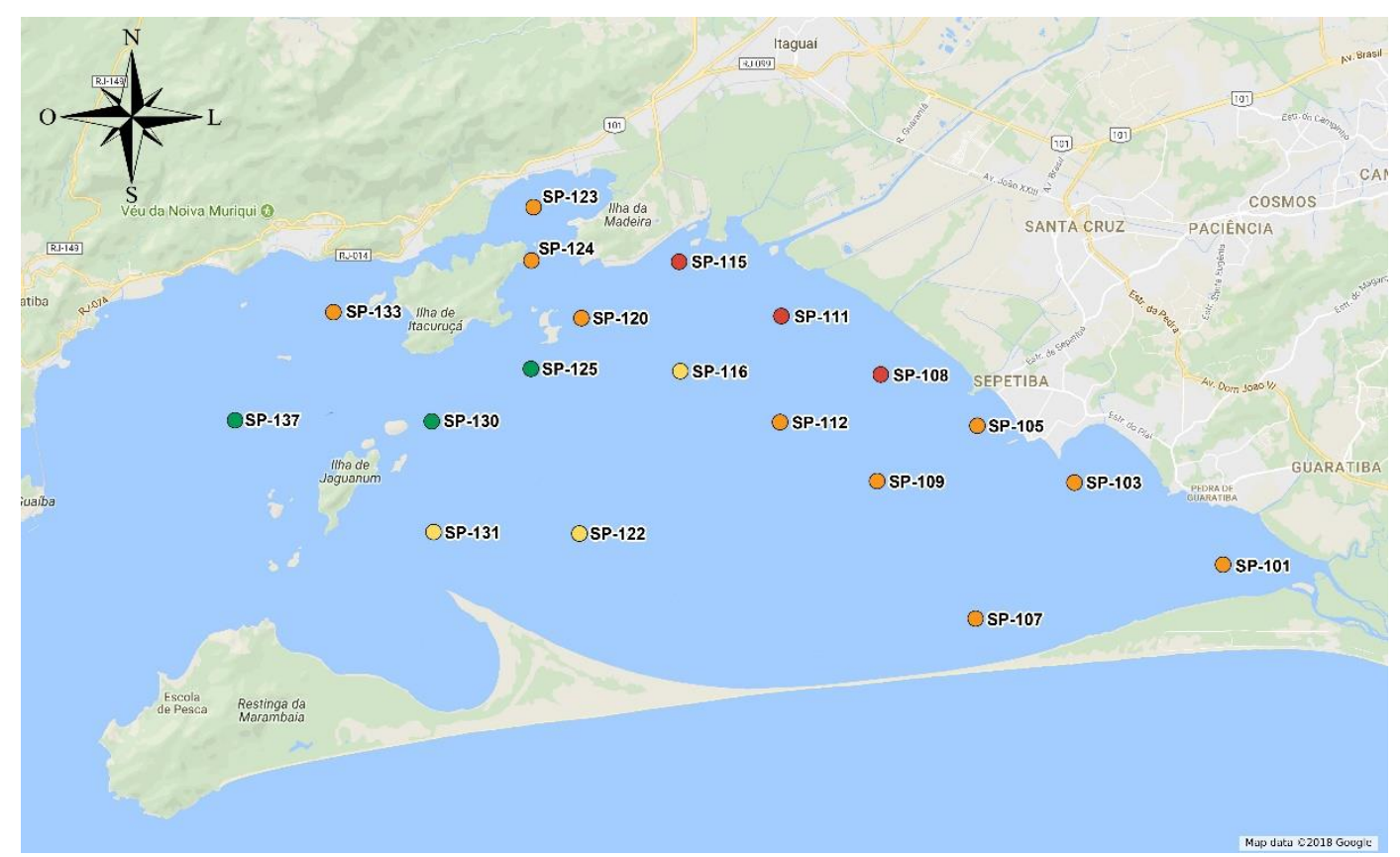

Figura 36: Malha amostral proposta para monitoramento ambiental da Baía de Sepetiba

A construção de diagramas de caixas, agrupando os resultados dos metais potencialmente tóxicos nos mesmos 4 grupos definidos pela distância de corte 3 no dendrograma (Figura 34) e utilizando o mesmo padrão de cores do mapa apresentado na Figura 35, fornece-nos as seguintes imagens.
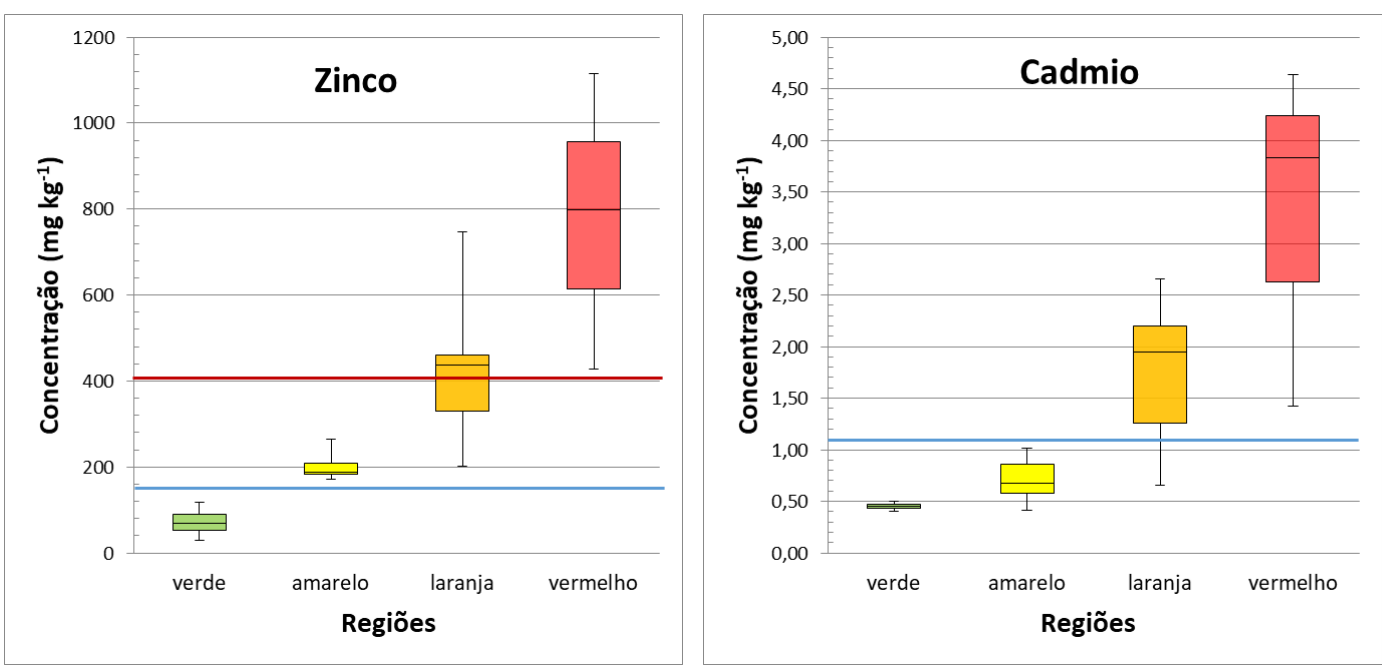

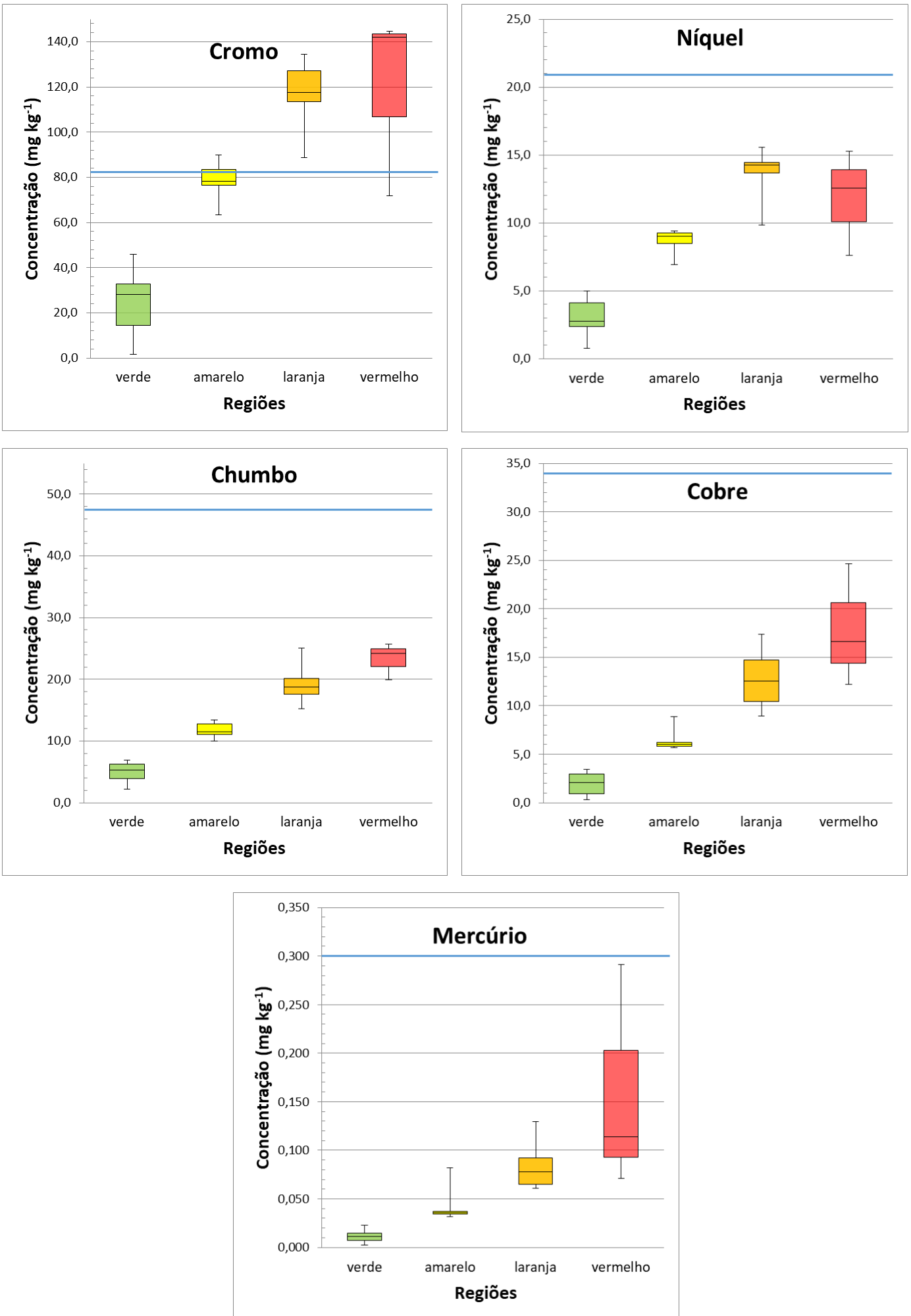

Figura 37: Diagramas de caixa (box-plot), metais $\mathrm{Zn}, \mathrm{Cd}, \mathrm{Cr}, \mathrm{Ni}, \mathrm{Pb}, \mathrm{Cu}$ e Hg organizados em 4 grupos de similaridade. Faixas azul e vermelha - níveis 1 e 2 do CONAMA 454/12 respectivamente.

Os diagramas apresentados na Figura 37 evidenciam os níveis de concentração encontrados para os metais determinados neste trabalho em cada uma das quatro regiões da baía de Sepetiba. Observa-se que a região vermelha é, de fato, 
a mais afetada pelo aporte antropogênico destes metais e requer maior atenção e cuidados no manejo do sedimento. Nesta região, todos os valores de concentração de Zn estão acima do nível 2 do CONAMA 454/12. Também se pode observar neste mesmo grupo, que os níveis de $\mathrm{Cd}$ e $\mathrm{Cr}$ estão acima do nível 1 desta mesma resolução, neste caso, recomenda-se testes mais específicos para a avaliação da ecotoxicidade do sedimento.

Nota-se também que há uma grande similaridade entre os grupos laranja e vermelho nas concentrações de $\mathrm{Ni}$ e Cr. Observando as superfícies de resposta (Figura 27 e 28), percebe-se que há uma dispersão maior destes elementos ao longo de toda área interna da baía de Sepetiba, seguindo o mesmo perfil do sedimento ainda não consolidado e de granulometria mais fina, menor que $0,06 \mathrm{~mm}$, que movimenta-se de forma análoga ao perfil hidrodinâmico da baía.

\section{2 \\ Testemunhos Sedimentares}

\subsection{1}

\section{Avaliação Preliminar dos Testemunhos}

Preliminarmente à datação $\operatorname{com}^{210} \mathrm{~Pb}$, foram realizadas avaliações dos dados de umidade e concentrações de metais tóxicos, com atenção especial para $\mathrm{Zn}$ e Cd, em cada camada dos testemunhos amostrado.

No teor de umidade, foi observado se os perfis apresentavam um padrão de decréscimo deste dado com o aumento da profundidade, o que indica um aumento crescente da taxa de compactação com o decorrer dos anos.

As concentrações de $\mathrm{Zn}$ e $\mathrm{Cd}$ foram avaliadas preliminarmente pois, sabe-se que durante muitos anos, foram despejadas grandes quantidades de resíduos contendo estes metais na Baía de Sepetiba (Viégas, 2006), logo, espera-se encontrar perfis de distribuição deste metal indicando variações nas concentrações com o passar dos anos. 


\subsubsection{1}

\section{Determinação de umidade}

A determinação do teor de umidade nas amostras oriundas do fatiamento dos testemunhos foi realizada conforme procedimento descrito no item 3.2 deste documento, os frascos foram pesados previamente à coleta das amostras e depois pesados novamente com toda a amostra úmida e após a secagem para a realização do cálculo da diferença entre as massas e a obtenção da massa seca total.

Os resultados destas determinações estão apresentados na Tabela 12, Anexo A, e a representação gráfica pode ser observada na Figura 38. Nota-se que o teor de água variou entre $75 \%$ e $85 \%$ na primeira camada e apresentou maior redução no testemunho T-8 chegando a $24 \%$ na última camada. O testemunho T-3 apresentou a menor variação de umidade entre a primeira e a última camada amostrada, que apresentaram umidades de $85 \%$ e $66 \%$, respectivamente. O testemunho T-20 apresentou comportamento semelhante ao T-3 da superfície, com $84 \%$ até $45 \mathrm{~cm}$ de profundidade, com $74 \%$ de umidade, a partir deste ponto observa-se uma redução significativa de umidade, sugerindo a existência de uma grande camada de mistura na região superior deste testemunho.

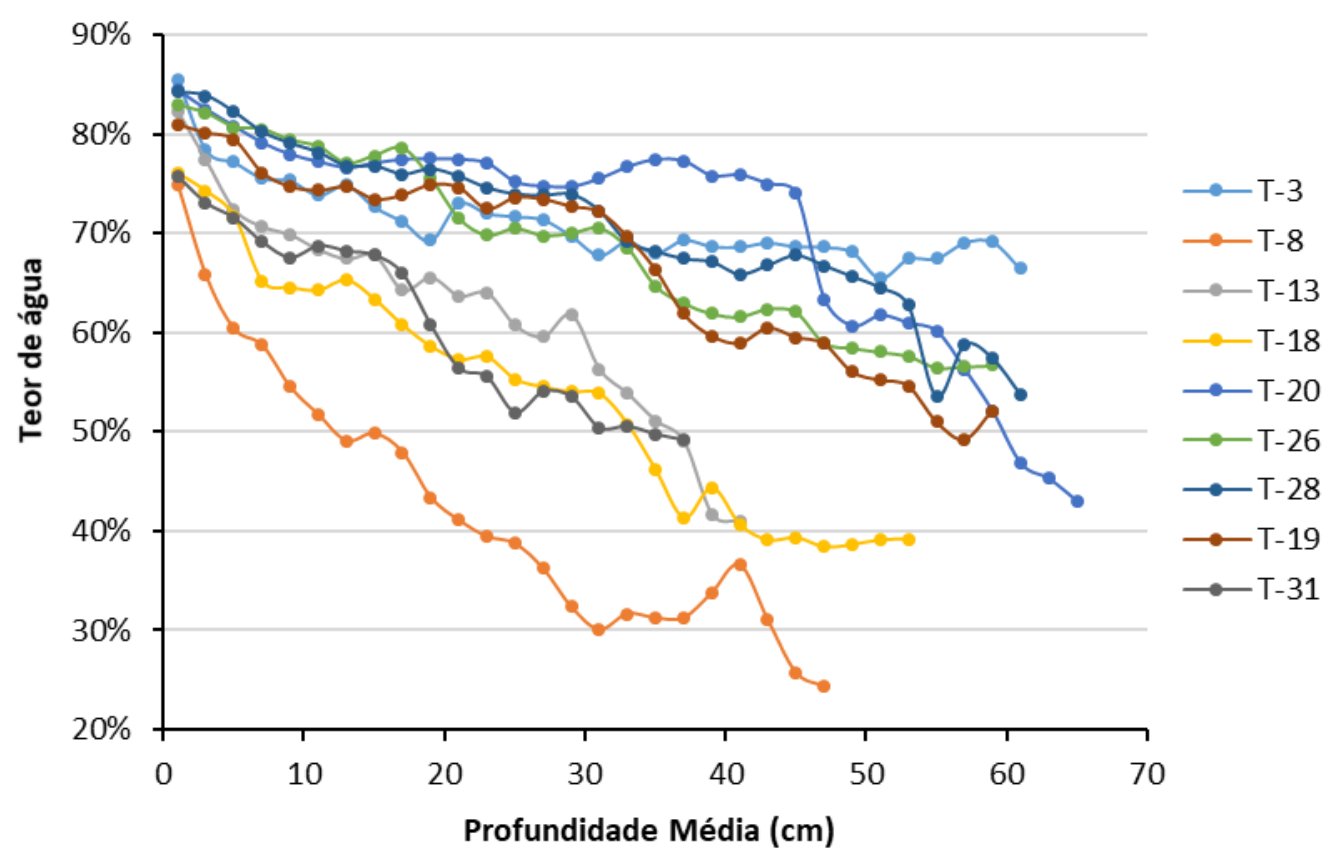

Figura 38: Teor de água nas camadas oriundas do fatiamento dos testemunhos sedimentares 
Para a realização das etapas seguintes de preparo das amostras para determinação dos contaminantes e datação das camadas, foi realizada uma avaliação inicial apenas com os teores de umidade.

Nesta avaliação qualitativa, embora os perfis de umidade dos testemunhos T3 e T-20 tenham apresentado comportamento diferente dos demais, não foi observado nada que pudesse desqualificar algum deles. Todos os demais apresentaram diferenças decrescentes de teor de água, isto indica que provavelmente não há uma zona de mistura muito grande entre as primeiras camadas de sedimento e que a compactação aumenta proporcionalmente ao aumento da profundidade, o que é esperado em testemunhos sedimentares.

\subsubsection{2 Determinação de Metais Totais}

A concentração dos metais cádmio, cromo, chumbo, níquel e zinco foram calculadas em $\mathrm{mg} \mathrm{kg}^{-1}$ de sedimento seco, levando-se em conta a massa de sedimento seco utilizado no preparo das soluções, o volume final destas e eventuais diluições extras para a determinação instrumental por ICP-MS.

Assim como na determinação destes metais nos sedimentos superficiais (4.1.5), as extrações foram realizadas em duplicata $\mathrm{e}$ as determinações instrumentais foram efetuadas com 5 leituras por elemento, conforme metodologia descrita em 3.3. Os isótopos utilizados foram ${ }^{66} \mathrm{Zn},{ }^{111} \mathrm{Cd},{ }^{53} \mathrm{Cr},{ }^{206} \mathrm{~Pb},{ }^{63} \mathrm{Cu}$ e ${ }^{60} \mathrm{Ni}$. A determinação de Mercúrio foi realizada por CVAAS, em triplicata, conforme descrito em 3.4, apenas nos testemunhos T-8, T-13 e T-18, pertencentes ao transecto que se inicia na foz dos principais rios afluentes e segue em direção ao centro da baía de Sepetiba.

Os metais apresentaram faixas de concentrações diferentes em cada um dos testemunhos analisados, porém, as correlações observadas entre estes contaminantes seguem o mesmo padrão observado na determinação destes metais nos sedimentos superficiais.

Destaca-se a forte correlação entre $\mathrm{Cr}$ e $\mathrm{Ni}$, com coeficientes superiores a 0,913. No entanto estes dois elementos apresentaram perfis monotônicos, ou seja, não houve variação significativa da concentração ao longo do perfil, novamente a 
concentração média, calculada ao longo do perfil, é compatível com a relatada por Gomes et al. (2009) para sedimentos da Baía da Ribeira, corroborando a hipótese de que a origem de ambos seja comum e natural.

Observa-se também, altas correlações entre $\mathrm{Zn}$ e $\mathrm{Cd}$, com coeficientes superiores a 0,863. Os perfis destes metais apresentaram altas variações de concentração, seja internamente, ou mesmo quando comparados testemunhos de regiões diferentes, este padrão é interessante pois indica variações nos níveis de contaminação ao longo dos anos e também níveis diferentes de contaminação quando se comparam áreas distintas da Baía de Sepetiba. A concentração de Zn variou entre $78 \mathrm{mg} \mathrm{kg}^{-1}$ em camadas mais profundas e $1370 \mathrm{mg} \mathrm{kg}^{-1}$ no ponto $\mathrm{T}-26$. Para o cádmio, os extremos de concentração também foram observados no ponto $\mathrm{T}-26$, sendo $0,10 \mathrm{mg} \mathrm{kg}^{-1} \mathrm{o}$ menor valor e $4,06 \mathrm{mg} \mathrm{kg}^{-1}$ o maior valor observado entre as camadas.

Para os demais metais determinados em todos os testemunhos sedimentares não foi observada nenhuma correlação significativa, além disso os resultados apresentaram perfis monotônicos sem variação significativa de concentração ao longo da profundidade, como pode ser observado no Anexo G.

A concentração de mercúrio, determinada apenas nos testemunhos T-8, T-13 e T-18, apresentou um perfil diferente dos demais metais, é possível observar um aumento de concentração gradativo e linear em relação a profundidade, sugerindo a existência de um aporte contínuo de Hg na região estudada, este caso específico será discutido mais adiante, no item 4.2.4.

\subsubsection{3}

\section{Concentração de Zn e Cd nos perfis sedimentares}

A distribuição vertical das concentrações de $\mathrm{Zn}$ e $\mathrm{Cd}$ em cada camada dos testemunhos sedimentares da Baía de Sepetiba possui um perfil singular, onde, em muitos casos, percebe-se claramente um pico bem significativo da concentração destes metais em determinada profundidade seguida por uma redução da concentração em camadas mais superiores.

Esta particularidade na concentração de $\mathrm{Zn}$ e $\mathrm{Cd}$ nos perfis sedimentares da Baía de Sepetiba é associada ao desastre ambiental ocorrido em 1996, quando o 
dique de contenção de resíduos da extinta Cia. Ingá Mercantil se rompeu e centenas de milhares de $\mathrm{m}^{3}$ vazaram para a baía.

A Figura 39 mostra os perfis de $\mathrm{Zn}$ registrados nos testemunhos amostrados. Os testemunhos sedimentares T-3 e T-31 não apresentaram perfis com picos evidentes na concentração de $\mathrm{Zn}$ como, ou seja, não se observa um aumento seguido de uma redução na concentração de $\mathrm{Zn}$, tal como observado nos demais perfis. Alguns fatores podem interferir na observação dos perfis sedimentares, atividades de dragagem, por exemplo, inviabilizam este tipo de avaliação, pois removem parte do sedimento.

O ponto T-3 localiza-se próximo à costa interna da baía, em frente aos principais rios afluentes, e, provavelmente, a velocidade de sedimentação neste ponto seja muito alta sendo necessária uma amostragem com um comprimento (profundidade) maior para uma melhor análise temporal desta região.

O testemunho sedimentar obtido no ponto T-31 não foi suficientemente profundo para alcançar as camadas onde se encontram sedimentos com idades anteriores ao principal acidente ocorrido na baía ou então o sedimento de região onde ocorreu a amostragem é constantemente revirado. Pode-se observar que há uma elevação da concentração de $\mathrm{Zn}$ a partir da camada 17 , que se mantém constante até a camada mais profunda deste testemunho.

O testemunho T-20, embora tenha apresentado um perfil de $\mathrm{Zn}$ com as características ideais para a realização dos ensaios de datação, também foi descartado desta determinação, pois dois parâmetros apontaram para uma camada de mistura muito extensa, o que influenciaria muito na precisão da datação. São eles: 1 - teor de umidade, pode-se observar na Figura 38 que a umidade deste perfil quase não muda até os $45 \mathrm{~cm}$ de profundidade, onde o decréscimo neste parâmetro foi de apenas 12,4 \% em relação a camada mais superficial. 2 - concentração de zinco em cada camada, entre os primeiros $35 \mathrm{~cm}$ deste testemunho a concentração de $\mathrm{Zn}$ variou entre 491 e $620 \mathrm{mg} \mathrm{kg}^{-1}$, com média igual a $559 \mathrm{mg} \mathrm{kg}^{-1}$ e desvio padrão de $36 \mathrm{mg} \mathrm{kg}^{-1}$, ou seja, quase não houve variação na concentração de $\mathrm{Zn}$ nestas camadas de testemunho, sugerindo que há uma mistura entre elas, corroborando a hipótese levantada pela observação dos teores de umidade. 

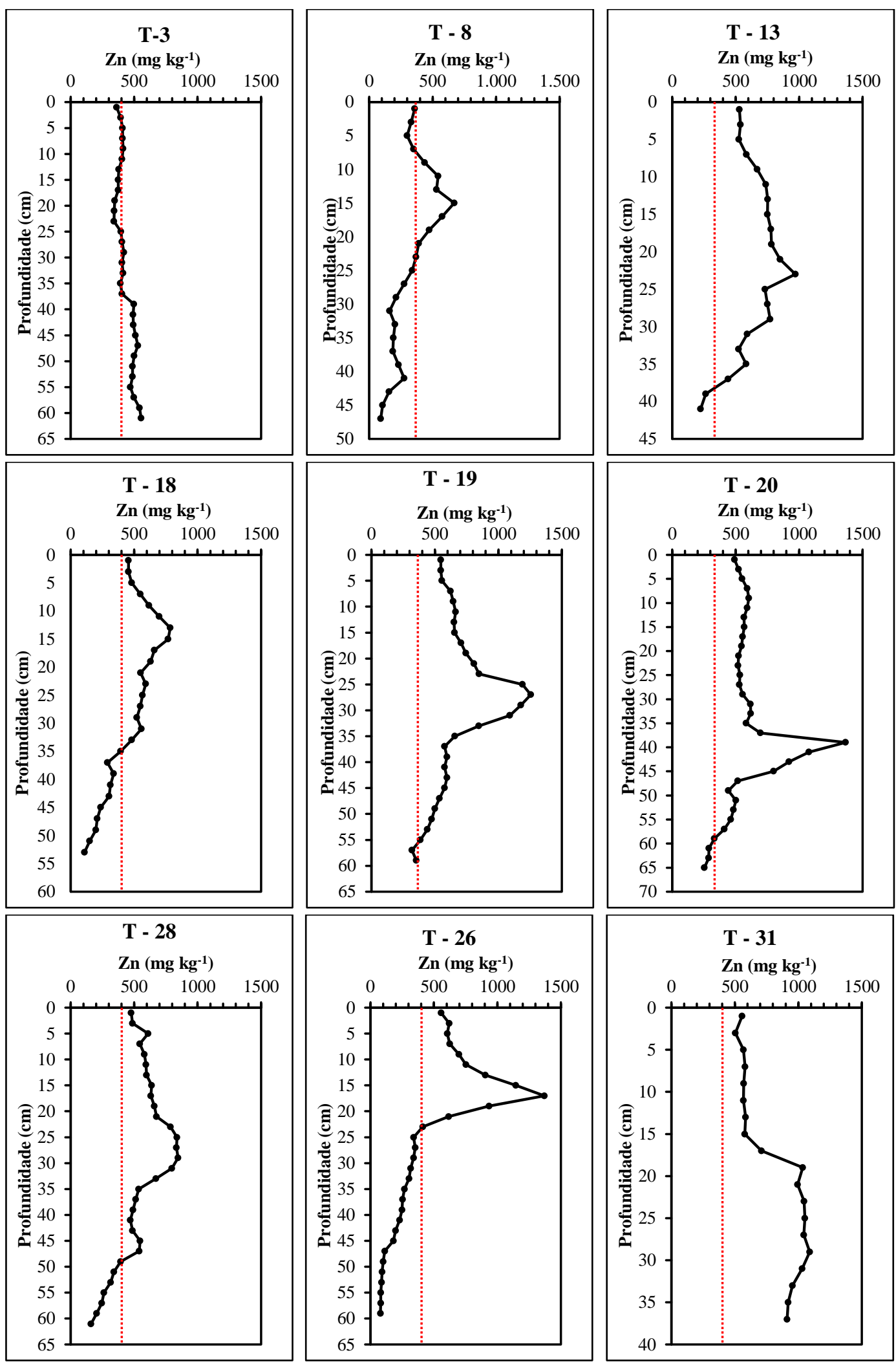

Figura 39: Perfis de concentração de Zn versus profundidade em diferentes pontos da Baía de Sepetiba, a faixa vermelha indica o nível $2\left(410 \mathrm{mg} \mathrm{kg}^{-1}\right)$ da resolução CONAMA 454/12

A mesma abordagem realizada na avaliação dos perfis de concentração de $\mathrm{Zn}$ foi aplicada para a avaliação dos perfis de concentração de Cd. A Figura 40 mostra 
os perfis obtidos e pode-se perceber que eles seguem o mesmo padrão de variação de concentração ao longo da profundidade, já observado nos perfis de Zn.
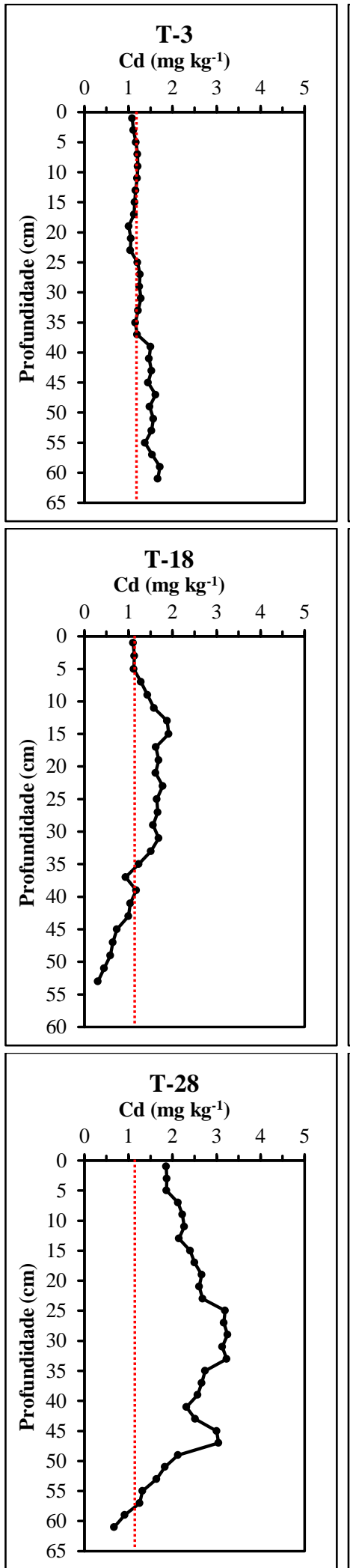
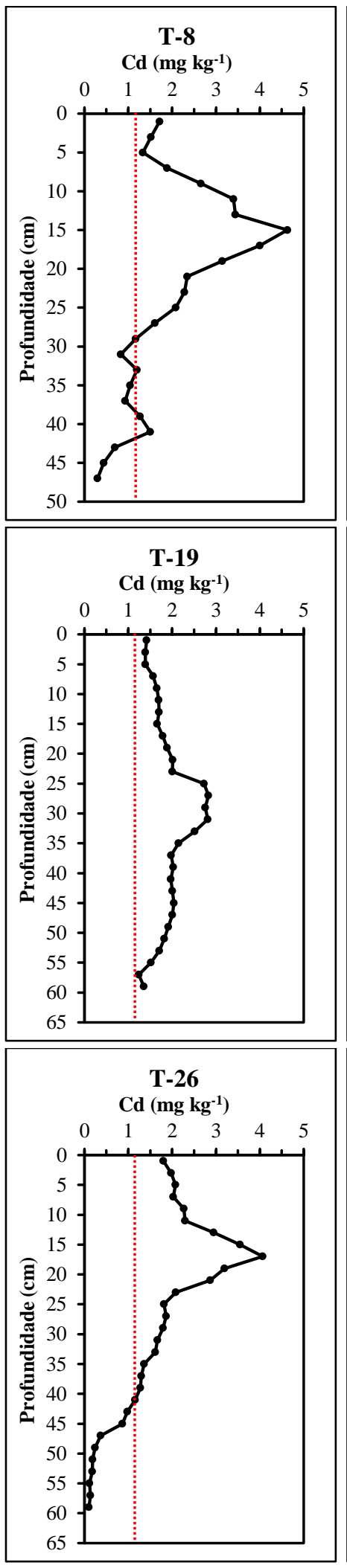
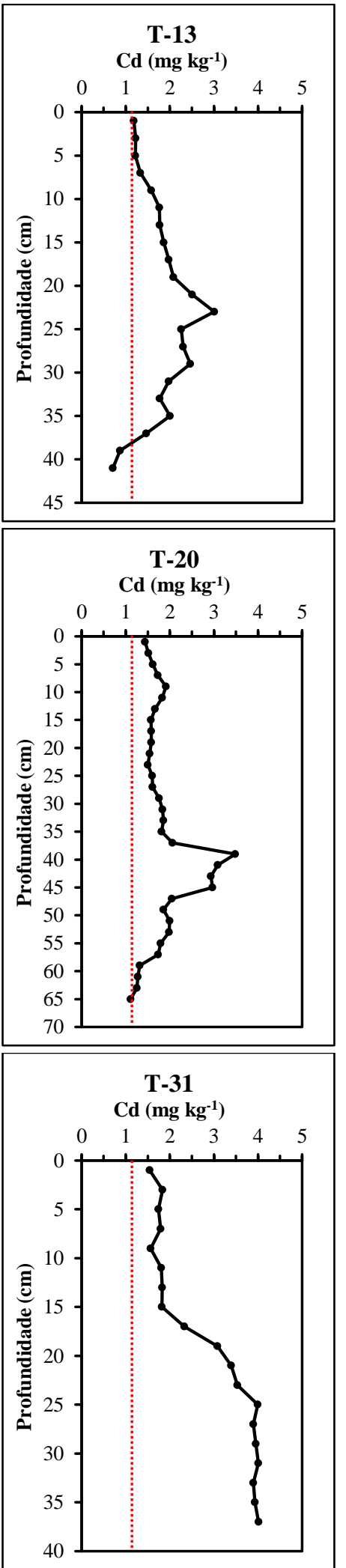

Figura 40: Perfis de concentração de Cd versus profundidade em diferentes pontos da Baía de Sepetiba, a faixa vermelha indica o nível $1\left(1,2 \mathrm{mg} \mathrm{kg}^{-1}\right)$ da resolução CONAMA 454/12 
Os testemunhos T3 e T31 também não apresentaram perfis com picos evidentes na concentração de $\mathrm{Cd}$ e o perfil observado no testemunho T-20 corrobora a avaliação realizada na observação do perfil de $\mathrm{Zn}$, onde provavelmente, há uma extensa camada de mistura, o que influenciaria na precisão da datação.

Diante do exposto, optou-se pela realização da datação com ${ }^{210} \mathrm{~Pb}$ apenas nos testemunhos $\underline{\mathrm{T}-8}, \underline{\mathrm{T}-13}, \underline{\mathrm{T}-18}, \underline{\mathrm{T}-19}, \underline{\mathrm{T}-28}$ e $\underline{\mathrm{T}-26}$.

\subsection{2 \\ Datação de sedimentos com ${ }^{210} \mathrm{~Pb}$}

Foram avaliadas as velocidades de sedimentação em seis pontos da Baía de Sepetiba, visando o cálculo das idades de cada camada seccionada dos testemunhos. A atividade de ${ }^{210} \mathrm{~Pb}$ foi determinada após lixiviação do material seco com $\mathrm{HBr}$ e posterior precipitação como $\mathrm{PbCrO}_{4}$, segundo metodologia proposta por Godoy (1998).

As idades de cada segmento foram calculadas utilizando-se o modelo CF:CR (Constant Flux : Constant Rate) e os dados de concentração de Zn foram empregados na validação da datação, uma vez que estão bem registrados os acidentes que despejaram toneladas deste metal na baía. O modelo $\mathrm{CF}$ :CR não se mostrou adequado para os dados obtidos no testemunho T-26, neste caso foi utilizado o modelo CRS (Constant Rate of Supply).

\subsubsection{Testemunho T-8}

Este perfil está localizado a aproximadamente 2,6 km da costa norte da Baía de Sepetiba, entre o rio Guandú e o canal do Itá. Os resultados de atividade de ${ }^{210} \mathrm{~Pb}$ neste testemunho ficaram muito baixos ou menores do que o limite de quantificação do método, impedindo a datação correta deste testemunho. 


\subsubsection{Testemunho T-13}

Este ponto está localizado no transecto linear que se inicia na margem norte na baía, próximo aos principais rios afluentes, e segue a sudoeste em direção ao centro da baía, e dista aproximadamente 4,6 km da costa norte da Baía de Sepetiba. O modelo CF:CR foi aplicado a este testemunho e o cálculo da velocidade de sedimentação foi realizado com o auxílio da curva de correlação (Figura 41) entre ${ }^{210} \mathrm{~Pb}\left(\mathrm{mBq} \mathrm{g}{ }^{-1}\right)$ e massa acumulada de sedimento, em $\mathrm{g} \mathrm{cm}^{-2}$.

Foi utilizada a expressão adaptada da lei de decaimento radioativo

$$
C(x)=C_{0} \cdot e^{-\lambda \cdot \frac{x}{w}}
$$

Como $\lambda$ é constante de decaimento do ${ }^{210} \mathrm{~Pb}\left(0,03114\right.$ ano $\left.^{-1}\right)$, a velocidade de sedimentação $(w)$ calculada foi de $(0,339 \pm 0,007) \mathrm{g} \mathrm{cm}^{-2}$ ano $^{-1}$

${ }^{210} \mathrm{~Pb}$ versus Massa Acumulada

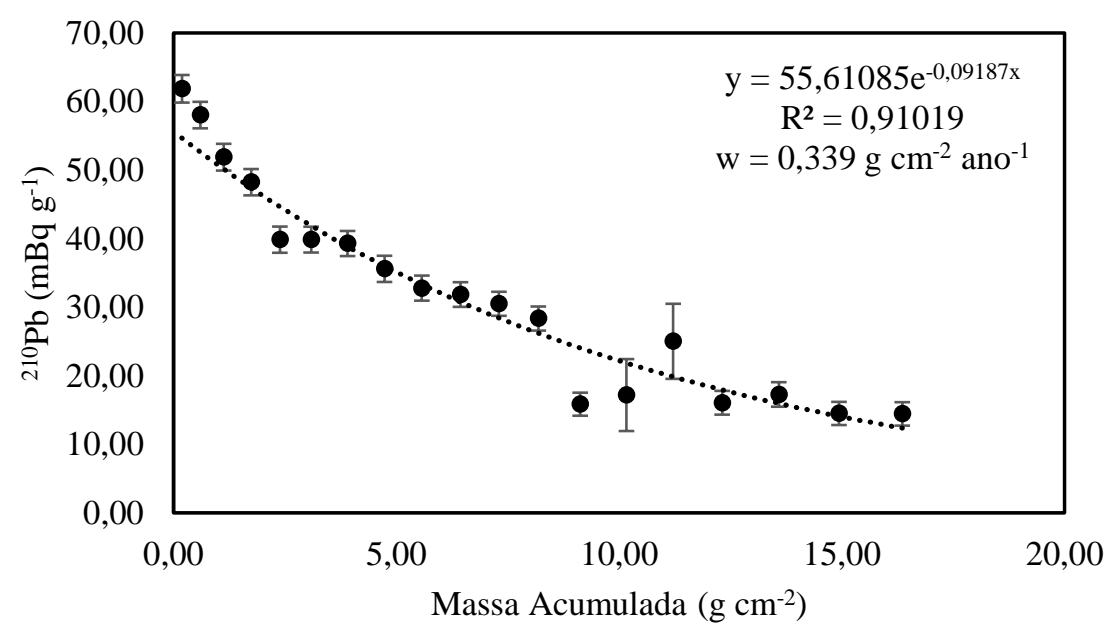

Figura 41: Testemunho T-13 - ${ }^{210}$ Pbexc versus massa acumulada

\subsubsection{Testemunho T-18}

O testemunho T-18 foi coletado na região central da Baía de Sepetiba e está localizado no mesmo transecto onde estão os pontos T-13, T-8 e T-3, sua distância para a foz dos principais rios afluentes é de aproximadamente 7,6 km. Nesta região há predominância de sedimentos de granulometria mais fina, com teores de argila + silte maiores do que $90 \%$. 
O modelo CF:CR mostrou-se adequado aos dados de atividade de ${ }^{210} \mathrm{~Pb}$ medidos em cada camada deste testemunho. Com o auxílio destas atividades da massa acumulada foi possível a construção do gráfico apresentado na Figura 42. Através do mesmo raciocínio demonstrado no Item 4.2.2.2 foi possível calcular a velocidade de sedimentação em $(0,261 \pm 0,011) \mathrm{g} \mathrm{cm}^{-2} \mathrm{ano}^{-1}$.

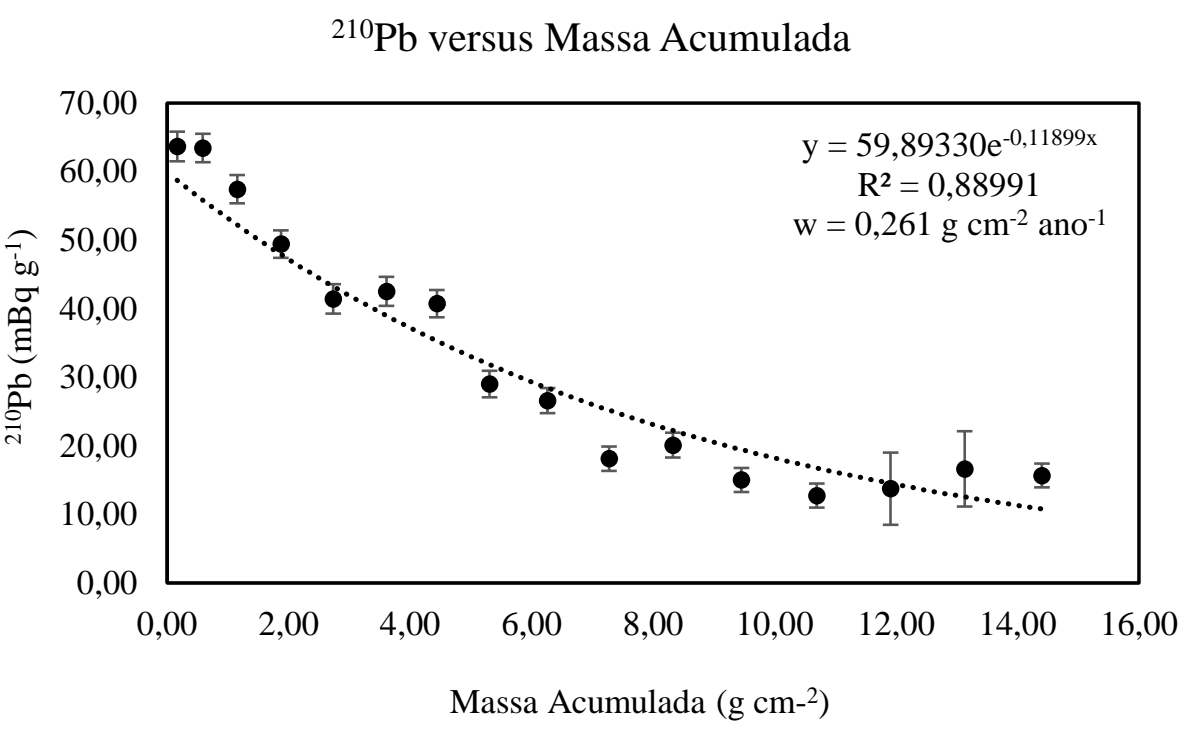

Figura 42: Testemunho T-18 - ${ }^{210}$ Pbexc versus massa acumulada

\subsubsection{Testemunho T-19}

Este testemunho localiza-se na região central da baía de Sepetiba, a profundidade medida nesta região no momento da amostragem foi de $6,0 \mathrm{~m} \mathrm{e}$ a distância deste ponto até a margem norte é de aproximadamente 7,2 km.

Os dados de atividade de ${ }^{210} \mathrm{~Pb}$ obtidos para cada camada deste testemunho se ajustaram bem ao modelo CF-CS, o gráfico apresentado na Figura 43 pôde ser construído com os dados de massa acumulada e das atividades de ${ }^{210} \mathrm{~Pb}$. A velocidade de sedimentação calculada neste ponto foi de $(0,311 \pm 0,009)$ $\mathrm{g} \mathrm{cm}^{-2} \mathrm{ano}^{-1}$. 


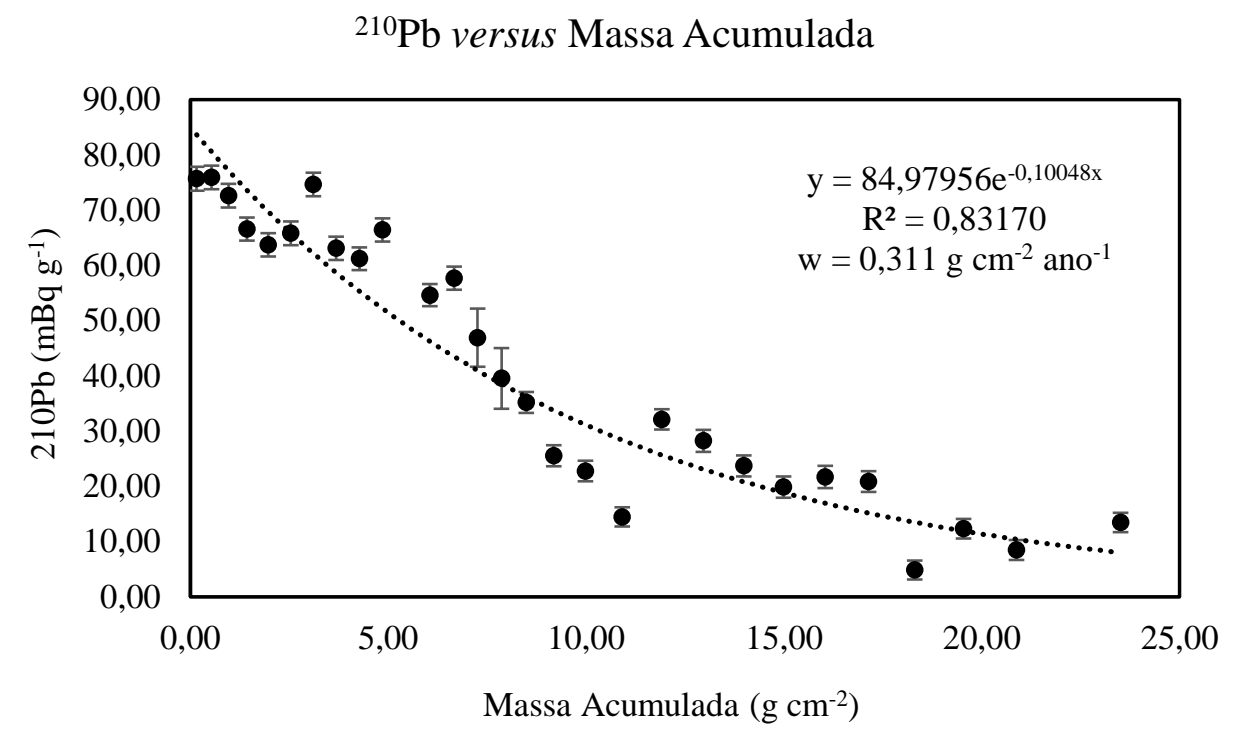

Figura 43: Testemunho T-19 - ${ }^{210}$ Pbexc versus massa acumulada

\subsubsection{Testemunho T-26}

Este testemunho localiza-se no transecto que liga a região central da baía de Sepetiba (testemunho T-18) até o manguezal localizado na margem leste, sendo este o ponto mais próximo do mangue, distando aproximadamente de 6,0 km desta região e com profundidade de 5,5 m no momento da amostragem.

A aplicação do modelo CRS nos dados de ${ }^{210} \mathrm{~Pb}$ obtidos nas diferentes camadas deste testemunho evidenciou a existência de duas épocas com velocidades de sedimentação bem distintas (Figura 44), sendo $0,278 \mathrm{~cm} \mathrm{ano}^{-1}$ da parte mais profunda do testemunho até a profundidade média de $35 \mathrm{~cm}$ e $0,946 \mathrm{~cm}_{\text {ano }}^{-1}$ desta profundidade até a superfície.

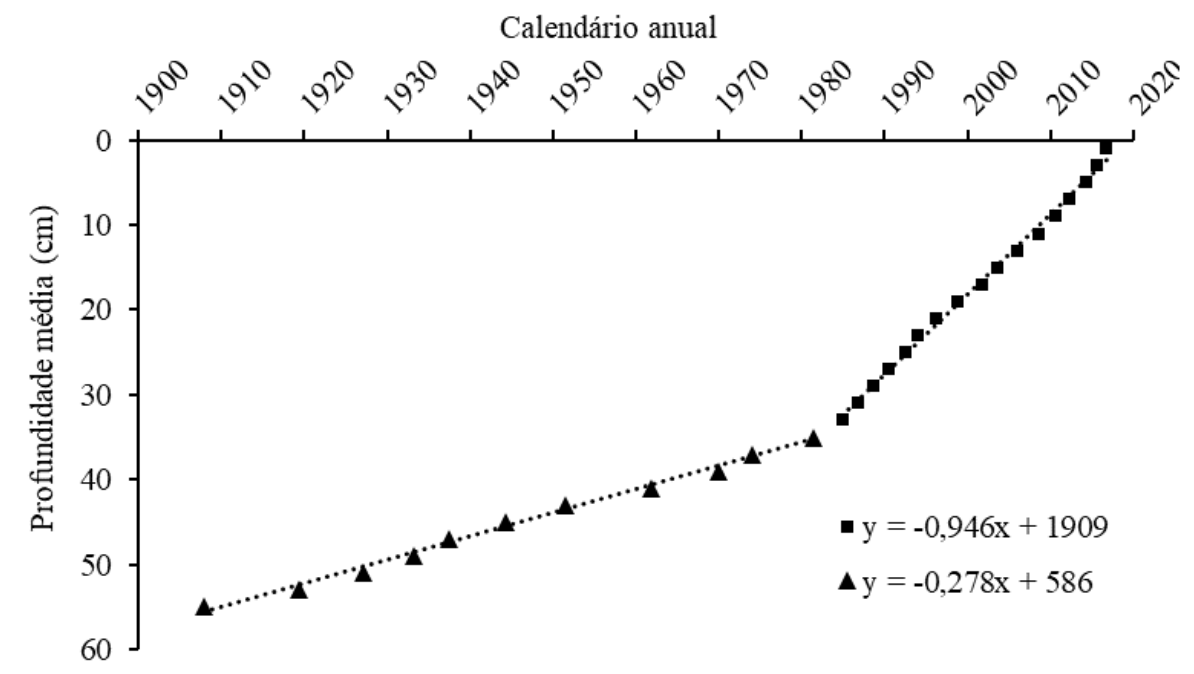

Figura 44: Testemunho T-26 - profundidade média versus calendário anual 
A alteração na velocidade de sedimentação deste perfil ocorreu entre os anos de 1981 e 1984, atualmente a velocidade de sedimentação é quase 4 vezes maior do que era até os anos 1970.

Esta alteração pode ter explicação pois este testemunho se localiza na parte leste da Baía de Sepetiba, uma região cercada por manguezais e pelos bairros de Guaratiba e Pedra de Guaratiba, ambos fundados em 1981. Segundo Mello (2015), o plano urbanístico do município do Rio de Janeiro, lançado em 1977, dividiu a cidade em cinco áreas que tinha como prioridade o ordenamento de terras $\mathrm{e}$ preservação de áreas ambientais. Os bairros de Guaratiba e Pedra de Guaratiba estão contidos na área 5.

Mello (2015) afirma que, após a fundação dos bairros, estes seguiram em franca expansão demográfica, acompanhada de grandes obras para a construção de ruas, definição de lotes habitacionais e redes de saneamento, com o alargamento de canais já existentes. Todo esse processo foi facilitado pela construção de uma rodovia que liga o Recreio dos Bandeirantes ao polo industrial de Santa Cruz.

\subsubsection{Testemunho T-28}

O testemunho T-28 localiza-se na porção leste da baía, distando aproximadamente 5,5 $\mathrm{km}$ da praia de Sepetiba, e 3,2 km da restinga da Marambaia. Nesta região há predominância de sedimentos finos, com o somatório de silte e argila sendo praticamente a totalidade do material, com teores de aproximadamente $80 \%$ e $20 \%$, respectivamente.

$\mathrm{O}$ modelo CF-CS ajustou-se bem aos dados de atividade de ${ }^{210} \mathrm{~Pb}$ medidos nas camadas deste testemunho, o gráfico apresentado na Figura 45 foi construído com os dados de massa acumulada e das atividades de ${ }^{210} \mathrm{~Pb}$. A velocidade de sedimentação calculada neste ponto foi de $(0,273 \pm 0,005) \mathrm{g} \mathrm{cm}^{-2} \mathrm{ano}^{-1}$. 


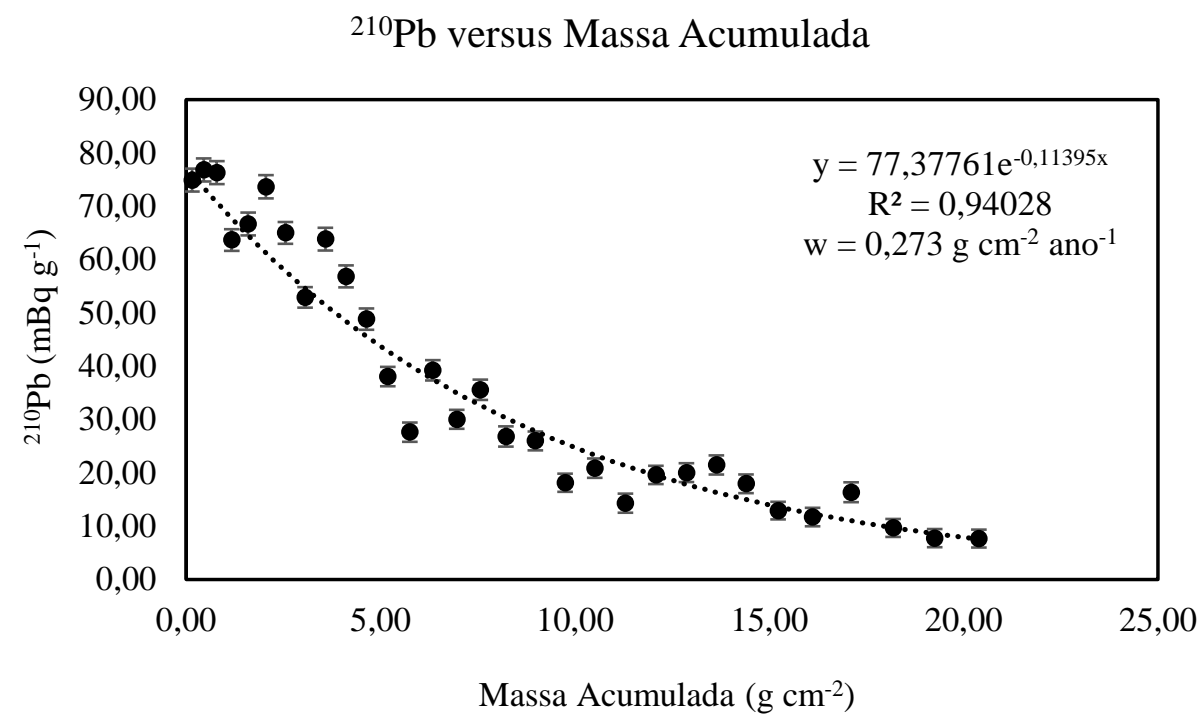

Figura 45: Testemunho T-28 - ${ }^{210}$ Pbexc versus massa acumulada

\subsection{3 \\ Validação da datação com ${ }^{210} \mathrm{~Pb}$}

A determinação da concentração dos metais realizada em conjunto com a reconstrução histórica das regiões amostradas é uma das ferramentas para a validação da datação obtida através da atividade de ${ }^{210} \mathrm{~Pb}$ presente nos sedimentos.

Neste sentido, a variação das concentrações de zinco e cádmio ao longo dos perfis sedimentares serve bem a este propósito. Em fevereiro de 1996 o dique de contenção da Cia. Ingá Mercantil se rompeu em decorrência das fortes chuvas e de falhas no projeto, despejando milhares de toneladas de resíduos, contendo estes metais, para a Baía de Sepetiba. A Figura 46 descreve o comportamento das concentrações destes metais em cada um dos perfis sedimentares onde foi possível a realização da datação com ${ }^{210} \mathrm{~Pb}$. 

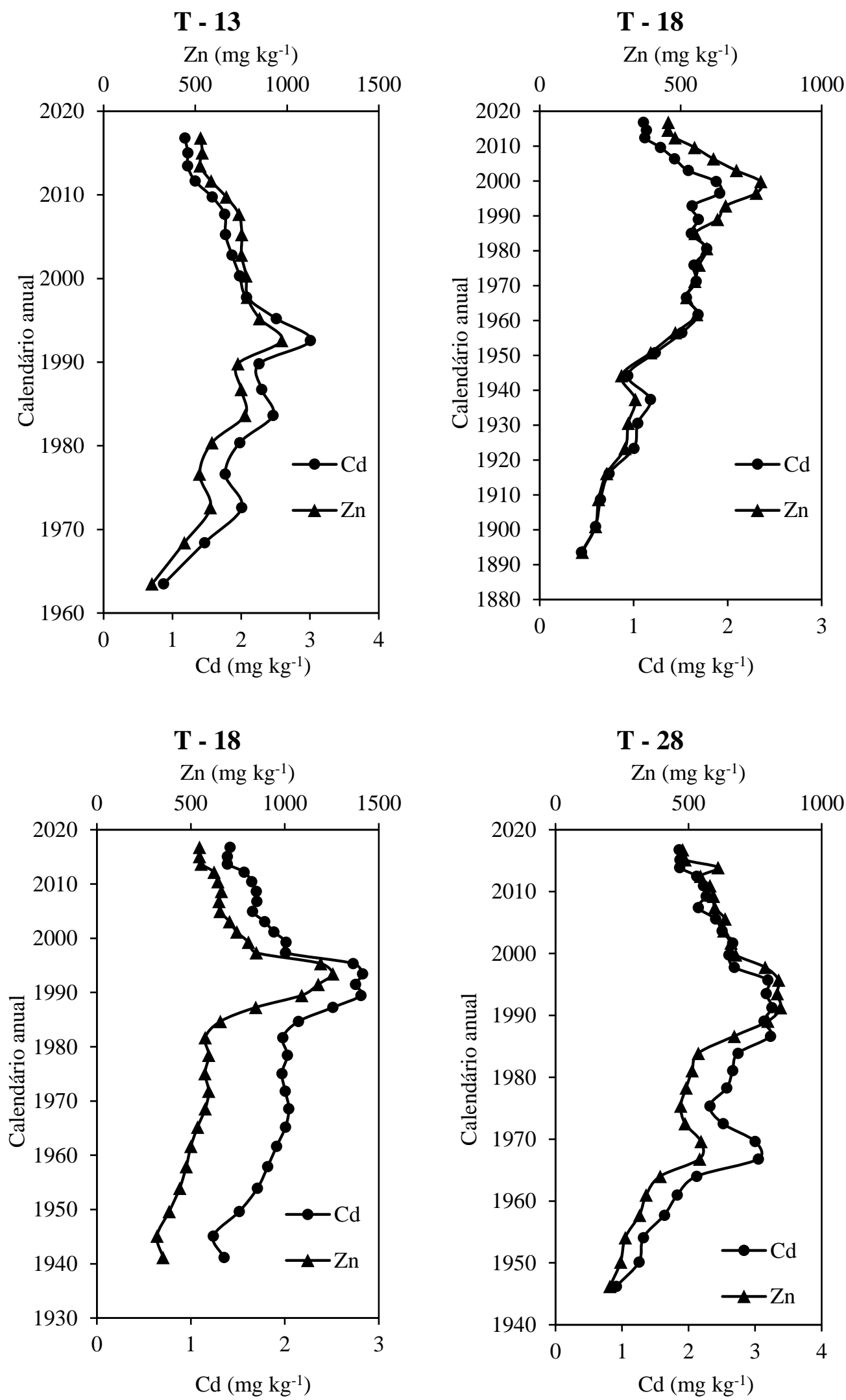


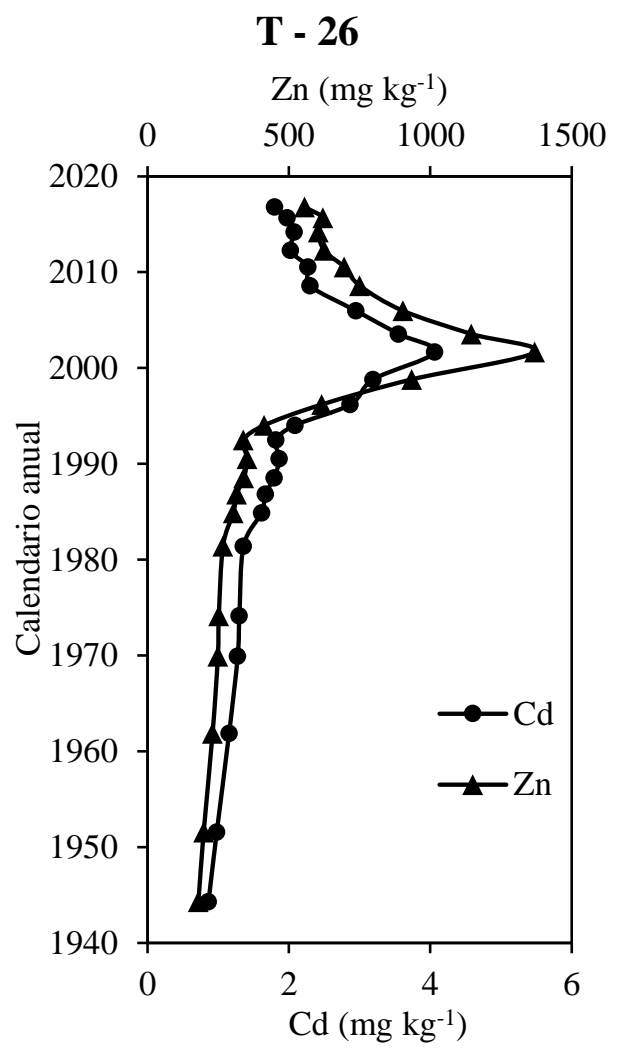

Figura 46: Idade versus concentrações de Zn e Cd para os testemunhos T-13, T-18, T-19, T-26 e T-28

A partir da observação da variação de $\mathrm{Zn}$ e $\mathrm{Cd}$ nos perfis apresentados na Figura 46, pode-se concluir que os modelos de cálculo geocronológico utilizados nestes perfis fornecem, como resultado principal, idades que se adequaram bem aos dados de concentração dos metais. Os perfis apresentaram concentrações máximas de Zn e Cd entre 1992 e 2001, com erro aproximado de \pm 4 anos, ou seja, estão em concordância com o fato histórico de grande relevância ocorrido em 1996, que despejou milhares de toneladas de resíduos tóxicos contendo principalmente estes dois metais.

A Tabela 10 resume as concentrações máximas de $\mathrm{Zn}$ e $\mathrm{Cd}$ e idade na qual este máximo foi observado em cada perfil.

Tabela 10: Concentrações máximas de Zn e Cd em testemunhos e data em que estes valores foram alcançados

\begin{tabular}{ccccc}
\hline Testemunho & $\mathrm{Zn}\left(\mathrm{mg} \mathrm{kg}^{-1}\right)$ & calendário & $\mathrm{Cd}\left(\mathrm{mg} \mathrm{kg}^{-1}\right)$ & calendário \\
\hline T-13 & 970 & $1993 \pm 1$ & 3,0 & $1993 \pm 1$ \\
T-18 & 784 & $2000 \pm 1$ & 1,9 & $1996 \pm 1$ \\
T-19 & 1255 & $1993 \pm 2$ & 2,8 & $1993 \pm 2$ \\
T-26 & 1369 & $2001 \pm 2$ & 4,1 & $2001 \pm 2$ \\
T-28 & 838 & $1996 \pm 1$ & 3,2 & $1996 \pm 1$ \\
\hline
\end{tabular}


As concentrações de $\mathrm{Zn}$ e $\mathrm{Cd}$ em sedimentos da baía alcançaram, na ocasião do acidente, valores bem acima dos níveis recomendados pelo CONAMA 454 (2012). Os cinco perfis sedimentares apresentaram camadas com concentrações de $\mathrm{Zn}$ acima do nível 2, em alguns casos os valores encontrados foram aproximadamente o triplo da maior concentração indicada pela resolução CONAMA, que é de $416 \mathrm{mg} \mathrm{kg}^{-1}$, sugerindo uma alta probabilidade de efeitos adversos à vida marinha. $\mathrm{O} \mathrm{Cd}$ também apresentou valores elevados, especificamente para este metal a resolução CONAMA sugere atenção especial aos valores acima de $1,2 \mathrm{mg} \mathrm{kg}^{-1} \mathrm{e}$, assim como o $\mathrm{Zn}$, em todos os perfis foram encontradas camadas onde a concentração determinada estava acima do limite indicado pela resolução.

Importante ressaltar que os dados obtidos nas camadas mais profundas do testemunho T-18, que correspondem a anos anteriores a 1900, e consequentemente, anteriores à industrialização da região, apontam para um nível basal de concentrações de $\mathrm{Zn}$ e Cd em torno de $110 \mathrm{mg} \mathrm{kg}^{-1}$ e $0,31 \mathrm{mg} \mathrm{kg}^{-1}$, respectivamente. Observa-se que os níveis de base estimados para estes dois metais se encontram abaixo do nível 1 apresentados pela resolução CONAMA 454/12, que indica $150 \mathrm{mg} \mathrm{kg}^{-1}$ para Zn e $1,2 \mathrm{mg} \mathrm{kg}^{-1}$ para Cd. Nesta mesma região Gomes et al. (2009) sugeriram um nível base de $54 \mathrm{mg} \mathrm{kg}^{-1}$ e $0,34 \mathrm{mg} \mathrm{kg}^{-1}$ para as concentrações de $\mathrm{Zn}$ e Cd, respectivamente.

Embora seja possível notar a redução dos valores de concentração dos metais nos anos seguintes ao acidente da Cia. Ingá Mercantil, as concentrações de Zn e Cd na superfície (Figura 23 e Figura 26) do sedimento continuam acima dos valores sugeridos na legislação brasileira. Há uma tendência de redução nos próximos anos, conforme pode ser observado na Figura 46, mas a instalação de novas indústrias siderúrgicas no entorno da baía de Sepetiba, como a Ternium em 2006, pode dificultar essa redução, pois estas também descartam parte de seus resíduos nos canais e rios afluentes da baía. 


\subsection{4}

\section{Concentração de Mercúrio}

$\mathrm{O}$ procedimento para a determinação de $\mathrm{Hg}$ em alíquotas de sedimentos retiradas de cada camada dos testemunhos seguiu o mesmo protocolo realizado na determinação de $\mathrm{Hg}$ nos sedimentos superficiais (3.4), adaptado de Campos (1980).

Para garantir a qualidade dos resultados obtidos, todas as bateladas de preparo das amostras foram acompanhadas por uma triplicata de material de referência certificado (MESS-3 Marine Sediment Reference Materials for Trace Metals and other Constituents) e três brancos de preparo contendo todos os reagentes utilizados e seguindo o mesmo processo adotado para as amostras.

Diferentemente do que foi observado nos outros metais tóxicos estudados neste trabalho, a concentração de $\mathrm{Hg}$ aumentou quase linearmente com o tempo. $\mathrm{Na}$ Figura 47 estão apresentadas as variações temporais deste metal ao longo dos testemunhos T-13 e T-18. As concentrações de Hg também foram determinadas nas camadas do testemunho T-8, mas o estudo temporal neste ponto não pôde ser realizado já que as atividades de ${ }^{210} \mathrm{~Pb}$ não foram suficientemente adequados para os cálculos das idades de cada camada.

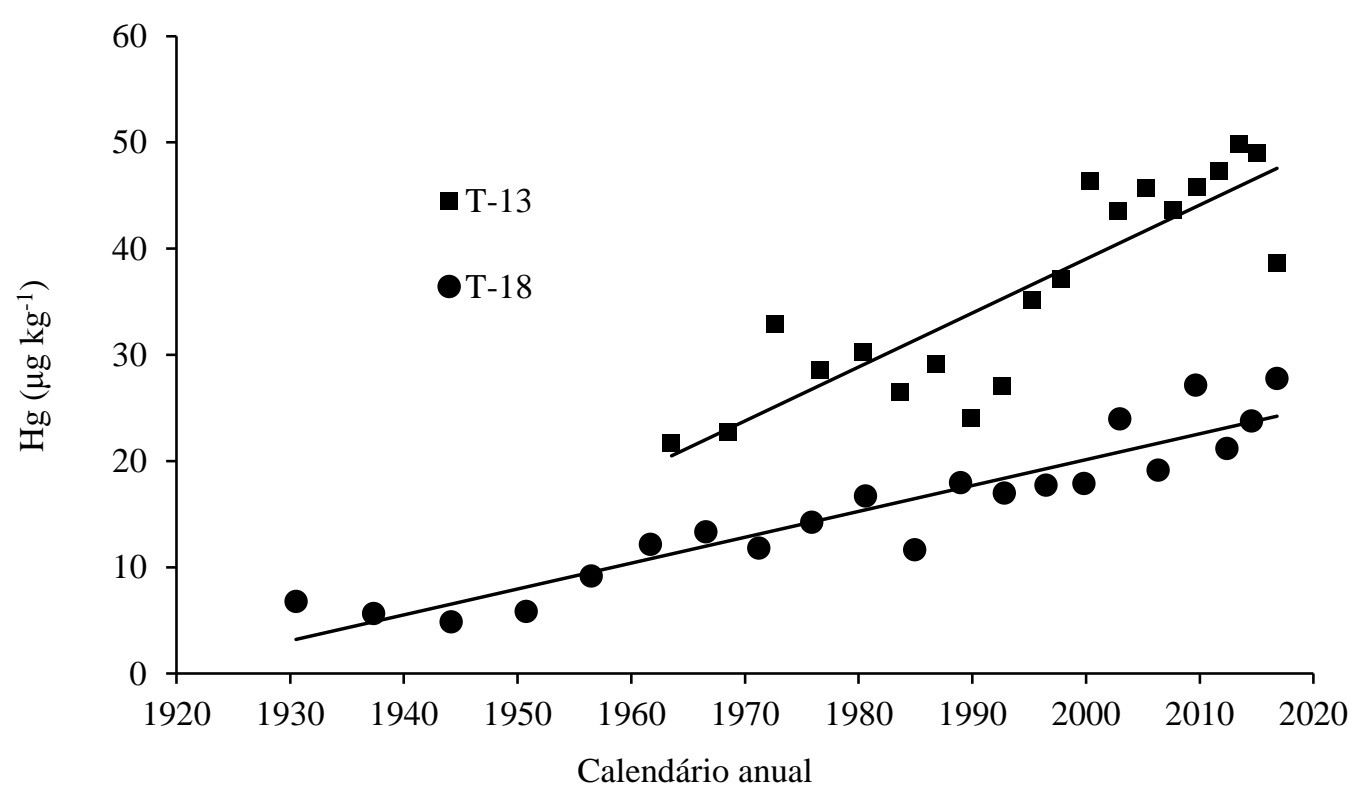

Figura 47: Variação temporal de Hg nos testemunhos T-13, T-18

As velocidades de sedimentação estimadas nos testemunhos T-13 e T-18 são de 0,34 e $0,26 \mathrm{~g} \mathrm{~cm}^{-2}$ ano $^{-1}$ respectivamente e foi constante no intervalo de tempo 
estudado. Pode-se, então, concluir que o fluxo de $\mathrm{Hg}$ para a baía tem aumentado linearmente ao longo dos anos, e o aumento anual da concentração de $\mathrm{Hg}$ nos sedimentos superficiais é de $0,62 \mu \mathrm{g} \mathrm{kg}^{-1}$ ano $^{-1}$ para T-13 e $0,29 \mu \mathrm{g} \mathrm{kg}^{-1}$ ano $^{-1}$ para $\mathrm{T}-18$.

Como não há informação sobre indústrias nesta região utilizando mercúrio nos seus processos, pode-se acreditar que as fontes deste metal são difusas, e o aporte de $\mathrm{Hg}$ pode ser oriundo de depósitos de resíduos sanitários, esgotos domésticos não tratados ou sistemas de drenagem pluvial da cidade, e aumentaram com o crescimento da população na região.

Este aumento constante na concentração de $\mathrm{Hg}$ nesta região é corroborado pela comparação dos dados observados no sedimento superficial coletado neste trabalho e em 2001 (4.1.6.2), em que fica evidente um aumento de $100 \%$ na concentração de Hg na região próxima aos principais rios afluentes em contraponto a outras regiões em que houve redução de até $100 \%$ na concentração deste metal.

Os dados obtidos nas camadas mais profundas do testemunho T-18, correspondentes a anos anteriores à 1960, permitem estimar um valor basal de $\mathrm{Hg}$ em torno de $5 \mu \mathrm{g} \mathrm{kg}^{-1}$, este valor é quatro vezes inferior ao valor proposto por Marins et al. (2004) para sedimentos finos da Baía de Sepetiba. 


\section{5 \\ Conclusão}

As superfícies de resposta obtidas para os parâmetros analisados neste trabalho demonstraram ser poderosas ferramentas para o melhor entendimento dos processos de disponibilidade e mobilidade dos poluentes, pode-se perceber claramente que metais como $\mathrm{Ni}$ e $\mathrm{Cr}$ distribuem-se mais para a região central da baía, acompanhando a mobilidade da fração mais fina do sedimento superficial ainda não consolidado.

Metais como $\mathrm{Pb}, \mathrm{Zn}, \mathrm{Cd}, \mathrm{Cu}$ e $\mathrm{Hg}$ possuem mobilidade mais restrita às partes norte e nordeste da baía, evidenciando que os metais possuem dinâmicas de mobilidade diferentes e o manejo deste sedimento deve levar em consideração a individualidade de cada caso.

$\mathrm{Na}$ parte interna da baía, nenhum dos valores da razão $\sum$ SEM/AVS ultrapassou a razão crítica de 1 que, segundo o conceito estabelecido por vários autores, indica que estes sedimentos apresentam uma baixa ecotoxicidade, ou seja, bioensaios para a quantificação da taxa de mortalidade apresentariam resultados baixos.

O modelo SEM/AVS também permitiu distinguir áreas mais sensíveis da baía de Sepetiba devido a sua baixa concentração de sulfetos, as estações SP-125, próxima ao canal de navegação, SP-124, nas proximidades da Ilha de Jaguanum e SP-139, SP-140 e SP-141, na parte externa da baía, apresentaram concentrações de sulfetos abaixo de $0,2 \mathrm{mmol} \mathrm{\textrm {kg } ^ { - 1 }}$. Nestes locais o despejo de sedimento contaminado poderá aumentar muito a toxicidade.

$\mathrm{Zn}$ e $\mathrm{Cd}$ apresentaram concentrações elevadas na maioria dos pontos estudados na baía. Especificamente para o Zn, algumas estações apresentaram o triplo da concentração indicada como nível 2 do CONAMA 454 (2012), mas devido às concentrações de sulfetos também elevadas, a toxicidade desta região ainda é baixa.

O mercúrio, metal extremamente tóxico, apresentou um aumento de concentração de $100 \%$ nos sedimentos localizados na costa norte da baía de Sepetiba, entre a Ilha da Madeira e a praia de Sepetiba, diferenciando-se dos demais 
metais deste estudo, que apresentaram concentrações iguais ou menores àquelas relatadas pela FEEMA em 2001. No entanto, há uma forte correlação entre Hg e Sulfeto, o que sugere que este metal também fique imobilizado nesta região da baía, não estando biodisponível. As altas concentrações de sulfeto associadas a uma condição anóxida no fundo da baía de Sepetiba impedem a metilação do mercúrio, o que aumentaria muito a sua toxicidade.

Ainda em comparação com os dados relatados pela FEEMA em 2001, pôdese perceber que $\mathrm{Zn}$ e $\mathrm{Cd}$ apresentaram reduções significativas nas concentrações, exceto na margem continental localizada entre os pontos de amostragem SP-123 e SP-102, onde as concentrações destes metais praticamente não sofreu variação, sugerindo outra fonte de contaminação, e não apenas a extinta Companhia Mercantil Industrial Ingá.

A análise de cluster demonstrou ser uma excelente ferramenta para uma melhor compreensão da distribuição dos contaminantes em toda área estudada, foi possível dividir a baía de Sepetiba em 4 grandes áreas com características bem distintas. Esta divisão é fundamental para futuros monitoramentos ambientais, por meio da análise deste parâmetro em conjunto com os outros determinados neste trabalho, foi possível propor uma redução na quantidade de estações de coleta, sem prejudicar a representatividade dos dados obtidos. A malha amostral utilizada pela FEEMA é composta por 39 estações, cobrindo toda a área da baía, a malha proposta contém apenas 19 estações, uma redução de aproximadamente $50 \%$.

As ilhas de Itacuruçá e Jaguanum podem ser utilizadas como referência geográfica para dividir a baía de Sepetiba em duas grandes regiões: a oeste, na parte externa da baía, encontram-se sedimentos mais arenosos; a leste destas ilhas, na parte interna da baía, com sedimentos mais finos, predominantemente uma mistura de silte e argila. De modo geral, o mesmo critério de divisão pode ser adotado para o teor de matéria orgânica, sulfetos e metais tóxicos, sendo as concentrações destes mais altas na parte interna da baía do que em sua região oceânica.

A datação $\operatorname{com}{ }^{210} \mathrm{~Pb}$ foi útil para fornecer registros temporais da contaminação dos sedimentos, os modelos de cálculo propostos se adequaram bem aos dados gerados, permitindo uma identificação direta de fontes históricas. Foram observados picos de concentrações de $\mathrm{Zn}$ e $\mathrm{Cd}$ com datas coincidentes ao rompimento do dique de contenção da Companhia Mercantil Industrial Ingá. Em paralelo pôde-se perceber nos perfis destes metais que a concentração vem 
reduzindo muito lentamente, estando ainda superiores aos valores apontados pelo nível 2 do CONAMA 454 (2012) como tóxicos à vida marinha, e também muito acima dos níveis anteriores às instalações das primeiras indústrias, na década de 1960.

As taxas de sedimentação estimadas para os testemunhos analisados variaram entre 0,26 e $0,86 \mathrm{~g} \mathrm{~cm}^{2} \mathrm{ano}^{-1}$, os maiores valores foram encontrados próximo a foz dos principais rios afluentes e no extremo leste da baía, próximo ao bairro de Pedra de Guaratiba, o menor valor de taxa de sedimentação encontra-se na região central da Baía de Sepetiba.

Com os dados obtidos da determinação de $\mathrm{Hg}$ nos testemunhos T-13 e T18, localizados no transecto que liga a foz do rio Guandu ao centro da baía, foi possível perceber um aumento na concentração de $\mathrm{Hg}$ quase linear com o tempo, ou seja, o fluxo de $\mathrm{Hg}$ para a baía tem aumentado linearmente ao longo dos anos, e o aumento anual da concentração de $\mathrm{Hg}$ nos sedimentos superficiais estimada é de $0,62 \mu \mathrm{g} \mathrm{kg}$ ${ }^{1}$ ano $^{-1}$ para $\mathrm{T}-13$ e $0,29 \mu \mathrm{g} \mathrm{kg}^{-1}$ ano $^{-1}$ para T-18.

Em relação ao $\mathrm{Hg}$, o principal desenvolvimento futuro é a realização de um estudo mais amplo, identificando novas fontes deste metal, bem como o aumento da emissão quando comparados os dados já relatados pela literatura. Este estudo permitirá a realização do balanço de massa de Hg na baía de Sepetiba e melhor compreensão acerca do aumento contínuo da concentração observado nas últimas décadas. 


\section{6 \\ Referências bibliográficas}

ABNT - ASSOCIAÇÃO BRASILEIRA DE NORMAS TÉCNICAS. NBR 6502: Rochas e solos. 1995.

AGILENT TECHNOLOGIES. Inductively Coupled Plasma Mass Spectrometry. 2005.

ALLEN, H. E.; FU, G.; BOOTHMAN, W.; DITORO, D. M.; MAHONY, J. D. Draft Analytical Method for Determination of Acid Volatile Sulfide in Sediment. Epa-821, 1991.

ALLEN, H. E.; FU, G.; DENG, B. Analysis of acid-volatile sulfide and simultaneously extracted metals for the estimation of potential toxicity in aquatic sediments. Environmental Toxicology and Chemistry, v. 12, p. 1441-1453, 1993.

ANKLEY, G. T.; MATTSON, V. R.; LEONARD, E. N.; WEST, C. W.; BENNETT, J. L. Predicting the acute toxicity of copper in freshwater sediments: Evaluation of the role of acid-volatile sulfide. Environmental Toxicology and Chemistry, v. 12, n. 2, p. 315-320, 1993. Wiley Periodicals, Inc.

ANKLEY, G. T.; DI TORO, D. M.; HANSEN, D. J.; BERRY, W. J. Technical basis and proposal for deriving sediment quality criteria for metals. Environmental Toxicology and Chemistry, v. 15, n. 12, p. 2056-2066, 1996.

ANTAG. Desempenho Portuário - ANTAQ. Disponível em: $<$ http://web.antaq.gov.br/Portalv3/SDPV2ServicosOnline/index.html>. Acesso em: 8/10/2018.

BARCELlOS, C. Geodinâmica de Cadmio e Zinco na Baía de Sepetiba, 1995. Universidade Federal Fluminense. 
BARCELLOS, C.; LACERDA, L. D. Cadmium and Zinc Source Assessment in The Sepetiba Bay ans Basin Region. Environmental Monitoring and Assessment, v. 29, p. 183-199, 1994.

BARCELlOS, C.; REZENDE, C. E.; PFEIFFER, W. C. Zn and Cd production and pollution in a Brazilian coastal region. Marine Pollution Bulletin, v. 22, n. 11, p. 558-561, 1991. Pergamon.

BORGES, H. V.; NITTROUER, C. A. Sedimentação costeira em um sistema de Ilha-de-Barreira tropical durante o último século na Baía de Sepetiba. Anuario do Instituto de Geociencias, v. 39, n. 2, p. 5-14, 2016.

BOtelho, R. G. M.; GUERRA, A. J. T.; SILVA, A. S. Erosão e conservação dos solos, temas e aplicações. Rio de Janeiro: Bertrand Brasil, 1999.

BRATKIČ, A.; OGRINC, N.; KOTNIK, J.; et al. Mercury speciation driven by seasonal changes in a contaminated estuarine environment. Environmental Research, v. 125, p. 171-178, 2013. Academic Press.

BREDARIOL, C. S. O Aprendizado da Negociação em Conflitos Ambientais. ANPPAS. Anais... . p.19, 2004.

BURTON, G. A. Sediment quality criteria in use around the world. Limnology, v. 3, p. 65-75, 2002.

CAMPOS, R. C. Estudo da determinação de mercúrio por espectrofotometria de absorção atômica sem chama pela técnica do vapor frio, 1980.

CASAS, A. M.; CRECELIUS, E. A. Relationship between acid volatile sulfide and the toxicity of zinc, lead and copper in marine sediments. Environmental Toxicology and Chemistry, v. 13, n. 3, p. 529-536, 1994. WileyBlackwell. 
CAVALCANTI, G. Ternium conclui aquisição da CSA e siderúrgica muda de nome - Jornal O Globo. Disponível em: $<$ https://oglobo.globo.com/economia/ternium-conclui-aquisicao-da-csasiderurgica-muda-de-nome-21797404>. Acesso em: 8/10/2018.

CONAMA - CONSELHO NACIONAL DO MEIO AMBIENTE. Resolução $n^{0}$ 430. 2011.

CONAMA - CONSELHO NACIONAL DO MEIO AMBIENTE. Resolução no 454. 2012.

CUNHA, C. DE L. DA N.; ROSMAN, P. C. C.; FERREIRA, A. P.; CARLOS DO NASCIMENTO MONTEIRO, T. Hydrodynamics and water quality models applied to Sepetiba Bay. Continental Shelf Research, v. 26, n. 16, p. 1940-1953, 2006. Pergamon.

ECOLOGUS. Estudo de Impacto Ambiental - EIA do Terminal Portuário Centro Atlântico. 2005.

FAGNANI, E.; GUIMARÃES, J. R.; MOZETO, A. A.; FADINI, P. S. Sulfetos volatilizáveis por acidificação e metais extraídos simultaneamente na avaliação de sedimentos de água doce. Quimica Nova, v. 34, n. 9, p. 1618-1628, 2011.

FEEMA. Baía de Sepetiba - Rios da baixada da Baía de Sepetiba diagnóstico de qualidade de água e sedimentos. 2006.

FERNANDES, L.; NAYAK, G. N.; ILANGOVAN, D.; BOROLE, D. V. Accumulation of sediment, organic matter and trace metals with space and time, in a creek along Mumbai coast, India. Estuarine, Coastal and Shelf Science, v. 91, n. 3, p. 388-399, 2011. Elsevier Ltd.

FERREIRA, M. M. ESTIMATIVA DOS FLUXOS DE ZN, CD, PB E CU NO SACO DO ENGENHO, BAÍA DE SEPETIBA, RJ, 2010. Universidade Federal Fluminense. 
FOLK, R. L. A Review of Grain-Size Parameters. Sedimentology, v. 6, n. 2, p. 73-93, 1966.

FONSECA, S. A. R.; GUERRA, J. V. Observações Dos Padrões De Circulação Nas Proximidades Do Canal De Navegação Da Baía De Sepetiba (RJ). X Encontro Nacional de Engenharia de Sedimentos. Anais..., 2011.

GAO, X.; YANG, Y.; WANG, C. Geochemistry of organic carbon and nitrogen in surface sediments of coastal Bohai Bay inferred from their ratios and stable isotopic signatures. Marine Pollution Bulletin, v. 64, p. 1148-1155, 2012.

GINÉ-ROSIAS, M. F. Espectrometria de Massas com Fonte de Plasma (ICP-MS). Piracicaba: CENA, 1999.

GODOY, J. M.; GODOY, M. L. D. P.; ARONNE, C. C. Application of inductively coupled plasma quadrupole mass spectrometry for the determination of monazite ages by lead isotope ratios. Journal of the Brazilian Chemical Society, v. 18, n. 5, p. 969-975, 2007. Brazilian Chemical Society.

GODOY, J. M.; MOREIRA, I.; BRAGANÇA, M. J.; WANDERLEY, C.; MENDES, L. B. A study of Guanabara Bay sedimentation rates. Journal of Radioanalytical and Nuclear Chemistry, v. 227, n. 1-2, p. 157-160, 1998.

GODOY, J. M.; MOREIRA, I.; WANDERLEY, C.; SIMÕES FILHO, F. F.; MOZETO, A. A. An Alternative Method for the Determination of Excess $210 \mathrm{~Pb}$ in Sediments. Radiation Protection Dosimetry, v. 75, n. 1-4, p. 111-115, 1998.

GOMES, F. DE C.; GODOY, J. M.; GODOY, M. L. D. P.; et al. Metal concentrations, fluxes, inventories and chronologies in sediments from Sepetiba and Ribeira Bays: A comparative study. Marine Pollution Bulletin, v. 59, n. 4-7, p. 123-133, 2009. Elsevier Ltd.

Grupo ARG | Porto Sudeste. .Disponível em: <http://grupoarg.izap.ws/plus/modulos/conteudo/?tac=porto-sudeste>. Acesso em: 22/9/2018. 
HANSEN, D. J.; DITORO, D. M.; BERRY, W. J.; et al. Procedures for the Derivation of Equilibrium Partitioning Sediment Benchmarks ( ESBs ) for the Protection of Benthic Organisms: Metal Mixtures ( Cadmium , Copper, Lead, Nickel, Silver, and Zinc). EPA/600/R02/011. Environmental Protection, p. 121, 2005 .

JORGE, P.; PORTELA, C. ANÁLISE ELEMENTAR E ISOTÓPICA DE SEDIMENTOS ESTUARINOS DO RIO ALCABRICHEL (TORRES VEDRAS) E DA RIBEIRA DE BENSAFRIM (LAGOS). 2013.

LACERDA, L. D.; MOLISANI, M. M. Three decades of $\mathrm{Cd}$ and $\mathrm{Zn}$ contamination in Sepetiba Bay, SE Brazil: Evidence from the mangrove oyster Crassostraea rhizophorae. Marine Pollution Bulletin, v. 52, n. 8, p. 974-977, 2006.

LARNER, B. L.; PALMER, A. S.; SEEN, A. J.; TOWNSEND, A. T. A comparison of an optimised sequential extraction procedure and dilute acid leaching of elements in anoxic sediments, including the effects of oxidation on sediment metal partitioning. Analytica Chimica Acta, v. 608, n. 2, p. 147-157, 2008. Elsevier.

LIMA, A. L. C. Geocronologia de Hidrocarbonetos Poliaromáticos (PAHs), Estudo de Caso: Baía de Guanabara, 1996. Pontifícia Universidade Católica do Rio de Janeiro.

LIMAVERDE, A. M.; CAMPOS, R. C. DE. Redução seletiva aplicada à especiação de mercúrio em peixes: uma adaptação do método de Magos. Química Nova, v. 22, n. 4, p. 477-482, 1999. SBQ.

LONG, E. R.; MORGAN, L. G. The Potential for Biological Effects of Sediment-Sorbed Contaminants Tested in the National Status and Trends Program. NOAA Technical Memorandum, 1990.

MACDONALD, D. D.; CARR, R. S.; CALDER, F. D.; LONG, E. R.; INGERSOLL, C. G. Development and evaluation of sediment quality guidelines for Florida coastal waters. 1996. 
MAGALHÃES, V. F.; PFEIFFER, W. C. Arsenic concentration in sediments near a metallurgical plant (Sepetiba Bay, Rio de Janeiro, Brazil). Journal of Geochemical Exploration, v. 52, n. 1-2, p. 175-181, 1995. Elsevier.

MARINS, R. V; DE, F. J.; FILHO, P.; ROBÉRIO, S.; MAIA, R. DISTRIBUIÇÃO DE MERCÚRIO TOTAL COMO INDICADOR DE POLUIÇÃO URBANA E INDUSTRIAL NA COSTA BRASILEIRA. Quim. Nova, v. 27, n. 5, p. 763-770, 2004.

MARINS, R. V; LACERDA, L. D.; PARAQUETTI, H. H. M.; DE PAIVA, E. C.; VILLAS BOAS, R. C. Geochemistry of Mercury in Sediments of a SubTropical Coastal Lagoon, Sepetiba Bay, Southeastern Brazil. Bull. Environ. Contam. Toxicol, v. 61, p. 57-64, 1998.

MCBRIDE, M. B. Reactions Controlling Heavy Metal Solubility in Soils. . p.1-56, 1989. Springer, New York, NY.

MELLO, D. F. DE. Pedra de Guaratiba: Um Lugar onde o Futuro Não Aconceteu, 2015.

MESTRINHO, S. S. P. Estudo do comportamento geoquímico dos metais pesados nos sedimentos da região estuarina do Rio Paraguaçu - Bahia, 22. jun. 1998. São Paulo: Biblioteca Digital de Teses e Dissertações da Universidade de São Paulo.

MEYERS, P. A. Preservation of elemental and isotopic source identification of sedimentary organic matter. Chemical Geology, v. 114, n. 3-4, p. 289-302, 1994. Elsevier.

MINISTÉRIO DA DEFESA. Programa de Desenvolvimento de Submarinos - PROSUB. Disponível em: 〈https://www.marinha.mil.br/prosub/>. Acesso em: $8 / 10 / 2018$.

MOLISANI, M. M.; MARINS, R. V.; MACHADO, W.; et al. Environmental changes in Sepetiba Bay, SE Brazil. Regional Environmental Change, v. 4, n. 1, p. 17-27, 2004. Springer-Verlag. 
MOORE, J.; BROOK, E.; WATER, C. J.-E. G. AND; 1989, U. Grain size partitioning of metals in contaminated, coarse-grained river floodplain sediment: Clark Fork River, Montana, USA. Springer, 1989.

MOZETO, A. A.; UMBUZEIRO, G. A.; JARDIM, W. DE F. Métodos de Coleta, Análises Físico-químicas e Ensaios Biológicos e Ecotoxicológicos de Sedimentos de Água Doce. Cubo Multimídia \& Propaganda, São Carlos, SP, Brazil, 2006.

OLIVEIRA, A. V. Cronologia da deposição de metais pesados associados aos sedimentos da Baía da Guanabara, 11. set. 2009. Rio de Janeiro, Brazil: PONTIFÍCIA UNIVERSIDADE CATÓLICA DO RIO DE JANEIRO.

PACS. Companhia Siderúrgica do Atlântico - Impactos e Irregularidades na Zona Oeste do Rio de Janeiro. $3^{\circ}$ ed. Rio de Janeiro: PACS, 2012.

PACS. Baía de Sepetiba: fronteira do desenvolvimentismo e os limites para a construção de alternativas. $1^{\circ}$ ed. Rio de Janeiro, 2015.

PARAQUETTI, H. H. M.; AYRES, G. A.; DE ALMEIDA, M. D.; MOLISANI, M. M.; LACERDA, L. D. DE. Mercury distribution, speciation and flux in the Sepetiba Bay tributaries, SE Brazil. Water Research, v. 38, n. 6, p. 1439-1448, 2004. Pergamon.

PARETKCSA. \#pare TKCSA. Disponível em: <http://paretkcsa.org/>. Acesso em: 8/10/2018.

PERILLO, G. M. E. Chapter 2 Definitions and Geomorphologic Classifications of Estuaries. Developments in Sedimentology, v. 53, p. 17-47, 1995. Elsevier.

PINTO, L. M. DE O. Implicações da Contaminação por Metais Pesados no Meio Ambiente da Baía de Sepetiba e Entorno: O Caso da Cia Mercantil Ingá, 2005.

PRITCHARD, D. W. What is an estuary: Physical Viewpoint. , 1967. American Association for the Advancement of Science. 
PROSUB - Programa de Desenvolvimeto de Submarinos. .Disponível em: <https://www.marinha.mil.br/prosub/>. Acesso em: 27/3/2018.

REZENDE, C. E.; PFEIFFER, W. C.; MARTINELLI, L. A.; et al. Lignin phenols used to infer organic matter sources to Sepetiba Bay - RJ, Brasil. Estuarine, Coastal and Shelf Science, v. 87, n. 3, p. 479-486, 2010.

RODRIGUES, S. K.; ABESSA, D. M. S.; RODRIGUES, A. P. DE C.; et al. Sediment quality in a metal-contaminated tropical bay assessed with a multiple lines of evidence approach. Environmental Pollution, v. 228, p. 265-276, 2017. Elsevier Ltd.

RZĄSA, S.; OWCZARZAK, W. Methods for the Granulometric Analysis of Soil for Acience and Practice. Journal of Soil Science, v. 46, n. 1, 2013.

SCHARTUP, A. T.; BALCOM, P. H.; MASON, R. P. Sediment-Porewater Partitioning, Total Sulfur, and Methylmercury Production in Estuaries. Environmental Science \& Technology, v. 48, n. 2, p. 954-960, 2014. American Chemical Society.

SCHLITZER, R. Ocen Data View, odv.awi.de. , 2017.

SILVÉRIO, P. F.; FONSECA, A. L.; BOTTA-PASCHOAL, C. M. R.; MOZETO, A. A. Release, bioavailability and toxicity of metals in lacustrine sediments: A case study of reservoirs and lakes in Southeast Brazil. Aquatic Ecosystem Health and Management, v. 8, n. 3, p. 313-322, 2005. Taylor \& Francis Group.

SIMPSON, S. L.; BATLEY, G. E.; CHARITON, A. A.; et al. Handbook for Sediment Quality Assessment. 2005.

SINDARIO. Sindicato das Agências de Navegação Marítima e Atividades Afins do Estado do Rio de Janeiro. Disponível em: <http://www.sindario.com.br/portos/itaguaí---sepetiba>. Acesso em: 8/10/2018. 
SROGI, K. Developments in the Determination of Trace Elements by Atomic Spectroscopic Techniques. Analytical Letters, v. 41, n. 5, p. 677-724, 2008. Taylor \& Francis Group.

SUGUIO, K. Rochas Sedimentares. $1^{\circ}$ ed. São Paulo: Edgard Blucher Ltda., 1980.

SWARTZ, R. C. Consensus sediment quality guidelines for polycyclic aromatic hydrocarbon mixtures. Environmental Toxicology and Chemistry, v. 18, n. 4, p. 780-787, 1999. Wiley-Blackwell.

THOMAS, R. A Beginner's Guide to ICP-MS - Part I. Spectroscopy, v. 16, n. April, p. 38-42, 2001.

THORNTON, S. F.; MCMANUS, J. Application of Organic Carbon and Nitrogen Stable Isotope and C/N Ratios as Source Indicators of Organic Matter Provenance in Estuarine Systems: Evidence from the Tay Estuary, Scotland. Estuarine, Coastal and Shelf Science, v. 38, n. 3, p. 219-233, 1994. Academic Press.

DI TORO, D. M.; MAHONY, J. D.; HANSEN, D. J.; et al. Toxicity of cadmium in sediments: The role of acid volatile sulfide. Environmental Toxicology and Chemistry, v. 9, n. 12, p. 1487-1502, 1990. Wiley Periodicals, Inc.

DI TORO, D. M.; MAHONY, J. D.; HANSEN, D. J.; BERRY, W. J. A model of the oxidation of iron and cadmium sulfide in sediments. Environmental Toxicology and Chemistry, v. 15, n. 12, p. 2168-2186, 1996.

DI TORO, D. M.; ZARBA, C. S.; HANSEN, D. J.; et al. Technical basis for establishing sediment quality criteria for nonionic organic chemicals using equilibrium partitioning. Environmental Toxicology and Chemistry, v. 10, n. 12, p. 1541-1583, 1991.

USEPA. 376.2 Sulfide (Colorimetric, Methylene Blue). 1978. 
USEPA. 3050B ACID DIGESTION OF SEDIMENTS, SLUDGES, AND SOILS. 1996.

USEPA. Equilibrium partitioning sediments guidelines (ESGs) for the protection of benthic organisms: metal mixtures (cadmium, copper, lead, nickel, silver and zinc). Washington, 2000.

USIMINAS. Usiminas iniciará recuperação de um dos maiores passivos ambientais do Brasil: Mineração Usiminas. Disponível em: $<$ https://www.usiminas.com/mineracao/usiminas-iniciara-recuperacao-de-um-dosmaiores-passivos-ambientais-do-brasil/> . Acesso em: 10/10/2018.

VIÉGAS, R. N. Desigualdade Ambiental e “ Zonas de Sacrifício ”, 2006.

WANDERLEY, C. V. DE A. Estudo comparativo de métodos de determinação de $210 \mathrm{~Pb}$ atmosférico em sedimentos da Baia de Guanabara visando a avaliação da velocidade de sedimentnação, 1995. Rio de Janeiro: Pontifícia Universidade Católica do Rio de Janeiro.

WELZ, B. Atomic absorption spectrometry. Wiley-VCH, 1999.

XU, G.; LIU, J.; HU, G.; JONELL, T. N.; CHEN, L. Distribution and source of organic matter in surface sediment from the muddy deposit along the Zhejiang coast, East China Sea. Marine Pollution Bulletin, v. 123, n. 1-2, p. 395-399, 2017. 
ANEXO A - Umidade

Tabela 11: \% de umidade em sedimentos superficiais da Baía de Sepetiba

\begin{tabular}{|c|c|c|c|}
\hline Estação & Sedimento úmido (g) & Sedimento seco $(\mathrm{g})$ & $\%$ umidade \\
\hline SP-101 & 100,51 & 29,86 & $70,3 \%$ \\
\hline SP-102 & 99,69 & 24,55 & $75,4 \%$ \\
\hline SP-103 & 103,20 & 24,25 & $76,5 \%$ \\
\hline SP-104 & 100,73 & 56,72 & $43,7 \%$ \\
\hline SP-105 & 102,58 & 28,60 & $72,1 \%$ \\
\hline SP-106 & 93,30 & 17,28 & $81,5 \%$ \\
\hline SP-107 & 100,71 & 31,47 & $68,8 \%$ \\
\hline SP-108 & 100,32 & 31,07 & $69,0 \%$ \\
\hline SP-109 & 95,80 & 23,22 & $75,8 \%$ \\
\hline SP-110 & 100,13 & 18,99 & $81,0 \%$ \\
\hline SP-111 & 102,88 & 33,24 & $67,7 \%$ \\
\hline SP-112 & 98,22 & 32,36 & $67,1 \%$ \\
\hline SP-113 & 99,20 & 24,79 & $75,0 \%$ \\
\hline SP-114 & 96,07 & 27,76 & $71,1 \%$ \\
\hline SP-115 & 102,99 & 49,12 & $52,3 \%$ \\
\hline SP-116 & 98,58 & 50,97 & $48,3 \%$ \\
\hline SP-117 & 105,21 & 41,54 & $60,5 \%$ \\
\hline SP-118 & 100,14 & 24,42 & $75,6 \%$ \\
\hline SP-119 & 91,70 & 41,07 & $55,2 \%$ \\
\hline SP-120 & 100,41 & 33,24 & $66,9 \%$ \\
\hline SP-121 & 102,81 & 60,62 & $41,0 \%$ \\
\hline SP-122 & 98,28 & 43,33 & $55,9 \%$ \\
\hline SP-123 & 100,80 & 30,90 & $69,3 \%$ \\
\hline SP-124 & 96,84 & 26,94 & $72,2 \%$ \\
\hline SP-125 & 102,34 & 82,10 & $19,8 \%$ \\
\hline SP-126 & 104,16 & 57,19 & $45,1 \%$ \\
\hline SP-130 & 111,76 & 76,90 & $31,2 \%$ \\
\hline SP-131 & 95,20 & 41,21 & $56,7 \%$ \\
\hline SP-132 & 100,64 & 37,72 & $62,5 \%$ \\
\hline SP-133 & 104,27 & 27,44 & $73,7 \%$ \\
\hline SP-134 & 100,80 & 62,57 & $37,9 \%$ \\
\hline SP-135 & 101,12 & 76,91 & $23,9 \%$ \\
\hline SP-136 & 101,07 & 63,05 & $37,6 \%$ \\
\hline SP-137 & 104,01 & 64,97 & $37,5 \%$ \\
\hline SP-138 & 102,60 & 67,99 & $33,7 \%$ \\
\hline SP-139 & 102,94 & 76,82 & $25,4 \%$ \\
\hline SP-140 & 100,84 & 85,17 & $15,5 \%$ \\
\hline SP-141 & 100,14 & 85,21 & $14,9 \%$ \\
\hline
\end{tabular}


Tabela 12: \% de umidade em camadas de testemunhos sedimentares da Baía de Sepetiba

\begin{tabular}{|c|c|c|c|c|c|c|c|c|c|}
\hline $\begin{array}{l}\text { Profundidade } \\
\text { média }(\mathrm{cm})\end{array}$ & $\mathbf{T}-\mathbf{3}$ & $\mathbf{T}-8$ & $T-13$ & $T-18$ & T - 19 & $T-20$ & T - 26 & T - 28 & $\mathbf{T}-\mathbf{3 1}$ \\
\hline 1 & $85,5 \%$ & $74,9 \%$ & $82,3 \%$ & $76,0 \%$ & $80,9 \%$ & $84,4 \%$ & $82,9 \%$ & $84,3 \%$ & $75,7 \%$ \\
\hline 3 & $78,4 \%$ & $65,8 \%$ & $77,4 \%$ & $74,2 \%$ & $80,2 \%$ & $82,5 \%$ & $82,1 \%$ & $83,9 \%$ & $73,1 \%$ \\
\hline 5 & $77,2 \%$ & $60,4 \%$ & $72,4 \%$ & $71,7 \%$ & $79,5 \%$ & $80,8 \%$ & $80,7 \%$ & $82,2 \%$ & $71,6 \%$ \\
\hline 7 & $75,6 \%$ & $58,7 \%$ & $70,7 \%$ & $65,2 \%$ & $76,1 \%$ & $79,1 \%$ & $80,4 \%$ & $80,2 \%$ & $69,1 \%$ \\
\hline 9 & $75,3 \%$ & $54,5 \%$ & $69,9 \%$ & $64,5 \%$ & $74,7 \%$ & $77,9 \%$ & $79,4 \%$ & $79,1 \%$ & $67,6 \%$ \\
\hline 11 & $73,9 \%$ & $51,7 \%$ & $68,4 \%$ & $64,3 \%$ & $74,3 \%$ & $77,2 \%$ & $78,7 \%$ & $78,2 \%$ & $68,8 \%$ \\
\hline 13 & $74,9 \%$ & $49,1 \%$ & $67,4 \%$ & $65,3 \%$ & $74,7 \%$ & $76,6 \%$ & $77,0 \%$ & $76,8 \%$ & $68,2 \%$ \\
\hline 15 & $72,7 \%$ & $49,9 \%$ & $67,8 \%$ & $63,3 \%$ & $73,5 \%$ & $77,1 \%$ & $77,8 \%$ & $76,8 \%$ & $67,8 \%$ \\
\hline 17 & $71,2 \%$ & $47,9 \%$ & $64,3 \%$ & $60,7 \%$ & $73,9 \%$ & $77,4 \%$ & $78,5 \%$ & $76,0 \%$ & $65,9 \%$ \\
\hline 19 & $69,3 \%$ & $43,4 \%$ & $65,6 \%$ & $58,6 \%$ & $74,9 \%$ & $77,5 \%$ & $75,5 \%$ & $76,5 \%$ & $60,8 \%$ \\
\hline 21 & $73,0 \%$ & $41,1 \%$ & $63,7 \%$ & $57,3 \%$ & $74,6 \%$ & $77,4 \%$ & $71,5 \%$ & $75,7 \%$ & $56,4 \%$ \\
\hline 23 & $72,0 \%$ & $39,4 \%$ & $64,0 \%$ & $57,5 \%$ & $72,5 \%$ & $77,0 \%$ & $69,8 \%$ & $74,6 \%$ & $55,5 \%$ \\
\hline 25 & $71,7 \%$ & $38,7 \%$ & $60,7 \%$ & $55,3 \%$ & $73,6 \%$ & $75,2 \%$ & $70,5 \%$ & $74,0 \%$ & $51,9 \%$ \\
\hline 27 & $71,4 \%$ & $36,2 \%$ & $59,6 \%$ & $54,5 \%$ & $73,4 \%$ & $74,7 \%$ & $69,8 \%$ & $73,8 \%$ & $54,0 \%$ \\
\hline 29 & $69,8 \%$ & $32,4 \%$ & $61,8 \%$ & $54,0 \%$ & $72,7 \%$ & $74,7 \%$ & $70,0 \%$ & $73,9 \%$ & $53,5 \%$ \\
\hline 31 & $67,8 \%$ & $30,0 \%$ & $56,3 \%$ & $53,8 \%$ & $72,2 \%$ & $75,5 \%$ & $70,5 \%$ & $72,3 \%$ & $50,4 \%$ \\
\hline 33 & $69,2 \%$ & $31,6 \%$ & $53,8 \%$ & $50,7 \%$ & $69,7 \%$ & $76,7 \%$ & $68,6 \%$ & $69,1 \%$ & $50,5 \%$ \\
\hline 35 & $68,0 \%$ & $31,2 \%$ & $51,1 \%$ & $46,1 \%$ & $66,3 \%$ & $77,4 \%$ & $64,7 \%$ & $68,2 \%$ & $49,7 \%$ \\
\hline 37 & $69,3 \%$ & $31,2 \%$ & $49,0 \%$ & $41,3 \%$ & $61,9 \%$ & $77,3 \%$ & $63,0 \%$ & $67,4 \%$ & $49,2 \%$ \\
\hline 39 & $68,7 \%$ & $33,7 \%$ & $41,6 \%$ & $44,4 \%$ & $59,6 \%$ & $75,8 \%$ & $61,9 \%$ & $67,1 \%$ & \\
\hline 41 & $68,6 \%$ & $36,6 \%$ & $41,0 \%$ & $40,6 \%$ & $58,9 \%$ & $75,9 \%$ & $61,6 \%$ & $65,9 \%$ & \\
\hline 43 & $69,1 \%$ & $31,1 \%$ & & $39,1 \%$ & $60,5 \%$ & $75,0 \%$ & $62,4 \%$ & $66,8 \%$ & \\
\hline 45 & $68,7 \%$ & $25,7 \%$ & & $39,3 \%$ & $59,5 \%$ & $74,0 \%$ & $62,1 \%$ & $67,8 \%$ & \\
\hline 47 & $68,6 \%$ & $24,3 \%$ & & $38,4 \%$ & $58,9 \%$ & $63,4 \%$ & $59,0 \%$ & $66,8 \%$ & \\
\hline 49 & $68,1 \%$ & & & $38,6 \%$ & $56,0 \%$ & $60,7 \%$ & $58,5 \%$ & $65,7 \%$ & \\
\hline 51 & $65,5 \%$ & & & $39,1 \%$ & $55,2 \%$ & $61,8 \%$ & $58,1 \%$ & $64,5 \%$ & \\
\hline 53 & $67,4 \%$ & & & $39,2 \%$ & $54,6 \%$ & $61,0 \%$ & $57,7 \%$ & $62,7 \%$ & \\
\hline 55 & $67,5 \%$ & & & & $51,0 \%$ & $60,1 \%$ & $56,5 \%$ & $53,6 \%$ & \\
\hline 57 & $69,1 \%$ & & & & $49,2 \%$ & $56,3 \%$ & $56,6 \%$ & $58,8 \%$ & \\
\hline 59 & $69,1 \%$ & & & & $52,1 \%$ & $52,0 \%$ & $56,7 \%$ & $57,4 \%$ & \\
\hline 61 & $66,4 \%$ & & & & & $46,8 \%$ & & $53,7 \%$ & \\
\hline 63 & & & & & & $45,3 \%$ & & & \\
\hline 65 & & & & & & $43,0 \%$ & & & \\
\hline
\end{tabular}




\section{ANEXO B - Granulometria}

Tabela 13: Determinação Granulométrica, SP-101.

\begin{tabular}{|c|c|}
\hline $\begin{array}{c}\text { Diâmetro } \\
(\mu \mathrm{m})\end{array}$ & $\begin{array}{c}\% \\
\text { (valor cumulativo) }\end{array}$ \\
\hline 0,04 & 0,5 \\
\hline 0,07 & 0,6 \\
\hline 0,1 & 0,76 \\
\hline 0,2 & 2,17 \\
\hline 0,3 & 3,95 \\
\hline 0,4 & 4,82 \\
\hline 0,5 & 4,82 \\
\hline 0,6 & 4,82 \\
\hline 0,7 & 4,82 \\
\hline 0,8 & 4,83 \\
\hline 0,9 & 4,89 \\
\hline 1 & 5,02 \\
\hline 1,1 & 5,22 \\
\hline 1,2 & 5,48 \\
\hline 1,3 & 5,8 \\
\hline 1,4 & 6,18 \\
\hline 1,6 & 7,09 \\
\hline 1,8 & 8,18 \\
\hline 2 & 9,4 \\
\hline 2,2 & 10,72 \\
\hline 2,4 & 12,1 \\
\hline 2,6 & 13,52 \\
\hline 3 & 16,41 \\
\hline 4 & 23,35 \\
\hline 5 & 29,43 \\
\hline 6 & 34,85 \\
\hline 6,5 & 37,37 \\
\hline 7 & 39,82 \\
\hline 7,5 & 42,24 \\
\hline 8 & 44,63 \\
\hline 8,5 & 47,03 \\
\hline 9 & 49,39 \\
\hline 10 & 54 \\
\hline 11 & 58,37 \\
\hline 12 & 62,44 \\
\hline 13 & 66,2 \\
\hline
\end{tabular}

\begin{tabular}{|c|c|}
\hline $\begin{array}{l}\text { Diâmetro } \\
(\mu \mathrm{m})\end{array}$ & $\begin{array}{c}\% \\
\text { (valor cumulativo) }\end{array}$ \\
\hline 14 & 69,6 \\
\hline 15 & 72,63 \\
\hline 16 & 75,31 \\
\hline 17 & 77,66 \\
\hline 18 & 79,7 \\
\hline 19 & 81,46 \\
\hline 20 & 82,98 \\
\hline 22 & 85,46 \\
\hline 25 & 88,15 \\
\hline 28 & 90,02 \\
\hline 32 & 91,74 \\
\hline 36 & 92,94 \\
\hline 38 & 93,45 \\
\hline 40 & 93,91 \\
\hline 45 & 94,96 \\
\hline 50 & 95,91 \\
\hline 53 & 96,44 \\
\hline 56 & 96,94 \\
\hline 63 & 97,94 \\
\hline 71 & 98,8 \\
\hline 75 & 99,11 \\
\hline 80 & 99,42 \\
\hline 85 & 99,64 \\
\hline 90 & 99,79 \\
\hline 95 & 99,89 \\
\hline 100 & 99,94 \\
\hline 106 & 99,99 \\
\hline 112 & 100 \\
\hline 125 & 100 \\
\hline 130 & 100 \\
\hline 140 & 100 \\
\hline 145 & 100 \\
\hline 150 & 100 \\
\hline
\end{tabular}

SP - 101

\begin{tabular}{|c|cc|}
\hline \multicolumn{3}{|c|}{ amostra analisada } \\
\hline argila & $9,4 \quad \%$ \\
\hline silte & $88,54 \%$ \\
\hline areia/cascalho & $2,06 \quad \%$ \\
\hline
\end{tabular}


Tabela 14: Determinação granulométrica, SP-102.

\begin{tabular}{|c|c|}
\hline $\begin{array}{l}\text { Diâmetro } \\
(\mu \mathrm{m})\end{array}$ & $\begin{array}{c}\% \\
\text { (valor cumulativo) }\end{array}$ \\
\hline 0,04 & 0,43 \\
\hline 0,07 & 0,5 \\
\hline 0,1 & 0,63 \\
\hline 0,2 & 1,82 \\
\hline 0,3 & 3,32 \\
\hline 0,4 & 4,06 \\
\hline 0,5 & 4,06 \\
\hline 0,6 & 4,06 \\
\hline 0,7 & 4,06 \\
\hline 0,8 & 4,06 \\
\hline 0,9 & 4,1 \\
\hline 1 & 4,19 \\
\hline 1,1 & 4,34 \\
\hline 1,2 & 4,55 \\
\hline 1,3 & 4,8 \\
\hline 1,4 & 5,11 \\
\hline 1,6 & 5,85 \\
\hline 1,8 & 6,76 \\
\hline 2 & 7,77 \\
\hline 2,2 & 8,88 \\
\hline 2,4 & 10,05 \\
\hline 2,6 & 11,26 \\
\hline 3 & 13,75 \\
\hline 4 & 19,88 \\
\hline 5 & 25,38 \\
\hline 6 & 30,34 \\
\hline 6,5 & 32,67 \\
\hline 7 & 34,95 \\
\hline 7,5 & 37,19 \\
\hline 8 & 39,43 \\
\hline 8,5 & 41,67 \\
\hline 9 & 43,89 \\
\hline 10 & 48,27 \\
\hline 11 & 52,51 \\
\hline 12 & 56,57 \\
\hline 13 & 60,41 \\
\hline 14 & 64,01 \\
\hline 15 & 67,35 \\
\hline 16 & 70,41 \\
\hline 17 & 73,22 \\
\hline
\end{tabular}

\begin{tabular}{|c|c|}
\hline $\begin{array}{l}\text { Diâmetro } \\
(\mu \mathrm{m})\end{array}$ & $\begin{array}{c}\% \\
\text { (valor cumulativo) }\end{array}$ \\
\hline 18 & 75,77 \\
\hline 19 & 78,1 \\
\hline 20 & 80,2 \\
\hline 22 & 83,82 \\
\hline 25 & 87,98 \\
\hline 28 & 91,02 \\
\hline 32 & 93,9 \\
\hline 36 & 95,89 \\
\hline 38 & 96,65 \\
\hline 40 & 97,29 \\
\hline 45 & 98,46 \\
\hline 50 & 99,19 \\
\hline 53 & 99,48 \\
\hline 56 & 99,68 \\
\hline 63 & 99,92 \\
\hline 71 & 100 \\
\hline 75 & 100 \\
\hline 80 & 100 \\
\hline 85 & 100 \\
\hline 90 & 100 \\
\hline 95 & 100 \\
\hline 100 & 100 \\
\hline 106 & 100 \\
\hline 112 & 100 \\
\hline 125 & 100 \\
\hline 130 & 100 \\
\hline 140 & 100 \\
\hline 145 & 100 \\
\hline 150 & 100 \\
\hline 160 & 100 \\
\hline 170 & 100 \\
\hline 180 & 100 \\
\hline 190 & 100 \\
\hline 200 & 100 \\
\hline 212 & 100 \\
\hline 242 & 100 \\
\hline 250 & 100 \\
\hline 300 & 100 \\
\hline 400 & 100 \\
\hline 500 & 100 \\
\hline
\end{tabular}

SP - 102

\begin{tabular}{|c|cc|}
\hline \multicolumn{3}{|c|}{ amostra original } \\
\hline argila & $\mathbf{7 , 7 7}$ & $\%$ \\
\hline silte & $\mathbf{9 2 , 1 5}$ & $\%$ \\
\hline areia/cascalho & $\mathbf{0 , 0 8}$ & $\%$ \\
\hline
\end{tabular}


Tabela 15: Determinação granulométrica, SP-103.

\begin{tabular}{|c|c|}
\hline $\begin{array}{c}\text { Diâmetro } \\
(\mu \mathrm{m})\end{array}$ & $\begin{array}{c}\% \\
\text { (valor cumulativo) }\end{array}$ \\
\hline 0,04 & 0,47 \\
\hline 0,07 & 0,55 \\
\hline 0,1 & 0,69 \\
\hline 0,2 & 1,99 \\
\hline 0,3 & 3,63 \\
\hline 0,4 & 4,42 \\
\hline 0,5 & 4,42 \\
\hline 0,6 & 4,42 \\
\hline 0,7 & 4,42 \\
\hline 0,8 & 4,45 \\
\hline 0,9 & 4,53 \\
\hline 1 & 4,68 \\
\hline 1,1 & 4,89 \\
\hline 1,2 & 5,16 \\
\hline 1,3 & 5,48 \\
\hline 1,4 & 5,84 \\
\hline 1,6 & 6,71 \\
\hline 1,8 & 7,74 \\
\hline 2 & 8,86 \\
\hline 2,2 & 10,08 \\
\hline 2,4 & 11,33 \\
\hline 2,6 & 12,62 \\
\hline 3 & 15,2 \\
\hline 4 & 21,3 \\
\hline 5 & 26,59 \\
\hline 6 & 31,29 \\
\hline 6,5 & 33,48 \\
\hline 7 & 35,61 \\
\hline 7,5 & 37,71 \\
\hline 8 & 39,78 \\
\hline 8,5 & 41,85 \\
\hline 9 & 43,9 \\
\hline 10 & 47,93 \\
\hline 11 & 51,82 \\
\hline 12 & 55,55 \\
\hline 13 & 59,11 \\
\hline 14 & 62,48 \\
\hline 15 & 65,66 \\
\hline 16 & 68,64 \\
\hline 17 & 71,44 \\
\hline
\end{tabular}

\begin{tabular}{|c|c|}
\hline $\begin{array}{l}\text { Diâmetro } \\
(\mu \mathrm{m})\end{array}$ & $\begin{array}{c}\% \\
\text { (valor cumulativo) }\end{array}$ \\
\hline 18 & 74,08 \\
\hline 19 & 76,57 \\
\hline 20 & 78,91 \\
\hline 22 & 83,09 \\
\hline 25 & 88,15 \\
\hline 28 & 91,97 \\
\hline 32 & 95,5 \\
\hline 36 & 97,7 \\
\hline 38 & 98,39 \\
\hline 40 & 98,91 \\
\hline 45 & 99,64 \\
\hline 50 & 99,9 \\
\hline 53 & 99,97 \\
\hline 56 & 100 \\
\hline 63 & 100 \\
\hline 71 & 100 \\
\hline 75 & 100 \\
\hline 80 & 100 \\
\hline 85 & 100 \\
\hline 90 & 100 \\
\hline 95 & 100 \\
\hline 100 & 100 \\
\hline 106 & 100 \\
\hline 112 & 100 \\
\hline 125 & 100 \\
\hline 130 & 100 \\
\hline 140 & 100 \\
\hline 145 & 100 \\
\hline 150 & 100 \\
\hline 160 & 100 \\
\hline 170 & 100 \\
\hline 180 & 100 \\
\hline 190 & 100 \\
\hline 200 & 100 \\
\hline 212 & 100 \\
\hline 242 & 100 \\
\hline 250 & 100 \\
\hline 300 & 100 \\
\hline 400 & 100 \\
\hline 500 & 100 \\
\hline
\end{tabular}

SP - 103

\begin{tabular}{|c|cc|}
\hline \multicolumn{3}{|c|}{ amostra original } \\
\hline argila & $\mathbf{8 , 8 6}$ & $\%$ \\
\hline silte & $\mathbf{9 1 , 1 4}$ & $\%$ \\
\hline areia/cascalho & --- & $\%$ \\
\hline
\end{tabular}


Tabela 16: Determinação granulométrica, SP-106.

\begin{tabular}{|c|c|}
\hline $\begin{array}{l}\text { Diâmetro } \\
\qquad(\mu \mathrm{m})\end{array}$ & $\begin{array}{c}\% \\
\text { (valor } \\
\text { cumulativo) }\end{array}$ \\
\hline 0,04 & 0,06 \\
\hline 0,07 & 0,06 \\
\hline 0,1 & 0,06 \\
\hline 0,2 & 0,14 \\
\hline 0,3 & 0,27 \\
\hline 0,4 & 0,33 \\
\hline 0,5 & 0,33 \\
\hline 0,6 & 0,33 \\
\hline 0,7 & 0,33 \\
\hline 0,8 & 0,34 \\
\hline 0,9 & 0,36 \\
\hline 1 & 0,39 \\
\hline 1,1 & 0,42 \\
\hline 1,2 & 0,46 \\
\hline 1,3 & 0,5 \\
\hline 1,4 & 0,54 \\
\hline 1,6 & 0,63 \\
\hline 1,8 & 0,74 \\
\hline 2 & 0,85 \\
\hline 2,2 & 0,97 \\
\hline 2,4 & 1,09 \\
\hline 2,6 & 1,21 \\
\hline 3 & 1,46 \\
\hline 4 & 2,07 \\
\hline 5 & 2,64 \\
\hline 6 & 3,17 \\
\hline 6,5 & 3,42 \\
\hline 7 & 3,68 \\
\hline 7,5 & 3,93 \\
\hline 8 & 4,18 \\
\hline 8,5 & 4,44 \\
\hline 9 & 4,7 \\
\hline 10 & 5,21 \\
\hline 11 & 5,72 \\
\hline 12 & 6,22 \\
\hline 13 & 6,71 \\
\hline 14 & 7,19 \\
\hline 15 & 7,66 \\
\hline 16 & 8,11 \\
\hline 17 & 8,54 \\
\hline
\end{tabular}

\begin{tabular}{|c|c|}
\hline $\begin{array}{l}\text { Diâmetro } \\
\qquad(\mu \mathrm{m})\end{array}$ & $\begin{array}{c}\% \\
\text { (valor } \\
\text { cumulativo) }\end{array}$ \\
\hline 18 & 8,96 \\
\hline 19 & 9,36 \\
\hline 20 & 9,74 \\
\hline 22 & 10,43 \\
\hline 25 & 11,31 \\
\hline 28 & 11,99 \\
\hline 32 & 12,61 \\
\hline 36 & 12,99 \\
\hline 38 & 13,12 \\
\hline 40 & 13,22 \\
\hline 45 & 13,42 \\
\hline 50 & 13,62 \\
\hline 53 & 13,76 \\
\hline 56 & 13,94 \\
\hline 63 & 14,5 \\
\hline 71 & 15,33 \\
\hline 75 & 15,8 \\
\hline 80 & 16,39 \\
\hline 85 & 16,95 \\
\hline 90 & 17,46 \\
\hline 95 & 17,9 \\
\hline 100 & 18,25 \\
\hline 106 & 18,56 \\
\hline 112 & 18,7 \\
\hline 125 & 18,7 \\
\hline 130 & 18,7 \\
\hline 140 & 18,7 \\
\hline 145 & 18,7 \\
\hline 150 & 18,7 \\
\hline 160 & 18,7 \\
\hline 170 & 18,7 \\
\hline 180 & 18,7 \\
\hline 190 & 18,7 \\
\hline 200 & 18,7 \\
\hline 212 & 18,7 \\
\hline 242 & 18,7 \\
\hline 250 & 18,7 \\
\hline 300 & 18,7 \\
\hline 400 & 21,4 \\
\hline 500 & 36,63 \\
\hline
\end{tabular}

\begin{tabular}{|c|c|}
\hline $\begin{array}{c}\text { Diâmetro } \\
(\boldsymbol{\mu m})\end{array}$ & $\begin{array}{c}\text { \% } \\
\text { (valor } \\
\text { cumulativo })\end{array}$ \\
\hline 600 & 54,16 \\
\hline 700 & 69,86 \\
\hline 800 & 81,76 \\
\hline 900 & 89,26 \\
\hline 1000 & 93,82 \\
\hline 1100 & 96,57 \\
\hline 1200 & 98,19 \\
\hline 1300 & 99,07 \\
\hline 1400 & 99,58 \\
\hline 1500 & 99,86 \\
\hline 1600 & 100 \\
\hline 1700 & 100 \\
\hline 1800 & 100 \\
\hline 1900 & 100 \\
\hline 2000 & 100 \\
\hline
\end{tabular}

\begin{tabular}{|c|cc|}
\hline \multicolumn{3}{|c|}{ amostra original } \\
\hline argila & $\mathbf{0 , 8 5}$ & $\%$ \\
\hline silte & $\mathbf{1 3 , 6 5}$ & $\%$ \\
\hline areia/cascalho & $\mathbf{8 5 , 5 0}$ & $\%$ \\
\hline
\end{tabular}


Tabela 17: Determinação granulométrica, SP-105.

\begin{tabular}{|c|c|}
\hline $\begin{array}{l}\text { Diâmetro } \\
\qquad(\mu \mathrm{m})\end{array}$ & $\begin{array}{c}\% \\
\text { (valor } \\
\text { cumulativo) }\end{array}$ \\
\hline 0,04 & 0,22 \\
\hline 0,07 & 0,24 \\
\hline 0,1 & 0,29 \\
\hline 0,2 & 0,87 \\
\hline 0,3 & 1,62 \\
\hline 0,4 & 1,98 \\
\hline 0,5 & 1,98 \\
\hline 0,6 & 1,98 \\
\hline 0,7 & 1,98 \\
\hline 0,8 & 1,99 \\
\hline 0,9 & 2,03 \\
\hline 1 & 2,1 \\
\hline 1,1 & 2,2 \\
\hline 1,2 & 2,32 \\
\hline 1,3 & 2,46 \\
\hline 1,4 & 2,63 \\
\hline 1,6 & 3,03 \\
\hline 1,8 & 3,5 \\
\hline 2 & 4,02 \\
\hline 2,2 & 4,58 \\
\hline 2,4 & 5,16 \\
\hline 2,6 & 5,75 \\
\hline 3 & 6,94 \\
\hline 4 & 9,77 \\
\hline 5 & 12,24 \\
\hline 6 & 14,45 \\
\hline 6,5 & 15,48 \\
\hline 7 & 16,49 \\
\hline 7,5 & 17,49 \\
\hline 8 & 18,47 \\
\hline 8,5 & 19,46 \\
\hline 9 & 20,44 \\
\hline 10 & 22,35 \\
\hline 11 & 24,2 \\
\hline 12 & 25,97 \\
\hline 13 & 27,65 \\
\hline 14 & 29,23 \\
\hline 15 & 30,71 \\
\hline 16 & 32,09 \\
\hline 17 & 33,37 \\
\hline
\end{tabular}

\begin{tabular}{|c|c|}
\hline $\begin{array}{c}\text { Diâmetro } \\
(\mu \mathrm{m})\end{array}$ & $\begin{array}{c}\% \\
\text { (valor } \\
\text { cumulativo) }\end{array}$ \\
\hline 18 & 34,57 \\
\hline 19 & 35,69 \\
\hline 20 & 36,73 \\
\hline 22 & 38,61 \\
\hline 25 & 40,99 \\
\hline 28 & 42,9 \\
\hline 32 & 44,77 \\
\hline 36 & 46 \\
\hline 38 & 46,42 \\
\hline 40 & 46,73 \\
\hline 45 & 47,15 \\
\hline 50 & 47,15 \\
\hline 53 & 47,15 \\
\hline 56 & 47,15 \\
\hline 63 & 47,15 \\
\hline 71 & 47,15 \\
\hline 75 & 47,15 \\
\hline 80 & 47,15 \\
\hline 85 & 47,15 \\
\hline 90 & 47,15 \\
\hline 95 & 47,15 \\
\hline 100 & 47,15 \\
\hline 106 & 47,15 \\
\hline 112 & 47,15 \\
\hline 125 & 47,15 \\
\hline 130 & 47,15 \\
\hline 140 & 47,15 \\
\hline 145 & 47,15 \\
\hline 150 & 47,15 \\
\hline 160 & 47,15 \\
\hline 170 & 47,15 \\
\hline 180 & 47,15 \\
\hline 190 & 47,15 \\
\hline 200 & 47,15 \\
\hline 212 & 47,15 \\
\hline 242 & 47,15 \\
\hline 250 & 47,15 \\
\hline 300 & 47,15 \\
\hline 400 & 47,15 \\
\hline 500 & 47,15 \\
\hline
\end{tabular}

\begin{tabular}{|c|c|}
\hline $\begin{array}{c}\text { Diâmetro } \\
(\boldsymbol{\mu m})\end{array}$ & $\begin{array}{c}\text { \% } \\
\text { (valor } \\
\text { cumulativo) }\end{array}$ \\
\hline 600 & 51,62 \\
\hline 700 & 59,01 \\
\hline 800 & 67,66 \\
\hline 900 & 75,9 \\
\hline 1000 & 82,66 \\
\hline 1100 & 87,76 \\
\hline 1200 & 91,53 \\
\hline 1300 & 94,23 \\
\hline 1400 & 96,21 \\
\hline 1500 & 97,66 \\
\hline 1600 & 98,71 \\
\hline 1700 & 99,22 \\
\hline 1800 & 99,57 \\
\hline 1900 & 99,81 \\
\hline 2000 & 99,95 \\
\hline 2100 & 100 \\
\hline
\end{tabular}

SP - 105
\begin{tabular}{|c|cc|}
\hline \multicolumn{3}{|c|}{ amostra original } \\
\hline argila & $\mathbf{4 , 0 2}$ & $\%$ \\
\hline silte & $\mathbf{4 3 , 1 3}$ & $\%$ \\
\hline areia/cascalho & $\mathbf{5 2 , 8 5}$ & $\%$ \\
\hline
\end{tabular}


Tabela 18: Determinação granulométrica, SP-106.

\begin{tabular}{|c|c|}
\hline $\begin{array}{c}\text { Diâmetro } \\
(\mu \mathrm{m})\end{array}$ & $\begin{array}{c}\% \\
\text { (valor cumulativo) }\end{array}$ \\
\hline 0,04 & 0,42 \\
\hline 0,07 & 0,49 \\
\hline 0,1 & 0,62 \\
\hline 0,2 & 1,79 \\
\hline 0,3 & 3,27 \\
\hline 0,4 & 3,99 \\
\hline 0,5 & 3,99 \\
\hline 0,6 & 3,99 \\
\hline 0,7 & 3,99 \\
\hline 0,8 & 4,01 \\
\hline 0,9 & 4,07 \\
\hline 1 & 4,18 \\
\hline 1,1 & 4,35 \\
\hline 1,2 & 4,57 \\
\hline 1,3 & 4,84 \\
\hline 1,4 & 5,14 \\
\hline 1,6 & 5,88 \\
\hline 1,8 & 6,76 \\
\hline 2 & 7,73 \\
\hline 2,2 & 8,78 \\
\hline 2,4 & 9,87 \\
\hline 2,6 & 10,99 \\
\hline 3 & 13,26 \\
\hline 4 & 18,66 \\
\hline 5 & 23,43 \\
\hline 6 & 27,73 \\
\hline 6,5 & 29,76 \\
\hline 7 & 31,75 \\
\hline 7,5 & 33,72 \\
\hline 8 & 35,68 \\
\hline 8,5 & 37,65 \\
\hline 9 & 39,61 \\
\hline 10 & 43,5 \\
\hline 11 & 47,32 \\
\hline 12 & 51,03 \\
\hline 13 & 54,61 \\
\hline 14 & 58,06 \\
\hline 15 & 61,36 \\
\hline 16 & 64,5 \\
\hline 17 & 67,5 \\
\hline
\end{tabular}

\begin{tabular}{|c|c|}
\hline $\begin{array}{l}\text { Diâmetro } \\
(\mu \mathrm{m})\end{array}$ & $\begin{array}{c}\% \\
\text { (valor cumulativo) }\end{array}$ \\
\hline 18 & 70,36 \\
\hline 19 & 73,11 \\
\hline 20 & 75,7 \\
\hline 22 & 80,41 \\
\hline 25 & 86,18 \\
\hline 28 & 90,57 \\
\hline 32 & 94,68 \\
\hline 36 & 97,26 \\
\hline 38 & 98,08 \\
\hline 40 & 98,69 \\
\hline 45 & 99,56 \\
\hline 50 & 99,88 \\
\hline 53 & 99,96 \\
\hline 56 & 100 \\
\hline 63 & 100 \\
\hline 71 & 100 \\
\hline 75 & 100 \\
\hline 80 & 100 \\
\hline 85 & 100 \\
\hline 90 & 100 \\
\hline 95 & 100 \\
\hline 100 & 100 \\
\hline 106 & 100 \\
\hline 112 & 100 \\
\hline 125 & 100 \\
\hline 130 & 100 \\
\hline 140 & 100 \\
\hline 145 & 100 \\
\hline 150 & 100 \\
\hline 160 & 100 \\
\hline 170 & 100 \\
\hline 180 & 100 \\
\hline 190 & 100 \\
\hline 200 & 100 \\
\hline 212 & 100 \\
\hline 242 & 100 \\
\hline 250 & 100 \\
\hline 300 & 100 \\
\hline 400 & 100 \\
\hline 500 & 100 \\
\hline
\end{tabular}

SP - 106

\begin{tabular}{|c|cc|}
\hline \multicolumn{3}{|c|}{ amostra original } \\
\hline argila & $\mathbf{7 , 7 3}$ & $\%$ \\
\hline silte & $\mathbf{9 2 , 2 7}$ & $\%$ \\
\hline areia/cascalho & --- & $\%$ \\
\hline
\end{tabular}


Tabela 19: Determinação granulométrica, SP-107.

\begin{tabular}{|c|c|}
\hline $\begin{array}{l}\text { Diâmetro } \\
(\mu \mathrm{m})\end{array}$ & $\begin{array}{c}\% \\
\text { (valor cumulativo) }\end{array}$ \\
\hline 0,04 & 0,34 \\
\hline 0,07 & 0,39 \\
\hline 0,1 & 0,49 \\
\hline 0,2 & 1,42 \\
\hline 0,3 & 2,61 \\
\hline 0,4 & 3,19 \\
\hline 0,5 & 3,19 \\
\hline 0,6 & 3,19 \\
\hline 0,7 & 3,19 \\
\hline 0,8 & 3,19 \\
\hline 0,9 & 3,23 \\
\hline 1 & 3,31 \\
\hline 1,1 & 3,43 \\
\hline 1,2 & 3,59 \\
\hline 1,3 & 3,79 \\
\hline 1,4 & 4,02 \\
\hline 1,6 & 4,59 \\
\hline 1,8 & 5,28 \\
\hline 2 & 6,06 \\
\hline 2,2 & 6,9 \\
\hline 2,4 & 7,8 \\
\hline 2,6 & 8,73 \\
\hline 3 & 10,65 \\
\hline 4 & 15,44 \\
\hline 5 & 19,83 \\
\hline 6 & 23,88 \\
\hline 6,5 & 25,81 \\
\hline 7 & 27,74 \\
\hline 7,5 & 29,67 \\
\hline 8 & 31,63 \\
\hline 8,5 & 33,64 \\
\hline 9 & 35,67 \\
\hline 10 & 39,77 \\
\hline 11 & 43,87 \\
\hline 12 & 47,87 \\
\hline 13 & 51,74 \\
\hline 14 & 55,41 \\
\hline 15 & 58,85 \\
\hline 16 & 62,03 \\
\hline 17 & 64,95 \\
\hline
\end{tabular}

\begin{tabular}{|c|c|}
\hline $\begin{array}{c}\text { Diâmetro } \\
(\mu \mathrm{m})\end{array}$ & $\begin{array}{c}\% \\
\text { (valor cumulativo) }\end{array}$ \\
\hline 18 & 67,62 \\
\hline 19 & 70,05 \\
\hline 20 & 72,24 \\
\hline 22 & 75,98 \\
\hline 25 & 80,17 \\
\hline 28 & 83,09 \\
\hline 32 & 85,67 \\
\hline 36 & 87,28 \\
\hline 38 & 87,84 \\
\hline 40 & 88,3 \\
\hline 45 & 89,18 \\
\hline 50 & 89,93 \\
\hline 53 & 90,35 \\
\hline 56 & 90,76 \\
\hline 63 & 91,69 \\
\hline 71 & 92,79 \\
\hline 75 & 93,37 \\
\hline 80 & 94,09 \\
\hline 85 & 94,8 \\
\hline 90 & 95,49 \\
\hline 95 & 96,13 \\
\hline 100 & 96,74 \\
\hline 106 & 97,38 \\
\hline 112 & 97,94 \\
\hline 125 & 98,86 \\
\hline 130 & 99,12 \\
\hline 140 & 99,51 \\
\hline 145 & 99,64 \\
\hline 150 & 99,74 \\
\hline 160 & 99,88 \\
\hline 170 & 99,96 \\
\hline 180 & 100 \\
\hline 190 & 100 \\
\hline 200 & 100 \\
\hline 212 & 100 \\
\hline 242 & 100 \\
\hline 250 & 100 \\
\hline 300 & 100 \\
\hline 400 & 100 \\
\hline 500 & 100 \\
\hline
\end{tabular}

SP-107

\begin{tabular}{|c|cc|}
\hline \multicolumn{3}{|c|}{ amostra original } \\
\hline argila & $\mathbf{6 , 0 6}$ & $\%$ \\
\hline silte & $\mathbf{8 5 , 6 3}$ & $\%$ \\
\hline areia/cascalho & $\mathbf{8 , 3 1}$ & $\%$ \\
\hline
\end{tabular}


Tabela 20: Determinação granulométrica, SP-108.

\begin{tabular}{|c|c|}
\hline $\begin{array}{c}\text { Diâmetro } \\
(\mu \mathrm{m})\end{array}$ & $\begin{array}{c}\% \\
\text { (valor cumulativo) }\end{array}$ \\
\hline 0,04 & 0,48 \\
\hline 0,07 & 0,56 \\
\hline 0,1 & 0,72 \\
\hline 0,2 & 2,06 \\
\hline 0,3 & 3,75 \\
\hline 0,4 & 4,59 \\
\hline 0,5 & 4,59 \\
\hline 0,6 & 4,59 \\
\hline 0,7 & 4,59 \\
\hline 0,8 & 4,59 \\
\hline 0,9 & 4,64 \\
\hline 1 & 4,74 \\
\hline 1,1 & 4,91 \\
\hline 1,2 & 5,15 \\
\hline 1,3 & 5,44 \\
\hline 1,4 & 5,78 \\
\hline 1,6 & 6,62 \\
\hline 1,8 & 7,63 \\
\hline 2 & 8,77 \\
\hline 2,2 & 10 \\
\hline 2,4 & 11,31 \\
\hline 2,6 & 12,66 \\
\hline 3 & 15,42 \\
\hline 4 & 22,15 \\
\hline 5 & 28,12 \\
\hline 6 & 33,48 \\
\hline 6,5 & 36 \\
\hline 7 & 38,47 \\
\hline 7,5 & 40,93 \\
\hline 8 & 43,4 \\
\hline 8,5 & 45,89 \\
\hline 9 & 48,38 \\
\hline 10 & 53,27 \\
\hline 11 & 57,97 \\
\hline 12 & 62,39 \\
\hline 13 & 66,49 \\
\hline 14 & 70,22 \\
\hline 15 & 73,57 \\
\hline 16 & 76,52 \\
\hline 17 & 79,11 \\
\hline
\end{tabular}

\begin{tabular}{|c|c|}
\hline $\begin{array}{l}\text { Diâmetro } \\
(\mu \mathrm{m})\end{array}$ & $\begin{array}{c}\% \\
\text { (valor cumulativo) }\end{array}$ \\
\hline 18 & 81,37 \\
\hline 19 & 83,31 \\
\hline 20 & 85 \\
\hline 22 & 87,77 \\
\hline 25 & 90,81 \\
\hline 28 & 92,99 \\
\hline 32 & 95,03 \\
\hline 36 & 96,48 \\
\hline 38 & 97,06 \\
\hline 40 & 97,57 \\
\hline 45 & 98,55 \\
\hline 50 & 99,21 \\
\hline 53 & 99,48 \\
\hline 56 & 99,68 \\
\hline 63 & 99,92 \\
\hline 71 & 100 \\
\hline 75 & 100 \\
\hline 80 & 100 \\
\hline 85 & 100 \\
\hline 90 & 100 \\
\hline 95 & 100 \\
\hline 100 & 100 \\
\hline 106 & 100 \\
\hline 112 & 100 \\
\hline 125 & 100 \\
\hline 130 & 100 \\
\hline 140 & 100 \\
\hline 145 & 100 \\
\hline 150 & 100 \\
\hline 160 & 100 \\
\hline 170 & 100 \\
\hline 180 & 100 \\
\hline 190 & 100 \\
\hline 200 & 100 \\
\hline 212 & 100 \\
\hline 242 & 100 \\
\hline 250 & 100 \\
\hline 300 & 100 \\
\hline 400 & 100 \\
\hline 500 & 100 \\
\hline
\end{tabular}

SP - 108

\begin{tabular}{|c|cc|}
\hline \multicolumn{3}{|c|}{ amostra original } \\
\hline argila & $\mathbf{8 , 7 7}$ & $\%$ \\
\hline silte & $\mathbf{9 1 , 1 5}$ & $\%$ \\
\hline areia/cascalho & $\mathbf{0 , 0 8}$ & $\%$ \\
\hline
\end{tabular}


Tabela 21: Determinação granulométrica, SP-109.

\begin{tabular}{|c|c|}
\hline $\begin{array}{c}\text { Diâmetro } \\
(\mu \mathrm{m})\end{array}$ & $\begin{array}{c}\% \\
\text { (valor cumulativo) }\end{array}$ \\
\hline 0,04 & 0,42 \\
\hline 0,07 & 0,5 \\
\hline 0,1 & 0,62 \\
\hline 0,2 & 1,8 \\
\hline 0,3 & 3,28 \\
\hline 0,4 & 4,01 \\
\hline 0,5 & 4,01 \\
\hline 0,6 & 4,01 \\
\hline 0,7 & 4,01 \\
\hline 0,8 & 4,02 \\
\hline 0,9 & 4,09 \\
\hline 1 & 4,21 \\
\hline 1,1 & 4,4 \\
\hline 1,2 & 4,64 \\
\hline 1,3 & 4,93 \\
\hline 1,4 & 5,27 \\
\hline 1,6 & 6,09 \\
\hline 1,8 & 7,05 \\
\hline 2 & 8,13 \\
\hline 2,2 & 9,29 \\
\hline 2,4 & 10,5 \\
\hline 2,6 & 11,75 \\
\hline 3 & 14,28 \\
\hline 4 & 20,37 \\
\hline 5 & 25,73 \\
\hline 6 & 30,54 \\
\hline 6,5 & 32,79 \\
\hline 7 & 35 \\
\hline 7,5 & 37,17 \\
\hline 8 & 39,34 \\
\hline 8,5 & 41,51 \\
\hline 9 & 43,66 \\
\hline 10 & 47,91 \\
\hline 11 & 52,02 \\
\hline 12 & 55,96 \\
\hline 13 & 59,7 \\
\hline 14 & 63,23 \\
\hline 15 & 66,52 \\
\hline 16 & 69,57 \\
\hline 17 & 72,39 \\
\hline
\end{tabular}

\begin{tabular}{|c|c|}
\hline $\begin{array}{l}\text { Diâmetro } \\
(\mu \mathrm{m})\end{array}$ & $\begin{array}{c}\% \\
\text { (valor cumulativo) }\end{array}$ \\
\hline 18 & 75,01 \\
\hline 19 & 77,44 \\
\hline 20 & 79,68 \\
\hline 22 & 83,63 \\
\hline 25 & 88,35 \\
\hline 28 & 91,9 \\
\hline 32 & 95,25 \\
\hline 36 & 97,42 \\
\hline 38 & 98,15 \\
\hline 40 & 98,7 \\
\hline 45 & 99,54 \\
\hline 50 & 99,87 \\
\hline 53 & 99,96 \\
\hline 56 & 100 \\
\hline 63 & 100 \\
\hline 71 & 100 \\
\hline 75 & 100 \\
\hline 80 & 100 \\
\hline 85 & 100 \\
\hline 90 & 100 \\
\hline 95 & 100 \\
\hline 100 & 100 \\
\hline 106 & 100 \\
\hline 112 & 100 \\
\hline 125 & 100 \\
\hline 130 & 100 \\
\hline 140 & 100 \\
\hline 145 & 100 \\
\hline 150 & 100 \\
\hline 160 & 100 \\
\hline 170 & 100 \\
\hline 180 & 100 \\
\hline 190 & 100 \\
\hline 200 & 100 \\
\hline 212 & 100 \\
\hline 242 & 100 \\
\hline 250 & 100 \\
\hline 300 & 100 \\
\hline 400 & 100 \\
\hline 500 & 100 \\
\hline
\end{tabular}

SP - 109

\begin{tabular}{|c|cc|}
\hline \multicolumn{3}{|c|}{ amostra original } \\
\hline argila & $\mathbf{8 , 1 3}$ & $\%$ \\
\hline silte & $\mathbf{9 1 , 8 7}$ & $\%$ \\
\hline areia/cascalho & --- & $\%$ \\
\hline
\end{tabular}


Tabela 22: Determinação granulométrica, SP-110.

\begin{tabular}{|c|c|}
\hline $\begin{array}{l}\text { Diâmetro } \\
(\mu \mathrm{m})\end{array}$ & $\begin{array}{c}\% \\
\text { (valor cumulativo) }\end{array}$ \\
\hline 0,04 & 0,44 \\
\hline 0,07 & 0,51 \\
\hline 0,1 & 0,65 \\
\hline 0,2 & 1,86 \\
\hline 0,3 & 3,4 \\
\hline 0,4 & 4,15 \\
\hline 0,5 & 4,15 \\
\hline 0,6 & 4,15 \\
\hline 0,7 & 4,15 \\
\hline 0,8 & 4,16 \\
\hline 0,9 & 4,22 \\
\hline 1 & 4,33 \\
\hline 1,1 & 4,5 \\
\hline 1,2 & 4,72 \\
\hline 1,3 & 4,99 \\
\hline 1,4 & 5,3 \\
\hline 1,6 & 6,05 \\
\hline 1,8 & 6,94 \\
\hline 2 & 7,93 \\
\hline 2,2 & 8,99 \\
\hline 2,4 & 10,11 \\
\hline 2,6 & 11,26 \\
\hline 3 & 13,58 \\
\hline 4 & 19,17 \\
\hline 5 & 24,08 \\
\hline 6 & 28,49 \\
\hline 6,5 & 30,55 \\
\hline 7 & 32,57 \\
\hline 7,5 & 34,56 \\
\hline 8 & 36,56 \\
\hline 8,5 & 38,56 \\
\hline 9 & 40,56 \\
\hline 10 & 44,53 \\
\hline 11 & 48,42 \\
\hline 12 & 52,19 \\
\hline 13 & 55,82 \\
\hline 14 & 59,29 \\
\hline 15 & 62,57 \\
\hline 16 & 65,67 \\
\hline 17 & 68,6 \\
\hline
\end{tabular}

\begin{tabular}{|c|c|}
\hline $\begin{array}{l}\text { Diâmetro } \\
(\mu \mathrm{m})\end{array}$ & $\begin{array}{c}\% \\
\text { (valor cumulativo) }\end{array}$ \\
\hline 18 & 71,36 \\
\hline 19 & 73,98 \\
\hline 20 & 76,43 \\
\hline 22 & 80,85 \\
\hline 25 & 86,27 \\
\hline 28 & 90,43 \\
\hline 32 & 94,41 \\
\hline 36 & 96,99 \\
\hline 38 & 97,85 \\
\hline 40 & 98,5 \\
\hline 45 & 99,47 \\
\hline 50 & 99,85 \\
\hline 53 & 99,95 \\
\hline 56 & 100 \\
\hline 63 & 100 \\
\hline 71 & 100 \\
\hline 75 & 100 \\
\hline 80 & 100 \\
\hline 85 & 100 \\
\hline 90 & 100 \\
\hline 95 & 100 \\
\hline 100 & 100 \\
\hline 106 & 100 \\
\hline 112 & 100 \\
\hline 125 & 100 \\
\hline 130 & 100 \\
\hline 140 & 100 \\
\hline 145 & 100 \\
\hline 150 & 100 \\
\hline 160 & 100 \\
\hline 170 & 100 \\
\hline 180 & 100 \\
\hline 190 & 100 \\
\hline 200 & 100 \\
\hline 212 & 100 \\
\hline 242 & 100 \\
\hline 250 & 100 \\
\hline 300 & 100 \\
\hline 400 & 100 \\
\hline 500 & 100 \\
\hline
\end{tabular}

SP - 110

\begin{tabular}{|c|cc|}
\hline \multicolumn{3}{|c|}{ amostra original } \\
\hline argila & $\mathbf{7 , 9 3}$ & $\%$ \\
\hline silte & $\mathbf{9 2 , 0 7}$ & $\%$ \\
\hline areia/cascalho & --- & $\%$ \\
\hline
\end{tabular}


Tabela 23: Determinação granulométrica, SP-111.

\begin{tabular}{|c|c|}
\hline $\begin{array}{l}\text { Diâmetro } \\
(\mu \mathrm{m})\end{array}$ & $\begin{array}{c}\% \\
\text { (valor cumulativo) }\end{array}$ \\
\hline 0,04 & 0,3 \\
\hline 0,07 & 0,33 \\
\hline 0,1 & 0,4 \\
\hline 0,2 & 1,17 \\
\hline 0,3 & 2,17 \\
\hline 0,4 & 2,65 \\
\hline 0,5 & 2,65 \\
\hline 0,6 & 2,65 \\
\hline 0,7 & 2,65 \\
\hline 0,8 & 2,69 \\
\hline 0,9 & 2,78 \\
\hline 1 & 2,9 \\
\hline 1,1 & 3,06 \\
\hline 1,2 & 3,26 \\
\hline 1,3 & 3,48 \\
\hline 1,4 & 3,73 \\
\hline 1,6 & 4,32 \\
\hline 1,8 & 4,99 \\
\hline 2 & 5,72 \\
\hline 2,2 & 6,5 \\
\hline 2,4 & 7,3 \\
\hline 2,6 & 8,11 \\
\hline 3 & 9,74 \\
\hline 4 & 13,55 \\
\hline 5 & 16,81 \\
\hline 6 & 19,7 \\
\hline 6,5 & 21,05 \\
\hline 7 & 22,38 \\
\hline 7,5 & 23,72 \\
\hline 8 & 25,08 \\
\hline 8,5 & 26,47 \\
\hline 9 & 27,87 \\
\hline 10 & 30,73 \\
\hline 11 & 33,59 \\
\hline 12 & 36,42 \\
\hline 13 & 39,19 \\
\hline 14 & 41,86 \\
\hline 15 & 44,4 \\
\hline 16 & 46,8 \\
\hline 17 & 49,07 \\
\hline
\end{tabular}

\begin{tabular}{|c|c|}
\hline $\begin{array}{l}\text { Diâmetro } \\
(\mu \mathrm{m})\end{array}$ & $\begin{array}{c}\% \\
\text { (valor cumulativo) }\end{array}$ \\
\hline 18 & 51,21 \\
\hline 19 & 53,22 \\
\hline 20 & 55,11 \\
\hline 22 & 58,58 \\
\hline 25 & 63,09 \\
\hline 28 & 67 \\
\hline 32 & 71,62 \\
\hline 36 & 75,79 \\
\hline 38 & 77,76 \\
\hline 40 & 79,65 \\
\hline 45 & 83,98 \\
\hline 50 & 87,71 \\
\hline 53 & 89,65 \\
\hline 56 & 91,37 \\
\hline 63 & 94,62 \\
\hline 71 & 97,12 \\
\hline 75 & 97,95 \\
\hline 80 & 98,71 \\
\hline 85 & 99,23 \\
\hline 90 & 99,58 \\
\hline 95 & 99,78 \\
\hline 100 & 99,9 \\
\hline 106 & 99,97 \\
\hline 112 & 100 \\
\hline 125 & 100 \\
\hline 130 & 100 \\
\hline 140 & 100 \\
\hline 145 & 100 \\
\hline 150 & 100 \\
\hline 160 & 100 \\
\hline 170 & 100 \\
\hline 180 & 100 \\
\hline 190 & 100 \\
\hline 200 & 100 \\
\hline 212 & 100 \\
\hline 242 & 100 \\
\hline 250 & 100 \\
\hline 300 & 100 \\
\hline 400 & 100 \\
\hline 500 & 100 \\
\hline
\end{tabular}

SP - 111

\begin{tabular}{|c|cc|}
\hline \multicolumn{3}{|c|}{ amostra original } \\
\hline argila & $\mathbf{5 , 7 2}$ & $\%$ \\
\hline silte & $\mathbf{8 8 , 9 0}$ & $\%$ \\
\hline areia/cascalho & $\mathbf{5 , 3 8}$ & $\%$ \\
\hline
\end{tabular}


Tabela 24: Determinação granulométrica, SP-112.

\begin{tabular}{|c|c|}
\hline $\begin{array}{l}\text { Diâmetro } \\
(\mu \mathrm{m})\end{array}$ & $\begin{array}{c}\% \\
\text { (valor cumulativo) }\end{array}$ \\
\hline 0,04 & 0,46 \\
\hline 0,07 & 0,53 \\
\hline 0,1 & 0,67 \\
\hline 0,2 & 1,95 \\
\hline 0,3 & 3,55 \\
\hline 0,4 & 4,35 \\
\hline 0,5 & 4,35 \\
\hline 0,6 & 4,35 \\
\hline 0,7 & 4,35 \\
\hline 0,8 & 4,35 \\
\hline 0,9 & 4,4 \\
\hline 1 & 4,5 \\
\hline 1,1 & 4,67 \\
\hline 1,2 & 4,9 \\
\hline 1,3 & 5,19 \\
\hline 1,4 & 5,53 \\
\hline 1,6 & 6,36 \\
\hline 1,8 & 7,36 \\
\hline 2 & 8,49 \\
\hline 2,2 & 9,72 \\
\hline 2,4 & 11,01 \\
\hline 2,6 & 12,35 \\
\hline 3 & 15,11 \\
\hline 4 & 21,89 \\
\hline 5 & 27,95 \\
\hline 6 & 33,41 \\
\hline 6,5 & 35,97 \\
\hline 7 & 38,47 \\
\hline 7,5 & 40,93 \\
\hline 8 & 43,38 \\
\hline 8,5 & 45,83 \\
\hline 9 & 48,25 \\
\hline 10 & 52,97 \\
\hline 11 & 57,44 \\
\hline 12 & 61,63 \\
\hline 13 & 65,49 \\
\hline 14 & 69,01 \\
\hline 15 & 72,18 \\
\hline 16 & 75 \\
\hline 17 & 77,5 \\
\hline
\end{tabular}

\begin{tabular}{|c|c|}
\hline $\begin{array}{l}\text { Diâmetro } \\
(\mu \mathrm{m})\end{array}$ & $\begin{array}{c}\% \\
\text { (valor cumulativo) }\end{array}$ \\
\hline 18 & 79,71 \\
\hline 19 & 81,65 \\
\hline 20 & 83,36 \\
\hline 22 & 86,19 \\
\hline 25 & 89,36 \\
\hline 28 & 91,62 \\
\hline 32 & 93,72 \\
\hline 36 & 95,17 \\
\hline 38 & 95,74 \\
\hline 40 & 96,24 \\
\hline 45 & 97,26 \\
\hline 50 & 98,05 \\
\hline 53 & 98,44 \\
\hline 56 & 98,77 \\
\hline 63 & 99,35 \\
\hline 71 & 99,74 \\
\hline 75 & 99,85 \\
\hline 80 & 99,93 \\
\hline 85 & 99,98 \\
\hline 90 & 100 \\
\hline 95 & 100 \\
\hline 100 & 100 \\
\hline 106 & 100 \\
\hline 112 & 100 \\
\hline 125 & 100 \\
\hline 130 & 100 \\
\hline 140 & 100 \\
\hline 145 & 100 \\
\hline 150 & 100 \\
\hline 160 & 100 \\
\hline 170 & 100 \\
\hline 180 & 100 \\
\hline 190 & 100 \\
\hline 200 & 100 \\
\hline 212 & 100 \\
\hline 242 & 100 \\
\hline 250 & 100 \\
\hline 300 & 100 \\
\hline 400 & 100 \\
\hline 500 & 100 \\
\hline
\end{tabular}

SP - 112

\begin{tabular}{|c|cc|}
\hline \multicolumn{3}{|c|}{ amostra original } \\
\hline argila & $\mathbf{8 , 4 9}$ & $\%$ \\
\hline silte & $\mathbf{9 0 , 8 6}$ & $\%$ \\
\hline areia/cascalho & $\mathbf{0 , 6 5}$ & $\%$ \\
\hline
\end{tabular}


Tabela 25: Determinação granulométrica, SP-113.

\begin{tabular}{|c|c|}
\hline $\begin{array}{c}\text { Diâmetro } \\
(\mu \mathrm{m})\end{array}$ & $\begin{array}{c}\% \\
\text { (valor cumulativo) }\end{array}$ \\
\hline 0,04 & 0,46 \\
\hline 0,07 & 0,55 \\
\hline 0,1 & 0,69 \\
\hline 0,2 & 1,99 \\
\hline 0,3 & 3,62 \\
\hline 0,4 & 4,42 \\
\hline 0,5 & 4,42 \\
\hline 0,6 & 4,42 \\
\hline 0,7 & 4,42 \\
\hline 0,8 & 4,43 \\
\hline 0,9 & 4,49 \\
\hline 1 & 4,6 \\
\hline 1,1 & 4,79 \\
\hline 1,2 & 5,04 \\
\hline 1,3 & 5,34 \\
\hline 1,4 & 5,7 \\
\hline 1,6 & 6,57 \\
\hline 1,8 & 7,61 \\
\hline 2 & 8,77 \\
\hline 2,2 & 10,04 \\
\hline 2,4 & 11,37 \\
\hline 2,6 & 12,75 \\
\hline 3 & 15,55 \\
\hline 4 & 22,37 \\
\hline 5 & 28,42 \\
\hline 6 & 33,86 \\
\hline 6,5 & 36,4 \\
\hline 7 & 38,88 \\
\hline 7,5 & 41,33 \\
\hline 8 & 43,75 \\
\hline 8,5 & 46,17 \\
\hline 9 & 48,56 \\
\hline 10 & 53,21 \\
\hline 11 & 57,64 \\
\hline 12 & 61,79 \\
\hline 13 & 65,64 \\
\hline 14 & 69,15 \\
\hline 15 & 72,34 \\
\hline 16 & 75,19 \\
\hline 17 & 77,75 \\
\hline
\end{tabular}

\begin{tabular}{|c|c|}
\hline $\begin{array}{l}\text { Diâmetro } \\
(\mu \mathrm{m})\end{array}$ & $\begin{array}{c}\% \\
\text { (valor cumulativo) }\end{array}$ \\
\hline 18 & 80,03 \\
\hline 19 & 82,07 \\
\hline 20 & 83,89 \\
\hline 22 & 87,01 \\
\hline 25 & 90,67 \\
\hline 28 & 93,42 \\
\hline 32 & 96,05 \\
\hline 36 & 97,77 \\
\hline 38 & 98,38 \\
\hline 40 & 98,85 \\
\hline 45 & 99,58 \\
\hline 50 & 99,88 \\
\hline 53 & 99,96 \\
\hline 56 & 100 \\
\hline 63 & 100 \\
\hline 71 & 100 \\
\hline 75 & 100 \\
\hline 80 & 100 \\
\hline 85 & 100 \\
\hline 90 & 100 \\
\hline 95 & 100 \\
\hline 100 & 100 \\
\hline 106 & 100 \\
\hline 112 & 100 \\
\hline 125 & 100 \\
\hline 130 & 100 \\
\hline 140 & 100 \\
\hline 145 & 100 \\
\hline 150 & 100 \\
\hline 160 & 100 \\
\hline 170 & 100 \\
\hline 180 & 100 \\
\hline 190 & 100 \\
\hline 200 & 100 \\
\hline 212 & 100 \\
\hline 242 & 100 \\
\hline 250 & 100 \\
\hline 300 & 100 \\
\hline 400 & 100 \\
\hline 500 & 100 \\
\hline
\end{tabular}

SP - 113

\begin{tabular}{|c|cc|}
\hline \multicolumn{2}{|c|}{ amostra original } \\
\hline argila & $\mathbf{8 , 7 7}$ & $\%$ \\
\hline silte & $\mathbf{9 1 , 2 3}$ & $\%$ \\
\hline areia/cascalho & --- & $\%$ \\
\hline
\end{tabular}


Tabela 26: Determinação granulométrica, SP-114.

\begin{tabular}{|c|c|}
\hline $\begin{array}{l}\text { Diâmetro } \\
(\mu \mathrm{m})\end{array}$ & $\begin{array}{c}\% \\
\text { (valor cumulativo) }\end{array}$ \\
\hline 0,04 & 0,33 \\
\hline 0,07 & 0,38 \\
\hline 0,1 & 0,47 \\
\hline 0,2 & 1,37 \\
\hline 0,3 & 2,51 \\
\hline 0,4 & 3,07 \\
\hline 0,5 & 3,07 \\
\hline 0,6 & 3,07 \\
\hline 0,7 & 3,07 \\
\hline 0,8 & 3,09 \\
\hline 0,9 & 3,17 \\
\hline 1 & 3,28 \\
\hline 1,1 & 3,45 \\
\hline 1,2 & 3,66 \\
\hline 1,3 & 3,91 \\
\hline 1,4 & 4,2 \\
\hline 1,6 & 4,88 \\
\hline 1,8 & 5,67 \\
\hline 2 & 6,54 \\
\hline 2,2 & 7,48 \\
\hline 2,4 & 8,45 \\
\hline 2,6 & 9,45 \\
\hline 3 & 11,46 \\
\hline 4 & 16,27 \\
\hline 5 & 20,54 \\
\hline 6 & 24,41 \\
\hline 6,5 & 26,24 \\
\hline 7 & 28,03 \\
\hline 7,5 & 29,78 \\
\hline 8 & 31,52 \\
\hline 8,5 & 33,24 \\
\hline 9 & 34,94 \\
\hline 10 & 38,27 \\
\hline 11 & 41,49 \\
\hline 12 & 44,59 \\
\hline 13 & 47,56 \\
\hline 14 & 50,42 \\
\hline 15 & 53,16 \\
\hline 16 & 55,79 \\
\hline 17 & 58,32 \\
\hline
\end{tabular}

\section{Diâmetro $(\mu \mathrm{m})$}

$\%$ (valor cumulativo)

\begin{tabular}{|c|c|}
\hline 18 & 60,75 \\
\hline 19 & 63,1 \\
\hline 20 & 65,36 \\
\hline 22 & 69,65 \\
\hline 25 & 75,56 \\
\hline
\end{tabular}

\begin{tabular}{|l|l|}
\hline 28 & 80,73 \\
\hline 32 & 86,28 \\
\hline 36 & 90,48 \\
\hline
\end{tabular}

\begin{tabular}{|l|l|}
\hline 36 & 90,48 \\
\hline 38 & 92,19 \\
\hline 40 & 93,66 \\
\hline 45 & 96,44 \\
\hline
\end{tabular}

\begin{tabular}{|l|l|}
\hline 45 & 96,44 \\
\hline 50 & 98,15 \\
\hline 53 & 98,81 \\
\hline 56 & 99,29 \\
\hline 63 & 99,82 \\
\hline
\end{tabular}

\begin{tabular}{|c|c|}
\hline 63 & 99,82 \\
\hline 71 & 100 \\
\hline 75 & 100 \\
\hline 80 & 100 \\
\hline
\end{tabular}

\begin{tabular}{|l|l|}
\hline 80 & 100 \\
\hline 85 & 100 \\
\hline 90 & 100 \\
\hline
\end{tabular}

\begin{tabular}{|c|c|}
\hline 90 & 100 \\
\hline 95 & 100 \\
\hline 100 & 100 \\
\hline 106 & 100 \\
\hline
\end{tabular}

P 1

\begin{tabular}{|l|l|}
\hline 112 & 100 \\
\hline 125 & 100 \\
\hline 130 & 100 \\
\hline 140 & 100 \\
\hline 145 & 100 \\
\hline 150 & 100 \\
\hline 160 & 100 \\
\hline 170 & 100 \\
\hline 180 & 100 \\
\hline 190 & 100 \\
\hline 200 & 100 \\
\hline 212 & 100 \\
\hline 242 & 100 \\
\hline 250 & 100 \\
\hline 300 & 100 \\
\hline 400 & 100 \\
\hline 500 & 100 \\
\hline
\end{tabular}

SP - 114

\begin{tabular}{|c|cc|}
\hline \multicolumn{3}{|c|}{ amostra original } \\
\hline argila & $\mathbf{6 , 5 4}$ & $\%$ \\
\hline silte & $\mathbf{9 3 , 2 8}$ & $\%$ \\
\hline areia/cascalho & $\mathbf{0 , 1 8}$ & $\%$ \\
\hline
\end{tabular}


Tabela 27: Determinação granulométrica, SP-115.

\begin{tabular}{|c|c|}
\hline $\begin{array}{l}\text { Diâmetro } \\
(\mu \mathrm{m})\end{array}$ & $\begin{array}{c}\% \\
\text { (valor cumulativo) }\end{array}$ \\
\hline 0,04 & 0,26 \\
\hline 0,07 & 0,29 \\
\hline 0,1 & 0,35 \\
\hline 0,2 & 1,04 \\
\hline 0,3 & 1,92 \\
\hline 0,4 & 2,35 \\
\hline 0,5 & 2,35 \\
\hline 0,6 & 2,35 \\
\hline 0,7 & 2,35 \\
\hline 0,8 & 2,38 \\
\hline 0,9 & 2,43 \\
\hline 1 & 2,53 \\
\hline 1,1 & 2,66 \\
\hline 1,2 & 2,82 \\
\hline 1,3 & 3,01 \\
\hline 1,4 & 3,23 \\
\hline 1,6 & 3,74 \\
\hline 1,8 & 4,34 \\
\hline 2 & 5 \\
\hline 2,2 & 5,71 \\
\hline 2,4 & 6,45 \\
\hline 2,6 & 7,21 \\
\hline 3 & 8,74 \\
\hline 4 & 12,44 \\
\hline 5 & 15,73 \\
\hline 6 & 18,73 \\
\hline 6,5 & 20,15 \\
\hline 7 & 21,54 \\
\hline 7,5 & 22,93 \\
\hline 8 & 24,33 \\
\hline 8,5 & 25,74 \\
\hline 9 & 27,16 \\
\hline 10 & 30,01 \\
\hline 11 & 32,85 \\
\hline 12 & 35,66 \\
\hline 13 & 38,41 \\
\hline 14 & 41,09 \\
\hline 15 & 43,67 \\
\hline 16 & 46,15 \\
\hline 17 & 48,53 \\
\hline
\end{tabular}

\begin{tabular}{|c|c|}
\hline $\begin{array}{l}\text { Diâmetro } \\
(\mu \mathrm{m})\end{array}$ & $\begin{array}{c}\% \\
\text { (valor cumulativo) }\end{array}$ \\
\hline 18 & 50,8 \\
\hline 19 & 52,97 \\
\hline 20 & 55,03 \\
\hline 22 & 58,86 \\
\hline 25 & 63,89 \\
\hline 28 & 68,15 \\
\hline 32 & 72,8 \\
\hline 36 & 76,5 \\
\hline 38 & 78,07 \\
\hline 40 & 79,5 \\
\hline 45 & 82,53 \\
\hline 50 & 84,98 \\
\hline 53 & 86,25 \\
\hline 56 & 87,4 \\
\hline 63 & 89,74 \\
\hline 71 & 91,92 \\
\hline 75 & 92,85 \\
\hline 80 & 93,88 \\
\hline 85 & 94,8 \\
\hline 90 & 95,6 \\
\hline 95 & 96,31 \\
\hline 100 & 96,94 \\
\hline 106 & 97,58 \\
\hline 112 & 98,11 \\
\hline 125 & 98,97 \\
\hline 130 & 99,2 \\
\hline 140 & 99,55 \\
\hline 145 & 99,67 \\
\hline 150 & 99,76 \\
\hline 160 & 99,89 \\
\hline 170 & 99,96 \\
\hline 180 & 100 \\
\hline 190 & 100 \\
\hline 200 & 100 \\
\hline 212 & 100 \\
\hline 242 & 100 \\
\hline 250 & 100 \\
\hline 300 & 100 \\
\hline 400 & 100 \\
\hline 500 & 100 \\
\hline
\end{tabular}

\begin{tabular}{|c|cc|}
\hline \multicolumn{3}{|c|}{ amostra analisada } \\
\hline argila & 5,00 & $\%$ \\
\hline silte & 84,74 & $\%$ \\
\hline areia/cascalho & 10,26 & $\%$ \\
\hline
\end{tabular}

\begin{tabular}{|c|cc|}
\hline Massa Total & $10,1863 \quad \mathrm{~g}$ \\
\hline Massa $>200 \mu \mathrm{m}$ & 4,6185 & $\mathrm{~g}$ \\
\hline
\end{tabular}

SP - 115

\begin{tabular}{|c|cc|}
\hline \multicolumn{3}{|c|}{ amostra original } \\
\hline argila & $\mathbf{2 , 7 3}$ & $\%$ \\
\hline silte & $\mathbf{4 6 , 3 2}$ & $\%$ \\
\hline areia/cascalho & $\mathbf{5 0 , 9 5}$ & $\%$ \\
\hline
\end{tabular}


Tabela 28: Determinação granulométrica, SP-116.

\begin{tabular}{|c|c|}
\hline $\begin{array}{c}\text { Diâmetro } \\
(\mu \mathrm{m})\end{array}$ & $\begin{array}{c}\% \\
\text { (valor cumulativo) }\end{array}$ \\
\hline 0,04 & 0,25 \\
\hline 0,07 & 0,27 \\
\hline 0,1 & 0,32 \\
\hline 0,2 & 0,95 \\
\hline 0,3 & 1,79 \\
\hline 0,4 & 2,19 \\
\hline 0,5 & 2,19 \\
\hline 0,6 & 2,19 \\
\hline 0,7 & 2,19 \\
\hline 0,8 & 2,22 \\
\hline 0,9 & 2,29 \\
\hline 1 & 2,39 \\
\hline 1,1 & 2,51 \\
\hline 1,2 & 2,66 \\
\hline 1,3 & 2,84 \\
\hline 1,4 & 3,04 \\
\hline 1,6 & 3,49 \\
\hline 1,8 & 4,02 \\
\hline 2 & 4,6 \\
\hline 2,2 & 5,21 \\
\hline 2,4 & 5,85 \\
\hline 2,6 & 6,5 \\
\hline 3 & 7,82 \\
\hline 4 & 10,99 \\
\hline 5 & 13,78 \\
\hline 6 & 16,29 \\
\hline 6,5 & 17,47 \\
\hline 7 & 18,64 \\
\hline 7,5 & 19,81 \\
\hline 8 & 20,99 \\
\hline 8,5 & 22,19 \\
\hline 9 & 23,4 \\
\hline 10 & 25,81 \\
\hline 11 & 28,2 \\
\hline 12 & 30,51 \\
\hline 13 & 32,72 \\
\hline 14 & 34,81 \\
\hline 15 & 36,76 \\
\hline 16 & 38,57 \\
\hline 17 & 40,23 \\
\hline
\end{tabular}

\section{Diâmetro $(\mu \mathrm{m})$}

$\%$ (valor cumulativo)

\begin{tabular}{|l|l|}
\hline 18 & 41,76 \\
\hline 19 & 43,16 \\
\hline 20 & 44,45 \\
\hline 22 & 46,69 \\
\hline 25 & 49,38 \\
\hline
\end{tabular}

\begin{tabular}{|l|l|}
\hline 28 & 51,44 \\
\hline 32 & 53,55 \\
\hline 36 & 55,16 \\
\hline
\end{tabular}

\begin{tabular}{|l|l|}
\hline 38 & 55,83 \\
\hline 40 & 56,44 \\
\hline 45 & 57,74 \\
\hline
\end{tabular}

\begin{tabular}{|l|l|}
\hline 45 & 57,74 \\
\hline 50 & 58,81 \\
\hline 53 & 59,36 \\
\hline 56 & 59,87 \\
\hline
\end{tabular}

\begin{tabular}{|c|c|}
\hline 56 & 59,87 \\
\hline 63 & 60,9 \\
\hline 71 & 61,94 \\
\hline 75 & 62,44 \\
\hline
\end{tabular}

\begin{tabular}{|l|l|}
\hline 75 & 62,44 \\
\hline 80 & 63,08 \\
\hline 85 & 63,75 \\
\hline 90 & 64,49 \\
\hline
\end{tabular}

\begin{tabular}{|c|c|}
\hline 90 & 64,49 \\
\hline 95 & 65,29 \\
\hline 100 & 66,16 \\
\hline 106 & 67,28 \\
\hline
\end{tabular}

\begin{tabular}{|c|c|}
\hline 112 & 68,46 \\
\hline 125 & 71,22 \\
\hline 130 & 72,31 \\
\hline 140 & 74,5 \\
\hline 145 & 75,59 \\
\hline 150 & 76,67 \\
\hline 160 & 78,74 \\
\hline 170 & 80,67 \\
\hline 180 & 82,45 \\
\hline 190 & 84,03 \\
\hline 200 & 85,45 \\
\hline 212 & 86,97 \\
\hline 242 & 89,97 \\
\hline 250 & 90,62 \\
\hline 300 & 93,74 \\
\hline 400 & 97,67 \\
\hline 500 & 99,67 \\
\hline
\end{tabular}

SP - 116

\begin{tabular}{|c|cc|}
\hline \multicolumn{3}{|c|}{ amostra original } \\
\hline argila & $\mathbf{4 , 6 0}$ & $\%$ \\
\hline silte & $\mathbf{5 6 , 3 0}$ & $\%$ \\
\hline areia/cascalho & $\mathbf{3 9 , 1 0}$ & $\%$ \\
\hline
\end{tabular}


Tabela 29: Determinação granulométrica, SP-117.

\begin{tabular}{|c|c|}
\hline $\begin{array}{c}\text { Diâmetro } \\
(\mu \mathrm{m})\end{array}$ & $\begin{array}{c}\% \\
\text { (valor cumulativo) }\end{array}$ \\
\hline 0,04 & 0,28 \\
\hline 0,07 & 0,31 \\
\hline 0,1 & 0,38 \\
\hline 0,2 & 1,12 \\
\hline 0,3 & 2,09 \\
\hline 0,4 & 2,55 \\
\hline 0,5 & 2,55 \\
\hline 0,6 & 2,55 \\
\hline 0,7 & 2,55 \\
\hline 0,8 & 2,59 \\
\hline 0,9 & 2,67 \\
\hline 1 & 2,79 \\
\hline 1,1 & 2,95 \\
\hline 1,2 & 3,14 \\
\hline 1,3 & 3,37 \\
\hline 1,4 & 3,62 \\
\hline 1,6 & 4,21 \\
\hline 1,8 & 4,89 \\
\hline 2 & 5,64 \\
\hline 2,2 & 6,45 \\
\hline 2,4 & 7,28 \\
\hline 2,6 & 8,14 \\
\hline 3 & 9,9 \\
\hline 4 & 14,19 \\
\hline 5 & 18,08 \\
\hline 6 & 21,65 \\
\hline 6,5 & 23,35 \\
\hline 7 & 25,02 \\
\hline 7,5 & 26,68 \\
\hline 8 & 28,34 \\
\hline 8,5 & 30,01 \\
\hline 9 & 31,68 \\
\hline 10 & 34,99 \\
\hline 11 & 38,24 \\
\hline 12 & 41,38 \\
\hline 13 & 44,41 \\
\hline 14 & 47,27 \\
\hline 15 & 49,96 \\
\hline 16 & 52,47 \\
\hline 17 & 54,8 \\
\hline
\end{tabular}

\section{Diâmetro $(\mu \mathrm{m})$}

$\%$ (valor cumulativo)

\begin{tabular}{|l|l|}
\hline 18 & 56,95 \\
\hline 19 & 58,94 \\
\hline 20 & 60,77 \\
\hline 22 & 63,97 \\
\hline 25 & 67,77 \\
\hline
\end{tabular}

\begin{tabular}{|l|l|}
\hline 28 & 70,64 \\
\hline 32 & 73,45 \\
\hline 36 & 75,49 \\
\hline
\end{tabular}

\begin{tabular}{|l|l|}
\hline 36 & 75,49 \\
\hline 38 & 76,31 \\
\hline 40 & 77,02 \\
\hline 45 & 78,49 \\
\hline
\end{tabular}

\begin{tabular}{|l|l|}
\hline 45 & 78,49 \\
\hline 50 & 79,64 \\
\hline 53 & 80,23 \\
\hline 56 & 80,75 \\
\hline
\end{tabular}

\begin{tabular}{|l|l|}
\hline 56 & 80,75 \\
\hline 63 & 81,85 \\
\hline 71 & 83,02 \\
\hline
\end{tabular}

\begin{tabular}{|l|l|}
\hline 71 & 83,02 \\
\hline 75 & 83,62 \\
\hline 80 & 84,41 \\
\hline 85 & 85,25 \\
\hline 90 & 86,14 \\
\hline
\end{tabular}

\begin{tabular}{|c|c|}
\hline 90 & 86,14 \\
\hline 95 & 87,1 \\
\hline 100 & 88,08 \\
\hline 106 & 89,25 \\
\hline
\end{tabular}

\begin{tabular}{|c|c|}
\hline 112 & 90,37 \\
\hline 125 & 92,59 \\
\hline 130 & 93,34 \\
\hline 140 & 94,7 \\
\hline 145 & 95,31 \\
\hline 150 & 95,86 \\
\hline 160 & 96,83 \\
\hline 170 & 97,62 \\
\hline 180 & 98,25 \\
\hline 190 & 98,72 \\
\hline 200 & 99,08 \\
\hline 212 & 99,4 \\
\hline 242 & 99,83 \\
\hline 250 & 99,88 \\
\hline 300 & 100 \\
\hline 400 & 100 \\
\hline 500 & 100 \\
\hline
\end{tabular}

SP - 117

\begin{tabular}{|c|cc|}
\hline \multicolumn{3}{|c|}{ amostra original } \\
\hline argila & $\mathbf{5 , 6 4}$ & $\%$ \\
\hline silte & $\mathbf{7 6 , 2 1}$ & $\%$ \\
\hline areia/cascalho & $\mathbf{1 8 , 1 5}$ & $\%$ \\
\hline
\end{tabular}


Tabela 30: Determinação granulométrica, SP-118.

\begin{tabular}{|c|c|}
\hline $\begin{array}{l}\text { Diâmetro } \\
(\mu \mathrm{m})\end{array}$ & $\begin{array}{c}\% \\
\text { (valor cumulativo) }\end{array}$ \\
\hline 0,04 & 0,45 \\
\hline 0,07 & 0,52 \\
\hline 0,1 & 0,66 \\
\hline 0,2 & 1,91 \\
\hline 0,3 & 3,47 \\
\hline 0,4 & 4,24 \\
\hline 0,5 & 4,24 \\
\hline 0,6 & 4,24 \\
\hline 0,7 & 4,24 \\
\hline 0,8 & 4,26 \\
\hline 0,9 & 4,33 \\
\hline 1 & 4,46 \\
\hline 1,1 & 4,66 \\
\hline 1,2 & 4,91 \\
\hline 1,3 & 5,21 \\
\hline 1,4 & 5,56 \\
\hline 1,6 & 6,39 \\
\hline 1,8 & 7,37 \\
\hline 2 & 8,45 \\
\hline 2,2 & 9,62 \\
\hline 2,4 & 10,84 \\
\hline 2,6 & 12,09 \\
\hline 3 & 14,62 \\
\hline 4 & 20,62 \\
\hline 5 & 25,86 \\
\hline 6 & 30,51 \\
\hline 6,5 & 32,68 \\
\hline 7 & 34,79 \\
\hline 7,5 & 36,87 \\
\hline 8 & 38,93 \\
\hline 8,5 & 41 \\
\hline 9 & 43,04 \\
\hline 10 & 47,05 \\
\hline 11 & 50,92 \\
\hline 12 & 54,62 \\
\hline 13 & 58,15 \\
\hline 14 & 61,49 \\
\hline 15 & 64,63 \\
\hline 16 & 67,57 \\
\hline 17 & 70,34 \\
\hline
\end{tabular}

\begin{tabular}{|c|c|}
\hline $\begin{array}{c}\text { Diâmetro } \\
(\mu \mathrm{m})\end{array}$ & $\begin{array}{c}\% \\
\text { (valor cumulativo) }\end{array}$ \\
\hline 18 & 72,93 \\
\hline 19 & 75,39 \\
\hline 20 & 77,69 \\
\hline 22 & 81,83 \\
\hline 25 & 86,94 \\
\hline 28 & 90,88 \\
\hline 32 & 94,66 \\
\hline 36 & 97,12 \\
\hline 38 & 97,95 \\
\hline 40 & 98,57 \\
\hline 45 & 99,5 \\
\hline 50 & 99,86 \\
\hline 53 & 99,95 \\
\hline 56 & 100 \\
\hline 63 & 100 \\
\hline 71 & 100 \\
\hline 75 & 100 \\
\hline 80 & 100 \\
\hline 85 & 100 \\
\hline 90 & 100 \\
\hline 95 & 100 \\
\hline 100 & 100 \\
\hline 106 & 100 \\
\hline 112 & 100 \\
\hline 125 & 100 \\
\hline 130 & 100 \\
\hline 140 & 100 \\
\hline 145 & 100 \\
\hline 150 & 100 \\
\hline 160 & 100 \\
\hline 170 & 100 \\
\hline 180 & 100 \\
\hline 190 & 100 \\
\hline 200 & 100 \\
\hline 212 & 100 \\
\hline 242 & 100 \\
\hline 250 & 100 \\
\hline 300 & 100 \\
\hline 400 & 100 \\
\hline 500 & 100 \\
\hline
\end{tabular}

SP - 118

\begin{tabular}{|c|cc|}
\hline \multicolumn{3}{|c|}{ amostra original } \\
\hline argila & $\mathbf{8 , 4 5}$ & $\%$ \\
\hline silte & $\mathbf{9 1 , 5 5}$ & $\%$ \\
\hline areia/cascalho & --- & $\%$ \\
\hline
\end{tabular}


Tabela 31: Determinação granulométrica, SP-119.

\begin{tabular}{|c|c|}
\hline $\begin{array}{c}\text { Diâmetro } \\
(\mu \mathrm{m})\end{array}$ & $\begin{array}{c}\% \\
\text { (valor cumulativo) }\end{array}$ \\
\hline 0,04 & 0,27 \\
\hline 0,07 & 0,3 \\
\hline 0,1 & 0,37 \\
\hline 0,2 & 1,09 \\
\hline 0,3 & 2,02 \\
\hline 0,4 & 2,47 \\
\hline 0,5 & 2,47 \\
\hline 0,6 & 2,47 \\
\hline 0,7 & 2,47 \\
\hline 0,8 & 2,5 \\
\hline 0,9 & 2,57 \\
\hline 1 & 2,68 \\
\hline 1,1 & 2,82 \\
\hline 1,2 & 2,99 \\
\hline 1,3 & 3,19 \\
\hline 1,4 & 3,42 \\
\hline 1,6 & 3,95 \\
\hline 1,8 & 4,56 \\
\hline 2 & 5,23 \\
\hline 2,2 & 5,95 \\
\hline 2,4 & 6,7 \\
\hline 2,6 & 7,46 \\
\hline 3 & 9 \\
\hline 4 & 12,71 \\
\hline 5 & 16,02 \\
\hline 6 & 19,06 \\
\hline 6,5 & 20,51 \\
\hline 7 & 21,94 \\
\hline 7,5 & 23,38 \\
\hline 8 & 24,83 \\
\hline 8,5 & 26,3 \\
\hline 9 & 27,78 \\
\hline 10 & 30,71 \\
\hline 11 & 33,6 \\
\hline 12 & 36,38 \\
\hline 13 & 39,06 \\
\hline 14 & 41,59 \\
\hline 15 & 43,96 \\
\hline 16 & 46,19 \\
\hline 17 & 48,26 \\
\hline
\end{tabular}

\section{Diâmetro ( $\mu \mathrm{m})$}

$\%$ (valor cumulativo)

\begin{tabular}{|l|l|}
\hline 18 & 50,19 \\
\hline 19 & 51,99 \\
\hline 20 & 53,68 \\
\hline 22 & 56,73 \\
\hline 25 & 60,66 \\
\hline
\end{tabular}

\begin{tabular}{|l|l|}
\hline 28 & 64,01 \\
\hline 32 & 67,91 \\
\hline 36 & 71,35 \\
\hline
\end{tabular}

\begin{tabular}{|l|l|}
\hline 36 & 71,35 \\
\hline 38 & 72,94 \\
\hline 40 & 74,46 \\
\hline 45 & 78,02 \\
\hline
\end{tabular}

\begin{tabular}{|l|l|}
\hline 45 & 78,02 \\
\hline 50 & 81,26 \\
\hline 53 & 83,05 \\
\hline 56 & 84,71 \\
\hline
\end{tabular}

\begin{tabular}{|l|l|}
\hline 56 & 84,71 \\
\hline 63 & 88,15 \\
\hline 71 & 91,39 \\
\hline 75 & 92,77 \\
\hline
\end{tabular}

\begin{tabular}{|l|l|}
\hline 75 & 92,77 \\
\hline 80 & 94,29 \\
\hline 85 & 95,57 \\
\hline 90 & 96,64 \\
\hline
\end{tabular}

\begin{tabular}{|c|c|}
\hline 90 & 96,64 \\
\hline 95 & 97,5 \\
\hline 100 & 98,19 \\
\hline 106 & 98,83 \\
\hline
\end{tabular}

\begin{tabular}{|c|c|}
\hline 112 & 99,28 \\
\hline 125 & 99,79 \\
\hline 130 & 99,89 \\
\hline 140 & 100 \\
\hline 145 & 100 \\
\hline 150 & 100 \\
\hline 160 & 100 \\
\hline 170 & 100 \\
\hline 180 & 100 \\
\hline 190 & 100 \\
\hline 200 & 100 \\
\hline 212 & 100 \\
\hline 242 & 100 \\
\hline 250 & 100 \\
\hline 300 & 100 \\
\hline 400 & 100 \\
\hline 500 & 100 \\
\hline
\end{tabular}

SP - 119

\begin{tabular}{|c|cc|}
\hline \multicolumn{3}{|c|}{ amostra original } \\
\hline argila & $\mathbf{5 , 2 3}$ & $\%$ \\
\hline silte & $\mathbf{8 2 , 9 2}$ & $\%$ \\
\hline areia/cascalho & $\mathbf{1 1 , 8 5}$ & $\%$ \\
\hline
\end{tabular}


Tabela 32: Determinação granulométrica, SP-120.

\begin{tabular}{|c|c|}
\hline $\begin{array}{c}\text { Diâmetro } \\
(\mu \mathrm{m})\end{array}$ & $\begin{array}{c}\% \\
\text { (valor cumulativo) }\end{array}$ \\
\hline 0,04 & 0,36 \\
\hline 0,07 & 0,42 \\
\hline 0,1 & 0,52 \\
\hline 0,2 & 1,52 \\
\hline 0,3 & 2,79 \\
\hline 0,4 & 3,41 \\
\hline 0,5 & 3,41 \\
\hline 0,6 & 3,41 \\
\hline 0,7 & 3,41 \\
\hline 0,8 & 3,42 \\
\hline 0,9 & 3,47 \\
\hline 1 & 3,56 \\
\hline 1,1 & 3,71 \\
\hline 1,2 & 3,9 \\
\hline 1,3 & 4,13 \\
\hline 1,4 & 4,41 \\
\hline 1,6 & 5,07 \\
\hline 1,8 & 5,86 \\
\hline 2 & 6,75 \\
\hline 2,2 & 7,71 \\
\hline 2,4 & 8,72 \\
\hline 2,6 & 9,76 \\
\hline 3 & 11,88 \\
\hline 4 & 17,05 \\
\hline 5 & 21,67 \\
\hline 6 & 25,86 \\
\hline 6,5 & 27,85 \\
\hline 7 & 29,79 \\
\hline 7,5 & 31,72 \\
\hline 8 & 33,64 \\
\hline 8,5 & 35,57 \\
\hline 9 & 37,49 \\
\hline 10 & 41,27 \\
\hline 11 & 44,92 \\
\hline 12 & 48,4 \\
\hline 13 & 51,68 \\
\hline 14 & 54,74 \\
\hline 15 & 57,56 \\
\hline 16 & 60,14 \\
\hline 17 & 62,51 \\
\hline
\end{tabular}

\section{Diâmetro ( $\mu \mathrm{m})$}

$\%$ (valor cumulativo)

\begin{tabular}{|l|l|}
\hline 18 & 64,66 \\
\hline 19 & 66,62 \\
\hline 20 & 68,41 \\
\hline 22 & 71,51 \\
\hline 25 & 75,22 \\
\hline
\end{tabular}

28

\begin{tabular}{|l|l|}
\hline 32 & 81,22 \\
\hline 36 & 83,82 \\
\hline 38 & 85,01 \\
\hline
\end{tabular}

\begin{tabular}{|l|l|}
\hline 38 & 85,01 \\
\hline 40 & 86,14 \\
\hline 45 & 88,75 \\
\hline
\end{tabular}

\begin{tabular}{|l|l|}
\hline 45 & 88,75 \\
\hline 50 & 91,07 \\
\hline 53 & 92,32 \\
\hline 56 & 93,45 \\
\hline
\end{tabular}

\begin{tabular}{|l|l|}
\hline 56 & 93,45 \\
\hline 63 & 95,68 \\
\hline 71 & 97,51 \\
\hline 75 & 98,17 \\
\hline
\end{tabular}

\begin{tabular}{|c|c|}
\hline 75 & 98,17 \\
\hline 80 & 98,8 \\
\hline 85 & 99,26 \\
\hline
\end{tabular}

\begin{tabular}{|c|c|}
\hline 85 & 99,26 \\
\hline 90 & 99,57 \\
\hline 95 & 99,77 \\
\hline 100 & 99,89 \\
\hline 106 & 99,97 \\
\hline
\end{tabular}

| 1

\begin{tabular}{|l|l|}
\hline 112 & 100 \\
\hline 125 & 100 \\
\hline 130 & 100 \\
\hline 140 & 100 \\
\hline 145 & 100 \\
\hline 150 & 100 \\
\hline 160 & 100 \\
\hline 170 & 100 \\
\hline 180 & 100 \\
\hline 190 & 100 \\
\hline 200 & 100 \\
\hline 212 & 100 \\
\hline 242 & 100 \\
\hline 250 & 100 \\
\hline 300 & 100 \\
\hline 400 & 100 \\
\hline 500 & 100 \\
\hline
\end{tabular}

SP - 120

\begin{tabular}{|c|cc|}
\hline \multicolumn{2}{|c|}{ amostra original } \\
\hline argila & $\mathbf{6 , 7 5}$ & $\%$ \\
\hline silte & $\mathbf{8 8 , 9 3}$ & $\%$ \\
\hline areia/cascalho & $\mathbf{4 , 3 2}$ & $\%$ \\
\hline
\end{tabular}


Tabela 33: Determinação granulométrica, SP-121.

\begin{tabular}{|c|c|}
\hline $\begin{array}{l}\text { Diâmetro } \\
(\mu \mathrm{m})\end{array}$ & $\begin{array}{c}\% \\
\text { (valor cumulativo) }\end{array}$ \\
\hline 0,04 & 0,22 \\
\hline 0,07 & 0,24 \\
\hline 0,1 & 0,29 \\
\hline 0,2 & 0,85 \\
\hline 0,3 & 1,6 \\
\hline 0,4 & 1,96 \\
\hline 0,5 & 1,96 \\
\hline 0,6 & 1,96 \\
\hline 0,7 & 1,96 \\
\hline 0,8 & 1,98 \\
\hline 0,9 & 2,05 \\
\hline 1 & 2,13 \\
\hline 1,1 & 2,25 \\
\hline 1,2 & 2,38 \\
\hline 1,3 & 2,55 \\
\hline 1,4 & 2,73 \\
\hline 1,6 & 3,15 \\
\hline 1,8 & 3,64 \\
\hline 2 & 4,17 \\
\hline 2,2 & 4,75 \\
\hline 2,4 & 5,35 \\
\hline 2,6 & 5,96 \\
\hline 3 & 7,21 \\
\hline 4 & 10,26 \\
\hline 5 & 13,03 \\
\hline 6 & 15,6 \\
\hline 6,5 & 16,82 \\
\hline 7 & 18,04 \\
\hline 7,5 & 19,26 \\
\hline 8 & 20,48 \\
\hline 8,5 & 21,73 \\
\hline 9 & 22,98 \\
\hline 10 & 25,46 \\
\hline 11 & 27,88 \\
\hline 12 & 30,22 \\
\hline 13 & 32,46 \\
\hline 14 & 34,56 \\
\hline 15 & 36,52 \\
\hline 16 & 38,33 \\
\hline 17 & 39,99 \\
\hline
\end{tabular}

\section{Diâmetro ( $\mu \mathrm{m})$}

$\%$ (valor cumulativo)

\begin{tabular}{|l|l|}
\hline 18 & 41,51 \\
\hline 19 & 42,91 \\
\hline 20 & 44,18 \\
\hline 22 & 46,39 \\
\hline 25 & 48,99 \\
\hline
\end{tabular}

\begin{tabular}{|l|l|}
\hline 25 & 48,99 \\
\hline 32 & 50,95 \\
\hline 36 & 52,92 \\
\hline 38,41 \\
\hline
\end{tabular}

\begin{tabular}{|l|l|}
\hline 36 & 54,41 \\
\hline 38 & 55,04 \\
\hline 40 & 55,61 \\
\hline 45 & 56,86 \\
\hline
\end{tabular}

\begin{tabular}{|l|l|}
\hline 45 & 56,86 \\
\hline 50 & 57,92 \\
\hline 53 & 58,49 \\
\hline 56 & 59,02 \\
\hline
\end{tabular}

\begin{tabular}{|l|l|}
\hline 56 & 59,02 \\
\hline 63 & 60,17 \\
\hline 71 & 61,42 \\
\hline 75 & 62,05 \\
\hline
\end{tabular}

\begin{tabular}{|l|l|}
\hline 75 & 62,05 \\
\hline 80 & 62,88 \\
\hline 85 & 63,75 \\
\hline 90 & 64,68 \\
\hline
\end{tabular}

\begin{tabular}{|c|c|}
\hline 90 & 64,68 \\
\hline 95 & 65,69 \\
\hline 100 & 66,74 \\
\hline 106 & 68,07 \\
\hline
\end{tabular}

\begin{tabular}{|c|c|}
\hline 112 & 69,46 \\
\hline 125 & 72,57 \\
\hline 130 & 73,78 \\
\hline 140 & 76,16 \\
\hline 145 & 77,34 \\
\hline 150 & 78,49 \\
\hline 160 & 80,67 \\
\hline 170 & 82,67 \\
\hline 180 & 84,45 \\
\hline 190 & 86 \\
\hline 200 & 87,36 \\
\hline 212 & 88,77 \\
\hline 242 & 91,52 \\
\hline 250 & 92,11 \\
\hline 300 & 94,9 \\
\hline 400 & 98,13 \\
\hline 500 & 99,74 \\
\hline
\end{tabular}

SP - 121

\begin{tabular}{|c|cc|}
\hline \multicolumn{3}{|c|}{ amostra original } \\
\hline argila & $\mathbf{4 , 1 7}$ & $\%$ \\
\hline silte & $\mathbf{5 6 , 0 0}$ & $\%$ \\
\hline areia/cascalho & $\mathbf{3 9 , 8 3}$ & $\%$ \\
\hline
\end{tabular}


Tabela 34: Determinação granulométrica, SP-122.

\begin{tabular}{|c|c|}
\hline $\begin{array}{l}\text { Diâmetro } \\
(\mu \mathrm{m})\end{array}$ & $\begin{array}{c}\% \\
\text { (valor cumulativo) }\end{array}$ \\
\hline 0,04 & 0,21 \\
\hline 0,07 & 0,23 \\
\hline 0,1 & 0,28 \\
\hline 0,2 & 0,82 \\
\hline 0,3 & 1,54 \\
\hline 0,4 & 1,89 \\
\hline 0,5 & 1,89 \\
\hline 0,6 & 1,89 \\
\hline 0,7 & 1,89 \\
\hline 0,8 & 1,91 \\
\hline 0,9 & 1,97 \\
\hline 1 & 2,05 \\
\hline 1,1 & 2,17 \\
\hline 1,2 & 2,3 \\
\hline 1,3 & 2,46 \\
\hline 1,4 & 2,64 \\
\hline 1,6 & 3,05 \\
\hline 1,8 & 3,54 \\
\hline 2 & 4,06 \\
\hline 2,2 & 4,63 \\
\hline 2,4 & 5,21 \\
\hline 2,6 & 5,81 \\
\hline 3 & 7,03 \\
\hline 4 & 9,95 \\
\hline 5 & 12,55 \\
\hline 6 & 14,92 \\
\hline 6,5 & 16,05 \\
\hline 7 & 17,17 \\
\hline 7,5 & 18,28 \\
\hline 8 & 19,4 \\
\hline 8,5 & 20,54 \\
\hline 9 & 21,69 \\
\hline 10 & 23,99 \\
\hline 11 & 26,27 \\
\hline 12 & 28,51 \\
\hline 13 & 30,7 \\
\hline 14 & 32,81 \\
\hline 15 & 34,86 \\
\hline 16 & 36,84 \\
\hline 17 & 38,75 \\
\hline
\end{tabular}

\begin{tabular}{|c|c|}
\hline $\begin{array}{l}\text { Diâmetro } \\
(\mu \mathrm{m})\end{array}$ & $\begin{array}{c}\% \\
\text { (valor cumulativo) }\end{array}$ \\
\hline 18 & 40,6 \\
\hline 19 & 42,4 \\
\hline 20 & 44,15 \\
\hline 22 & 47,51 \\
\hline 25 & 52,27 \\
\hline 28 & 56,66 \\
\hline 32 & 61,79 \\
\hline 36 & 66,11 \\
\hline 38 & 68,01 \\
\hline 40 & 69,73 \\
\hline 45 & 73,42 \\
\hline 50 & 76,35 \\
\hline 53 & 77,85 \\
\hline 56 & 79,19 \\
\hline 63 & 81,86 \\
\hline 71 & 84,41 \\
\hline 75 & 85,55 \\
\hline 80 & 86,87 \\
\hline 85 & 88,09 \\
\hline 90 & 89,21 \\
\hline 95 & 90,23 \\
\hline 100 & 91,17 \\
\hline 106 & 92,19 \\
\hline 112 & 93,11 \\
\hline 125 & 94,78 \\
\hline 130 & 95,33 \\
\hline 140 & 96,27 \\
\hline 145 & 96,67 \\
\hline 150 & 97,04 \\
\hline 160 & 97,67 \\
\hline 170 & 98,18 \\
\hline 180 & 98,59 \\
\hline 190 & 98,93 \\
\hline 200 & 99,19 \\
\hline 212 & 99,44 \\
\hline 242 & 99,8 \\
\hline 250 & 99,86 \\
\hline 300 & 100 \\
\hline 400 & 100 \\
\hline 500 & 100 \\
\hline
\end{tabular}

\begin{tabular}{|c|cc|}
\hline \multicolumn{3}{|c|}{ amostra analisada } \\
\hline argila & 4,06 & $\%$ \\
\hline silte & 77,80 & $\%$ \\
\hline areia/cascalho & 18,14 & $\%$ \\
\hline
\end{tabular}

\begin{tabular}{|c|cc|}
\hline Massa Total & 6,6107 & $\mathrm{~g}$ \\
\hline Massa $>200 \mu \mathrm{m}$ & 1,7658 & $\mathrm{~g}$ \\
\hline
\end{tabular}

SP - 122

\begin{tabular}{|c|cc|}
\hline \multicolumn{3}{|c|}{ amostra original } \\
\hline argila & $\mathbf{2 , 9 8}$ & $\%$ \\
\hline silte & $\mathbf{5 7 , 0 2}$ & $\%$ \\
\hline areia/cascalho & $\mathbf{4 0 , 0 1}$ & $\%$ \\
\hline
\end{tabular}


Tabela 35: Determinação granulométrica, SP-123.

\begin{tabular}{|c|c|}
\hline $\begin{array}{l}\text { Diâmetro } \\
(\mu \mathrm{m})\end{array}$ & $\begin{array}{c}\% \\
\text { (valor cumulativo) }\end{array}$ \\
\hline 0,04 & 0,32 \\
\hline 0,07 & 0,36 \\
\hline 0,1 & 0,44 \\
\hline 0,2 & 1,29 \\
\hline 0,3 & 2,38 \\
\hline 0,4 & 2,91 \\
\hline 0,5 & 2,91 \\
\hline 0,6 & 2,91 \\
\hline 0,7 & 2,91 \\
\hline 0,8 & 2,93 \\
\hline 0,9 & 2,98 \\
\hline 1 & 3,07 \\
\hline 1,1 & 3,19 \\
\hline 1,2 & 3,35 \\
\hline 1,3 & 3,54 \\
\hline 1,4 & 3,76 \\
\hline 1,6 & 4,28 \\
\hline 1,8 & 4,9 \\
\hline 2 & 5,58 \\
\hline 2,2 & 6,32 \\
\hline 2,4 & 7,08 \\
\hline 2,6 & 7,87 \\
\hline 3 & 9,47 \\
\hline 4 & 13,33 \\
\hline 5 & 16,75 \\
\hline 6 & 19,86 \\
\hline 6,5 & 21,34 \\
\hline 7 & 22,8 \\
\hline 7,5 & 24,27 \\
\hline 8 & 25,76 \\
\hline 8,5 & 27,29 \\
\hline 9 & 28,84 \\
\hline 10 & 31,96 \\
\hline 11 & 35,1 \\
\hline 12 & 38,18 \\
\hline 13 & 41,17 \\
\hline 14 & 44,04 \\
\hline 15 & 46,75 \\
\hline 16 & 49,3 \\
\hline 17 & 51,68 \\
\hline
\end{tabular}

\section{Diâmetro} $(\mu \mathrm{m})$

$\%$ (valor cumulativo)

\begin{tabular}{|l|l|}
\hline 18 & 53,89 \\
\hline 19 & 55,95 \\
\hline 20 & 57,86 \\
\hline 22 & 61,29 \\
\hline 25 & 65,59 \\
\hline
\end{tabular}

28

\begin{tabular}{|l|l|}
\hline 32 & 73,14 \\
\hline 36 & 76,58 \\
\hline 38 & 78,16 \\
\hline
\end{tabular}

\begin{tabular}{|l|l|}
\hline 38 & 78,16 \\
\hline 40 & 79,66 \\
\hline 45 & 83,17 \\
\hline 50 & 86,42 \\
\hline
\end{tabular}

\begin{tabular}{|l|l|}
\hline 50 & 86,42 \\
\hline 53 & 88,19 \\
\hline 56 & 89,82 \\
\hline 63 & 93,03 \\
\hline
\end{tabular}

\begin{tabular}{|l|l|}
\hline 63 & 93,03 \\
\hline 71 & 95,78 \\
\hline 75 & 96,82 \\
\hline 80 & 97,86 \\
\hline
\end{tabular}

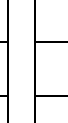

\begin{tabular}{|c|c|}
\hline 85 & 98,64 \\
\hline 90 & 99,2 \\
\hline 95 & 99,55 \\
\hline 100 & 99,78 \\
\hline 106 & 99,94 \\
\hline 112 & 100 \\
\hline 125 & 100 \\
\hline 130 & 100 \\
\hline 140 & 100 \\
\hline 145 & 100 \\
\hline 150 & 100 \\
\hline 160 & 100 \\
\hline 170 & 100 \\
\hline 180 & 100 \\
\hline 190 & 100 \\
\hline 200 & 100 \\
\hline 212 & 100 \\
\hline 242 & 100 \\
\hline 250 & 100 \\
\hline 300 & 100 \\
\hline 400 & 100 \\
\hline 500 & 100 \\
\hline
\end{tabular}

SP - 123

\begin{tabular}{|c|cc|}
\hline \multicolumn{2}{|c|}{ amostra original } \\
\hline argila & $\mathbf{5 , 5 8}$ & $\%$ \\
\hline silte & $\mathbf{8 7 , 4 5}$ & $\%$ \\
\hline areia/cascalho & $\mathbf{6 , 9 7}$ & $\%$ \\
\hline
\end{tabular}


Tabela 36: Determinação granulométrica, SP-124.

\begin{tabular}{|c|c|}
\hline $\begin{array}{l}\text { Diâmetro } \\
(\mu \mathrm{m})\end{array}$ & $\begin{array}{c}\% \\
\text { (valor cumulativo) }\end{array}$ \\
\hline 0,04 & 0,43 \\
\hline 0,07 & 0,5 \\
\hline 0,1 & 0,62 \\
\hline 0,2 & 1,8 \\
\hline 0,3 & 3,3 \\
\hline 0,4 & 4,03 \\
\hline 0,5 & 4,03 \\
\hline 0,6 & 4,03 \\
\hline 0,7 & 4,03 \\
\hline 0,8 & 4,04 \\
\hline 0,9 & 4,09 \\
\hline 1 & 4,2 \\
\hline 1,1 & 4,37 \\
\hline 1,2 & 4,59 \\
\hline 1,3 & 4,85 \\
\hline 1,4 & 5,16 \\
\hline 1,6 & 5,91 \\
\hline 1,8 & 6,81 \\
\hline 2 & 7,81 \\
\hline 2,2 & 8,89 \\
\hline 2,4 & 10,03 \\
\hline 2,6 & 11,2 \\
\hline 3 & 13,59 \\
\hline 4 & 19,4 \\
\hline 5 & 24,61 \\
\hline 6 & 29,38 \\
\hline 6,5 & 31,64 \\
\hline 7 & 33,87 \\
\hline 7,5 & 36,09 \\
\hline 8 & 38,3 \\
\hline 8,5 & 40,53 \\
\hline 9 & 42,74 \\
\hline 10 & 47,06 \\
\hline 11 & 51,19 \\
\hline 12 & 55,06 \\
\hline 13 & 58,65 \\
\hline 14 & 61,95 \\
\hline 15 & 64,94 \\
\hline 16 & 67,62 \\
\hline 17 & 70,02 \\
\hline
\end{tabular}

\section{Diâmetro} $(\mu \mathrm{m})$

$\%$ (valor cumulativo)

\begin{tabular}{|l|l|}
\hline 18 & 72,18 \\
\hline 19 & 74,11 \\
\hline 20 & 75,85 \\
\hline 22 & 78,85 \\
\hline 25 & 82,49 \\
\hline
\end{tabular}

28

\begin{tabular}{|l|l|}
\hline 32 & 88,85 \\
\hline 36 & 91,73 \\
\hline 38 & 92,98 \\
\hline
\end{tabular}

\begin{tabular}{|l|l|}
\hline 38 & 92,98 \\
\hline 40 & 94,12 \\
\hline 45 & 96,43 \\
\hline
\end{tabular}

\begin{tabular}{|c|c|}
\hline 45 & 96,43 \\
\hline 50 & 98,03 \\
\hline 53 & 98,7 \\
\hline
\end{tabular}

\begin{tabular}{|c|c|}
\hline 53 & 98,7 \\
\hline 56 & 99,19 \\
\hline 63 & 99,79 \\
\hline 71 & 100 \\
\hline
\end{tabular}

\begin{tabular}{|l|l|}
\hline 71 & 100 \\
\hline 75 & 100 \\
\hline 80 & 100 \\
\hline 85 & 100 \\
\hline 90 & 100 \\
\hline
\end{tabular}

\begin{tabular}{|c|c|}
\hline 90 & 100 \\
\hline 95 & 100 \\
\hline 100 & 100 \\
\hline 106 & 100 \\
\hline
\end{tabular}

P 1

\begin{tabular}{|l|l|}
\hline 112 & 100 \\
\hline 125 & 100 \\
\hline 130 & 100 \\
\hline 140 & 100 \\
\hline 145 & 100 \\
\hline 150 & 100 \\
\hline 160 & 100 \\
\hline 170 & 100 \\
\hline 180 & 100 \\
\hline 190 & 100 \\
\hline 200 & 100 \\
\hline 212 & 100 \\
\hline 242 & 100 \\
\hline 250 & 100 \\
\hline 300 & 100 \\
\hline 400 & 100 \\
\hline 500 & 100 \\
\hline
\end{tabular}

SP - 124

\begin{tabular}{|c|cc|}
\hline \multicolumn{3}{|c|}{ amostra original } \\
\hline argila & $\mathbf{7 , 8 1}$ & $\%$ \\
\hline silte & $\mathbf{9 1 , 9 8}$ & $\%$ \\
\hline areia/cascalho & $\mathbf{0 , 2 1}$ & $\%$ \\
\hline
\end{tabular}


Tabela 37: Determinação granulométrica, SP-125.

\begin{tabular}{|c|c|}
\hline $\begin{array}{c}\text { Diâmetro } \\
(\mu \mathrm{m})\end{array}$ & $\begin{array}{c}\% \\
\text { (valor } \\
\text { cumulativo) }\end{array}$ \\
\hline 0,04 & 0,1 \\
\hline 0,07 & 0,1 \\
\hline 0,1 & 0,1 \\
\hline 0,2 & 0,23 \\
\hline 0,3 & 0,44 \\
\hline 0,4 & 0,53 \\
\hline 0,5 & 0,53 \\
\hline 0,6 & 0,53 \\
\hline 0,7 & 0,53 \\
\hline 0,8 & 0,58 \\
\hline 0,9 & 0,64 \\
\hline 1 & 0,71 \\
\hline 1,1 & 0,79 \\
\hline 1,2 & 0,87 \\
\hline 1,3 & 0,96 \\
\hline 1,4 & 1,06 \\
\hline 1,6 & 1,27 \\
\hline 1,8 & 1,5 \\
\hline 2 & 1,74 \\
\hline 2,2 & 1,99 \\
\hline 2,4 & 2,24 \\
\hline 2,6 & 2,49 \\
\hline 3 & 2,98 \\
\hline 4 & 4,12 \\
\hline 5 & 5,12 \\
\hline 6 & 6,03 \\
\hline 6,5 & 6,46 \\
\hline 7 & 6,89 \\
\hline 7,5 & 7,33 \\
\hline 8 & 7,77 \\
\hline 8,5 & 8,21 \\
\hline 9 & 8,67 \\
\hline 10 & 9,57 \\
\hline 11 & 10,45 \\
\hline 12 & 11,3 \\
\hline 13 & 12,11 \\
\hline 14 & 12,86 \\
\hline 15 & 13,56 \\
\hline 16 & 14,21 \\
\hline 17 & 14,8 \\
\hline
\end{tabular}

\begin{tabular}{|c|c|c|c|}
\hline $\begin{array}{c}\text { Diâmetro } \\
\qquad(\mu \mathrm{m})\end{array}$ & $\begin{array}{c}\% \\
\text { (valor } \\
\text { cumulativo) }\end{array}$ & $\begin{array}{c}\text { Diâmetro } \\
(\mu \mathrm{m})\end{array}$ & $\begin{array}{c}\% \\
\text { (valor } \\
\text { cumulativo) }\end{array}$ \\
\hline 18 & 15,35 & 600 & 100 \\
\hline 19 & 15,85 & 700 & 100 \\
\hline 20 & 16,31 & 800 & 100 \\
\hline 22 & 17,12 & 900 & 100 \\
\hline 25 & 18,13 & 1000 & 100 \\
\hline
\end{tabular}

\begin{tabular}{|c|c|}
\hline 28 & 18,97 \\
\hline 32 & 19,9 \\
\hline 36 & 20,71 \\
\hline 38 & 21,08 \\
\hline
\end{tabular}

\begin{tabular}{|l|l|}
\hline 38 & 21,08 \\
\hline 40 & 21,44 \\
\hline 45 & 22,27 \\
\hline 50 & 23,05 \\
\hline
\end{tabular}

\begin{tabular}{|c|c|}
\hline 50 & 23,05 \\
\hline 53 & 23,5 \\
\hline 56 & 23,94 \\
\hline 63 & 24,91 \\
\hline
\end{tabular}

\begin{tabular}{|c|c|}
\hline 63 & 24,91 \\
\hline 71 & 26 \\
\hline 75 & 26,53 \\
\hline 80 & 27,21 \\
\hline
\end{tabular}

\begin{tabular}{|l|l|}
\hline 80 & 27,21 \\
\hline 85 & 27,89 \\
\hline 90 & 28,58 \\
\hline
\end{tabular}

\begin{tabular}{|c|c|}
\hline 95 & 29,29 \\
\hline 100 & 30,02 \\
\hline 106 & 30,9 \\
\hline
\end{tabular}

\begin{tabular}{|l|c|}
\hline 106 & 30,9 \\
\hline 112 & 31,81 \\
\hline 125 & 33,82 \\
\hline 130 & 34,61 \\
\hline
\end{tabular}

\begin{tabular}{|l|l|}
\hline 130 & 34,61 \\
\hline 140 & 36,21 \\
\hline 145 & 37,02 \\
\hline 150 & 37,83 \\
\hline 160 & 39,46 \\
\hline
\end{tabular}

\begin{tabular}{|c|cc|}
\hline \multicolumn{3}{|c|}{ amostra analisada } \\
\hline argila & 1,74 & $\%$ \\
\hline silte & 23,17 & $\%$ \\
\hline areia/cascalho & 75,09 & $\%$ \\
\hline
\end{tabular}

\begin{tabular}{|c|c|}
\hline 160 & 39,46 \\
\hline 170 & 41,11 \\
\hline 180 & 42,78 \\
\hline 190 & 44,46 \\
\hline 200 & 46,16 \\
\hline 212 & 48,22 \\
\hline 242 & 53,53 \\
\hline 250 & 54,99 \\
\hline 300 & 64,87 \\
\hline 400 & 86,01 \\
\hline 500 & 98 \\
\hline
\end{tabular}

\begin{tabular}{|c|cc|}
\hline Massa Total & 16,364 & $\mathrm{~g}$ \\
\hline Massa > $200 \mu \mathrm{m}$ & 9,7655 & $\mathrm{~g}$ \\
\hline \multicolumn{3}{|c|}{} \\
SP - 125 \\
\hline \multicolumn{2}{|c|}{ amostra original } \\
\hline argila & $\mathbf{0 , 7 0}$ & $\%$ \\
\hline silte & $\mathbf{9 , 3 4}$ & $\%$ \\
\hline areia/cascalho & $\mathbf{8 9 , 9 6}$ & $\%$ \\
\hline
\end{tabular}


Tabela 38: Determinação granulométrica, SP-126.

\begin{tabular}{|c|c|}
\hline $\begin{array}{c}\text { Diâmetro } \\
(\mu \mathrm{m})\end{array}$ & $\begin{array}{c}\% \\
\text { (valor } \\
\text { cumulativo) }\end{array}$ \\
\hline 0,04 & 0,21 \\
\hline 0,07 & 0,22 \\
\hline 0,1 & 0,26 \\
\hline 0,2 & 0,78 \\
\hline 0,3 & 1,48 \\
\hline 0,4 & 1,81 \\
\hline 0,5 & 1,81 \\
\hline 0,6 & 1,81 \\
\hline 0,7 & 1,81 \\
\hline 0,8 & 1,85 \\
\hline 0,9 & 1,92 \\
\hline 1 & 2,02 \\
\hline 1,1 & 2,15 \\
\hline 1,2 & 2,3 \\
\hline 1,3 & 2,47 \\
\hline 1,4 & 2,66 \\
\hline 1,6 & 3,11 \\
\hline 1,8 & 3,63 \\
\hline 2 & 4,19 \\
\hline 2,2 & 4,79 \\
\hline 2,4 & 5,42 \\
\hline 2,6 & 6,06 \\
\hline 3 & 7,37 \\
\hline 4 & 10,59 \\
\hline 5 & 13,48 \\
\hline 6 & 16,1 \\
\hline 6,5 & 17,34 \\
\hline 7 & 18,55 \\
\hline 7,5 & 19,77 \\
\hline 8 & 21 \\
\hline 8,5 & 22,25 \\
\hline 9 & 23,5 \\
\hline 10 & 26,03 \\
\hline 11 & 28,53 \\
\hline 12 & 30,97 \\
\hline 13 & 33,33 \\
\hline 14 & 35,57 \\
\hline 15 & 37,68 \\
\hline 16 & 39,65 \\
\hline 17 & 41,48 \\
\hline
\end{tabular}

\begin{tabular}{|c|c|c|c|}
\hline $\begin{array}{c}\text { Diâmetro } \\
(\mu \mathrm{m})\end{array}$ & $\begin{array}{c}\% \\
\text { (valor } \\
\text { cumulativo) }\end{array}$ & $\begin{array}{c}\text { Diâmetro } \\
(\mu \mathrm{m})\end{array}$ & $\begin{array}{c}\% \\
\text { (valor } \\
\text { cumulativo) }\end{array}$ \\
\hline 18 & 43,18 & 600 & 100 \\
\hline 19 & 44,74 & 700 & 100 \\
\hline 20 & 46,19 & 800 & 100 \\
\hline 22 & 48,74 & 900 & 100 \\
\hline 25 & 51,85 & 1000 & 100 \\
\hline
\end{tabular}

\begin{tabular}{|l|l|}
\hline 28 & 54,29 \\
\hline 32 & 56,85 \\
\hline 36 & 58,88 \\
\hline 38 & 59,76 \\
\hline
\end{tabular}

\begin{tabular}{|l|l|}
\hline 38 & 59,76 \\
\hline 40 & 60,57 \\
\hline 45 & 62,37 \\
\hline 50 & 63,95 \\
\hline
\end{tabular}

\begin{tabular}{|l|l|}
\hline 50 & 63,95 \\
\hline 53 & 64,82 \\
\hline 56 & 65,65 \\
\hline 63 & 67,47 \\
\hline
\end{tabular}

\begin{tabular}{|c|c|}
\hline 63 & 67,47 \\
\hline 71 & 69,4 \\
\hline 75 & 70,33 \\
\hline 80 & 71,46 \\
\hline
\end{tabular}

\begin{tabular}{|c|c|}
\hline 80 & 71,46 \\
\hline 85 & 72,57 \\
\hline 90 & 73,65 \\
\hline 95 & 74,7 \\
\hline
\end{tabular}

\begin{tabular}{|c|c|}
\hline 95 & 74,7 \\
\hline 100 & 75,71 \\
\hline 106 & 76,88 \\
\hline
\end{tabular}

\begin{tabular}{|l|l|}
\hline 106 & 76,88 \\
\hline 112 & 77,99 \\
\hline 125 & 80,18 \\
\hline 130 & 80,93 \\
\hline
\end{tabular}

\begin{tabular}{|c|c|}
\hline 130 & 80,93 \\
\hline 140 & 82,3 \\
\hline 145 & 82,91 \\
\hline 150 & 83,47 \\
\hline 160 & 84,49 \\
\hline 170 & 85,35 \\
\hline 180 & 86,09 \\
\hline 190 & 86,71 \\
\hline 200 & 87,27 \\
\hline 212 & 87,86 \\
\hline 242 & 89,27 \\
\hline 250 & 89,64 \\
\hline 300 & 92,04 \\
\hline 400 & 96,69 \\
\hline 500 & 99,53 \\
\hline
\end{tabular}

\begin{tabular}{|c|cc|}
\hline \multicolumn{2}{|c|}{ SP - 126} & \\
\hline \multicolumn{2}{|c|}{ amostra original } \\
\hline argila & $\mathbf{4 , 1 9}$ & $\%$ \\
\hline silte & $\mathbf{6 3 , 2 8}$ & $\%$ \\
\hline areia/cascalho & $\mathbf{3 2 , 5 3}$ & $\%$ \\
\hline
\end{tabular}


Tabela 39: Determinação granulométrica, SP-130.

\begin{tabular}{|c|c|}
\hline $\begin{array}{c}\text { Diâmetro } \\
(\mu \mathrm{m})\end{array}$ & $\begin{array}{c}\% \\
\text { (valor } \\
\text { cumulativo) }\end{array}$ \\
\hline 0,04 & 0,24 \\
\hline 0,07 & 0,25 \\
\hline 0,1 & 0,27 \\
\hline 0,2 & 0,57 \\
\hline 0,3 & 0,99 \\
\hline 0,4 & 1,18 \\
\hline 0,5 & 1,18 \\
\hline 0,6 & 1,18 \\
\hline 0,7 & 1,18 \\
\hline 0,8 & 1,23 \\
\hline 0,9 & 1,31 \\
\hline 1 & 1,4 \\
\hline 1,1 & 1,51 \\
\hline 1,2 & 1,64 \\
\hline 1,3 & 1,78 \\
\hline 1,4 & 1,93 \\
\hline 1,6 & 2,26 \\
\hline 1,8 & 2,64 \\
\hline 2 & 3,04 \\
\hline 2,2 & 3,46 \\
\hline 2,4 & 3,89 \\
\hline 2,6 & 4,33 \\
\hline 3 & 5,22 \\
\hline 4 & 7,34 \\
\hline 5 & 9,24 \\
\hline 6 & 10,98 \\
\hline 6,5 & 11,81 \\
\hline 7 & 12,63 \\
\hline 7,5 & 13,45 \\
\hline 8 & 14,28 \\
\hline 8,5 & 15,13 \\
\hline 9 & 15,99 \\
\hline 10 & 17,71 \\
\hline 11 & 19,42 \\
\hline 12 & 21,1 \\
\hline 13 & 22,73 \\
\hline 14 & 24,29 \\
\hline 15 & 25,78 \\
\hline 16 & 27,18 \\
\hline 17 & 28,49 \\
\hline
\end{tabular}

\begin{tabular}{|c|c|}
\hline $\begin{array}{l}\text { Diâmetro } \\
\qquad(\mu \mathrm{m})\end{array}$ & $\begin{array}{c}\% \\
\text { (valor } \\
\text { cumulativo) }\end{array}$ \\
\hline 18 & 29,73 \\
\hline 19 & 30,89 \\
\hline 20 & 31,97 \\
\hline 22 & 33,93 \\
\hline 25 & 36,4 \\
\hline 28 & 38,44 \\
\hline 32 & 40,64 \\
\hline 36 & 42,42 \\
\hline 38 & 43,19 \\
\hline 40 & 43,91 \\
\hline 45 & 45,51 \\
\hline 50 & 46,95 \\
\hline 53 & 47,77 \\
\hline 56 & 48,59 \\
\hline 63 & 50,53 \\
\hline 71 & 52,9 \\
\hline 75 & 54,18 \\
\hline 80 & 55,84 \\
\hline 85 & 57,56 \\
\hline 90 & 59,32 \\
\hline 95 & 61,13 \\
\hline 100 & 62,94 \\
\hline 106 & 65,09 \\
\hline 112 & 67,19 \\
\hline 125 & 71,47 \\
\hline 130 & 72,98 \\
\hline 140 & 75,73 \\
\hline 145 & 76,96 \\
\hline 150 & 78,11 \\
\hline 160 & 80,14 \\
\hline 170 & 81,86 \\
\hline 180 & 83,3 \\
\hline 190 & 84,47 \\
\hline 200 & 85,45 \\
\hline 212 & 86,43 \\
\hline 242 & 88,29 \\
\hline 250 & 88,7 \\
\hline 300 & 91,09 \\
\hline 400 & 96,29 \\
\hline 500 & 99,47 \\
\hline
\end{tabular}

\begin{tabular}{|c|c|}
\hline $\begin{array}{c}\text { Diâmetro } \\
(\boldsymbol{\mu m})\end{array}$ & $\begin{array}{c}\% \\
\text { (valor } \\
\text { cumulativo) }\end{array}$ \\
\hline 600 & 100 \\
\hline 700 & 100 \\
\hline 800 & 100 \\
\hline 900 & 100 \\
\hline 1000 & 100 \\
\hline
\end{tabular}

\begin{tabular}{|c|cc|}
\hline \multicolumn{3}{|c|}{ amostra analisada } \\
\hline argila & 3,04 & $\%$ \\
\hline silte & 47,49 & $\%$ \\
\hline areia/cascalho & 49,47 & $\%$ \\
\hline
\end{tabular}

\begin{tabular}{|c|rc|}
\hline Massa Total & 9,1927 & $\mathrm{~g}$ \\
\hline Massa $>200 \mu \mathrm{m}$ & 2,5955 & $\mathrm{~g}$ \\
\hline
\end{tabular}

SP - 130

\begin{tabular}{|c|cc|}
\hline \multicolumn{3}{|c|}{ amostra original } \\
\hline argila & $\mathbf{2 , 1 8}$ & $\%$ \\
\hline silte & $\mathbf{3 4 , 0 8}$ & $\%$ \\
\hline areia/cascalho & $\mathbf{6 3 , 7 4}$ & $\%$ \\
\hline
\end{tabular}


Tabela 40: Determinação granulométrica, SP-131.

\begin{tabular}{|c|c|}
\hline $\begin{array}{c}\text { Diâmetro } \\
(\mu \mathrm{m})\end{array}$ & $\begin{array}{c}\% \\
\text { (valor cumulativo) }\end{array}$ \\
\hline 0,04 & 0,39 \\
\hline 0,07 & 0,44 \\
\hline 0,1 & 0,54 \\
\hline 0,2 & 1,57 \\
\hline 0,3 & 2,9 \\
\hline 0,4 & 3,54 \\
\hline 0,5 & 3,54 \\
\hline 0,6 & 3,54 \\
\hline 0,7 & 3,54 \\
\hline 0,8 & 3,58 \\
\hline 0,9 & 3,68 \\
\hline 1 & 3,83 \\
\hline 1,1 & 4,03 \\
\hline 1,2 & 4,27 \\
\hline 1,3 & 4,56 \\
\hline 1,4 & 4,88 \\
\hline 1,6 & 5,65 \\
\hline 1,8 & 6,54 \\
\hline 2 & 7,51 \\
\hline 2,2 & 8,55 \\
\hline 2,4 & 9,64 \\
\hline 2,6 & 10,75 \\
\hline 3 & 13,01 \\
\hline 4 & 18,42 \\
\hline 5 & 23,16 \\
\hline 6 & 27,4 \\
\hline 6,5 & 29,38 \\
\hline 7 & 31,32 \\
\hline 7,5 & 33,25 \\
\hline 8 & 35,19 \\
\hline 8,5 & 37,15 \\
\hline 9 & 39,12 \\
\hline 10 & 43,04 \\
\hline 11 & 46,92 \\
\hline 12 & 50,69 \\
\hline 13 & 54,32 \\
\hline 14 & 57,76 \\
\hline 15 & 60,99 \\
\hline 16 & 63,99 \\
\hline 17 & 66,77 \\
\hline
\end{tabular}

\begin{tabular}{|c|c|}
\hline $\begin{array}{l}\text { Diâmetro } \\
\qquad(\mu \mathrm{m})\end{array}$ & $\begin{array}{c}\% \\
\text { (valor cumulativo) }\end{array}$ \\
\hline 18 & 69,34 \\
\hline 19 & 71,7 \\
\hline 20 & 73,86 \\
\hline 22 & 77,64 \\
\hline 25 & 82,1 \\
\hline 28 & 85,47 \\
\hline 32 & 88,83 \\
\hline 36 & 91,28 \\
\hline 38 & 92,27 \\
\hline 40 & 93,13 \\
\hline 45 & 94,85 \\
\hline 50 & 96,14 \\
\hline 53 & 96,77 \\
\hline 56 & 97,3 \\
\hline 63 & 98,26 \\
\hline 71 & 99 \\
\hline 75 & 99,26 \\
\hline 80 & 99,51 \\
\hline 85 & 99,69 \\
\hline 90 & 99,82 \\
\hline 95 & 99,9 \\
\hline 100 & 99,95 \\
\hline 106 & 99,99 \\
\hline 112 & 100 \\
\hline 125 & 100 \\
\hline 130 & 100 \\
\hline 140 & 100 \\
\hline 145 & 100 \\
\hline 150 & 100 \\
\hline 160 & 100 \\
\hline 170 & 100 \\
\hline 180 & 100 \\
\hline 190 & 100 \\
\hline 200 & 100 \\
\hline 212 & 100 \\
\hline 242 & 100 \\
\hline 250 & 100 \\
\hline 300 & 100 \\
\hline 400 & 100 \\
\hline 500 & 100 \\
\hline
\end{tabular}

\begin{tabular}{|c|cc|}
\hline \multicolumn{3}{|c|}{ amostra analisada } \\
\hline argila & 7,51 & $\%$ \\
\hline silte & 90,75 & $\%$ \\
\hline areia/cascalho & 1,74 & $\%$ \\
\hline
\end{tabular}

\begin{tabular}{|c|cc|}
\hline Massa Total & 5,6825 & $\mathrm{~g}$ \\
\hline Massa $>200 \mu \mathrm{m}$ & 0,8596 & $\mathrm{~g}$ \\
\hline
\end{tabular}

\section{SP - 131}

\begin{tabular}{|c|cc|}
\hline \multicolumn{3}{|c|}{ amostra original } \\
\hline argila & $\mathbf{6 , 3 7}$ & $\%$ \\
\hline silte & $\mathbf{7 7 , 0 2}$ & $\%$ \\
\hline areia/cascalho & $\mathbf{1 6 , 6 0}$ & $\%$ \\
\hline
\end{tabular}


Tabela 41: Determinação granulométrica, SP-132.

\begin{tabular}{|c|c|}
\hline $\begin{array}{c}\text { Diâmetro } \\
(\mu \mathrm{m})\end{array}$ & $\begin{array}{c}\% \\
\text { (valor cumulativo) }\end{array}$ \\
\hline 0,04 & 0,31 \\
\hline 0,07 & 0,34 \\
\hline 0,1 & 0,42 \\
\hline 0,2 & 1,23 \\
\hline 0,3 & 2,28 \\
\hline 0,4 & 2,78 \\
\hline 0,5 & 2,78 \\
\hline 0,6 & 2,78 \\
\hline 0,7 & 2,78 \\
\hline 0,8 & 2,82 \\
\hline 0,9 & 2,9 \\
\hline 1 & 3,02 \\
\hline 1,1 & 3,19 \\
\hline 1,2 & 3,4 \\
\hline 1,3 & 3,63 \\
\hline 1,4 & 3,9 \\
\hline 1,6 & 4,53 \\
\hline 1,8 & 5,26 \\
\hline 2 & 6,06 \\
\hline 2,2 & 6,91 \\
\hline 2,4 & 7,79 \\
\hline 2,6 & 8,69 \\
\hline 3 & 10,52 \\
\hline 4 & 14,91 \\
\hline 5 & 18,82 \\
\hline 6 & 22,37 \\
\hline 6,5 & 24,05 \\
\hline 7 & 25,7 \\
\hline 7,5 & 27,34 \\
\hline 8 & 28,97 \\
\hline 8,5 & 30,62 \\
\hline 9 & 32,27 \\
\hline 10 & 35,55 \\
\hline 11 & 38,78 \\
\hline 12 & 41,93 \\
\hline 13 & 44,99 \\
\hline 14 & 47,92 \\
\hline 15 & 50,71 \\
\hline 16 & 53,35 \\
\hline 17 & 55,83 \\
\hline
\end{tabular}

\begin{tabular}{|c|c|}
\hline $\begin{array}{l}\text { Diâmetro } \\
(\mu \mathrm{m})\end{array}$ & $\begin{array}{c}\% \\
\text { (valor cumulativo) }\end{array}$ \\
\hline 18 & 58,16 \\
\hline 19 & 60,35 \\
\hline 20 & 62,39 \\
\hline 22 & 66,04 \\
\hline 25 & 70,54 \\
\hline 28 & 74,05 \\
\hline 32 & 77,51 \\
\hline 36 & 79,98 \\
\hline 38 & 80,94 \\
\hline 40 & 81,77 \\
\hline 45 & 83,38 \\
\hline 50 & 84,54 \\
\hline 53 & 85,1 \\
\hline 56 & 85,6 \\
\hline 63 & 86,61 \\
\hline 71 & 87,75 \\
\hline 75 & 88,38 \\
\hline 80 & 89,2 \\
\hline 85 & 90,04 \\
\hline 90 & 90,9 \\
\hline 95 & 91,74 \\
\hline 100 & 92,57 \\
\hline 106 & 93,53 \\
\hline 112 & 94,42 \\
\hline 125 & 96,13 \\
\hline 130 & 96,69 \\
\hline 140 & 97,63 \\
\hline 145 & 98,01 \\
\hline 150 & 98,35 \\
\hline 160 & 98,88 \\
\hline 170 & 99,28 \\
\hline 180 & 99,56 \\
\hline 190 & 99,74 \\
\hline 200 & 99,85 \\
\hline 212 & 99,94 \\
\hline 242 & 100 \\
\hline 250 & 100 \\
\hline 300 & 100 \\
\hline 400 & 100 \\
\hline 500 & 100 \\
\hline
\end{tabular}

SP - 132

\begin{tabular}{|c|cc|}
\hline \multicolumn{3}{|c|}{ amostra original } \\
\hline argila & $\mathbf{6 , 0 6}$ & $\%$ \\
\hline silte & $\mathbf{8 0 , 5 5}$ & $\%$ \\
\hline areia/cascalho & $\mathbf{1 3 , 3 9}$ & $\%$ \\
\hline
\end{tabular}


Tabela 42: Determinação granulométrica, SP-133.

\begin{tabular}{|c|c|}
\hline $\begin{array}{l}\text { Diâmetro } \\
(\mu \mathrm{m})\end{array}$ & $\begin{array}{c}\% \\
\text { (valor cumulativo) }\end{array}$ \\
\hline 0,04 & 0,26 \\
\hline 0,07 & 0,29 \\
\hline 0,1 & 0,32 \\
\hline 0,2 & 0,65 \\
\hline 0,3 & 1,1 \\
\hline 0,4 & 1,33 \\
\hline 0,5 & 1,33 \\
\hline 0,6 & 1,33 \\
\hline 0,7 & 1,33 \\
\hline 0,8 & 1,33 \\
\hline 0,9 & 1,36 \\
\hline 1 & 1,39 \\
\hline 1,1 & 1,45 \\
\hline 1,2 & 1,52 \\
\hline 1,3 & 1,61 \\
\hline 1,4 & 1,7 \\
\hline 1,6 & 1,93 \\
\hline 1,8 & 2,2 \\
\hline 2 & 2,5 \\
\hline 2,2 & 2,82 \\
\hline 2,4 & 3,15 \\
\hline 2,6 & 3,49 \\
\hline 3 & 4,18 \\
\hline 4 & 5,83 \\
\hline 5 & 7,29 \\
\hline 6 & 8,61 \\
\hline 6,5 & 9,24 \\
\hline 7 & 9,85 \\
\hline 7,5 & 10,46 \\
\hline 8 & 11,07 \\
\hline 8,5 & 11,68 \\
\hline 9 & 12,29 \\
\hline 10 & 13,48 \\
\hline 11 & 14,63 \\
\hline 12 & 15,74 \\
\hline 13 & 16,79 \\
\hline 14 & 17,78 \\
\hline 15 & 18,71 \\
\hline 16 & 19,58 \\
\hline 17 & 20,4 \\
\hline
\end{tabular}

\begin{tabular}{|c|c|}
\hline $\begin{array}{c}\text { Diâmetro } \\
(\mu \mathrm{m})\end{array}$ & $\begin{array}{c}\% \\
\text { (valor cumulativo) }\end{array}$ \\
\hline 18 & 21,18 \\
\hline 19 & 21,91 \\
\hline 20 & 22,6 \\
\hline 22 & 23,9 \\
\hline 25 & 25,65 \\
\hline 28 & 27,18 \\
\hline 32 & 28,8 \\
\hline 36 & 29,95 \\
\hline 38 & 30,37 \\
\hline 40 & 30,7 \\
\hline 45 & 31,15 \\
\hline 50 & 31,15 \\
\hline 53 & 31,15 \\
\hline 56 & 31,15 \\
\hline 63 & 31,15 \\
\hline 71 & 31,15 \\
\hline 75 & 31,15 \\
\hline 80 & 31,15 \\
\hline 85 & 31,15 \\
\hline 90 & 31,15 \\
\hline 95 & 31,15 \\
\hline 100 & 31,15 \\
\hline 106 & 31,15 \\
\hline 112 & 31,15 \\
\hline 125 & 31,15 \\
\hline 130 & 31,15 \\
\hline 140 & 31,15 \\
\hline 145 & 31,15 \\
\hline 150 & 31,15 \\
\hline 160 & 31,15 \\
\hline 170 & 31,15 \\
\hline 180 & 31,15 \\
\hline 190 & 31,15 \\
\hline 200 & 31,15 \\
\hline 212 & 31,15 \\
\hline 242 & 31,15 \\
\hline 250 & 31,15 \\
\hline 300 & 31,15 \\
\hline 400 & 31,15 \\
\hline 500 & 31,15 \\
\hline
\end{tabular}

SP - 133

\begin{tabular}{|c|cc|}
\hline \multicolumn{3}{|c|}{ amostra original } \\
\hline argila & $\mathbf{2 , 5 0}$ & $\%$ \\
\hline silte & $\mathbf{2 8 , 6 5}$ & $\%$ \\
\hline areia/cascalho & $\mathbf{6 8 , 8 5}$ & $\%$ \\
\hline
\end{tabular}


Tabela 43: Determinação granulométrica, SP-134.

\begin{tabular}{|c|c|}
\hline $\begin{array}{c}\text { Diâmetro } \\
(\mu \mathrm{m})\end{array}$ & $\begin{array}{c}\% \\
\text { (valor } \\
\text { cumulativo) }\end{array}$ \\
\hline 0,04 & 0,56 \\
\hline 0,07 & 0,61 \\
\hline 0,1 & 0,68 \\
\hline 0,2 & 1,36 \\
\hline 0,3 & 2,29 \\
\hline 0,4 & 2,73 \\
\hline 0,5 & 2,77 \\
\hline 0,6 & 2,78 \\
\hline 0,7 & 2,8 \\
\hline 0,8 & 2,91 \\
\hline 0,9 & 3,08 \\
\hline 1 & 3,27 \\
\hline 1,1 & 3,49 \\
\hline 1,2 & 3,73 \\
\hline 1,3 & 3,99 \\
\hline 1,4 & 4,27 \\
\hline 1,6 & 4,89 \\
\hline 1,8 & 5,57 \\
\hline 2 & 6,28 \\
\hline 2,2 & 7,02 \\
\hline 2,4 & 7,76 \\
\hline 2,6 & 8,51 \\
\hline 3 & 9,96 \\
\hline 4 & 13,23 \\
\hline 5 & 15,93 \\
\hline 6 & 18,27 \\
\hline 6,5 & 19,35 \\
\hline 7 & 20,41 \\
\hline 7,5 & 21,45 \\
\hline 8 & 22,49 \\
\hline 8,5 & 23,54 \\
\hline 9 & 24,59 \\
\hline 10 & 26,67 \\
\hline 11 & 28,69 \\
\hline 12 & 30,62 \\
\hline 13 & 32,46 \\
\hline 14 & 34,19 \\
\hline 15 & 35,8 \\
\hline 16 & 37,28 \\
\hline 17 & 38,65 \\
\hline
\end{tabular}

\begin{tabular}{|c|c|}
\hline $\begin{array}{c}\text { Diâmetro } \\
(\mu \mathrm{m})\end{array}$ & $\begin{array}{c}\% \\
\text { (valor } \\
\text { cumulativo) }\end{array}$ \\
\hline 18 & 39,91 \\
\hline 19 & 41,07 \\
\hline 20 & 42,14 \\
\hline 22 & 44,05 \\
\hline 25 & 46,44 \\
\hline 28 & 48,4 \\
\hline 32 & 50,57 \\
\hline 36 & 52,36 \\
\hline 38 & 53,17 \\
\hline 40 & 53,92 \\
\hline 45 & 55,62 \\
\hline 50 & 57,13 \\
\hline 53 & 57,97 \\
\hline 56 & 58,75 \\
\hline 63 & 60,42 \\
\hline 71 & 62,08 \\
\hline 75 & 62,82 \\
\hline 80 & 63,67 \\
\hline 85 & 64,44 \\
\hline 90 & 65,14 \\
\hline 95 & 65,77 \\
\hline 100 & 66,35 \\
\hline 106 & 66,98 \\
\hline 112 & 67,55 \\
\hline 125 & 68,63 \\
\hline 130 & 69,01 \\
\hline 140 & 69,72 \\
\hline 145 & 70,06 \\
\hline 150 & 70,39 \\
\hline 160 & 71,04 \\
\hline 170 & 71,7 \\
\hline 180 & 72,37 \\
\hline 190 & 73,06 \\
\hline 200 & 73,78 \\
\hline 212 & 74,69 \\
\hline 242 & 77,18 \\
\hline 250 & 77,91 \\
\hline 300 & 82,8 \\
\hline 400 & 92,88 \\
\hline 500 & 98,98 \\
\hline
\end{tabular}

\begin{tabular}{|c|c|}
\hline $\begin{array}{c}\text { Diâmetro } \\
(\boldsymbol{\mu m})\end{array}$ & $\begin{array}{c}\% \\
\text { (valor } \\
\text { cumulativo) }\end{array}$ \\
\hline 600 & 100 \\
\hline 700 & 100 \\
\hline 800 & 100 \\
\hline 900 & 100 \\
\hline 1000 & 100 \\
\hline
\end{tabular}

\begin{tabular}{|c|cr|}
\hline \multicolumn{3}{|c|}{ amostra analisada } \\
\hline argila & 6,28 & $\%$ \\
\hline silte & 54,14 & $\%$ \\
\hline areia/cascalho & 39,58 & $\%$ \\
\hline
\end{tabular}

\begin{tabular}{|c|cc|}
\hline Massa Total & 15,0399 & $\mathrm{~g}$ \\
\hline Massa $>200 \mu \mathrm{m}$ & 8,1387 & $\mathrm{~g}$ \\
\hline
\end{tabular}

SP - 134

\begin{tabular}{|c|cc|}
\hline \multicolumn{3}{|c|}{ amostra original } \\
\hline argila & $\mathbf{2 , 8 8}$ & $\%$ \\
\hline silte & $\mathbf{2 4 , 8 4}$ & $\%$ \\
\hline areia/cascalho & $\mathbf{7 2 , 2 8}$ & $\%$ \\
\hline
\end{tabular}


Tabela 44: Determinação granulométrica, SP-135.

\begin{tabular}{|c|c|}
\hline $\begin{array}{c}\text { Diâmetro } \\
(\mu \mathrm{m})\end{array}$ & $\begin{array}{c}\% \\
\text { (valor } \\
\text { cumulativo) }\end{array}$ \\
\hline 0,04 & 0,3 \\
\hline 0,07 & 0,31 \\
\hline 0,1 & 0,34 \\
\hline 0,2 & 0,7 \\
\hline 0,3 & 1,21 \\
\hline 0,4 & 1,45 \\
\hline 0,5 & 1,45 \\
\hline 0,6 & 1,45 \\
\hline 0,7 & 1,45 \\
\hline 0,8 & 1,49 \\
\hline 0,9 & 1,55 \\
\hline 1 & 1,63 \\
\hline 1,1 & 1,74 \\
\hline 1,2 & 1,85 \\
\hline 1,3 & 1,98 \\
\hline 1,4 & 2,13 \\
\hline 1,6 & 2,46 \\
\hline 1,8 & 2,84 \\
\hline 2 & 3,25 \\
\hline 2,2 & 3,68 \\
\hline 2,4 & 4,13 \\
\hline 2,6 & 4,6 \\
\hline 3 & 5,53 \\
\hline 4 & 7,79 \\
\hline 5 & 9,78 \\
\hline 6 & 11,56 \\
\hline 6,5 & 12,4 \\
\hline 7 & 13,22 \\
\hline 7,5 & 14,05 \\
\hline 8 & 14,88 \\
\hline 8,5 & 15,73 \\
\hline 9 & 16,59 \\
\hline 10 & 18,32 \\
\hline 11 & 20,03 \\
\hline 12 & 21,71 \\
\hline 13 & 23,33 \\
\hline 14 & 24,86 \\
\hline 15 & 26,3 \\
\hline 16 & 27,62 \\
\hline 17 & 28,85 \\
\hline
\end{tabular}

\begin{tabular}{|c|c|c|c|}
\hline $\begin{array}{c}\text { Diâmetro } \\
\qquad(\mu \mathrm{m})\end{array}$ & $\begin{array}{c}\% \\
\text { (valor } \\
\text { cumulativo) }\end{array}$ & $\begin{array}{c}\text { Diâmetro } \\
(\mu \mathrm{m})\end{array}$ & $\begin{array}{c}\% \\
\text { (valor } \\
\text { cumulativo) }\end{array}$ \\
\hline 18 & 29,97 & 600 & 100 \\
\hline 19 & 31 & 700 & 100 \\
\hline 20 & 31,93 & 800 & 100 \\
\hline 22 & 33,56 & 900 & 100 \\
\hline 25 & 35,5 & 1000 & 100 \\
\hline
\end{tabular}

\begin{tabular}{|c|c|}
\hline 28 & 36,97 \\
\hline 32 & 38,43 \\
\hline 36 & 39,5 \\
\hline 38
\end{tabular}

\begin{tabular}{|c|c|}
\hline 38 & 39,93 \\
\hline 40 & 40,32 \\
\hline 45 & 41,1 \\
\hline 50 & 41,73 \\
\hline
\end{tabular}

\begin{tabular}{|l|l|}
\hline 50 & 41,73 \\
\hline 53 & 42,05 \\
\hline 56 & 42,35 \\
\hline 63 & 42,97 \\
\hline
\end{tabular}

\begin{tabular}{|l|l|}
\hline 63 & 42,97 \\
\hline 71 & 43,65 \\
\hline 75 & 43,99 \\
\hline 80 & 44,41 \\
\hline
\end{tabular}

\begin{tabular}{|l|l|}
\hline 80 & 44,41 \\
\hline 85 & 44,83 \\
\hline 90 & 45,25 \\
\hline 95 & 45,68 \\
\hline
\end{tabular}

\begin{tabular}{|c|c|}
\hline 95 & 45,68 \\
\hline 100 & 46,09 \\
\hline 106 & 46,58 \\
\hline 112 & 47,06 \\
\hline 125 & 48,02 \\
\hline 130 & 48,36 \\
\hline
\end{tabular}

\begin{tabular}{|c|c|}
\hline 130 & 48,36 \\
\hline 140 & 49 \\
\hline 145 & 49,28 \\
\hline 150 & 49,56 \\
\hline
\end{tabular}

\begin{tabular}{|c|cc|}
\hline \multicolumn{3}{|c|}{ amostra analisada } \\
\hline argila & 3,25 & $\%$ \\
\hline silte & 39,72 & $\%$ \\
\hline areia/cascalho & 57,03 & $\%$ \\
\hline
\end{tabular}

\begin{tabular}{|c|c|}
\hline 160 & 50,1 \\
\hline 170 & 50,65 \\
\hline 180 & 51,23 \\
\hline 190 & 51,86 \\
\hline 200 & 52,56 \\
\hline 212 & 53,51 \\
\hline 242 & 56,54 \\
\hline 250 & 57,53 \\
\hline 300 & 65,49 \\
\hline 400 & 86,17 \\
\hline 500 & 98,02 \\
\hline
\end{tabular}

\begin{tabular}{|c|cc|}
\hline Massa Total & 18,8969 & $\mathrm{~g}$ \\
\hline Massa $>200 \mu \mathrm{m}$ & 12,0618 & $\mathrm{~g}$ \\
\hline
\end{tabular}

SP - 135

\begin{tabular}{|c|rr|}
\hline \multicolumn{3}{|c|}{ amostra original } \\
\hline argila & $\mathbf{1 , 1 8}$ & $\%$ \\
\hline silte & $\mathbf{1 4 , 3 7}$ & $\%$ \\
\hline areia/cascalho & $\mathbf{8 4 , 4 6}$ & $\%$ \\
\hline
\end{tabular}


Tabela 45: Determinação granulométrica, SP-136.

\begin{tabular}{|c|c|}
\hline $\begin{array}{l}\text { Diâmetro } \\
(\mu \mathrm{m})\end{array}$ & $\begin{array}{c}\% \\
\text { (valor cumulativo) }\end{array}$ \\
\hline 0,04 & 0,43 \\
\hline 0,07 & 0,46 \\
\hline 0,1 & 0,55 \\
\hline 0,2 & 1,62 \\
\hline 0,3 & 3,04 \\
\hline 0,4 & 3,71 \\
\hline 0,5 & 3,74 \\
\hline 0,6 & 3,75 \\
\hline 0,7 & 3,76 \\
\hline 0,8 & 3,91 \\
\hline 0,9 & 4,12 \\
\hline 1 & 4,39 \\
\hline 1,1 & 4,69 \\
\hline 1,2 & 5,03 \\
\hline 1,3 & 5,39 \\
\hline 1,4 & 5,79 \\
\hline 1,6 & 6,68 \\
\hline 1,8 & 7,66 \\
\hline 2 & 8,69 \\
\hline 2,2 & 9,78 \\
\hline 2,4 & 10,87 \\
\hline 2,6 & 11,97 \\
\hline 3 & 14,13 \\
\hline 4 & 19,03 \\
\hline 5 & 23,17 \\
\hline 6 & 26,84 \\
\hline 6,5 & 28,55 \\
\hline 7 & 30,22 \\
\hline 7,5 & 31,88 \\
\hline 8 & 33,53 \\
\hline 8,5 & 35,19 \\
\hline 9 & 36,84 \\
\hline 10 & 40,08 \\
\hline 11 & 43,23 \\
\hline 12 & 46,25 \\
\hline 13 & 49,13 \\
\hline 14 & 51,84 \\
\hline 15 & 54,37 \\
\hline 16 & 56,73 \\
\hline 17 & 58,93 \\
\hline
\end{tabular}

\begin{tabular}{|c|c|}
\hline $\begin{array}{c}\text { Diâmetro } \\
(\mu \mathrm{m})\end{array}$ & $\begin{array}{c}\% \\
\text { (valor cumulativo) }\end{array}$ \\
\hline 18 & 60,97 \\
\hline 19 & 62,86 \\
\hline 20 & 64,62 \\
\hline 22 & 67,79 \\
\hline 25 & 71,76 \\
\hline 28 & 75 \\
\hline 32 & 78,47 \\
\hline 36 & 81,24 \\
\hline 38 & 82,42 \\
\hline 40 & 83,51 \\
\hline 45 & 85,88 \\
\hline 50 & 87,87 \\
\hline 53 & 88,92 \\
\hline 56 & 89,88 \\
\hline 63 & 91,81 \\
\hline 71 & 93,6 \\
\hline 75 & 94,36 \\
\hline 80 & 95,19 \\
\hline 85 & 95,92 \\
\hline 90 & 96,56 \\
\hline 95 & 97,12 \\
\hline 100 & 97,6 \\
\hline 106 & 98,1 \\
\hline 112 & 98,51 \\
\hline 125 & 99,18 \\
\hline 130 & 99,36 \\
\hline 140 & 99,64 \\
\hline 145 & 99,74 \\
\hline 150 & 99,81 \\
\hline 160 & 99,91 \\
\hline 170 & 99,97 \\
\hline 180 & 100 \\
\hline 190 & 100 \\
\hline 200 & 100 \\
\hline 212 & 100 \\
\hline 242 & 100 \\
\hline 250 & 100 \\
\hline 300 & 100 \\
\hline 400 & 100 \\
\hline 500 & 100 \\
\hline
\end{tabular}

\begin{tabular}{|c|cc|}
\hline \multicolumn{3}{|c|}{ amostra analisada } \\
\hline argila & 8,69 & $\%$ \\
\hline silte & 83,12 & $\%$ \\
\hline areia/cascalho & 8,19 & $\%$ \\
\hline
\end{tabular}

\begin{tabular}{|c|cc|}
\hline Massa Total & 16,05 & $\mathrm{~g}$ \\
\hline Massa $>200 \mu \mathrm{m}$ & 12,47 & $\mathrm{~g}$ \\
\hline
\end{tabular}

\section{SP - 136}

\begin{tabular}{|c|cc|}
\hline \multicolumn{3}{|c|}{ amostra original } \\
\hline argila & $\mathbf{1 , 9 4}$ & $\%$ \\
\hline silte & $\mathbf{1 8 , 5 4}$ & $\%$ \\
\hline areia/cascalho & $\mathbf{7 9 , 5 2}$ & $\%$ \\
\hline
\end{tabular}


Tabela 46: Determinação granulométrica, SP-137.

\begin{tabular}{|c|c|}
\hline $\begin{array}{c}\text { Diâmetro } \\
(\mu \mathrm{m})\end{array}$ & $\begin{array}{c}\% \\
\text { (valor } \\
\text { cumulativo) }\end{array}$ \\
\hline 0,04 & 0,18 \\
\hline 0,07 & 0,18 \\
\hline 0,1 & 0,19 \\
\hline 0,2 & 0,41 \\
\hline 0,3 & 0,73 \\
\hline 0,4 & 0,87 \\
\hline 0,5 & 0,87 \\
\hline 0,6 & 0,87 \\
\hline 0,7 & 0,87 \\
\hline 0,8 & 0,92 \\
\hline 0,9 & 0,98 \\
\hline 1 & 1,06 \\
\hline 1,1 & 1,15 \\
\hline 1,2 & 1,25 \\
\hline 1,3 & 1,36 \\
\hline 1,4 & 1,48 \\
\hline 1,6 & 1,75 \\
\hline 1,8 & 2,05 \\
\hline 2 & 2,36 \\
\hline 2,2 & 2,69 \\
\hline 2,4 & 3,03 \\
\hline 2,6 & 3,37 \\
\hline 3 & 4,05 \\
\hline 4 & 5,67 \\
\hline 5 & 7,16 \\
\hline 6 & 8,57 \\
\hline 6,5 & 9,25 \\
\hline 7 & 9,93 \\
\hline 7,5 & 10,61 \\
\hline 8 & 11,29 \\
\hline 8,5 & 11,98 \\
\hline 9 & 12,67 \\
\hline 10 & 14,05 \\
\hline 11 & 15,42 \\
\hline 12 & 16,76 \\
\hline 13 & 18,08 \\
\hline 14 & 19,36 \\
\hline 15 & 20,61 \\
\hline 16 & 21,83 \\
\hline 17 & 23,01 \\
\hline
\end{tabular}

\begin{tabular}{|c|c|}
\hline $\begin{array}{l}\text { Diâmetro } \\
(\mu \mathrm{m})\end{array}$ & $\begin{array}{c}\% \\
\text { (valor } \\
\text { cumulativo) }\end{array}$ \\
\hline 18 & 24,16 \\
\hline 19 & 25,27 \\
\hline 20 & 26,35 \\
\hline 22 & 28,4 \\
\hline 25 & 31,21 \\
\hline 28 & 33,68 \\
\hline 32 & 36,42 \\
\hline 36 & 38,6 \\
\hline 38 & 39,51 \\
\hline 40 & 40,32 \\
\hline 45 & 42 \\
\hline 50 & 43,26 \\
\hline 53 & 43,89 \\
\hline 56 & 44,45 \\
\hline 63 & 45,59 \\
\hline 71 & 46,87 \\
\hline 75 & 47,56 \\
\hline 80 & 48,5 \\
\hline 85 & 49,54 \\
\hline 90 & 50,71 \\
\hline 95 & 52,01 \\
\hline 100 & 53,42 \\
\hline 106 & 55,22 \\
\hline 112 & 57,14 \\
\hline 125 & 61,54 \\
\hline 130 & 63,27 \\
\hline 140 & 66,7 \\
\hline 145 & 68,4 \\
\hline 150 & 70,05 \\
\hline 160 & 73,21 \\
\hline 170 & 76,12 \\
\hline 180 & 78,75 \\
\hline 190 & 81,05 \\
\hline 200 & 83,08 \\
\hline 212 & 85,19 \\
\hline 242 & 89,2 \\
\hline 250 & 90,03 \\
\hline 300 & 93,74 \\
\hline 400 & 97,76 \\
\hline 500 & 99,68 \\
\hline
\end{tabular}

\begin{tabular}{|c|c|}
\hline $\begin{array}{c}\text { Diâmetro } \\
(\boldsymbol{\mu m})\end{array}$ & $\begin{array}{c}\text { \% } \\
\text { (valor } \\
\text { cumulativo) }\end{array}$ \\
\hline 600 & 100 \\
\hline 700 & 100 \\
\hline 800 & 100 \\
\hline 900 & 100 \\
\hline 1000 & 100 \\
\hline
\end{tabular}


Tabela 47: Determinação granulométrica, SP-138.

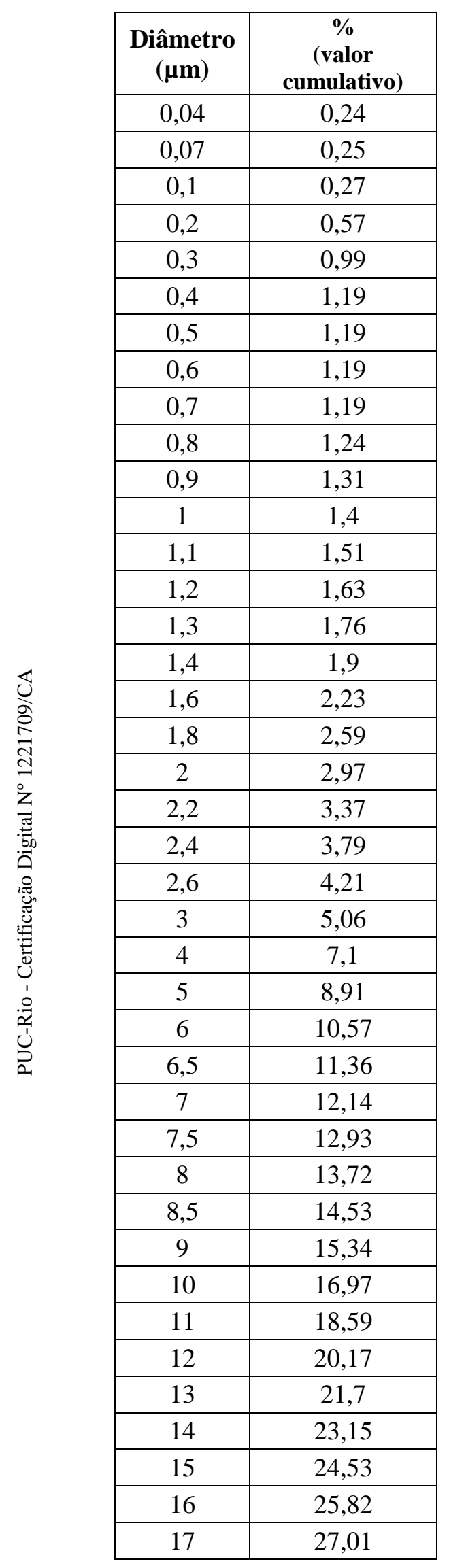

\begin{tabular}{|c|c|}
\hline $\begin{array}{c}\text { Diâmetro } \\
(\mu \mathrm{m})\end{array}$ & $\begin{array}{c}\% \\
\text { (valor } \\
\text { cumulativo) }\end{array}$ \\
\hline 18 & 28,13 \\
\hline 19 & 29,16 \\
\hline 20 & 30,12 \\
\hline 22 & 31,81 \\
\hline 25 & 33,88 \\
\hline 28 & 35,49 \\
\hline 32 & 37,14 \\
\hline 36 & 38,39 \\
\hline 38 & 38,9 \\
\hline 40 & 39,37 \\
\hline 45 & 40,36 \\
\hline 50 & 41,18 \\
\hline 53 & 41,63 \\
\hline 56 & 42,07 \\
\hline 63 & 43,11 \\
\hline 71 & 44,46 \\
\hline 75 & 45,23 \\
\hline 80 & 46,3 \\
\hline 85 & 47,49 \\
\hline 90 & 48,81 \\
\hline 95 & 50,25 \\
\hline 100 & 51,8 \\
\hline 106 & 53,76 \\
\hline 112 & 55,81 \\
\hline 125 & 60,43 \\
\hline 130 & 62,21 \\
\hline 140 & 65,72 \\
\hline 145 & 67,44 \\
\hline 150 & 69,11 \\
\hline 160 & 72,28 \\
\hline 170 & 75,18 \\
\hline 180 & 77,8 \\
\hline 190 & 80,09 \\
\hline 200 & 82,11 \\
\hline 212 & 84,22 \\
\hline 242 & 88,27 \\
\hline 250 & 89,11 \\
\hline 300 & 93 \\
\hline 400 & 97,45 \\
\hline 500 & 99,64 \\
\hline
\end{tabular}

\begin{tabular}{|c|c|}
\hline $\begin{array}{c}\text { Diâmetro } \\
(\boldsymbol{\mu m})\end{array}$ & $\begin{array}{c}\text { \% } \\
\text { (valor } \\
\text { cumulativo) }\end{array}$ \\
\hline 600 & 100 \\
\hline 700 & 100 \\
\hline 800 & 100 \\
\hline 900 & 100 \\
\hline 1000 & 100 \\
\hline
\end{tabular}

\begin{tabular}{|c|cc|}
\hline \multicolumn{3}{|c|}{ amostra analisada } \\
\hline argila & 2,97 & $\%$ \\
\hline silte & 40,14 & $\%$ \\
\hline areia/cascalho & 56,89 & $\%$ \\
\hline
\end{tabular}

\begin{tabular}{|c|cc|}
\hline Massa Total & 10,0612 & $\mathrm{~g}$ \\
\hline Massa $>200 \mu \mathrm{m}$ & 0,6154 & $\mathrm{~g}$ \\
\hline
\end{tabular}

SP - 138

\begin{tabular}{|c|cc|}
\hline \multicolumn{3}{|c|}{ amostra original } \\
\hline argila & $\mathbf{2 , 7 9}$ & $\%$ \\
\hline silte & $\mathbf{3 7 , 6 8}$ & $\%$ \\
\hline areia/cascalho & $\mathbf{5 9 , 5 3}$ & $\%$ \\
\hline
\end{tabular}


Tabela 48: Determinação granulométrica, SP-139.

\begin{tabular}{|c|c|}
\hline $\begin{array}{c}\text { Diâmetro } \\
(\mu \mathrm{m})\end{array}$ & $\begin{array}{c}\% \\
\text { (valor } \\
\text { cumulativo) }\end{array}$ \\
\hline 0,04 & 0,13 \\
\hline 0,07 & 0,13 \\
\hline 0,1 & 0,13 \\
\hline 0,2 & 0,29 \\
\hline 0,3 & 0,56 \\
\hline 0,4 & 0,67 \\
\hline 0,5 & 0,67 \\
\hline 0,6 & 0,67 \\
\hline 0,7 & 0,67 \\
\hline 0,8 & 0,73 \\
\hline 0,9 & 0,8 \\
\hline 1 & 0,89 \\
\hline 1,1 & 0,98 \\
\hline 1,2 & 1,07 \\
\hline 1,3 & 1,18 \\
\hline 1,4 & 1,29 \\
\hline 1,6 & 1,52 \\
\hline 1,8 & 1,77 \\
\hline 2 & 2,03 \\
\hline 2,2 & 2,29 \\
\hline 2,4 & 2,56 \\
\hline 2,6 & 2,82 \\
\hline 3 & 3,33 \\
\hline 4 & 4,46 \\
\hline 5 & 5,42 \\
\hline 6 & 6,27 \\
\hline 6,5 & 6,68 \\
\hline 7 & 7,08 \\
\hline 7,5 & 7,49 \\
\hline 8 & 7,89 \\
\hline 8,5 & 8,31 \\
\hline 9 & 8,72 \\
\hline 10 & 9,55 \\
\hline 11 & 10,36 \\
\hline 12 & 11,13 \\
\hline 13 & 11,86 \\
\hline 14 & 12,55 \\
\hline 15 & 13,19 \\
\hline 16 & 13,78 \\
\hline 17 & 14,32 \\
\hline
\end{tabular}

\begin{tabular}{|c|c|}
\hline $\begin{array}{l}\text { Diâmetro } \\
\qquad(\mu \mathrm{m})\end{array}$ & $\begin{array}{c}\% \\
\text { (valor } \\
\text { cumulativo) }\end{array}$ \\
\hline 18 & 14,81 \\
\hline 19 & 15,27 \\
\hline 20 & 15,68 \\
\hline 22 & 16,42 \\
\hline 25 & 17,34 \\
\hline 28 & 18,11 \\
\hline 32 & 19,01 \\
\hline 36 & 19,82 \\
\hline 38 & 20,2 \\
\hline 40 & 20,58 \\
\hline 45 & 21,5 \\
\hline 50 & 22,38 \\
\hline 53 & 22,88 \\
\hline 56 & 23,36 \\
\hline 63 & 24,38 \\
\hline 71 & 25,38 \\
\hline 75 & 25,81 \\
\hline 80 & 26,29 \\
\hline 85 & 26,72 \\
\hline 90 & 27,12 \\
\hline 95 & 27,49 \\
\hline 100 & 27,85 \\
\hline 106 & 28,3 \\
\hline 112 & 28,77 \\
\hline 125 & 29,92 \\
\hline 130 & 30,44 \\
\hline 140 & 31,62 \\
\hline 145 & 32,29 \\
\hline 150 & 33,02 \\
\hline 160 & 34,59 \\
\hline 170 & 36,33 \\
\hline 180 & 38,21 \\
\hline 190 & 40,22 \\
\hline 200 & 42,32 \\
\hline 212 & 44,9 \\
\hline 242 & 51,51 \\
\hline 250 & 53,28 \\
\hline 300 & 64,53 \\
\hline 400 & 85,95 \\
\hline 500 & 98 \\
\hline
\end{tabular}

\begin{tabular}{|c|c|}
\hline $\begin{array}{c}\text { Diâmetro } \\
(\boldsymbol{\mu m})\end{array}$ & $\begin{array}{c}\% \\
\text { (valor } \\
\text { cumulativo) }\end{array}$ \\
\hline 600 & 99,8 \\
\hline 700 & 100 \\
\hline 800 & 100 \\
\hline 900 & 100 \\
\hline 1000 & 100 \\
\hline
\end{tabular}

\begin{tabular}{|c|cc|}
\hline \multicolumn{3}{|c|}{ amostra analisada } \\
\hline argila & 2,03 & $\%$ \\
\hline silte & 22,35 & $\%$ \\
\hline areia/cascalho & 75,62 & $\%$ \\
\hline
\end{tabular}

\begin{tabular}{|c|cc|}
\hline Massa Total & 18,5931 & $\mathrm{~g}$ \\
\hline Massa $>200 \mu \mathrm{m}$ & 5,0122 & $\mathrm{~g}$ \\
\hline
\end{tabular}

SP - 139

\begin{tabular}{|c|cc|}
\hline \multicolumn{3}{|c|}{ amostra original } \\
\hline argila & $\mathbf{1 , 4 8}$ & $\%$ \\
\hline silte & $\mathbf{1 6 , 3 3}$ & $\%$ \\
\hline areia/cascalho & $\mathbf{8 2 , 1 9}$ & $\%$ \\
\hline
\end{tabular}


Tabela 49: Determinação granulométrica, SP-140.

\begin{tabular}{|c|c|}
\hline $\begin{array}{c}\text { Diâmetro } \\
(\mu \mathrm{m})\end{array}$ & $\begin{array}{c}\% \\
\text { (valor } \\
\text { cumulativo) }\end{array}$ \\
\hline 0,04 & 0 \\
\hline 0,07 & 0 \\
\hline 0,1 & 0 \\
\hline 0,2 & 0 \\
\hline 0,3 & 0 \\
\hline 0,4 & 0 \\
\hline 0,5 & 0 \\
\hline 0,6 & 0 \\
\hline 0,7 & 0 \\
\hline 0,8 & 0 \\
\hline 0,9 & 0 \\
\hline 1 & 0 \\
\hline 1,1 & 0,01 \\
\hline 1,2 & 0,02 \\
\hline 1,3 & 0,04 \\
\hline 1,4 & 0,05 \\
\hline 1,6 & 0,08 \\
\hline 1,8 & 0,1 \\
\hline 2 & 0,13 \\
\hline 2,2 & 0,15 \\
\hline 2,4 & 0,17 \\
\hline 2,6 & 0,18 \\
\hline 3 & 0,22 \\
\hline 4 & 0,28 \\
\hline 5 & 0,28 \\
\hline 6 & 0,28 \\
\hline 6,5 & 0,3 \\
\hline 7 & 0,32 \\
\hline 7,5 & 0,34 \\
\hline 8 & 0,37 \\
\hline 8,5 & 0,39 \\
\hline 9 & 0,41 \\
\hline 10 & 0,46 \\
\hline 11 & 0,5 \\
\hline 12 & 0,54 \\
\hline 13 & 0,57 \\
\hline 14 & 0,61 \\
\hline 15 & 0,63 \\
\hline 16 & 0,66 \\
\hline 17 & 0,68 \\
\hline
\end{tabular}

\begin{tabular}{|c|c|}
\hline $\begin{array}{c}\text { Diâmetro } \\
\qquad(\mu \mathrm{m})\end{array}$ & $\begin{array}{c}\% \\
\text { (valor } \\
\text { cumulativo) }\end{array}$ \\
\hline 18 & 0,7 \\
\hline 19 & 0,72 \\
\hline 20 & 0,74 \\
\hline 22 & 0,77 \\
\hline 25 & 0,83 \\
\hline 28 & 0,89 \\
\hline 32 & 0,98 \\
\hline 36 & 1,07 \\
\hline 38 & 1,11 \\
\hline 40 & 1,15 \\
\hline 45 & 1,21 \\
\hline 50 & 1,21 \\
\hline 53 & 1,21 \\
\hline 56 & 1,21 \\
\hline 63 & 1,21 \\
\hline 71 & 1,21 \\
\hline 75 & 1,21 \\
\hline 80 & 1,21 \\
\hline 85 & 1,21 \\
\hline 90 & 1,21 \\
\hline 95 & 1,21 \\
\hline 100 & 1,21 \\
\hline 106 & 1,21 \\
\hline 112 & 1,21 \\
\hline 125 & 1,21 \\
\hline 130 & 1,21 \\
\hline 140 & 1,21 \\
\hline 145 & 1,21 \\
\hline 150 & 1,21 \\
\hline 160 & 1,21 \\
\hline 170 & 1,21 \\
\hline 180 & 1,21 \\
\hline 190 & 1,21 \\
\hline 200 & 1,21 \\
\hline 212 & 1,21 \\
\hline 242 & 1,21 \\
\hline 250 & 1,21 \\
\hline 300 & 1,21 \\
\hline 400 & 12,91 \\
\hline 500 & 37,52 \\
\hline
\end{tabular}

\begin{tabular}{|c|c|}
\hline $\begin{array}{c}\text { Diâmetro } \\
(\boldsymbol{\mu m})\end{array}$ & $\begin{array}{c}\text { \% } \\
\text { (valor } \\
\text { cumulativo) }\end{array}$ \\
\hline 600 & 60,83 \\
\hline 700 & 78,4 \\
\hline 800 & 89,43 \\
\hline 900 & 95,57 \\
\hline 1000 & 98,48 \\
\hline 1100 & 99,64 \\
\hline 1200 & 100 \\
\hline 1300 & 100 \\
\hline 1400 & 100 \\
\hline
\end{tabular}

\begin{tabular}{|c|cr|}
\hline \multicolumn{3}{|c|}{ amostra analisada } \\
\hline argila & 0,13 & $\%$ \\
\hline silte & 1,08 & $\%$ \\
\hline areia/cascalho & 98,79 & $\%$ \\
\hline
\end{tabular}

\begin{tabular}{|c|cc|}
\hline Massa Total & 42,8323 & $\mathrm{~g}$ \\
\hline Massa $>200 \mu \mathrm{m}$ & 36,0674 & $\mathrm{~g}$ \\
\hline
\end{tabular}

SP - 140

\begin{tabular}{|c|rr|}
\hline \multicolumn{3}{|c|}{ amostra original } \\
\hline argila & $\mathbf{0 , 0 2}$ & $\%$ \\
\hline silte & $\mathbf{0 , 1 7}$ & $\%$ \\
\hline areia/cascalho & $\mathbf{9 9 , 8 1}$ & $\%$ \\
\hline
\end{tabular}


Tabela 50: Determinação granulométrica, SP-141.

\begin{tabular}{|c|c|}
\hline $\begin{array}{c}\text { Diâmetro } \\
(\mu \mathrm{m})\end{array}$ & $\begin{array}{c}\% \\
\text { (valor } \\
\text { cumulativo) }\end{array}$ \\
\hline 0,04 & 0 \\
\hline 0,07 & 0 \\
\hline 0,1 & 0 \\
\hline 0,2 & 0 \\
\hline 0,3 & 0 \\
\hline 0,4 & 0 \\
\hline 0,5 & 0 \\
\hline 0,6 & 0 \\
\hline 0,7 & 0 \\
\hline 0,8 & 0 \\
\hline 0,9 & 0 \\
\hline 1 & 0 \\
\hline 1,1 & 0,01 \\
\hline 1,2 & 0,03 \\
\hline 1,3 & 0,05 \\
\hline 1,4 & 0,07 \\
\hline 1,6 & 0,1 \\
\hline 1,8 & 0,13 \\
\hline 2 & 0,16 \\
\hline 2,2 & 0,19 \\
\hline 2,4 & 0,22 \\
\hline 2,6 & 0,24 \\
\hline 3 & 0,26 \\
\hline 4 & 0,26 \\
\hline 5 & 0,26 \\
\hline 6 & 0,26 \\
\hline 6,5 & 0,26 \\
\hline 7 & 0,26 \\
\hline 7,5 & 0,26 \\
\hline 8 & 0,26 \\
\hline 8,5 & 0,27 \\
\hline 9 & 0,29 \\
\hline 10 & 0,31 \\
\hline 11 & 0,31 \\
\hline 12 & 0,31 \\
\hline 13 & 0,33 \\
\hline 14 & 0,35 \\
\hline 15 & 0,37 \\
\hline 16 & 0,37 \\
\hline 17 & 0,37 \\
\hline
\end{tabular}

\begin{tabular}{|c|c|}
\hline $\begin{array}{l}\text { Diâmetro } \\
\qquad(\mu \mathrm{m})\end{array}$ & $\begin{array}{c}\% \\
\text { (valor } \\
\text { cumulativo) }\end{array}$ \\
\hline 18 & 0,37 \\
\hline 19 & 0,37 \\
\hline 20 & 0,38 \\
\hline 22 & 0,41 \\
\hline 25 & 0,46 \\
\hline 28 & 0,5 \\
\hline 32 & 0,54 \\
\hline 36 & 0,58 \\
\hline 38 & 0,6 \\
\hline 40 & 0,61 \\
\hline 45 & 0,65 \\
\hline 50 & 0,68 \\
\hline 53 & 0,7 \\
\hline 56 & 0,73 \\
\hline 63 & 0,82 \\
\hline 71 & 0,96 \\
\hline 75 & 1,05 \\
\hline 80 & 1,18 \\
\hline 85 & 1,32 \\
\hline 90 & 1,47 \\
\hline 95 & 1,62 \\
\hline 100 & 1,77 \\
\hline 106 & 1,95 \\
\hline 112 & 2,12 \\
\hline 125 & 2,44 \\
\hline 130 & 2,55 \\
\hline 140 & 2,71 \\
\hline 145 & 2,76 \\
\hline 150 & 2,81 \\
\hline 160 & 2,9 \\
\hline 170 & 2,98 \\
\hline 180 & 3,08 \\
\hline 190 & 3,23 \\
\hline 200 & 3,44 \\
\hline 212 & 3,8 \\
\hline 242 & 5,43 \\
\hline 250 & 6,08 \\
\hline 300 & 12,35 \\
\hline 400 & 34,83 \\
\hline 500 & 59,22 \\
\hline
\end{tabular}

\begin{tabular}{|c|c|}
\hline $\begin{array}{c}\text { Diâmetro } \\
(\boldsymbol{\mu m})\end{array}$ & $\begin{array}{c}\text { \% } \\
\text { (valor } \\
\text { cumulativo) }\end{array}$ \\
\hline 600 & 77,23 \\
\hline 700 & 88,65 \\
\hline 800 & 94,92 \\
\hline 900 & 98,05 \\
\hline 1000 & 99,38 \\
\hline 1100 & 99,86 \\
\hline 1200 & 100 \\
\hline 1300 & 100 \\
\hline 1400 & 100 \\
\hline
\end{tabular}

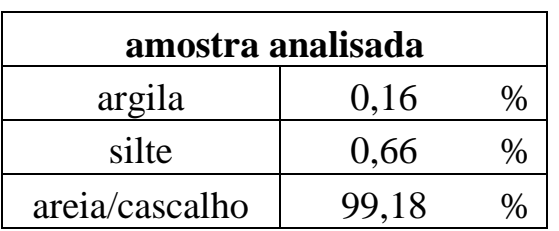

\begin{tabular}{|c|cc|}
\hline Massa Total & 28,7508 & $\mathrm{~g}$ \\
\hline Massa $>200 \mu \mathrm{m}$ & 26,4477 & $\mathrm{~g}$ \\
\hline
\end{tabular}

SP - 141

\begin{tabular}{|c|cc|}
\hline \multicolumn{3}{|c|}{ amostra original } \\
\hline argila & $\mathbf{0 , 0 1}$ & $\%$ \\
\hline silte & $\mathbf{0 , 0 5}$ & $\%$ \\
\hline areia/cascalho & $\mathbf{9 9 , 9 3}$ & $\%$ \\
\hline
\end{tabular}




\section{ANEXO C - Carbono e Nitrogênio}

Tabela 51: Determinação elementar e isotópica de carbono e nitrogênio

\begin{tabular}{|c|c|c|c|c|c|c|c|c|c|}
\hline \multirow{3}{*}{ Amostra } & \multicolumn{5}{|c|}{ CARBONO } & \multirow{2}{*}{\multicolumn{2}{|c|}{$\begin{array}{c}\text { NITROGÊNIO } \\
\text { Total }\end{array}$}} & \multirow{3}{*}{$(\mathrm{C} / \mathrm{N})$} & \multirow{3}{*}{$\begin{array}{l}\% \mathrm{MO} \\
\text { terrestre }\end{array}$} \\
\hline & \multicolumn{2}{|c|}{ Orgânico } & \multicolumn{2}{|c|}{ Total } & \multirow{2}{*}{$\begin{array}{l}\mathrm{C}_{\text {Inorg }} \\
(\%)\end{array}$} & & & & \\
\hline & $\mathrm{C}_{\text {Org }}(\%)$ & $\delta^{13} \mathrm{C}(\%)$ & $\mathrm{C}_{\text {Total }}(\%)$ & $\delta^{13} \mathrm{C}(\%)$ & & $\begin{array}{l}\mathrm{N}_{\text {Total }} \\
(\%)\end{array}$ & $\begin{array}{l}\delta^{15} \mathrm{~N} \\
(\%) \\
\end{array}$ & & \\
\hline SP - 101 & 0,97 & $-21,0$ & 1,53 & $-17,9$ & 0,56 & 0,16 & 6,5 & 7,12 & $103 \%$ \\
\hline SP - 102 & 1,46 & $-20,9$ & 2,40 & $-17,5$ & 0,94 & 0,24 & 6,3 & 7,14 & $103 \%$ \\
\hline SP - 103 & 1,16 & $-22,1$ & 2,43 & $-18,3$ & 1,26 & 0,20 & 6,9 & 6,70 & $105 \%$ \\
\hline SP - 104 & 0,57 & $-20,2$ & 0,73 & $-19,5$ & 0,16 & 0,10 & 5,7 & 6,48 & $106 \%$ \\
\hline SP - 105 & 1,95 & $-20,1$ & 2,40 & $-18,8$ & 0,46 & 0,27 & 7,1 & 8,29 & $97 \%$ \\
\hline SP - 106 & 1,10 & $-20,5$ & 2,38 & $-19,6$ & 1,28 & 0,20 & 6,5 & 6,33 & $107 \%$ \\
\hline SP - 107 & 1,06 & $-20,0$ & 1,56 & $-19,0$ & 0,50 & 0,20 & 7,0 & 6,18 & $107 \%$ \\
\hline SP - 108 & 1,64 & $-20,3$ & 1,88 & $-16,8$ & 0,23 & 0,18 & 7,0 & 10,54 & $86 \%$ \\
\hline SP - 109 & 1,17 & $-19,6$ & 2,62 & $-17,4$ & 1,45 & 0,24 & 6,5 & 5,60 & $110 \%$ \\
\hline SP - 110 & 1,34 & $-22,8$ & 2,11 & $-21,8$ & 0,76 & 0,22 & 5,1 & 7,07 & $103 \%$ \\
\hline SP - 111 & 1,30 & $-22,9$ & 1,50 & $-19,9$ & 0,20 & 0,18 & 7,0 & 8,32 & $97 \%$ \\
\hline SP - 112 & 1,49 & $-21,0$ & 2,29 & $-20,0$ & 0,79 & 0,27 & 6,4 & 6,45 & $106 \%$ \\
\hline SP - 113 & 1,00 & $-20,6$ & 2,28 & $-19,9$ & 1,29 & 0,19 & 6,5 & 6,07 & $108 \%$ \\
\hline SP - 114 & 0,98 & $-21,5$ & 1,85 & $-20,3$ & 0,87 & 0,16 & 6,0 & 7,04 & $103 \%$ \\
\hline SP - 115 & 1,51 & $-20,6$ & 2,11 & $-16,5$ & 0,59 & 0,14 & 5,7 & 12,84 & $75 \%$ \\
\hline SP - 116 & 0,98 & $-19,8$ & 1,01 & $-19,5$ & 0,03 & 0,12 & 5,7 & 9,59 & $91 \%$ \\
\hline SP - 117 & 0,84 & $-20,1$ & 1,42 & $-18,5$ & 0,58 & 0,15 & 6,4 & 6,66 & $105 \%$ \\
\hline SP - 118 & 0,48 & $-20,3$ & 2,60 & $-18,6$ & 2,12 & 0,32 & 7,4 & 1,72 & $129 \%$ \\
\hline SP - 119 & 1,24 & $-22,3$ & 1,36 & $-21,0$ & 0,12 & 0,14 & 5,8 & 10,49 & $86 \%$ \\
\hline SP - 120 & 1,45 & $-20,4$ & 2,00 & $-19,5$ & 0,55 & 0,20 & 6,9 & 8,37 & $97 \%$ \\
\hline SP - 121 & 0,75 & $-20,2$ & 0,81 & $-18,6$ & 0,05 & 0,10 & 5,1 & 8,91 & $94 \%$ \\
\hline SP - 122 & 0,51 & $-20,0$ & 1,85 & $-15,9$ & 1,34 & 0,08 & 6,1 & 7,28 & $102 \%$ \\
\hline SP - 123 & 1,51 & $-21,6$ & 2,35 & $-20,4$ & 0,84 & 0,25 & 6,8 & 7,10 & $103 \%$ \\
\hline SP - 124 & 1,59 & $-19,9$ & 2,04 & $-19,7$ & 0,45 & 0,23 & 6,2 & 8,18 & $98 \%$ \\
\hline SP - 125 & 0,29 & $-20,4$ & 2,00 & $-1,6$ & 1,71 & 0,04 & 4,3 & 8,78 & $95 \%$ \\
\hline SP - 126 & 1,05 & $-21,0$ & 1,12 & $-20,4$ & 0,07 & 0,11 & 5,6 & 10,81 & $85 \%$ \\
\hline SP - 130 & 0,65 & $-19,4$ & 0,81 & $-16,5$ & 0,16 & 0,08 & 5,1 & 9,86 & $89 \%$ \\
\hline SP - 131 & 1,40 & $-21,0$ & 2,29 & $-19,8$ & 0,89 & 0,17 & 6,2 & 9,49 & $91 \%$ \\
\hline SP - 132 & 0,60 & $-20,9$ & 1,84 & $-16,3$ & 1,24 & 0,10 & 6,4 & 6,85 & $104 \%$ \\
\hline SP - 133 & 2,38 & $-20,6$ & 2,93 & $-17,5$ & 0,55 & 0,33 & 6,3 & 8,46 & $96 \%$ \\
\hline SP - 134 & 0,46 & $-20,1$ & 6,35 & $-1,4$ & 5,89 & 0,08 & 5,4 & 6,68 & $105 \%$ \\
\hline SP - 135 & 0,38 & $-19,8$ & 1,38 & $-4,4$ & 1,00 & 0,06 & 3,9 & 7,56 & $101 \%$ \\
\hline SP - 136 & 0,87 & $-17,9$ & 5,70 & $-1,1$ & 4,45 & 0,10 & 5,6 & 10,10 & $88 \%$ \\
\hline SP - 137 & 0,43 & $-22,1$ & 0,82 & $-15,0$ & 0,39 & 0,07 & 4,8 & 7,36 & $102 \%$ \\
\hline SP - 138 & 0,57 & $-21,2$ & 0,70 & $-14,1$ & 0,14 & 0,07 & 4,2 & 9,37 & $92 \%$ \\
\hline SP - 139 & 0,26 & $-21,4$ & 0,74 & $-4,6$ & 0,57 & 0,03 & 3,4 & 9,43 & $92 \%$ \\
\hline SP - 140 & 0,09 & $-21,5$ & 0,94 & $-1,7$ & 0,85 & $<0,02$ & --- & --- & --- \\
\hline SP - 141 & 0,08 & $-23,3$ & 0,29 & $-1,4$ & 0,21 & $<0,02$ & --- & --- & --- \\
\hline
\end{tabular}




\section{ANEXO D - AVS / SEM}

Tabela 52: Concentração de SEM e AVS, ¿SEM e razão $\Sigma S E M / A V S$

\begin{tabular}{|c|c|c|c|c|c|c|c|c|}
\hline \multirow{2}{*}{ Amostra } & \multicolumn{5}{|c|}{$\operatorname{SEM}\left(\mu \mathrm{mol} \mathrm{g}{ }^{-1}\right)$} & \multirow{2}{*}{$\begin{array}{c}\sum \mathrm{SEM} \\
\left(\mu \mathrm{mol} \mathrm{g}{ }^{-1}\right)\end{array}$} & \multirow{2}{*}{$\begin{array}{c}\text { AVS } \\
\left.(\mu \mathrm{mol} \mathrm{g})^{-1}\right)\end{array}$} & \multirow{2}{*}{ SEM/AVS } \\
\hline & zinco & chumbo & níquel & cobre & cádmio & & & \\
\hline SP - 101 & $1,22 \mathrm{E}+00$ & $1,05 \mathrm{E}-02$ & $1,04 \mathrm{E}-02$ & $1,38 \mathrm{E}-02$ & $4,63 \mathrm{E}-03$ & 1,26 & 4,01 & 0,31 \\
\hline SP - 102 & $1,28 \mathrm{E}+00$ & $1,39 \mathrm{E}-02$ & $<1,02 \mathrm{E}-02$ & $3,21 \mathrm{E}-02$ & $4,13 \mathrm{E}-03$ & 1,33 & 12,8 & 0,10 \\
\hline SP - 103 & $1,66 \mathrm{E}+00$ & $1,61 \mathrm{E}-02$ & $<1,02 \mathrm{E}-02$ & $3,37 \mathrm{E}-02$ & $5,15 \mathrm{E}-03$ & 1,72 & 20,0 & 0,09 \\
\hline SP - 104 & $7,13 \mathrm{E}-01$ & $8,31 \mathrm{E}-03$ & $<1,02 \mathrm{E}-02$ & $1,51 \mathrm{E}-02$ & $2,26 \mathrm{E}-03$ & 0,74 & 6,54 & 0,11 \\
\hline SP - 105 & $1,79 \mathrm{E}+00$ & $2,37 \mathrm{E}-02$ & $1,05 \mathrm{E}-02$ & $4,32 \mathrm{E}-02$ & $5,68 \mathrm{E}-03$ & 1,87 & 16,1 & 0,12 \\
\hline SP - 106 & $1,10 \mathrm{E}+00$ & $1,17 \mathrm{E}-02$ & $<1,02 \mathrm{E}-02$ & 1,97E-02 & $2,99 \mathrm{E}-03$ & 1,13 & 13,7 & 0,08 \\
\hline SP - 107 & $1,66 \mathrm{E}+00$ & $1,45 \mathrm{E}-02$ & $1,18 \mathrm{E}-02$ & $2,46 \mathrm{E}-02$ & $5,66 \mathrm{E}-03$ & 1,71 & 6,13 & 0,28 \\
\hline SP - 108 & $4,58 \mathrm{E}+00$ & $2,52 \mathrm{E}-02$ & $<1,02 \mathrm{E}-02$ & $4,51 \mathrm{E}-02$ & $1,26 \mathrm{E}-02$ & 4,67 & 12,1 & 0,39 \\
\hline SP - 109 & $1,59 \mathrm{E}+00$ & 1,39E-02 & $<1,02 \mathrm{E}-02$ & $2,40 \mathrm{E}-02$ & $4,54 \mathrm{E}-03$ & 1,64 & 11,4 & 0,14 \\
\hline SP - 110 & $8,43 \mathrm{E}-01$ & $<9,65 \mathrm{E}-03$ & $<1,02 \mathrm{E}-02$ & $4,05 \mathrm{E}-02$ & $2,56 \mathrm{E}-03$ & 0,89 & 12,3 & 0,07 \\
\hline SP - 111 & $1,46 \mathrm{E}+00$ & $<9,65 \mathrm{E}-03$ & 2,39E-02 & $6,01 \mathrm{E}-02$ & $3,49 \mathrm{E}-03$ & 1,55 & 30,6 & 0,05 \\
\hline SP - 112 & $6,68 \mathrm{E}-01$ & $1,28 \mathrm{E}-02$ & 1,19E-02 & $2,52 \mathrm{E}-02$ & $<1,78 \mathrm{E}-03$ & 0,72 & 4,89 & 0,15 \\
\hline SP - 113 & $1,46 \mathrm{E}+00$ & $1,48 \mathrm{E}-02$ & $<1,02 \mathrm{E}-02$ & $3,08 \mathrm{E}-02$ & 3,94E-03 & 1,51 & 8,49 & 0,18 \\
\hline SP - 114 & $1,61 \mathrm{E}+00$ & $1,63 \mathrm{E}-02$ & $1,06 \mathrm{E}-02$ & $2,64 \mathrm{E}-02$ & $5,70 \mathrm{E}-03$ & 1,67 & 5,78 & 0,29 \\
\hline SP - 115 & $4,28 \mathrm{E}+00$ & $2,90 \mathrm{E}-02$ & $1,07 \mathrm{E}-02$ & $4,83 \mathrm{E}-02$ & $1,28 \mathrm{E}-02$ & 4,38 & 15,6 & 0,28 \\
\hline SP - 116 & $1,65 \mathrm{E}+00$ & $1,71 \mathrm{E}-02$ & $1,25 \mathrm{E}-02$ & $2,67 \mathrm{E}-02$ & $4,58 \mathrm{E}-03$ & 1,71 & 5,81 & 0,29 \\
\hline
\end{tabular}




\begin{tabular}{|c|c|c|c|c|c|c|c|c|}
\hline \multirow{2}{*}{ Amostra } & \multicolumn{5}{|c|}{$\operatorname{SEM}\left(\mu \mathrm{mol} \mathrm{g}{ }^{-1}\right)$} & \multirow{2}{*}{$\begin{array}{c}\sum \text { SEM } \\
\left(\mu \mathrm{mol} \mathrm{g}{ }^{-1}\right)\end{array}$} & \multirow{2}{*}{$\begin{array}{c}\text { AVS } \\
\left(\mu \mathrm{mol} \mathrm{g}{ }^{-1}\right)\end{array}$} & \multirow{2}{*}{$\sum \mathrm{SEM} / \mathrm{AVS}$} \\
\hline & zinco & chumbo & níquel & cobre & cádmio & & & \\
\hline SP - 117 & $1,19 \mathrm{E}+00$ & $1,46 \mathrm{E}-02$ & $1,37 \mathrm{E}-02$ & $2,71 \mathrm{E}-02$ & $3,20 \mathrm{E}-03$ & 1,25 & 6,38 & 0,20 \\
\hline SP - 118 & $8,64 \mathrm{E}-01$ & $1,33 \mathrm{E}-02$ & $1,03 \mathrm{E}-02$ & $2,52 \mathrm{E}-02$ & $2,45 \mathrm{E}-03$ & 0,91 & 12,4 & 0,07 \\
\hline SP - 119 & $7,17 \mathrm{E}-01$ & $1,38 \mathrm{E}-02$ & $<1,02 \mathrm{E}-02$ & $2,55 \mathrm{E}-02$ & $2,02 \mathrm{E}-03$ & 0,76 & 6,50 & 0,12 \\
\hline SP - 120 & $7,12 \mathrm{E}-01$ & $1,42 \mathrm{E}-02$ & $1,52 \mathrm{E}-02$ & $3,05 \mathrm{E}-02$ & $1,82 \mathrm{E}-03$ & 0,77 & 5,54 & 0,14 \\
\hline SP - 121 & $6,72 \mathrm{E}-01$ & $1,16 \mathrm{E}-02$ & $<1,02 \mathrm{E}-02$ & $1,76 \mathrm{E}-02$ & $<1,78 \mathrm{E}-03$ & 0,70 & 4,50 & 0,16 \\
\hline SP - 122 & 4,72E-01 & $1,11 \mathrm{E}-02$ & $<1,02 \mathrm{E}-02$ & $1,74 \mathrm{E}-02$ & $<1,78 \mathrm{E}-03$ & 0,50 & 5,50 & 0,09 \\
\hline SP - 123 & $1,37 \mathrm{E}+00$ & $1,99 \mathrm{E}-02$ & $1,13 \mathrm{E}-02$ & $4,16 \mathrm{E}-02$ & $3,40 \mathrm{E}-03$ & 1,45 & 6,41 & 0,23 \\
\hline SP - 124 & $6,03 \mathrm{E}-01$ & $1,36 \mathrm{E}-02$ & $<1,02 \mathrm{E}-02$ & $2,42 \mathrm{E}-02$ & $1,81 \mathrm{E}-03$ & 0,64 & 6,14 & 0,10 \\
\hline SP - 125 & $1,16 \mathrm{E}-01$ & $<9,65 \mathrm{E}-03$ & $<1,02 \mathrm{E}-02$ & $3,94 \mathrm{E}-03$ & $<1,78 \mathrm{E}-03$ & 0,12 & 0,01 & 12,33 \\
\hline SP - 126 & $4,04 \mathrm{E}-01$ & $1,06 \mathrm{E}-02$ & $<1,02 \mathrm{E}-02$ & $1,86 \mathrm{E}-02$ & $<1,78 \mathrm{E}-03$ & 0,43 & 3,55 & 0,12 \\
\hline SP - 130 & $3,06 \mathrm{E}-01$ & $<9,65 \mathrm{E}-03$ & $<1,02 \mathrm{E}-02$ & $1,29 \mathrm{E}-02$ & $<1,78 \mathrm{E}-03$ & 0,32 & 3,01 & 0,11 \\
\hline SP - 131 & $6,23 \mathrm{E}-01$ & $1,32 \mathrm{E}-02$ & $<1,02 \mathrm{E}-02$ & $1,89 \mathrm{E}-02$ & 1,99E-03 & 0,66 & 6,03 & 0,11 \\
\hline SP - 132 & $6,04 \mathrm{E}-01$ & $1,41 \mathrm{E}-02$ & $1,16 \mathrm{E}-02$ & $1,67 \mathrm{E}-02$ & $1,82 \mathrm{E}-03$ & 0,65 & 4,17 & 0,16 \\
\hline SP - 133 & $6,64 \mathrm{E}-01$ & $1,42 \mathrm{E}-02$ & 1,13E-02 & $2,77 \mathrm{E}-02$ & $<1,78 \mathrm{E}-03$ & 0,72 & 13,1 & 0,05 \\
\hline SP - 134 & $2,29 \mathrm{E}-01$ & $<9,65 \mathrm{E}-03$ & $<1,02 \mathrm{E}-02$ & $6,34 \mathrm{E}-03$ & $<1,78 \mathrm{E}-03$ & 0,24 & 0,04 & 6,07 \\
\hline SP - 135 & $1,78 \mathrm{E}-01$ & $<9,65 \mathrm{E}-03$ & $<1,02 \mathrm{E}-02$ & $1,38 \mathrm{E}-02$ & $<1,78 \mathrm{E}-03$ & 0,19 & 0,21 & 0,89 \\
\hline SP - 136 & $3,17 \mathrm{E}-01$ & $<9,65 \mathrm{E}-03$ & $<1,02 \mathrm{E}-02$ & $1,05 \mathrm{E}-02$ & $<1,78 \mathrm{E}-03$ & 0,33 & 3,18 & 0,10 \\
\hline SP - 137 & $3,93 \mathrm{E}-01$ & $<9,65 \mathrm{E}-03$ & $<1,02 \mathrm{E}-02$ & $1,47 \mathrm{E}-02$ & $<1,78 \mathrm{E}-03$ & 0,41 & 3,64 & 0,11 \\
\hline SP - 138 & $2,14 \mathrm{E}-01$ & $<9,65 \mathrm{E}-03$ & $<1,02 \mathrm{E}-02$ & $1,13 \mathrm{E}-02$ & $<1,78 \mathrm{E}-03$ & 0,23 & 2,94 & 0,08 \\
\hline SP - 139 & $2,27 \mathrm{E}-01$ & $<9,65 \mathrm{E}-03$ & $<1,02 \mathrm{E}-02$ & $6,00 \mathrm{E}-03$ & $<1,78 \mathrm{E}-03$ & 0,23 & 0,04 & 5,76 \\
\hline SP - 140 & $2,21 \mathrm{E}-02$ & $<9,65 \mathrm{E}-03$ & $<1,02 \mathrm{E}-02$ & $2,13 \mathrm{E}-03$ & $<1,78 \mathrm{E}-03$ & 0,02 & --- & --- \\
\hline SP - 141 & $1,79 \mathrm{E}-02$ & $<9,65 \mathrm{E}-03$ & $<1,02 \mathrm{E}-02$ & $1,33 \mathrm{E}-03$ & $<1,78 \mathrm{E}-03$ & 0,02 & --- & --- \\
\hline
\end{tabular}




\section{ANEXO E - Metais Totais}

Tabela 53: Determinação de $\mathrm{Zn}, \mathrm{Cd}, \mathrm{Cr}, \mathrm{Pb}, \mathrm{Ni}$, Cu e Hg em sedimentos superficiais da Baía de Sepetiba

\begin{tabular}{|c|c|c|c|c|c|c|c|c|c|c|c|c|c|c|}
\hline \multirow{2}{*}{$\begin{array}{l}\text { Amostra / } \\
\text { replicata }\end{array}$} & \multicolumn{12}{|c|}{ Concentração $\left(\mathrm{mg} \mathrm{kg}^{-1}\right)$} & \multicolumn{2}{|c|}{ Concentração $\left(\mu \mathrm{g} \mathrm{kg}^{-1}\right)$} \\
\hline & Zinco & média & Cadmio & média & Cromo & média & Chumbo & média & Níquel & média & Cobre & média & Mecúrio & média \\
\hline SP - $101 \mathrm{~A}$ & 339 & \multirow{3}{*}{347} & 1,9 & \multirow{3}{*}{2} & 113 & \multirow{3}{*}{113} & 20 & \multirow{3}{*}{20} & 14 & \multirow{3}{*}{14} & 10 & \multirow{3}{*}{10} & 67,9 & \multirow{2}{*}{64,6} \\
\hline SP - $101 \mathrm{~B}$ & 360 & & 2,0 & & 113 & & 20 & & 14 & & 10 & & 61,3 & \\
\hline SP - 101 C & 343 & & 2,0 & & 112 & & 19 & & 14 & & 10 & & --- & --- \\
\hline SP - $102 \mathrm{~A}$ & 443 & \multirow{3}{*}{445} & 2,3 & \multirow{3}{*}{2} & 115 & \multirow{3}{*}{116} & 20 & \multirow{3}{*}{21} & 14 & \multirow{3}{*}{14} & 15 & \multirow{3}{*}{15} & 97,8 & \multirow{2}{*}{91,8} \\
\hline SP - $102 \mathrm{~B}$ & 433 & & 2,3 & & 115 & & 20 & & 14 & & 14 & & 85,7 & \\
\hline SP - $102 \mathrm{C}$ & 459 & & 2,3 & & 118 & & 21 & & 14 & & 15 & & --- & --- \\
\hline SP - $103 \mathrm{~A}$ & 586 & \multirow{3}{*}{584} & 2,8 & \multirow{3}{*}{3} & 128 & \multirow{3}{*}{129} & 25 & \multirow{3}{*}{24} & 15 & \multirow{3}{*}{15} & 16 & \multirow{3}{*}{17} & 96,8 & \multirow{2}{*}{92,2} \\
\hline SP - $103 \mathrm{~B}$ & 590 & & 2,5 & & 129 & & 24 & & 15 & & 17 & & 87,6 & \\
\hline SP - $103 \mathrm{C}$ & 576 & & 2,7 & & 129 & & 24 & & 14 & & 17 & & --- & --- \\
\hline SP - $104 \mathrm{~A}$ & 113 & \multirow{3}{*}{112} & 0,5 & \multirow{3}{*}{0} & 23,1 & \multirow{3}{*}{25} & 4,9 & \multirow{3}{*}{5} & 3,6 & \multirow{3}{*}{4} & 2,9 & \multirow{3}{*}{3} & 14,1 & \multirow{2}{*}{15,1} \\
\hline SP - $104 \mathrm{~B}$ & 116 & & 0,5 & & 24,8 & & 5,5 & & 3,7 & & 3,0 & & 16,1 & \\
\hline SP - $104 \mathrm{C}$ & 108 & & 0,5 & & 27,0 & & 5,4 & & 3,8 & & 3,2 & & --- & --- \\
\hline SP - 105 A & 569 & \multirow{3}{*}{556} & 2,8 & \multirow{3}{*}{3} & 131 & & 26 & & 14 & & 18 & & 139 & 130 \\
\hline SP - $105 \mathrm{~B}$ & 537 & & 2,5 & & 127 & 128 & 25 & 25 & 14 & 14 & 17 & 17 & 120 & 150 \\
\hline$S P-105 C$ & 563 & & 2,6 & & 125 & & 24 & & 14 & & 17 & & --- & --- \\
\hline
\end{tabular}




\begin{tabular}{|c|c|c|c|c|c|c|c|c|c|c|c|c|c|c|}
\hline \multirow{2}{*}{$\begin{array}{c}\text { Amostra / } \\
\text { replicata }\end{array}$} & \multicolumn{12}{|c|}{ Concentração (mg kg $\left.{ }^{-1}\right)$} & \multicolumn{2}{|c|}{ Concentração $\left(\mu \mathrm{g} \mathrm{kg}^{-1}\right)$} \\
\hline & Zinco & média & Cadmio & média & Cromo & média & Chumbo & média & Níquel & média & Cobre & média & Mecúrio & média \\
\hline SP - $106 \mathrm{~A}$ & 458 & \multirow{3}{*}{457} & 2,1 & \multirow{3}{*}{2} & 120 & \multirow{3}{*}{118} & 20 & \multirow{3}{*}{19} & 15 & \multirow{3}{*}{14} & 14 & \multirow{3}{*}{14} & 99,0 & \multirow{2}{*}{92,7} \\
\hline SP - $106 \mathrm{~B}$ & 460 & & 2,0 & & 117 & & 19 & & 15 & & 14 & & 86,5 & \\
\hline SP - $106 \mathrm{C}$ & 454 & & 1,9 & & 117 & & 19 & & 14 & & 14 & & --- & --- \\
\hline SP - $107 \mathrm{~A}$ & 440 & \multirow{3}{*}{452} & 2,2 & \multirow{3}{*}{2} & 89,9 & \multirow{3}{*}{90} & 15 & \multirow{3}{*}{15} & 11 & \multirow{3}{*}{11} & 8,9 & \multirow{3}{*}{9} & 57,4 & \multirow{2}{*}{61,0} \\
\hline SP - 107 B & 449 & & 2,2 & & 89,1 & & 15 & & 11 & & 8,8 & & 64,6 & \\
\hline SP - $107 \mathrm{C}$ & 468 & & 2,2 & & 91,6 & & 16 & & 11 & & 9,1 & & --- & --- \\
\hline SP - $108 \mathrm{~A}$ & 1130 & \multirow{3}{*}{1116} & 4,7 & \multirow{3}{*}{5} & 146 & \multirow{3}{*}{142} & 27 & \multirow{3}{*}{26} & 13 & \multirow{3}{*}{13} & 17 & \multirow{3}{*}{17} & 112 & \multirow{2}{*}{114} \\
\hline SP - 108 B & 1130 & & 4,6 & & 142 & & 25 & & 13 & & 17 & & 117 & \\
\hline SP - $108 \mathrm{C}$ & 1088 & & 4,6 & & 139 & & 25 & & 12 & & 16 & & --- & --- \\
\hline SP - $109 \mathrm{~A}$ & 1100 & \multirow{3}{*}{746} & 2,3 & \multirow{3}{*}{2} & 124 & \multirow{3}{*}{127} & 22 & \multirow{3}{*}{22} & 14 & \multirow{3}{*}{14} & 14 & \multirow{3}{*}{15} & 115 & 115 \\
\hline SP - $109 \mathrm{~B}$ & 593 & & 2,4 & & 129 & & 22 & & 15 & & 15 & & 116 & 115 \\
\hline SP - $109 \mathrm{C}$ & 545 & & 2,3 & & 127 & & 22 & & 14 & & 15 & & --- & --- \\
\hline SP - $110 \mathrm{~A}$ & 377 & & 1,6 & & 117 & & 18 & & 15 & & 13 & & 91,5 & \\
\hline SP - $110 \mathrm{~B}$ & 384 & 389 & 1,7 & 2 & 117 & 117 & 18 & 18 & 14 & 14 & 13 & 13 & 92,9 & 92,2 \\
\hline$S P-110 C$ & 405 & & 1,6 & & 116 & & 18 & & 14 & & 13 & & --- & --- \\
\hline SP - 111A & 433 & & 1,4 & & 145 & & 24 & & 15 & & 25 & & 285 & \\
\hline SP - $111 \mathrm{~B}$ & 428 & 427 & 1,4 & 1 & 145 & 145 & 25 & 24 & 15 & 15 & 25 & 25 & 297 & 291 \\
\hline SP - $111 \mathrm{C}$ & 421 & & 1,5 & & 144 & & 24 & & 15 & & 25 & & --- & --- \\
\hline $\mathrm{SP}-112 \mathrm{~A}$ & 393 & & 1,8 & & 87,1 & & 16 & & 10 & & 9 & & 76,1 & 742 \\
\hline SP - 112 B & 425 & 405 & 2,0 & 2 & 90,5 & 89 & 17 & 16 & 10 & 10 & 10 & 10 & 72,3 & 74,2 \\
\hline $\mathrm{SP}-112 \mathrm{C}$ & 399 & & 2,0 & & 88,6 & & 16 & & 10 & & 10 & & --- & --- \\
\hline
\end{tabular}




\begin{tabular}{|c|c|c|c|c|c|c|c|c|c|c|c|c|c|c|}
\hline \multirow{2}{*}{$\begin{array}{c}\text { Amostra / } \\
\text { replicata }\end{array}$} & \multicolumn{12}{|c|}{ Concentração $\left(\mathrm{mg} \mathrm{kg}^{-1}\right)$} & \multicolumn{2}{|c|}{ Concentração $\left(\mu \mathrm{g} \mathrm{kg}^{-1}\right)$} \\
\hline & Zinco & média & Cadmio & média & Cromo & média & Chumbo & média & Níquel & média & Cobre & média & Mecúrio & média \\
\hline SP - $113 \mathrm{~A}$ & 439 & \multirow{3}{*}{439} & 1,8 & \multirow{3}{*}{2} & 119 & \multirow{3}{*}{121} & 18 & \multirow{3}{*}{18} & 14 & \multirow{3}{*}{14} & 12 & \multirow{3}{*}{12} & 82,7 & \multirow{2}{*}{79,9} \\
\hline SP - 113 B & 435 & & 1,8 & & 123 & & 18 & & 15 & & 13 & & 77,1 & \\
\hline SP - $113 \mathrm{C}$ & 443 & & 1,7 & & 120 & & 18 & & 14 & & 12 & & --- & --- \\
\hline SP - $114 \mathrm{~A}$ & 420 & \multirow{3}{*}{434} & 2,1 & \multirow{3}{*}{2} & 114 & \multirow{3}{*}{114} & 19 & \multirow{3}{*}{19} & 14 & \multirow{3}{*}{14} & 10 & \multirow{3}{*}{10} & 60,5 & \multirow{2}{*}{61,0} \\
\hline SP - 114 B & 428 & & 2,1 & & 113 & & 19 & & 14 & & 10 & & 61,6 & \\
\hline SP - $114 \mathrm{C}$ & 454 & & 2,2 & & 114 & & 19 & & 14 & & 11 & & --- & --- \\
\hline $\mathrm{SP}-115 \mathrm{~A}$ & 818 & \multirow{3}{*}{799} & 3,9 & \multirow{3}{*}{4} & 72,4 & \multirow{3}{*}{72} & 21 & \multirow{3}{*}{20} & 7,4 & \multirow{3}{*}{8} & 12 & \multirow{3}{*}{12} & 75,0 & \multirow{2}{*}{71,0} \\
\hline$S P-115 B$ & 821 & & 4,0 & & 76,1 & & 21 & & 8,2 & & 13 & & 67,0 & \\
\hline SP - $115 \mathrm{C}$ & 759 & & 3,6 & & 66,7 & & 19 & & 7,2 & & 12 & & --- & --- \\
\hline SP - $116 \mathrm{~A}$ & 248 & \multirow{3}{*}{265} & 1,0 & \multirow{3}{*}{1} & 60,7 & \multirow{3}{*}{63} & 11 & \multirow{3}{*}{11} & 6,8 & \multirow{3}{*}{7} & 5,7 & \multirow{3}{*}{6} & 36,9 & 373 \\
\hline SP - $116 \mathrm{~B}$ & 280 & & 1,0 & & 66,2 & & 11 & & 7,1 & & 6,4 & & 37,5 & $3 /, 2$ \\
\hline SP - $116 \mathrm{C}$ & 268 & & 1,0 & & 63,2 & & 11 & & 6,9 & & 6,0 & & --- & --- \\
\hline SP - $117 \mathrm{~A}$ & 226 & & 0,9 & & 77,2 & & 11 & & 8,8 & & 6,2 & & 32,1 & \\
\hline SP - $117 \mathrm{~B}$ & 195 & 217 & 0,9 & 1 & 79,0 & 78 & 12 & 11 & 9,2 & 9 & 6,4 & 6 & 35,7 & 35,9 \\
\hline$S P-117 C$ & 232 & & 0,9 & & 76,7 & & 11 & & 8,7 & & 6,2 & & --- & --- \\
\hline $\mathrm{SP}-118 \mathrm{~A}$ & 276 & & 1,1 & & 117 & & 17 & & 15 & & 12 & & 60,0 & \\
\hline SP - $118 \mathrm{~B}$ & 264 & 273 & 1,0 & 1 & 114 & 115 & 17 & 17 & 14 & 15 & 11 & 12 & 65,9 & 03,0 \\
\hline SP - $118 \mathrm{C}$ & 278 & & 1,0 & & 116 & & 16 & & 15 & & 12 & & --- & -- \\
\hline SP - 119A & 176 & & 0,7 & & 78,5 & & 13 & & 10 & & 8,8 & & 81,7 & 817 \\
\hline SP - $119 \mathrm{~B}$ & 190 & 187 & 0,7 & 1 & 78,9 & 79 & 13 & 13 & 9,1 & 9 & 8,8 & 9 & 81,7 & 81,1 \\
\hline SP - $119 \mathrm{C}$ & 194 & & 0,7 & & 79,9 & & 13 & & 8,7 & & 9,0 & & --- & --- \\
\hline
\end{tabular}




\begin{tabular}{|c|c|c|c|c|c|c|c|c|c|c|c|c|c|c|}
\hline \multirow{2}{*}{$\begin{array}{c}\text { Amostra / } \\
\text { replicata }\end{array}$} & \multicolumn{12}{|c|}{ Concentração (mg kg $\left.{ }^{-1}\right)$} & \multicolumn{2}{|c|}{ Concentração $\left(\mu \mathrm{g} \mathrm{kg}^{-1}\right)$} \\
\hline & Zinco & média & Cadmio & média & Cromo & média & Chumbo & média & Níquel & média & Cobre & média & Mecúrio & média \\
\hline SP - $120 \mathrm{~A}$ & 198 & \multirow{3}{*}{202} & 0,6 & \multirow{3}{*}{1} & 99,0 & \multirow{3}{*}{100} & 15 & \multirow{3}{*}{15} & 13 & \multirow{3}{*}{13} & 10 & \multirow{3}{*}{10} & 66,2 & \multirow{2}{*}{66,8} \\
\hline SP - $120 \mathrm{~B}$ & 189 & & 0,7 & & 100 & & 16 & & 13 & & 10 & & 67,3 & \\
\hline SP - $120 \mathrm{C}$ & 220 & & 0,7 & & 102 & & 15 & & 13 & & 10 & & --- & --- \\
\hline SP - $121 \mathrm{~A}$ & 106 & \multirow{3}{*}{118} & 0,4 & \multirow{3}{*}{0} & 43,9 & \multirow{3}{*}{44} & 6,8 & \multirow{3}{*}{7} & 5,0 & \multirow{3}{*}{5} & 3,4 & \multirow{3}{*}{3} & 21,5 & \multirow{2}{*}{23,0} \\
\hline SP - $121 \mathrm{~B}$ & 113 & & 0,4 & & 44,7 & & 6,9 & & 5,1 & & 3,4 & & 24,4 & \\
\hline SP - $121 \mathrm{C}$ & 135 & & 0,4 & & 43,5 & & 6,8 & & 4,8 & & 3,4 & & --- & --- \\
\hline$S P-122 A$ & 178 & \multirow{3}{*}{181} & 0,4 & \multirow{3}{*}{0} & 82,9 & \multirow{3}{*}{76} & 10 & \multirow{3}{*}{10} & 8,7 & \multirow{3}{*}{8} & 5,9 & \multirow{3}{*}{6} & 31,7 & \multirow{2}{*}{31,3} \\
\hline SP - $122 \mathrm{~B}$ & 191 & & 0,4 & & 75,1 & & 10 & & 8,5 & & 5,7 & & 30,8 & \\
\hline SP - $122 \mathrm{C}$ & 173 & & 0,4 & & 70,7 & & 10 & & 8,0 & & 5,5 & & --- & --- \\
\hline $\mathrm{SP}-123 \mathrm{~A}$ & 466 & \multirow{3}{*}{466} & 1,4 & \multirow{3}{*}{1} & 134 & \multirow{3}{*}{134} & 20 & \multirow{3}{*}{20} & 15 & \multirow{3}{*}{15} & 15 & \multirow{3}{*}{15} & 75,0 & 754 \\
\hline SP - $123 \mathrm{~B}$ & 463 & & 1,3 & & 135 & & 21 & & 15 & & 15 & & 75,8 & 15,4 \\
\hline SP - $123 \mathrm{C}$ & 469 & & 1,3 & & 133 & & 19 & & 15 & & 15 & & --- & --- \\
\hline SP - $124 \mathrm{~A}$ & 277 & & 0,7 & & 128 & & 19 & & 13 & & 12 & & 85,3 & \\
\hline SP - $124 \mathrm{~B}$ & 259 & 261 & 0,7 & 1 & 125 & 126 & 18 & 18 & 13 & 13 & 12 & 12 & 88,6 & 86,9 \\
\hline $\mathrm{SP}-124 \mathrm{C}$ & 248 & & 0,7 & & 124 & & 18 & & 13 & & 12 & & --- & --- \\
\hline $\mathrm{SP}-125 \mathrm{~A}$ & 56,3 & & $<0,2$ & & 15,8 & & 2,7 & & $<0,5$ & & 0,8 & & 3,9 & \\
\hline SP - $125 \mathrm{~B}$ & 52,1 & 53 & $<0,2$ & $<0,2$ & 12,0 & 14 & 2,2 & 2 & $<0,5$ & $<0,5$ & 0,6 & 1 & 3,9 & 3,9 \\
\hline SP - $125 \mathrm{C}$ & 51,6 & & $<0,2$ & & 14,4 & & 1,9 & & $<0,5$ & & 0,8 & & --- & --- \\
\hline $\mathrm{SP}-126 \mathrm{~A}$ & 96,6 & & $<0,2$ & & 48,9 & & 6,8 & & 5,0 & & 3,3 & & 22,5 & 217 \\
\hline SP - $126 \mathrm{~B}$ & 104 & 101 & $<0,2$ & $<0,2$ & 46,3 & 46 & 6,4 & 6 & 4,7 & 5 & 3,2 & 3 & 21,0 & 21,7 \\
\hline SP - $126 \mathrm{C}$ & 101 & & $<0,2$ & & 42,6 & & 6,2 & & 4,1 & & 3,0 & & --- & --- \\
\hline
\end{tabular}




\begin{tabular}{|c|c|c|c|c|c|c|c|c|c|c|c|c|c|c|}
\hline \multirow{2}{*}{$\begin{array}{l}\text { Amostra / } \\
\text { replicata }\end{array}$} & \multicolumn{12}{|c|}{ Concentração (mg kg $\left.{ }^{-1}\right)$} & \multicolumn{2}{|c|}{ Concentração $\left(\mu \mathrm{g} \mathrm{kg}^{-1}\right)$} \\
\hline & Zinco & média & Cadmio & média & Cromo & média & Chumbo & média & Níquel & média & Cobre & média & Mecúrio & média \\
\hline SP - $130 \mathrm{~A}$ & 79,1 & \multirow{3}{*}{69} & $<0,2$ & \multirow{3}{*}{$<0,2$} & 35,3 & \multirow{3}{*}{30} & 7,0 & \multirow{3}{*}{6} & 3,2 & \multirow{3}{*}{3} & 2,1 & \multirow{3}{*}{2} & 12,3 & \multirow{2}{*}{12,6} \\
\hline SP - $130 \mathrm{~B}$ & 67,1 & & $<0,2$ & & 27,1 & & 5,9 & & 2,4 & & 1,7 & & 13,0 & \\
\hline SP - $130 \mathrm{C}$ & 60,4 & & $<0,2$ & & 27,4 & & 5,6 & & 2,6 & & 2,2 & & --- & --- \\
\hline SP - $131 \mathrm{~A}$ & 163 & \multirow{3}{*}{170} & 0,4 & \multirow{3}{*}{1} & 81,1 & \multirow{3}{*}{85} & 11 & \multirow{3}{*}{12} & 8,8 & \multirow{3}{*}{9} & 5,6 & \multirow{3}{*}{6} & 34,1 & \multirow{2}{*}{35,7} \\
\hline SP - $131 \mathrm{~B}$ & 178 & & 0,5 & & 86,3 & & 12 & & 10 & & 6 & & 37,3 & \\
\hline SP - $131 \mathrm{C}$ & 171 & & 0,7 & & 87,4 & & 12 & & 9,5 & & 6,6 & & --- & --- \\
\hline SP - $132 \mathrm{~A}$ & 188 & \multirow{3}{*}{186} & 0,6 & \multirow{3}{*}{1} & 90,3 & \multirow{3}{*}{90} & 14 & \multirow{3}{*}{13} & 9,3 & \multirow{3}{*}{9} & 5,6 & \multirow{3}{*}{6} & 36,9 & \multirow{2}{*}{36,3} \\
\hline SP - $132 \mathrm{~B}$ & 183 & & 0,6 & & 89,4 & & 13 & & 9,4 & & 5,5 & & 35,7 & \\
\hline SP - $132 \mathrm{C}$ & 188 & & 0,8 & & 89,8 & & 13 & & 10 & & 6,1 & & --- & --- \\
\hline SP - $133 \mathrm{~A}$ & 280 & \multirow{3}{*}{276} & 0,7 & \multirow{3}{*}{1} & 132 & \multirow{3}{*}{131} & 20 & \multirow{3}{*}{19} & 16 & \multirow{3}{*}{16} & 12 & \multirow{3}{*}{13} & 69,4 & 640 \\
\hline SP - $133 \mathrm{~B}$ & 277 & & 0,8 & & 132 & & 18 & & 16 & & 12 & & 60,5 & 64,9 \\
\hline SP - $133 \mathrm{C}$ & 271 & & 1,0 & & 130 & & 18 & & 15 & & 13 & & --- & --- \\
\hline SP - $134 \mathrm{~A}$ & 81,0 & & $<0,2$ & & 33,8 & & 4,2 & & 2,8 & & 1,9 & & 9,0 & \\
\hline SP - 134 B & 76,6 & 79 & $<0,2$ & $<0,2$ & 32,0 & 33 & 4,7 & 4 & 2,6 & 3 & 1,9 & 2 & 8,2 & 8,6 \\
\hline SP - $134 \mathrm{C}$ & 78,9 & & $<0,2$ & & 32,4 & & 3,6 & & 2,7 & & 2,4 & & --- & --- \\
\hline SP - $135 \mathrm{~A}$ & 49,7 & & $<0,2$ & & 16,2 & & 2,6 & & $<0,5$ & & 1,3 & & 5,5 & 58 \\
\hline SP - $135 \mathrm{~B}$ & 46,2 & 48 & $<0,2$ & $<0,2$ & 13,5 & 14 & 2,3 & 2 & $<0,5$ & $<0,5$ & 1,0 & 1 & 6,1 & 5,8 \\
\hline SP - $135 \mathrm{C}$ & 49,5 & & $<0,2$ & & 13,6 & & 1,8 & & $<0,5$ & & 1,4 & & --- & --- \\
\hline SP - $136 \mathrm{~A}$ & 70,1 & & $<0,2$ & & 28,6 & & 4,3 & & 2,5 & & 2,3 & & 10,7 & 115 \\
\hline SP - $136 \mathrm{~B}$ & 93,9 & 83 & $<0,2$ & $<0,2$ & 29,0 & 28 & 3,6 & 4 & 2,3 & 2 & 2,4 & 2 & 12,2 & 11,5 \\
\hline SP - $136 \mathrm{C}$ & 86,1 & & $<0,2$ & & 27,1 & & 3,8 & & 2,3 & & 2,6 & & --- & --- \\
\hline
\end{tabular}




\begin{tabular}{|c|c|c|c|c|c|c|c|c|c|c|c|c|c|c|}
\hline \multirow{2}{*}{$\begin{array}{c}\text { Amostra / } \\
\text { replicata }\end{array}$} & \multicolumn{12}{|c|}{ Concentração $\left(\mathrm{mg} \mathrm{kg}^{-1}\right)$} & \multicolumn{2}{|c|}{ Concentração $\left(\mu \mathrm{g} \mathrm{kg}^{-1}\right)$} \\
\hline & Zinco & média & Cadmio & média & Cromo & média & Chumbo & média & Níquel & média & Cobre & média & Mecúrio & média \\
\hline SP - $137 \mathrm{~A}$ & 87,6 & \multirow{3}{*}{91} & $<0,2$ & \multirow{3}{*}{$<0,2$} & 43,5 & \multirow{3}{*}{44} & 6,1 & \multirow{3}{*}{6} & 4,2 & \multirow{3}{*}{4} & 2,7 & \multirow{3}{*}{3} & 14,4 & \multirow{2}{*}{14,2} \\
\hline SP - $137 \mathrm{~B}$ & 91,5 & & $<0,2$ & & 44,5 & & 7,0 & & 4,1 & & 3,0 & & 14,1 & \\
\hline SP - $137 \mathrm{C}$ & 93,6 & & $<0,2$ & & 43,5 & & 6,0 & & 4,1 & & 3,3 & & --- & --- \\
\hline SP - $138 \mathrm{~A}$ & 63,0 & \multirow{3}{*}{63} & $<0,2$ & \multirow{3}{*}{$<0,2$} & 30,7 & \multirow{3}{*}{29} & 5,7 & \multirow{3}{*}{5} & 2,4 & \multirow{3}{*}{2} & 2,0 & \multirow{3}{*}{2} & 9,9 & \multirow{2}{*}{10,5} \\
\hline SP - $138 \mathrm{~B}$ & 63,1 & & $<0,2$ & & 29,0 & & 5,4 & & 2,4 & & 1,9 & & 11,1 & \\
\hline SP - $138 \mathrm{C}$ & 62,9 & & $<0,2$ & & 28,5 & & 4,9 & & 2,2 & & 2,4 & & --- & --- \\
\hline SP - 139 A & 60,5 & \multirow{3}{*}{60} & $<0,2$ & \multirow{3}{*}{$<0,2$} & 18,9 & \multirow{3}{*}{19} & 3,8 & \multirow{3}{*}{4} & 0,7 & \multirow{3}{*}{1} & 0,8 & \multirow{3}{*}{1} & 2,5 & \multirow{2}{*}{2,3} \\
\hline SP - $139 \mathrm{~B}$ & 61,5 & & $<0,2$ & & 19,4 & & 3,6 & & 0,8 & & 0,8 & & 2,1 & \\
\hline $\mathrm{SP}-139 \mathrm{C}$ & 57,3 & & $<0,2$ & & 19,4 & & 4,3 & & 0,8 & & 1,2 & & --- & --- \\
\hline SP - $140 \mathrm{~A}$ & 27,5 & \multirow{3}{*}{30} & $<0,2$ & \multirow{3}{*}{$<0,2$} & 1,7 & \multirow{3}{*}{2} & $<1,0$ & \multirow{3}{*}{$<1,0$} & $<0,5$ & \multirow{3}{*}{$<0,5$} & 0,3 & \multirow{3}{*}{0} & $<2,0$ & \multirow{2}{*}{$<2,0$} \\
\hline SP - $140 \mathrm{~B}$ & 30,0 & & $<0,2$ & & 1,5 & & $<1,0$ & & $<0,5$ & & 0,2 & & $<2,0$ & \\
\hline $\mathrm{SP}-140 \mathrm{C}$ & 31,8 & & $<0,2$ & & 1,5 & & $<1,0$ & & $<0,5$ & & 0,6 & & --- & --- \\
\hline $\mathrm{SP}-141 \mathrm{~A}$ & 33,1 & \multirow{3}{*}{30} & $<0,2$ & \multirow{3}{*}{$<0,2$} & 1,9 & & $<1,0$ & & $<0,5$ & & 0,2 & & $<2,0$ & $<20$ \\
\hline SP - $141 \mathrm{~B}$ & 28,0 & & $<0,2$ & & 1,8 & 2 & $<1,0$ & $<1,0$ & $<0,5$ & $<0,5$ & 0,1 & 0 & $<2,0$ & $-2,0$ \\
\hline SP - $141 \mathrm{C}$ & 27,9 & & $<0,2$ & & 2,0 & & $<1,0$ & & $<0,5$ & & 0,6 & & --- & --- \\
\hline
\end{tabular}


Tabela 54: Determinação de $\mathrm{Cr}, \mathrm{Ni}, \mathrm{Cu}, \mathrm{Zn}, \mathrm{Cd}$ e Pb em testemunho sedimentar, $\mathrm{T}$-3.

\begin{tabular}{|c|c|c|c|c|c|c|c|c|c|c|c|c|}
\hline \multicolumn{13}{|c|}{ Testemunho $\mathrm{T}-\mathbf{3}$} \\
\hline \multirow{2}{*}{$\begin{array}{l}\text { Profundidade } \\
\text { média }(\mathrm{cm}) / \\
\text { replicata }\end{array}$} & \multicolumn{12}{|c|}{ Concentração (mg kg-1) } \\
\hline & cromo & média & níquel & média & cobre & média & zinco & média & cádmio & média & chumbo & média \\
\hline $1-\mathrm{A}$ & 186,7 & \multirow{2}{*}{185,6} & 21,7 & \multirow{2}{*}{21,6} & 29,1 & \multirow{2}{*}{28,9} & 363,5 & \multirow{2}{*}{362,3} & 1,1 & \multirow{2}{*}{1,1} & 27,8 & \multirow{2}{*}{27,9} \\
\hline $1-\mathrm{B}$ & 184,4 & & 21,5 & & 28,8 & & 361,1 & & 1,1 & & 27,9 & \\
\hline $3-A$ & 196,6 & \multirow{2}{*}{195,6} & 22,8 & \multirow{2}{*}{22,7} & 28,3 & \multirow{2}{*}{28,1} & 387,6 & \multirow{2}{*}{394,7} & 1,1 & \multirow{2}{*}{1,1} & 28,7 & \multirow{2}{*}{28,7} \\
\hline $3-\mathrm{B}$ & 194,6 & & 22,5 & & 27,8 & & 401,8 & & 1,1 & & 28,6 & \\
\hline $5-A$ & 200,8 & \multirow{2}{*}{197,4} & 23,2 & \multirow{2}{*}{22,8} & 29,2 & \multirow{2}{*}{28,6} & 415,1 & \multirow{2}{*}{408,0} & 1,2 & \multirow{2}{*}{1,2} & 29,8 & \multirow{2}{*}{29,5} \\
\hline $5-B$ & 194,0 & & 22,4 & & 28,0 & & 400,9 & & 1,2 & & 29,3 & \\
\hline $7-A$ & 197,7 & \multirow{2}{*}{195,7} & 22,9 & \multirow{2}{*}{22,8} & 29,3 & \multirow{2}{*}{29,1} & 412,7 & \multirow{2}{*}{408,5} & 1,2 & \multirow{2}{*}{1,2} & 30,1 & \multirow{2}{*}{30,3} \\
\hline $7-B$ & 193,7 & & 22,7 & & 28,9 & & 404,3 & & 1,2 & & 30,4 & \\
\hline $9-A$ & 203,7 & \multirow{2}{*}{200,2} & 23,7 & \multirow{2}{*}{23,3} & 31,7 & \multirow{2}{*}{30,6} & 419,2 & \multirow{2}{*}{412,8} & 1,2 & \multirow{2}{*}{1,2} & 32,6 & \\
\hline $9-\mathrm{B}$ & 196,8 & & 22,9 & & 29,5 & & 406,5 & & 1,2 & & 31,9 & 32,3 \\
\hline $11-\mathrm{A}$ & 196,6 & & 23,1 & & 29,6 & 207 & 403,3 & & 1,2 & & 32,1 & \\
\hline $11-B$ & 196,7 & 196,6 & 23,3 & 23,2 & 29,7 & 29,1 & 407,0 & 405,2 & 1,2 & 1,2 & 32,7 & 32,4 \\
\hline $13-\mathrm{A}$ & 194,0 & 1043 & 23,0 & 330 & 28,8 & 287 & 389,5 & $378 ?$ & 1,2 & & 33,0 & 330 \\
\hline $13-\mathrm{B}$ & 194,5 & 194,3 & 23,0 & 23,0 & 28,6 & 28,1 & 366,8 & $3 / 8,2$ & 1,2 & 1,2 & 33,0 & 33,0 \\
\hline $15-\mathrm{A}$ & 192,8 & 1007 & 23,5 & & 28,3 & & 372,6 & & 1,1 & & 33,2 & \\
\hline $15-\mathrm{B}$ & 188,6 & 190,7 & 22,8 & 23,1 & 27,5 & 27,9 & 377,6 & $3 / 5,1$ & 1,1 & 1,1 & 32,8 & 33,0 \\
\hline $17-\mathrm{A}$ & 191,9 & & 23,4 & & 28,0 & & 374,4 & & 1,1 & & 33,2 & \\
\hline $17-B$ & 196,9 & 194,4 & 23,9 & 23,6 & 28,5 & 28,2 & 376,4 & 375,4 & 1,1 & 1,1 & 34,2 & 33,7 \\
\hline
\end{tabular}




\begin{tabular}{|c|c|c|c|c|c|c|c|c|c|c|c|c|}
\hline \multirow{2}{*}{$\begin{array}{l}\text { Profundidade } \\
\text { média }(\mathrm{cm}) / \\
\text { replicata }\end{array}$} & \multicolumn{12}{|c|}{ Concentração $\left(\mathrm{mg} \mathrm{kg}^{-1}\right)$} \\
\hline & cromo & média & níquel & média & cobre & média & zinco & média & cádmio & média & chumbo & média \\
\hline $19-\mathrm{A}$ & 195,1 & \multirow{2}{*}{194,9} & 23,8 & \multirow{2}{*}{23,8} & 29,7 & \multirow{2}{*}{29,5} & 350,1 & \multirow{2}{*}{346,8} & 1,0 & \multirow{2}{*}{1,0} & 33,3 & \multirow{2}{*}{33,2} \\
\hline $19-\mathrm{B}$ & 194,6 & & 23,8 & & 29,2 & & 343,5 & & 1,0 & & 33,1 & \\
\hline $21-A$ & 203,5 & \multirow{2}{*}{200,8} & 24,4 & \multirow{2}{*}{23,9} & 32,6 & \multirow{2}{*}{32,2} & 343,7 & \multirow{2}{*}{342,5} & 1,1 & \multirow{2}{*}{1,1} & 35,8 & \multirow{2}{*}{35,4} \\
\hline $21-\mathrm{B}$ & 198,2 & & 23,4 & & 31,7 & & 341,3 & & 1,0 & & 35,0 & \\
\hline $23-A$ & 202,5 & \multirow{2}{*}{196,6} & 24,3 & \multirow{2}{*}{23,6} & 32,4 & \multirow{2}{*}{31,5} & 348,7 & \multirow{2}{*}{341,3} & 1,1 & \multirow{2}{*}{1,0} & 35,7 & \multirow{2}{*}{34,9} \\
\hline $23-B$ & 190,6 & & 22,9 & & 30,6 & & 333,9 & & 1,0 & & 34,2 & \\
\hline $25-A$ & 196,6 & \multirow{2}{*}{195,1} & 23,4 & \multirow{2}{*}{22,7} & 30,3 & \multirow{2}{*}{30,2} & 395,1 & \multirow{2}{*}{395,0} & 1,2 & \multirow{2}{*}{1,2} & 35,1 & \multirow{2}{*}{34,8} \\
\hline $25-B$ & 193,7 & & 22,1 & & 30,1 & & 394,9 & & 1,2 & & 34,5 & \\
\hline $27-A$ & 195,8 & \multirow{2}{*}{196,0} & 22,3 & \multirow{2}{*}{22,2} & 31,4 & \multirow{2}{*}{31,4} & 406,6 & \multirow{2}{*}{404,2} & 1,3 & \multirow{2}{*}{1,3} & 35,4 & 254 \\
\hline $27-B$ & 196,2 & & 22,1 & & 31,5 & & 401,7 & & 1,2 & & 35,4 & 3J,4 \\
\hline $29-\mathrm{A}$ & 198,3 & 2002 & 22,8 & 220 & 30,6 & 300 & 419,4 & 1103 & 1,2 & 12 & 35,3 & 256 \\
\hline $29-B$ & 202,1 & 200,2 & 23,1 & 22,9 & 31,2 & 30,9 & 419,2 & 419,3 & 1,2 & 1,2 & 35,9 & 50,6 \\
\hline $31-A$ & 200,7 & 2005 & 23,1 & 232 & 31,0 & 314 & 403,6 & 1045 & 1,3 & 13 & 35,6 & 360 \\
\hline $31-B$ & 204,4 & 202,3 & 23,4 & 23,3 & 31,9 & 31,4 & 405,4 & 404,5 & 1,3 & 1,3 & 36,3 & 50,0 \\
\hline $33-A$ & 205,0 & 2040 & 23,8 & 230 & 31,4 & 313 & 410,3 & 4124 & 1,2 & 12 & 36,5 & 364 \\
\hline $33-B$ & 203,1 & & 23,9 & & 31,2 & נו, & 414,4 & 412,4 & 1,2 & 1,2 & 36,4 & 30,4 \\
\hline $35-A$ & 200,6 & 2012 & 23,7 & 237 & 30,8 & 310 & 384,5 & 3007 & 1,2 & 12 & 35,3 & 352 \\
\hline $35-\mathrm{B}$ & 201,7 & 201,2 & 23,7 & 25,1 & 31,2 & $J 1,0$ & 396,9 & (3), & 1,1 & 1,2 & 35,2 & $J J, 2$ \\
\hline $37-A$ & 201,9 & 2006 & 23,3 & 233 & 30,7 & 308 & 400,7 & 4048 & 1,2 & 12 & 35,4 & 352 \\
\hline $37-\mathrm{B}$ & 203,3 & & 23,3 & & 30,9 & & 409,0 & & 1,2 & & 35,0 & \\
\hline $39-A$ & 213,3 & 2105 & 23,2 & 230 & 32,2 & 319 & 501,3 & 4987 & 1,5 & 15 & 36,8 & 366 \\
\hline $39-\mathrm{B}$ & 207,6 & & 22,7 & & 31,5 & & 496,2 & & 1,5 & & 36,4 & \\
\hline
\end{tabular}




\begin{tabular}{|c|c|c|c|c|c|c|c|c|c|c|c|c|}
\hline \multirow{2}{*}{$\begin{array}{l}\text { Profundidade } \\
\text { média }(\mathrm{cm}) / \\
\text { replicata }\end{array}$} & \multicolumn{12}{|c|}{ Concentração $\left(\mathrm{mg} \mathrm{kg}^{-1}\right)$} \\
\hline & cromo & média & níquel & média & cobre & média & zinco & média & cádmio & média & chumbo & média \\
\hline $41-\mathrm{A}$ & 204,0 & \multirow{2}{*}{204,5} & 22,3 & \multirow{2}{*}{22,6} & 29,2 & \multirow{2}{*}{31,4} & 491,6 & \multirow{2}{*}{492,3} & 1,4 & \multirow{2}{*}{1,5} & 34,1 & \multirow{2}{*}{34,2} \\
\hline $41-B$ & 205,1 & & 22,9 & & 33,7 & & 492,9 & & 1,5 & & 34,2 & \\
\hline $43-\mathrm{A}$ & 202,6 & \multirow{2}{*}{204,4} & 22,2 & \multirow{2}{*}{22,4} & 29,5 & \multirow{2}{*}{29,8} & 486,2 & \multirow{2}{*}{492,7} & 1,5 & \multirow{2}{*}{1,5} & 34,4 & \multirow{2}{*}{34,5} \\
\hline $43-B$ & 206,3 & & 22,6 & & 30,0 & & 499,2 & & 1,5 & & 34,6 & \\
\hline $45-\mathrm{A}$ & 204,9 & \multirow{2}{*}{205,5} & 22,6 & \multirow{2}{*}{22,7} & 30,1 & \multirow{2}{*}{30,1} & 481,7 & \multirow{2}{*}{511,5} & 1,4 & \multirow{2}{*}{1,4} & 33,9 & \multirow{2}{*}{34,0} \\
\hline $45-B$ & 206,0 & & 22,8 & & 30,1 & & 541,4 & & 1,5 & & 34,1 & \\
\hline $47-A$ & 210,2 & \multirow{2}{*}{210,7} & 22,6 & \multirow{2}{*}{22,7} & 29,5 & \multirow{2}{*}{29,8} & 526,4 & \multirow{2}{*}{528,8} & 1,6 & \multirow{2}{*}{1,6} & 34,0 & \multirow{2}{*}{34,2} \\
\hline $47-B$ & 211,2 & & 22,8 & & 30,1 & & 531,3 & & 1,6 & & 34,5 & \\
\hline $49-\mathrm{A}$ & 210,3 & \multirow{2}{*}{210,1} & 22,6 & \multirow{2}{*}{22,5} & 29,2 & \multirow{2}{*}{29,3} & 497,8 & \multirow{2}{*}{500,1} & 1,5 & \multirow{2}{*}{1,5} & 32,8 & 238 \\
\hline $49-B$ & 209,9 & & 22,4 & & 29,4 & & 502,4 & & 1,5 & & 32,7 & 52,0 \\
\hline $51-\mathrm{A}$ & 205,0 & 2040 & 21,5 & 216 & 30,1 & 200 & 488,4 & 1867 & 1,6 & 16 & 33,7 & 234 \\
\hline $51-B$ & 202,9 & $20+, 0$ & 21,6 & 21,0 & 29,7 & 25,3 & 485,0 & too, & 1,6 & 1,0 & 33,1 & $3 \mathrm{~J}, 4$ \\
\hline $53-A$ & 210,9 & 2107 & 22,1 & 22 & 30,1 & 302 & 491,9 & 1875 & 1,5 & 15 & 33,5 & 326 \\
\hline $53-B$ & 210,5 & 210,1 & 22,1 & $2 L, 1$ & 30,2 & 30,2 & 483,1 & $48 /, 5$ & 1,5 & 1,3 & 33,7 & 35,0 \\
\hline $55-\mathrm{A}$ & 199,6 & 2008 & 21,0 & 211 & 28,6 & 288 & 469,0 & 4702 & 1,3 & 14 & 31,8 & 318 \\
\hline $55-\mathrm{B}$ & 202,0 & 200,0 & 21,3 & 21,1 & 29,0 & 20,0 & 471,4 & $4 / 10,2$ & 1,4 & 1,4 & 31,9 & J1, \\
\hline $57-A$ & 201,8 & 2017 & 21,5 & 215 & 30,2 & 300 & 517,1 & 1986 & 1,6 & 15 & 33,4 & 335 \\
\hline $57-B$ & 201,6 & & 21,5 & & 29,9 & & 480,1 & & 1,5 & & 33,6 & \\
\hline $59-A$ & 210,1 & 2004 & 22,4 & 224 & 29,9 & 200 & 548,1 & 5416 & 1,7 & 17 & 34,9 & 348 \\
\hline $59-\mathrm{B}$ & 208,7 & & 22,3 & & 29,8 & & 535,2 & & 1,7 & & 34,7 & \\
\hline $61-A$ & 212,3 & 2143 & 22,6 & 228 & 29,3 & 203 & 551,5 & 5540 & 1,7 & 17 & 34,2 & 343 \\
\hline $61-B$ & 216,2 & & 23,0 & & 29,3 & & 558,2 & & 1,7 & $1, r$ & 34,4 & \\
\hline
\end{tabular}


Tabela 55: Determinação de $\mathrm{Cr}, \mathrm{Ni}, \mathrm{Cu}, \mathrm{Zn}, \mathrm{Cd}$ e Pb em testemunho sedimentar, $\mathrm{T}-8$.

\begin{tabular}{|c|c|c|c|c|c|c|c|c|c|c|c|c|}
\hline \multicolumn{13}{|c|}{ Testemunho T-8 } \\
\hline \multirow{2}{*}{$\begin{array}{l}\text { Profundidade } \\
\text { média }(\mathrm{cm}) / \\
\text { replicata }\end{array}$} & \multicolumn{12}{|c|}{ Concentração $\left(\mathrm{mg} \mathrm{kg}^{-1}\right)$} \\
\hline & cromo & média & níquel & média & cobre & média & zinco & média & cádmio & média & chumbo & média \\
\hline $1-\mathrm{A}$ & 126,1 & \multirow{2}{*}{125,2} & 13,8 & \multirow{2}{*}{13,5} & 13,3 & \multirow{2}{*}{13,0} & 358,2 & \multirow{2}{*}{357,5} & 1,8 & \multirow{2}{*}{1,7} & 20,9 & \multirow{2}{*}{20,5} \\
\hline $1-\mathrm{B}$ & 124,3 & & 13,3 & & 12,7 & & 356,7 & & 1,7 & & 20,2 & \\
\hline $3-\mathrm{A}$ & 113,5 & \multirow{2}{*}{115,1} & 11,9 & \multirow{2}{*}{12,2} & 11,7 & \multirow{2}{*}{11,8} & 323,0 & \multirow{2}{*}{330,8} & 1,5 & \multirow{2}{*}{1,5} & 18,5 & \multirow{2}{*}{18,7} \\
\hline $3-\mathrm{B}$ & 116,6 & & 12,5 & & 11,8 & & 338,6 & & 1,5 & & 18,9 & \\
\hline $5-\mathrm{A}$ & 97,2 & \multirow{2}{*}{97,9} & 10,3 & \multirow{2}{*}{10,3} & 9,5 & \multirow{2}{*}{9,5} & 292,3 & \multirow{2}{*}{298,4} & 1,3 & \multirow{2}{*}{1,3} & 16,7 & \multirow{2}{*}{16,7} \\
\hline $5-B$ & 98,6 & & 10,3 & & 9,5 & & 304,5 & & 1,3 & & 16,7 & \\
\hline $7-\mathrm{A}$ & 108,3 & \multirow{2}{*}{105,9} & 11,4 & \multirow{2}{*}{11,3} & 10,5 & \multirow{2}{*}{10,4} & 352,2 & \multirow{2}{*}{350,2} & 1,9 & \multirow{2}{*}{1,9} & 21,0 & \multirow{2}{*}{20,6} \\
\hline $7-B$ & 103,5 & & 11,1 & & 10,3 & & 348,2 & & 1,8 & & 20,1 & \\
\hline $9-\mathrm{A}$ & 121,0 & \multirow{2}{*}{120,7} & 12,8 & \multirow{2}{*}{12,9} & 11,9 & \multirow{2}{*}{11,9} & 440,7 & \multirow{2}{*}{437,0} & 2,7 & \multirow{2}{*}{2,7} & 28,8 & ne e \\
\hline $9-\mathrm{B}$ & 120,4 & & 13,0 & & 11,9 & & 433,4 & & 2,6 & & 28,8 & $28, \delta$ \\
\hline $11-\mathrm{A}$ & 136,8 & 1250 & 14,4 & 143 & 13,6 & 135 & 549,1 & 5430 & 3,4 & 34 & 36,2 & 350 \\
\hline $11-\mathrm{B}$ & 135,1 & 135,9 & 14,1 & 14,3 & 13,4 & 13,5 & 538,6 & 543,9 & 3,4 & 3,4 & 35,7 & 35,9 \\
\hline $13-\mathrm{A}$ & 138,4 & 1301 & 14,6 & 146 & 13,7 & 137 & 523,1 & 5313 & 3,4 & 34 & 36,7 & 370 \\
\hline $13-\mathrm{B}$ & 139,9 & 139,1 & 14,5 & 14,6 & 13,8 & 13,1 & 539,4 & 531,3 & 3,5 & 3,4 & 37,3 & $3 /, 0$ \\
\hline $15-\mathrm{A}$ & 172,6 & 1740 & 18,4 & 185 & 17,3 & 175 & 651,3 & 6607 & 4,6 & 46 & 47,4 & 483 \\
\hline $15-\mathrm{B}$ & 175,4 & $1 / 4,0$ & 18,7 & 18,3 & 17,7 & $1 /, 3$ & 688,1 & 669, 1 & 4,7 & 4,6 & 49,2 & 48,3 \\
\hline $17-\mathrm{A}$ & 159,4 & 1501 & 17,1 & 173 & 15,9 & 160 & 573,5 & 5740 & 3,9 & 40 & 41,1 & 418 \\
\hline $17-\mathrm{B}$ & 158,8 & 159,1 & 17,5 & $1 /, 3$ & 16,1 & 16,0 & 574,4 & $3 / 4,0$ & 4,1 & 4,0 & 42,4 & 41,8 \\
\hline
\end{tabular}




\begin{tabular}{|c|c|c|c|c|c|c|c|c|c|c|c|c|}
\hline \multirow{2}{*}{$\begin{array}{l}\text { Profundidade } \\
\text { média }(\mathrm{cm}) / \\
\text { replicata }\end{array}$} & \multicolumn{12}{|c|}{ Concentração (mg kg-1) } \\
\hline & cromo & média & níquel & média & cobre & média & zinco & média & cádmio & média & chumbo & média \\
\hline $19-\mathrm{A}$ & 150,4 & \multirow{2}{*}{147,8} & 16,5 & \multirow{2}{*}{16,2} & 15,2 & \multirow{2}{*}{14,8} & 476,0 & \multirow{2}{*}{472,2} & 3,2 & \multirow{2}{*}{3,1} & 34,5 & \multirow{2}{*}{34,0} \\
\hline $19-\mathrm{B}$ & 145,2 & & 15,9 & & 14,4 & & 468,4 & & 3,1 & & 33,5 & \\
\hline $21-\mathrm{A}$ & 128,3 & \multirow{2}{*}{126,7} & 14,1 & \multirow{2}{*}{13,9} & 12,8 & \multirow{2}{*}{12,6} & 399,5 & \multirow{2}{*}{389,3} & 2,4 & \multirow{2}{*}{2,3} & 27,8 & \multirow{2}{*}{27,4} \\
\hline $21-\mathrm{B}$ & 125,1 & & 13,7 & & 12,5 & & 379,0 & & 2,3 & & 27,0 & \\
\hline $23-\mathrm{A}$ & 126,1 & \multirow{2}{*}{125,0} & 14,1 & \multirow{2}{*}{14,0} & 12,4 & \multirow{2}{*}{12,3} & 366,0 & \multirow{2}{*}{369,1} & 2,3 & \multirow{2}{*}{2,3} & 26,8 & \multirow{2}{*}{26,5} \\
\hline $23-\mathrm{B}$ & 124,0 & & 13,9 & & 12,3 & & 372,1 & & 2,2 & & 26,2 & \\
\hline $25-\mathrm{A}$ & 127,6 & \multirow{2}{*}{126,8} & 14,7 & \multirow{2}{*}{14,8} & 12,5 & \multirow{2}{*}{12,5} & 339,7 & \multirow{2}{*}{338,3} & 2,1 & \multirow{2}{*}{2,1} & 26,3 & \multirow{2}{*}{26,2} \\
\hline $25-\mathrm{B}$ & 126,0 & & 14,8 & & 12,5 & & 336,9 & & 2,1 & & 26,1 & \\
\hline $27-A$ & 121,8 & \multirow{2}{*}{121,8} & 14,4 & \multirow{2}{*}{14,3} & 11,9 & \multirow{2}{*}{11,8} & 274,2 & \multirow{2}{*}{275,6} & 1,6 & \multirow{2}{*}{1,6} & 24,6 & 245 \\
\hline $27-B$ & 121,7 & & 14,2 & & 11,8 & & 277,0 & & 1,6 & & 24,4 & $24, \mathrm{~J}$ \\
\hline $29-\mathrm{A}$ & 101,5 & 1028 & 12,0 & 120 & 9,5 & 06 & 209,3 & 2124 & 1,2 & 12 & 20,3 & 5 \\
\hline $29-\mathrm{B}$ & 104,1 & 102,0 & 12,0 & 12,0 & 9,6 &,, 0 & 215,5 & 212,4 & 1,2 & 1,2 & 20,6 & $20, J$ \\
\hline $31-\mathrm{A}$ & 86,3 & 863 & 10,1 & 101 & 7,8 & 77 & 159,1 & 1601 & 0,8 & 08 & 16,4 & 165 \\
\hline $31-B$ & 86,3 & & 10,1 & 10,1 & 7,7 & $1, r$ & 161,1 & 100,1 & 0,8 & 0,0 & 16,6 & (10, \\
\hline $33-\mathrm{A}$ & 102,3 & 1006 & 12,0 & 110 & 9,5 & 03 & 206,5 & 2030 & 1,2 & 12 & 20,2 & 100 \\
\hline $33-\mathrm{B}$ & 99,0 & 100,0 & 11,7 & 11,9 & 9,1 & 9,3 & 199,5 & 200,0 & 1,2 & 1,2 & 19,6 & 19,9 \\
\hline $35-A$ & 92,8 & 040 & 11,0 & 111 & 8,5 & 86 & 189,4 & 1017 & 1,0 & 10 & 18,6 & 101 \\
\hline $35-\mathrm{B}$ & 97,0 & 34,9 & 11,3 & 11,1 & 8,7 & 0,0 & 194,0 & 171,1 & 1,1 & 1,0 & 19,6 & 17,1 \\
\hline $37-\mathrm{A}$ & 91,2 & 920 & 10,7 & 107 & 8,4 & 84 & 181,6 & 1861 & 0,9 & 09 & 18,5 & 185 \\
\hline $37-\mathrm{B}$ & 92,8 & & 10,7 & & 8,4 & & 190,6 & & 1,0 & & 18,5 & \\
\hline $39-\mathrm{A}$ & 100,3 & 1030 & 11,6 & 120 & 9,5 & 08 & 231,7 & 2312 & 1,2 & 13 & 21,1 & 218 \\
\hline $39-\mathrm{B}$ & 107,4 & 105,3 & 12,4 & 12,0 & 10,1 & ,,O & 230,6 & $2 J 1,2$ & 1,3 & 1,3 & 22,4 & \\
\hline
\end{tabular}




\begin{tabular}{|c|c|c|c|c|c|c|c|c|c|c|c|c|}
\hline \multirow{2}{*}{$\begin{array}{l}\text { Profundidade } \\
\text { média }(\mathrm{cm}) / \\
\text { replicata }\end{array}$} & \multicolumn{12}{|c|}{ Concentração $\left(\mathrm{mg} \mathrm{kg}^{-1}\right)$} \\
\hline & cromo & média & níquel & média & cobre & média & zinco & média & cádmio & média & chumbo & média \\
\hline $41-\mathrm{A}$ & 126,0 & \multirow{2}{*}{123,3} & 14,9 & \multirow{2}{*}{14,6} & 12,3 & \multirow{2}{*}{12,1} & 280,0 & \multirow{2}{*}{275,0} & 1,5 & \multirow{2}{*}{1,5} & 26,5 & \multirow{2}{*}{25,8} \\
\hline $41-\mathrm{B}$ & 120,5 & & 14,2 & & 11,9 & & 270,0 & & 1,4 & & 25,1 & \\
\hline $43-\mathrm{A}$ & 86,3 & \multirow{2}{*}{88,6} & 10,3 & \multirow{2}{*}{10,6} & 8,0 & \multirow{2}{*}{8,3} & 152,8 & \multirow{2}{*}{156,7} & 0,7 & \multirow{2}{*}{0,7} & 16,3 & \multirow{2}{*}{16,6} \\
\hline $43-\mathrm{B}$ & 91,0 & & 10,9 & & 8,5 & & 160,6 & & 0,7 & & 16,9 & \\
\hline $45-\mathrm{A}$ & 61,3 & \multirow{2}{*}{61,2} & 7,0 & \multirow{2}{*}{7,0} & 5,0 & \multirow{2}{*}{5,0} & 108,5 & \multirow{2}{*}{106,6} & 0,4 & \multirow{2}{*}{0,4} & 12,0 & \multirow{2}{*}{11,8} \\
\hline $45-\mathrm{B}$ & 61,0 & & 6,9 & & 5,0 & & 104,8 & & 0,4 & & 11,7 & \\
\hline $47-\mathrm{A}$ & 52,1 & \multirow{2}{*}{54,3} & 5,8 & \multirow{2}{*}{6,0} & 4,0 & \multirow{2}{*}{4,2} & 87,5 & \multirow{2}{*}{90,7} & 0,3 & \multirow{2}{*}{0,3} & 10,2 & \multirow{2}{*}{10,6} \\
\hline $47-B$ & 56,5 & & 6,2 & & 4,4 & & 94,0 & & 0,3 & & 11,0 & \\
\hline
\end{tabular}


Tabela 56: Determinação de $\mathrm{Cr}, \mathrm{Ni}, \mathrm{Cu}, \mathrm{Zn}, \mathrm{Cd}$ e Pb em testemunho sedimentar, T-13.

\begin{tabular}{|c|c|c|c|c|c|c|c|c|c|c|c|c|}
\hline \multicolumn{13}{|c|}{ Testemunho $\mathrm{T}-13$} \\
\hline \multirow{2}{*}{$\begin{array}{l}\text { Profundidade } \\
\text { média }(\mathrm{cm}) / \\
\text { replicata }\end{array}$} & \multicolumn{12}{|c|}{ Concentração $\left(\mathrm{mg} \mathrm{kg}^{-1}\right)$} \\
\hline & cromo & média & níquel & média & cobre & média & zinco & média & cádmio & média & chumbo & média \\
\hline $1-\mathrm{A}$ & 159,9 & \multirow{2}{*}{160,1} & 13,9 & \multirow{2}{*}{13,8} & 12,5 & \multirow{2}{*}{12,4} & 525,2 & \multirow{2}{*}{529,0} & 1,2 & \multirow{2}{*}{1,2} & 22,8 & \multirow{2}{*}{22,8} \\
\hline $1-\mathrm{B}$ & 160,2 & & 13,8 & & 12,2 & & 532,7 & & 1,2 & & 22,9 & \\
\hline $3-\mathrm{A}$ & 164,8 & \multirow{2}{*}{161,5} & 13,9 & \multirow{2}{*}{13,5} & 12,5 & \multirow{2}{*}{12,1} & 532,9 & \multirow{2}{*}{537,7} & 1,2 & \multirow{2}{*}{1,2} & 24,5 & \multirow{2}{*}{24,3} \\
\hline $3-\mathrm{B}$ & 158,3 & & 13,1 & & 11,7 & & 542,6 & & 1,2 & & 24,2 & \\
\hline $5-\mathrm{A}$ & 147,5 & \multirow{2}{*}{148,9} & 11,4 & \multirow{2}{*}{11,7} & 10,0 & \multirow{2}{*}{10,1} & 526,0 & \multirow{2}{*}{526,2} & 1,2 & \multirow{2}{*}{1,2} & 23,4 & \multirow{2}{*}{23,4} \\
\hline $5-B$ & 150,3 & & 11,9 & & 10,2 & & 526,4 & & 1,2 & & 23,5 & \\
\hline $7-\mathrm{A}$ & 151,8 & \multirow{2}{*}{150,7} & 12,1 & \multirow{2}{*}{11,8} & 10,2 & \multirow{2}{*}{9,8} & 599,4 & \multirow{2}{*}{585,7} & 1,4 & \multirow{2}{*}{1,3} & 24,3 & \multirow{2}{*}{24,2} \\
\hline $7-B$ & 149,6 & & 11,4 & & 9,5 & & 572,1 & & 1,3 & & 24,1 & \\
\hline $9-\mathrm{A}$ & 154,5 & \multirow{2}{*}{151,8} & 12,3 & \multirow{2}{*}{11,9} & 10,6 & \multirow{2}{*}{10,0} & 682,4 & \multirow{2}{*}{669,0} & 1,6 & \multirow{2}{*}{1,6} & 25,7 & 255 \\
\hline $9-\mathrm{B}$ & 149,1 & & 11,4 & & 9,5 & & 655,6 & & 1,5 & & 25,3 & 25,5 \\
\hline $11-\mathrm{A}$ & 155,0 & 1564 & 12,5 & 125 & 10,2 & 102 & 734,7 & 7376 & 1,7 & 18 & 26,9 & 271 \\
\hline $11-\mathrm{B}$ & 157,8 & 150,4 & 12,6 & 12,0 & 10,3 & 10,2 & 740,5 & 131,0 & 1,8 & 1,8 & 27,4 & 27,1 \\
\hline $13-\mathrm{A}$ & 154,8 & 1555 & 12,0 & $12 ?$ & 9,8 & 00 & 757,2 & 7535 & 1,8 & 18 & 27,0 & 272 \\
\hline $13-\mathrm{B}$ & 156,2 & 155,0 & 12,4 & 12,2 & 10,0 & 9,9 & 749,9 & 155,5 & 1,7 & 1,8 & 27,4 & 21,2 \\
\hline $15-\mathrm{A}$ & 150,6 & 1504 & 11,4 & 116 & 9,2 & 03 & 754,0 & 7514 & 1,9 & 10 & 27,2 & 271 \\
\hline $15-\mathrm{B}$ & 150,2 & 150,4 & 11,7 & 11,0 & 9,3 & 9,3 & 748,9 & 131,4 & 1,9 & 1,9 & 27,0 & 27,1 \\
\hline $17-\mathrm{A}$ & 153,6 & 1531 & 11,8 & 118 & 9,1 & 01 & 781,6 & 7771 & 2,0 & 20 & 28,1 & 281 \\
\hline $17-\mathrm{B}$ & 152,5 & 153,1 & 11,9 & 11,8 & 9,2 & 9,1 & 772,5 & $1 / 1,1$ & 1,9 & 2,0 & 28,2 & 28,1 \\
\hline
\end{tabular}




\begin{tabular}{|c|c|c|c|c|c|c|c|c|c|c|c|c|}
\hline \multirow{2}{*}{$\begin{array}{l}\text { Profundidade } \\
\text { média }(\mathrm{cm}) / \\
\text { replicata }\end{array}$} & \multicolumn{12}{|c|}{ Concentração (mg kg-1) } \\
\hline & cromo & média & níquel & média & cobre & média & zinco & média & cádmio & média & chumbo & média \\
\hline $19-\mathrm{A}$ & 152,7 & \multirow{2}{*}{153,5} & 11,7 & \multirow{2}{*}{11,9} & 9,0 & \multirow{2}{*}{9,1} & 775,0 & \multirow{2}{*}{783,2} & 2,1 & \multirow{2}{*}{2,1} & 29,0 & \multirow{2}{*}{29,0} \\
\hline $19-\mathrm{B}$ & 154,3 & & 12,0 & & 9,1 & & 791,5 & & 2,1 & & 29,0 & \\
\hline $21-\mathrm{A}$ & 177,6 & \multirow{2}{*}{176,5} & 15,2 & \multirow{2}{*}{15,1} & 11,1 & \multirow{2}{*}{11,1} & 865,5 & \multirow{2}{*}{850,8} & 2,5 & \multirow{2}{*}{2,5} & 35,3 & \multirow{2}{*}{35,2} \\
\hline $21-\mathrm{B}$ & 175,5 & & 15,0 & & 11,0 & & 836,1 & & 2,5 & & 35,0 & \\
\hline $23-\mathrm{A}$ & 189,2 & \multirow{2}{*}{191,2} & 16,6 & \multirow{2}{*}{16,8} & 12,5 & \multirow{2}{*}{12,5} & 958,5 & \multirow{2}{*}{970,3} & 3,0 & \multirow{2}{*}{3,0} & 38,9 & \multirow{2}{*}{39,3} \\
\hline $23-\mathrm{B}$ & 193,2 & & 17,1 & & 12,5 & & 982,1 & & 3,0 & & 39,8 & \\
\hline $25-\mathrm{A}$ & 143,4 & \multirow{2}{*}{143,9} & 10,2 & \multirow{2}{*}{10,4} & 6,5 & \multirow{2}{*}{6,6} & 718,4 & \multirow{2}{*}{732,0} & 2,3 & \multirow{2}{*}{2,3} & 30,2 & \multirow{2}{*}{30,2} \\
\hline $25-\mathrm{B}$ & 144,3 & & 10,5 & & 6,8 & & 745,6 & & 2,3 & & 30,2 & \\
\hline $27-A$ & 158,8 & \multirow{2}{*}{157,9} & 12,6 & \multirow{2}{*}{12,3} & 8,4 & \multirow{2}{*}{8,2} & 747,5 & \multirow{2}{*}{750,0} & 2,3 & \multirow{2}{*}{2,3} & 33,6 & 325 \\
\hline $27-B$ & 156,9 & & 12,0 & & 7,9 & & 752,5 & & 2,3 & & 33,5 & כ5,כ \\
\hline $29-\mathrm{A}$ & 178,9 & 1781 & 15,0 & 140 & 10,0 & 100 & 785,4 & 7706 & 2,5 & 25 & 38,5 & $30 ?$ \\
\hline $29-\mathrm{B}$ & 177,2 & 170,1 & 14,8 & 14,5 & 9,9 & 10,0 & 755,9 & 1110,0 & 2,4 & $2, J$ & 37,9 & Jo,L \\
\hline $31-\mathrm{A}$ & 149,2 & 1481 & 11,7 & 117 & 6,3 & 63 & 590,5 & 5006 & 2,0 & 20 & 32,4 & 321 \\
\hline $31-\mathrm{B}$ & 147,0 & 140,1 & 11,6 & 11,1 & 6,3 & 0,3 & 590,8 & & 2,0 & 2,0 & 31,7 & $3 Z, 1$ \\
\hline $33-\mathrm{A}$ & 157,6 & 1566 & 13,4 & 133 & 6,9 & 60 & 520,7 & 5233 & 1,8 & 18 & 32,0 & 318 \\
\hline $33-\mathrm{B}$ & 155,5 & 150,0 & 13,2 & 15,3 & 6,9 & 0,3 & 525,8 & 525,3 & 1,8 & 1,0 & 31,6 & J1, \\
\hline $35-\mathrm{A}$ & 185,9 & 1854 & 16,9 & 160 & 9,9 & 98 & 580,4 & $582 ?$ & 2,0 & 20 & 37,0 & 368 \\
\hline $35-\mathrm{B}$ & 184,9 & 100,4 & 16,9 & 10,3 & 9,7 & & 584,0 & & 2,0 & & 36,7 & \\
\hline $37-\mathrm{A}$ & 165,6 & 1671 & 15,1 & 152 & 7,7 & 80 & 435,0 & 4403 & 1,5 & 15 & 31,6 & 319 \\
\hline $37-\mathrm{B}$ & 168,7 & & 15,3 & & 8,4 & & 445,7 & & 1,5 & & 32,2 & \\
\hline $39-\mathrm{A}$ & 124,7 & 1248 & 9,5 & 06 & 3,0 & 30 & 263,1 & 2635 & 0,9 & 00 & 22,5 & 223 \\
\hline $39-\mathrm{B}$ & 124,9 & 124,0 & 9,7 & , & 2,9 & 3,0 & 263,8 & $20 J, 5$ & 0,9 & 0,9 & 22,1 & \\
\hline
\end{tabular}




\begin{tabular}{|c|c|c|c|c|c|c|c|c|c|c|c|c|}
\hline \multirow{2}{*}{$\begin{array}{l}\text { Profundidade } \\
\text { média }(\mathrm{cm}) / \\
\text { replicata }\end{array}$} & \multicolumn{12}{|c|}{ Concentração $\left(\mathrm{mg} \mathrm{kg}^{-1}\right)$} \\
\hline & cromo & média & níquel & média & cobre & média & zinco & média & cádmio & média & chumbo & média \\
\hline $41-\mathrm{A}$ & 114,5 & \multirow{2}{*}{114,9} & 8,3 & \multirow{2}{*}{8,4} & 1,7 & \multirow{2}{*}{1,7} & 222,8 & \multirow{2}{*}{223,9} & 0,7 & \multirow{2}{*}{0,7} & 20,2 & \multirow{2}{*}{20,2} \\
\hline $41-\mathrm{B}$ & 115,4 & & 8,5 & & 1,6 & & 225,0 & & 0,7 & & 20,2 & \\
\hline
\end{tabular}


Tabela 57: Determinação de $\mathrm{Cr}, \mathrm{Ni}, \mathrm{Cu}, \mathrm{Zn}, \mathrm{Cd}$ e Pb em testemunho sedimentar, T-18.

\begin{tabular}{|c|c|c|c|c|c|c|c|c|c|c|c|c|}
\hline \multicolumn{13}{|c|}{ Testemunho $\mathrm{T}-18$} \\
\hline \multirow{2}{*}{$\begin{array}{l}\text { Profundidade } \\
\text { média }(\mathrm{cm}) / \\
\text { replicata }\end{array}$} & \multicolumn{12}{|c|}{ Concentração $\left(\mathrm{mg} \mathrm{kg}^{-1}\right)$} \\
\hline & cromo & média & níquel & média & cobre & média & zinco & média & cádmio & média & chumbo & média \\
\hline $1-\mathrm{A}$ & 142,7 & \multirow{2}{*}{142,2} & 12,4 & \multirow{2}{*}{12,2} & 15,7 & \multirow{2}{*}{15,6} & 445,3 & \multirow{2}{*}{455,8} & 1,1 & \multirow{2}{*}{1,1} & 19,3 & \multirow{2}{*}{19,3} \\
\hline $1-\mathrm{B}$ & 141,6 & & 12,1 & & 15,5 & & 466,3 & & 1,1 & & 19,3 & \\
\hline $3-\mathrm{A}$ & 143,4 & \multirow{2}{*}{143,8} & 12,5 & \multirow{2}{*}{12,4} & 15,7 & \multirow{2}{*}{15,6} & 450,8 & \multirow{2}{*}{455,2} & 1,1 & \multirow{2}{*}{1,1} & 19,5 & \multirow{2}{*}{19,5} \\
\hline $3-\mathrm{B}$ & 144,2 & & 12,2 & & 15,6 & & 459,7 & & 1,1 & & 19,6 & \\
\hline $5-\mathrm{A}$ & 137,3 & \multirow{2}{*}{139,3} & 11,1 & \multirow{2}{*}{11,5} & 14,8 & \multirow{2}{*}{14,9} & 476,5 & \multirow{2}{*}{480,2} & 1,1 & \multirow{2}{*}{1,1} & 19,0 & \multirow{2}{*}{19,2} \\
\hline $5-B$ & 141,3 & & 11,9 & & 15,0 & & 484,0 & & 1,1 & & 19,5 & \\
\hline $7-\mathrm{A}$ & 140,2 & \multirow{2}{*}{141,5} & 11,4 & \multirow{2}{*}{11,6} & 14,9 & \multirow{2}{*}{15,0} & 550,4 & \multirow{2}{*}{549,0} & 1,3 & \multirow{2}{*}{1,3} & 19,2 & \multirow{2}{*}{19,4} \\
\hline $7-B$ & 142,8 & & 11,8 & & 15,1 & & 547,6 & & 1,3 & & 19,7 & \\
\hline $9-\mathrm{A}$ & 140,8 & \multirow{2}{*}{141,9} & 11,7 & \multirow{2}{*}{11,7} & 14,7 & \multirow{2}{*}{14,8} & 604,0 & \multirow{2}{*}{616,2} & 1,4 & \multirow{2}{*}{1,4} & 19,5 & 107 \\
\hline $9-\mathrm{B}$ & 142,9 & & 11,7 & & 15,0 & & 628,4 & & 1,4 & & 20,0 & 19,1 \\
\hline $11-\mathrm{A}$ & 136,9 & 1388 & 10,9 & 111 & 14,9 & 140 & 681,2 & 6072 & 1,6 & 16 & 19,7 & 201 \\
\hline $11-\mathrm{B}$ & 140,7 & 158,8 & 11,3 & 11,1 & 14,8 & 14,9 & 713,2 & 091,2 & 1,6 & 1,0 & 20,4 & 20,1 \\
\hline $13-\mathrm{A}$ & 147,9 & 1457 & 12,0 & 117 & 15,2 & 150 & 786,9 & 7843 & 1,9 & 10 & 21,3 & 211 \\
\hline $13-\mathrm{B}$ & 143,5 & $145, I$ & 11,4 & 11,1 & 14,8 & 15,0 & 781,8 & 184,3 & 1,8 & 1,9 & 21,0 & 21,1 \\
\hline $15-\mathrm{A}$ & 146,7 & 1450 & 11,7 & 116 & 14,6 & 145 & 762,0 & 7677 & 1,9 & 10 & 21,5 & 214 \\
\hline $15-\mathrm{B}$ & 143,2 & 145,0 & 11,5 & 11,0 & 14,4 & 14,3 & 773,3 & $10 \%, 1$ & 1,9 & 1,9 & 21,2 & 21,4 \\
\hline $17-\mathrm{A}$ & 130,0 & 1321 & 9,8 & 100 & 13,2 & 133 & 653,2 & 6504 & 1,6 & 16 & 19,9 & 200 \\
\hline $17-\mathrm{B}$ & 134,3 & 152,1 & 10,3 & 10,0 & 13,4 & 13,3 & 665,5 & 059,4 & 1,6 & 1,6 & 20,1 & 20,0 \\
\hline
\end{tabular}




\begin{tabular}{|c|c|c|c|c|c|c|c|c|c|c|c|c|}
\hline \multirow{2}{*}{$\begin{array}{l}\text { Profundidade } \\
\text { média }(\mathrm{cm}) / \\
\text { replicata }\end{array}$} & \multicolumn{12}{|c|}{ Concentração $\left(\mathrm{mg} \mathrm{kg}^{-1}\right)$} \\
\hline & cromo & média & níquel & média & cobre & média & zinco & média & cádmio & média & chumbo & média \\
\hline $19-\mathrm{A}$ & 130,7 & \multirow{2}{*}{129,7} & 9,5 & \multirow{2}{*}{9,5} & 13,0 & \multirow{2}{*}{12,8} & 627,9 & \multirow{2}{*}{630,5} & 1,7 & \multirow{2}{*}{1,7} & 20,3 & \multirow{2}{*}{20,2} \\
\hline $19-\mathrm{B}$ & 128,7 & & 9,4 & & 12,6 & & 633,0 & & 1,7 & & 20,0 & \\
\hline $21-\mathrm{A}$ & 127,1 & \multirow{2}{*}{126,0} & 8,8 & \multirow{2}{*}{8,7} & 12,3 & \multirow{2}{*}{12,1} & 549,4 & \multirow{2}{*}{550,4} & 1,6 & \multirow{2}{*}{1,6} & 20,2 & \multirow{2}{*}{20,0} \\
\hline $21-\mathrm{B}$ & 124,9 & & 8,7 & & 12,0 & & 551,4 & & 1,6 & & 19,7 & \\
\hline $23-\mathrm{A}$ & 131,5 & \multirow{2}{*}{130,0} & 9,6 & \multirow{2}{*}{9,3} & 12,4 & \multirow{2}{*}{12,3} & 597,5 & \multirow{2}{*}{591,7} & 1,8 & \multirow{2}{*}{1,8} & 21,1 & \multirow{2}{*}{20,7} \\
\hline $23-\mathrm{B}$ & 128,4 & & 8,9 & & 12,1 & & 586,0 & & 1,8 & & 20,4 & \\
\hline $25-\mathrm{A}$ & 124,8 & \multirow{2}{*}{127,1} & 8,4 & \multirow{2}{*}{8,9} & 12,0 & \multirow{2}{*}{12,0} & 559,7 & \multirow{2}{*}{565,5} & 1,6 & \multirow{2}{*}{1,6} & 19,8 & \multirow{2}{*}{20,2} \\
\hline $25-B$ & 129,5 & & 9,3 & & 12,0 & & 571,3 & & 1,7 & & 20,6 & \\
\hline $27-A$ & 127,8 & \multirow{2}{*}{128,8} & 9,5 & \multirow{2}{*}{9,5} & 5,9 & \multirow{2}{*}{6,0} & 545,8 & \multirow{2}{*}{549,4} & 1,6 & \multirow{2}{*}{1,7} & 20,5 & 206 \\
\hline $27-B$ & 129,8 & & 9,5 & & 6,0 & & 552,9 & & 1,7 & & 20,7 & 20,0 \\
\hline $29-\mathrm{A}$ & 129,9 & 1703 & 9,1 & 02 & 7,0 & 63 & 519,7 & 5214 & 1,6 & 16 & 20,3 & 3 \\
\hline $29-B$ & 128,8 & 129,3 & 9,2 & 9,2 & 5,7 & 0,3 & 523,2 & 521,4 & 1,5 & 1,0 & 20,4 & 20,3 \\
\hline $31-\mathrm{A}$ & 130,7 & 1215 & 9,6 & 06 & 5,9 & 60 & 555,8 & 5568 & 1,7 & 17 & 20,7 & $20 \mathrm{Q}$ \\
\hline $31-B$ & 132,4 & 151,5 & 9,6 & 9,0 & 6,0 & 0,0 & 557,7 & 556,8 & 1,7 & 1,1 & 21,0 & 20,8 \\
\hline $33-A$ & 123,4 & 1226 & 8,3 & 83 & 5,2 & 52 & 477,3 & 1811 & 1,5 & 15 & 19,9 & 100 \\
\hline $33-\mathrm{B}$ & 121,8 & 122,0 & 8,4 & $0, J$ & 5,2 & $J, 2$ & 485,0 & 401,1 & 1,5 & $1, J$ & 19,8 & 19,9 \\
\hline $35-\mathrm{A}$ & 119,4 & 1188 & 6,7 & 67 & 3,9 & 30 & 401,3 & 3034 & 1,2 & 12 & 17,4 & 173 \\
\hline $35-B$ & 118,1 & & 6,7 & & 3,8 & & 385,5 & & 1,2 & & 17,3 & \\
\hline $37-\mathrm{A}$ & 127,7 & 1284 & 7,1 & 60 & 3,2 & 31 & 288,0 & 2800 & 1,0 & 00 & 17,2 & 170 \\
\hline $37-\mathrm{B}$ & 129,2 & & 6,8 & & 3,0 & & 291,8 & & 0,9 & & 16,9 & \\
\hline $39-\mathrm{A}$ & 133,3 & 1310 & 9,3 & 80 & 5,0 & 48 & 345,5 & 3380 & 1,2 & 12 & 20,3 & 200 \\
\hline $39-B$ & 128,7 & 151,0 & 8,5 & 8,9 & 4,6 & $4, \delta$ & 332,2 & 538,9 & 1,2 & 1,2 & 19,7 & 20,0 \\
\hline
\end{tabular}




\begin{tabular}{|c|c|c|c|c|c|c|c|c|c|c|c|c|}
\hline \multirow{2}{*}{$\begin{array}{l}\text { Profundidade } \\
\text { média }(\mathrm{cm}) / \\
\text { replicata }\end{array}$} & \multicolumn{12}{|c|}{ Concentração $\left(\mathrm{mg} \mathrm{kg}^{-1}\right)$} \\
\hline & cromo & média & níquel & média & cobre & média & zinco & média & cádmio & média & chumbo & média \\
\hline $41-\mathrm{A}$ & 122,7 & \multirow{2}{*}{124,7} & 7,7 & \multirow{2}{*}{7,9} & 4,0 & \multirow{2}{*}{4,2} & 310,0 & \multirow{2}{*}{313,9} & 1,0 & \multirow{2}{*}{1,0} & 18,8 & \multirow{2}{*}{19,0} \\
\hline $41-B$ & 126,7 & & 8,1 & & 4,3 & & 317,7 & & 1,0 & & 19,3 & \\
\hline $43-\mathrm{A}$ & 127,1 & \multirow{2}{*}{128,5} & 8,4 & \multirow{2}{*}{8,5} & 4,3 & \multirow{2}{*}{4,3} & 299,4 & \multirow{2}{*}{302,5} & 1,0 & \multirow{2}{*}{1,0} & 19,1 & \multirow{2}{*}{20,1} \\
\hline $43-B$ & 129,9 & & 8,6 & & 4,4 & & 305,6 & & 1,0 & & 21,1 & \\
\hline $45-\mathrm{A}$ & 133,8 & \multirow{2}{*}{133,8} & 9,6 & \multirow{2}{*}{9,6} & 4,5 & \multirow{2}{*}{4,5} & 238,3 & \multirow{2}{*}{237,4} & 0,7 & \multirow{2}{*}{0,7} & 18,2 & \multirow{2}{*}{18,3} \\
\hline $45-B$ & 133,8 & & 9,6 & & 4,5 & & 236,6 & & 0,7 & & 18,3 & \\
\hline $47-\mathrm{A}$ & 131,9 & \multirow{2}{*}{133,0} & 9,6 & \multirow{2}{*}{9,7} & 4,4 & \multirow{2}{*}{4,4} & 205,7 & \multirow{2}{*}{208,7} & 0,6 & \multirow{2}{*}{0,6} & 17,2 & \multirow{2}{*}{17,3} \\
\hline $47-\mathrm{B}$ & 134,2 & & 9,8 & & 4,4 & & 211,7 & & 0,7 & & 17,4 & \\
\hline $49-\mathrm{A}$ & 128,9 & \multirow{2}{*}{129,2} & 9,2 & \multirow{2}{*}{9,2} & 4,1 & \multirow{2}{*}{4,2} & 201,2 & \multirow{2}{*}{197,6} & 0,6 & \multirow{2}{*}{0,6} & 17,0 & \multirow{2}{*}{17,0} \\
\hline $49-\mathrm{B}$ & 129,5 & & 9,3 & & 4,4 & & 193,9 & & 0,6 & & 17,0 & \\
\hline $51-\mathrm{A}$ & 136,1 & \multirow{2}{*}{137,1} & 9,6 & \multirow{2}{*}{9,6} & 5,0 & \multirow{2}{*}{4,5} & 149,7 & & 0,4 & & 16,3 & \\
\hline $51-\mathrm{B}$ & 138,1 & & 9,6 & & 3,9 & & 151,2 & 150,5 & 0,4 & 0,4 & 16,3 & 10,3 \\
\hline $53-\mathrm{A}$ & 136,7 & 1354 & 9,3 & & 3,5 & & 110,6 & & 0,3 & & 15,6 & 153 \\
\hline $53-\mathrm{B}$ & 134,1 & 135,4 & 8,8 & 9,0 & 3,3 & 3,4 & 106,9 & 108,8 & 0,3 & 0,3 & 15,1 & 15,3 \\
\hline
\end{tabular}


Tabela 58: Determinação de $\mathrm{Cr}, \mathrm{Ni}, \mathrm{Cu}, \mathrm{Zn}, \mathrm{Cd}$ e Pb em testemunho sedimentar, T-19.

\begin{tabular}{|c|c|c|c|c|c|c|c|c|c|c|c|c|}
\hline \multicolumn{13}{|c|}{ Testemunho T-19 } \\
\hline \multirow{2}{*}{$\begin{array}{l}\text { Profundidade } \\
\text { média }(\mathrm{cm}) / \\
\text { replicata }\end{array}$} & \multicolumn{12}{|c|}{ Concentração $\left(\mathrm{mg} \mathrm{kg}^{-1}\right)$} \\
\hline & cromo & média & níquel & média & cobre & média & zinco & média & cádmio & média & chumbo & média \\
\hline $1-\mathrm{A}$ & 170,5 & \multirow{2}{*}{165,6} & 18,3 & \multirow{2}{*}{17,8} & 16,9 & \multirow{2}{*}{16,3} & 550,2 & \multirow{2}{*}{547,0} & 1,5 & \multirow{2}{*}{1,4} & 22,5 & \multirow{2}{*}{22,0} \\
\hline $1-\mathrm{B}$ & 160,7 & & 17,2 & & 15,8 & & 543,7 & & 1,4 & & 21,5 & \\
\hline $3-\mathrm{A}$ & 162,8 & \multirow{2}{*}{160,3} & 17,3 & \multirow{2}{*}{17,1} & 16,1 & \multirow{2}{*}{15,9} & 554,8 & \multirow{2}{*}{546,9} & 1,4 & \multirow{2}{*}{1,4} & 22,0 & \multirow{2}{*}{21,9} \\
\hline $3-\mathrm{B}$ & 157,8 & & 16,9 & & 15,7 & & 539,1 & & 1,4 & & 21,8 & \\
\hline $5-\mathrm{A}$ & 160,6 & \multirow{2}{*}{159,4} & 17,4 & \multirow{2}{*}{17,1} & 15,9 & \multirow{2}{*}{15,8} & 551,2 & \multirow{2}{*}{555,0} & 1,4 & \multirow{2}{*}{1,4} & 22,1 & \multirow{2}{*}{22,0} \\
\hline $5-B$ & 158,2 & & 16,9 & & 15,8 & & 558,8 & & 1,4 & & 22,0 & \\
\hline $7-A$ & 161,7 & \multirow{2}{*}{163,7} & 17,1 & \multirow{2}{*}{17,2} & 15,9 & \multirow{2}{*}{16,0} & 619,3 & \multirow{2}{*}{623,7} & 1,5 & \multirow{2}{*}{1,6} & 22,5 & \multirow{2}{*}{22,9} \\
\hline 7 - B & 165,7 & & 17,3 & & 16,0 & & 628,0 & & 1,6 & & 23,2 & \\
\hline $9-\mathrm{A}$ & 171,8 & \multirow{2}{*}{170,2} & 18,3 & \multirow{2}{*}{18,3} & 16,8 & \multirow{2}{*}{16,7} & 654,8 & \multirow{2}{*}{643,6} & 1,6 & \multirow{2}{*}{1,6} & 23,6 & \\
\hline $9-B$ & 168,6 & & 18,3 & & 16,6 & & 632,4 & & 1,7 & & 23,5 & 23,6 \\
\hline $11-\mathrm{A}$ & 176,1 & & 18,9 & & 17,4 & & 671,1 & & 1,7 & & 24,6 & \\
\hline $11-\mathrm{B}$ & 177,2 & 176,6 & 19,2 & 19,0 & 17,4 & 17,4 & 656,0 & 663,5 & 1,7 & 1,7 & 24,4 & 24,5 \\
\hline $13-\mathrm{A}$ & 179,4 & & 19,4 & & 17,7 & & 655,6 & & 1,7 & & 24,8 & \\
\hline $13-\mathrm{B}$ & 176,7 & 178,0 & 18,9 & 19,2 & 17,4 & 17,6 & 644,9 & 650,2 & 1,7 & 1,7 & 24,9 & 24,9 \\
\hline $15-\mathrm{A}$ & 175,1 & $175 \mathrm{e}$ & 18,7 & 180 & 17,4 & 175 & 645,2 & 6557 & 1,6 & 17 & 24,4 & 247 \\
\hline $15-\mathrm{B}$ & 176,4 & $1 / 5,8$ & 18,9 & 18,8 & 17,6 & $1 /, 2$ & 666,3 & 6ว5,I & 1,7 & 1,1 & 25,1 & 24,1 \\
\hline $17-\mathrm{A}$ & 178,0 & 1780 & 18,7 & 180 & 18,6 & 180 & 689,5 & 7050 & 1,9 & 18 & 25,4 & 253 \\
\hline $17-\mathrm{B}$ & 178,0 & $1 / 8,0$ & 18,8 & 18,8 & 17,3 & 18,0 & 722,3 & 105,9 & 1,7 & 1,8 & 25,1 & 25,3 \\
\hline
\end{tabular}




\begin{tabular}{|c|c|c|c|c|c|c|c|c|c|c|c|c|}
\hline \multirow{2}{*}{$\begin{array}{l}\text { Profundidade } \\
\text { média }(\mathrm{cm}) / \\
\text { replicata }\end{array}$} & \multicolumn{12}{|c|}{ Concentração $\left(\mathrm{mg} \mathrm{kg}^{-1}\right)$} \\
\hline & cromo & média & níquel & média & cobre & média & zinco & média & cádmio & média & chumbo & média \\
\hline $19-\mathrm{A}$ & 180,6 & \multirow{2}{*}{176,6} & 18,8 & \multirow{2}{*}{18,6} & 17,7 & \multirow{2}{*}{17,4} & 758,8 & \multirow{2}{*}{744,3} & 1,9 & \multirow{2}{*}{1,9} & 25,9 & \multirow{2}{*}{25,6} \\
\hline $19-\mathrm{B}$ & 172,6 & & 18,3 & & 17,1 & & 729,8 & & 1,8 & & 25,2 & \\
\hline $21-\mathrm{A}$ & 175,9 & \multirow{2}{*}{180,1} & 18,2 & \multirow{2}{*}{18,7} & 17,1 & \multirow{2}{*}{17,4} & 789,3 & \multirow{2}{*}{807,1} & 2,0 & \multirow{2}{*}{2,0} & 25,5 & \multirow{2}{*}{26,1} \\
\hline $21-B$ & 184,3 & & 19,2 & & 17,7 & & 824,9 & & 2,0 & & 26,6 & \\
\hline $23-\mathrm{A}$ & 174,8 & \multirow{2}{*}{174,4} & 18,1 & \multirow{2}{*}{18,1} & 16,5 & \multirow{2}{*}{16,6} & 859,9 & \multirow{2}{*}{847,8} & 2,0 & \multirow{2}{*}{2,0} & 25,3 & \multirow{2}{*}{25,3} \\
\hline $23-B$ & 173,9 & & 18,1 & & 16,7 & & 835,8 & & 2,0 & & 25,4 & \\
\hline $25-\mathrm{A}$ & 172,8 & \multirow{2}{*}{171,3} & 17,6 & \multirow{2}{*}{17,4} & 16,3 & \multirow{2}{*}{16,2} & 1197,0 & \multirow{2}{*}{1190,3} & 2,7 & \multirow{2}{*}{2,7} & 26,1 & \multirow{2}{*}{25,9} \\
\hline $25-\mathrm{B}$ & 169,8 & & 17,2 & & 16,0 & & 1183,6 & & 2,7 & & 25,7 & \\
\hline $27-\mathrm{A}$ & 164,6 & \multirow{2}{*}{164,1} & 16,6 & \multirow{2}{*}{16,5} & 15,3 & \multirow{2}{*}{15,2} & 1257,0 & \multirow{2}{*}{1255,2} & 2,8 & \multirow{2}{*}{2,8} & 25,1 & \\
\hline $27-B$ & 163,6 & & 16,4 & & 15,1 & & 1253,3 & & 2,8 & & 24,9 & 25,0 \\
\hline $29-\mathrm{A}$ & 161,2 & & 16,1 & & 14,8 & & 1168,8 & 11780 & 2,8 & & 25,3 & \\
\hline $29-B$ & 157,5 & 159,3 & 15,6 & 15,8 & 14,4 & 14,0 & 1187,2 & $11 / 8,0$ & 2,7 & 2,8 & 25,0 & 25,1 \\
\hline $31-\mathrm{A}$ & 155,7 & 1578 & 15,4 & 156 & 13,9 & & 1050,8 & 10908 & 2,7 & 28 & 25,1 & 254 \\
\hline $31-\mathrm{B}$ & 159,8 & $15 /, 8$ & 15,9 & 15,0 & 14,3 & 14,1 & 1130,9 & 1090,8 & 2,9 & 2,8 & 25,8 & 25,4 \\
\hline $33-\mathrm{A}$ & 149,0 & 1467 & 15,0 & 146 & 12,6 & 124 & 859,3 & 8455 & 2,6 & 25 & 24,7 & 245 \\
\hline $33-\mathrm{B}$ & 144,3 & 140,1 & 14,2 & 14,0 & 12,2 & 12,4 & 831,7 & 845,5 & 2,5 & 2,3 & 24,4 & 24,5 \\
\hline $35-\mathrm{A}$ & 140,8 & 1378 & 13,4 & 130 & 11,3 & 109 & 666,6 & 6574 & 2,3 & 21 & 24,1 & 234 \\
\hline $35-\mathrm{B}$ & 134,8 & 151,0 & 12,6 & 15,0 & 10,6 & 10,9 & 648,2 & (4), & 2,0 & 2,1 & 22,7 & 25,4 \\
\hline $37-\mathrm{A}$ & 134,1 & 1344 & 12,4 & 126 & 10,3 & 104 & 569,4 & 5763 & 2,0 & 20 & 22,4 & 226 \\
\hline $37-\mathrm{B}$ & 134,8 & 154,4 & 12,7 & 12,0 & 10,5 & 10,4 & 583,2 & $5 / 0,3$ & 2,0 & 2,0 & 22,9 & $2<, 0$ \\
\hline $39-\mathrm{A}$ & 136,7 & 1385 & 12,9 & 131 & 10,5 & 107 & 584,9 & 5958 & 2,0 & 20 & 23,0 & 232 \\
\hline $39-\mathrm{B}$ & 140,2 & 158,5 & 13,2 & 15,1 & 10,8 & 10,1 & 606,8 & 595,8 & 2,1 & 2,0 & 23,4 & 25,2 \\
\hline
\end{tabular}




\begin{tabular}{|c|c|c|c|c|c|c|c|c|c|c|c|c|}
\hline \multirow{2}{*}{$\begin{array}{l}\text { Profundidade } \\
\text { média }(\mathrm{cm}) / \\
\text { replicata }\end{array}$} & \multicolumn{12}{|c|}{ Concentração $\left(\mathrm{mg} \mathrm{kg}^{-1}\right)$} \\
\hline & cromo & média & níquel & média & cobre & média & zinco & média & cádmio & média & chumbo & média \\
\hline $41-\mathrm{A}$ & 135,7 & \multirow{2}{*}{137,6} & 12,5 & \multirow{2}{*}{12,9} & 10,2 & \multirow{2}{*}{10,4} & 562,0 & \multirow{2}{*}{575,5} & 1,9 & \multirow{2}{*}{2,0} & 22,2 & \multirow{2}{*}{22,8} \\
\hline $41-B$ & 139,5 & & 13,2 & & 10,6 & & 588,9 & & 2,0 & & 23,4 & \\
\hline $43-\mathrm{A}$ & 142,1 & \multirow{2}{*}{140,9} & 13,4 & \multirow{2}{*}{13,3} & 10,7 & \multirow{2}{*}{10,7} & 595,7 & \multirow{2}{*}{594,9} & 2,0 & \multirow{2}{*}{2,0} & 23,4 & \multirow{2}{*}{23,3} \\
\hline $43-B$ & 139,7 & & 13,1 & & 10,7 & & 594,2 & & 2,0 & & 23,1 & \\
\hline $45-\mathrm{A}$ & 143,5 & \multirow{2}{*}{141,9} & 13,7 & \multirow{2}{*}{13,7} & 11,0 & \multirow{2}{*}{10,9} & 585,7 & \multirow{2}{*}{576,9} & 2,0 & \multirow{2}{*}{2,0} & 23,8 & \multirow{2}{*}{23,6} \\
\hline $45-\mathrm{B}$ & 140,4 & & 13,6 & & 10,8 & & 568,1 & & 2,1 & & 23,4 & \\
\hline $47-\mathrm{A}$ & 141,9 & \multirow{2}{*}{142,5} & 13,6 & \multirow{2}{*}{13,7} & 10,7 & \multirow{2}{*}{10,7} & 525,6 & \multirow{2}{*}{535,5} & 2,0 & \multirow{2}{*}{2,0} & 23,6 & \multirow{2}{*}{23,7} \\
\hline $47-B$ & 143,0 & & 13,8 & & 10,8 & & 545,5 & & 2,0 & & 23,7 & \\
\hline $49-\mathrm{A}$ & 138,6 & \multirow{2}{*}{140,6} & 13,2 & \multirow{2}{*}{13,3} & 10,3 & \multirow{2}{*}{10,5} & 493,3 & \multirow{2}{*}{500,1} & 1,9 & \multirow{2}{*}{1,9} & 23,1 & \multirow{2}{*}{23,4} \\
\hline $49-\mathrm{B}$ & 142,5 & & 13,5 & & 10,6 & & 506,8 & & 1,9 & & 23,8 & \\
\hline $51-\mathrm{A}$ & 144,9 & 1430 & 14,0 & 130 & 10,6 & 106 & 480,0 & 4755 & 1,8 & 18 & 23,9 & 230 \\
\hline $51-\mathrm{B}$ & 142,9 & 145,9 & 13,8 & 15,9 & 10,5 & 10,0 & 471,0 & $4 / 5,3$ & 1,8 & 1,8 & 23,8 & 23,9 \\
\hline $53-\mathrm{A}$ & 143,2 & 1425 & 13,6 & 135 & 10,2 & 102 & 443,0 & 4410 & 1,7 & 17 & 23,5 & 233 \\
\hline $53-\mathrm{B}$ & 141,9 & 142,5 & 13,3 & 13,2 & 10,2 & 10,2 & 438,9 & 441,0 & 1,7 & 1,1 & 23,1 & 25,3 \\
\hline $55-\mathrm{A}$ & 137,7 & 1393 & 12,7 & 129 & 9,4 & 97 & 381,8 & 3840 & 1,5 & 15 & 22,3 & 226 \\
\hline $55-\mathrm{B}$ & 140,9 & 159,3 & 13,1 & 12,9 & 10,0 & 9,1 & 388,0 & 384,9 & 1,5 & 1,5 & 22,9 & $\angle 2,0$ \\
\hline $57-\mathrm{A}$ & 131,1 & 1336 & 11,7 & 119 & 8,5 & 240 & 312,2 & 3198 & 1,2 & 12 & 20,0 & 204 \\
\hline $57-\mathrm{B}$ & 136,1 & 150,0 & 12,2 & & 39,6 & 24,0 & 327,4 & 319,8 & 1,3 & 1,2 & 20,7 & 20,4 \\
\hline $59-\mathrm{A}$ & 146,1 & 1464 & 14,4 & 143 & 10,0 & 100 & 348,0 & 3525 & 1,3 & 14 & 22,2 & 222 \\
\hline $59-\mathrm{B}$ & 146,7 & 140,4 & 14,2 & 14,3 & 10,0 & & 357,1 & $35 \angle, 3$ & 1,4 & 1,4 & 22,3 & 22,2 \\
\hline
\end{tabular}


Tabela 59: Determinação de $\mathrm{Cr}, \mathrm{Ni}, \mathrm{Cu}, \mathrm{Zn}, \mathrm{Cd}$ e Pb em testemunho sedimentar, T-20.

\begin{tabular}{|c|c|c|c|c|c|c|c|c|c|c|c|c|}
\hline \multicolumn{13}{|c|}{ Testemunho T-20 } \\
\hline \multirow{2}{*}{$\begin{array}{l}\text { Profundidade } \\
\text { média }(\mathrm{cm}) / \\
\text { replicata }\end{array}$} & \multicolumn{12}{|c|}{ Concentração $\left(\mathrm{mg} \mathrm{kg}^{-1}\right)$} \\
\hline & cromo & média & níquel & média & cobre & média & zinco & média & cádmio & média & chumbo & média \\
\hline $1-\mathrm{A}$ & 157,8 & \multirow{2}{*}{159,0} & 17,1 & \multirow{2}{*}{17,3} & 16,9 & \multirow{2}{*}{17,1} & 497,3 & \multirow{2}{*}{490,6} & 1,4 & \multirow{2}{*}{1,4} & 21,2 & \multirow{2}{*}{21,3} \\
\hline $1-\mathrm{B}$ & 160,2 & & 17,5 & & 17,2 & & 484,0 & & 1,4 & & 21,4 & \\
\hline $3-\mathrm{A}$ & 165,9 & \multirow{2}{*}{166,8} & 18,3 & \multirow{2}{*}{18,5} & 17,6 & \multirow{2}{*}{17,7} & 522,6 & \multirow{2}{*}{523,3} & 1,5 & \multirow{2}{*}{1,5} & 22,3 & \multirow{2}{*}{22,4} \\
\hline $3-\mathrm{B}$ & 167,8 & & 18,7 & & 17,8 & & 523,9 & & 1,5 & & 22,6 & \\
\hline $5-\mathrm{A}$ & 171,5 & \multirow{2}{*}{170,7} & 18,9 & \multirow{2}{*}{18,7} & 17,6 & \multirow{2}{*}{17,5} & 555,9 & \multirow{2}{*}{551,8} & 1,6 & \multirow{2}{*}{1,6} & 22,7 & \multirow{2}{*}{22,6} \\
\hline $5-B$ & 169,8 & & 18,6 & & 17,5 & & 547,6 & & 1,6 & & 22,6 & \\
\hline $7-\mathrm{A}$ & 174,8 & \multirow{2}{*}{179,1} & 19,0 & \multirow{2}{*}{19,7} & 17,9 & \multirow{2}{*}{18,3} & 581,6 & \multirow{2}{*}{590,8} & 1,7 & \multirow{2}{*}{1,7} & 23,1 & \multirow{2}{*}{23,5} \\
\hline $7-B$ & 183,4 & & 20,3 & & 18,7 & & 600,0 & & 1,8 & & 24,0 & \\
\hline $9-\mathrm{A}$ & 174,8 & \multirow{2}{*}{175,9} & 19,2 & \multirow{2}{*}{19,2} & 18,3 & \multirow{2}{*}{18,2} & 597,9 & \multirow{2}{*}{603,4} & 2,0 & \multirow{2}{*}{1,9} & 24,2 & 240 \\
\hline $9-B$ & 177,0 & & 19,2 & & 18,1 & & 608,8 & & 1,8 & & 23,9 & 24,0 \\
\hline $11-\mathrm{A}$ & 173,6 & 1743 & 18,9 & & 18,0 & 180 & 594,1 & 5014 & 1,8 & 18 & 23,6 & 236 \\
\hline $11-\mathrm{B}$ & 174,9 & $1 / 4,3$ & 19,1 & 19,0 & 18,0 & 18,0 & 588,7 & 591,4 & 1,8 & 1,8 & 23,7 & 25,6 \\
\hline $13-\mathrm{A}$ & 175,1 & 1728 & 19,1 & 100 & 18,2 & 180 & 566,0 & 5658 & 1,7 & 17 & 23,6 & 234 \\
\hline $13-\mathrm{B}$ & 170,4 & $1 / 2,8$ & 18,8 & 19,0 & 17,7 & 18,0 & 565,6 & 505,8 & 1,7 & 1,1 & 23,3 & 25,4 \\
\hline $15-\mathrm{A}$ & 167,7 & 1607 & 18,4 & 185 & 17,5 & 176 & 568,5 & 5684 & 1,6 & 16 & 26,4 & 266 \\
\hline $15-\mathrm{B}$ & 171,6 & 109,1 & 18,6 & 10,0 & 17,7 & $1 /, 0$ & 568,4 & 500,4 & 1,6 & 1,0 & 26,9 & 20,0 \\
\hline $17-\mathrm{A}$ & 173,4 & 1724 & 19,3 & 101 & 18,1 & 170 & 562,8 & 5541 & 1,6 & 16 & 23,6 & 235 \\
\hline $17-\mathrm{B}$ & 171,3 & $1 / 2,4$ & 18,9 & 19,1 & 17,7 & 17,9 & 545,4 & 554,1 & 1,6 & 1,6 & 23,3 & 25,3 \\
\hline
\end{tabular}




\begin{tabular}{|c|c|c|c|c|c|c|c|c|c|c|c|c|}
\hline \multirow{2}{*}{$\begin{array}{l}\text { Profundidade } \\
\text { média }(\mathrm{cm}) / \\
\text { replicata }\end{array}$} & \multicolumn{12}{|c|}{ Concentração $\left(\mathrm{mg} \mathrm{kg}^{-1}\right)$} \\
\hline & cromo & média & níquel & média & cobre & média & zinco & média & cádmio & média & chumbo & média \\
\hline $19-\mathrm{A}$ & 169,5 & \multirow{2}{*}{167,8} & 18,6 & \multirow{2}{*}{18,3} & 17,6 & \multirow{2}{*}{17,4} & 558,4 & \multirow{2}{*}{546,6} & 1,6 & \multirow{2}{*}{1,6} & 23,2 & \multirow{2}{*}{23,1} \\
\hline $19-\mathrm{B}$ & 166,1 & & 18,0 & & 17,2 & & 534,7 & & 1,6 & & 23,1 & \\
\hline $21-\mathrm{A}$ & 169,4 & \multirow{2}{*}{171,0} & 18,4 & \multirow{2}{*}{18,6} & 17,5 & \multirow{2}{*}{17,6} & 514,6 & \multirow{2}{*}{523,7} & 1,5 & \multirow{2}{*}{1,5} & 23,3 & \multirow{2}{*}{23,4} \\
\hline $21-B$ & 172,7 & & 18,9 & & 17,7 & & 532,9 & & 1,6 & & 23,5 & \\
\hline $23-A$ & 165,5 & \multirow{2}{*}{166,3} & 18,1 & \multirow{2}{*}{18,2} & 17,3 & \multirow{2}{*}{17,4} & 520,2 & \multirow{2}{*}{518,4} & 1,5 & \multirow{2}{*}{1,5} & 22,8 & \multirow{2}{*}{23,0} \\
\hline $23-B$ & 167,2 & & 18,4 & & 17,5 & & 516,6 & & 1,5 & & 23,1 & \\
\hline $25-\mathrm{A}$ & 162,8 & \multirow{2}{*}{162,5} & 17,7 & \multirow{2}{*}{17,7} & 17,1 & \multirow{2}{*}{17,1} & 546,5 & \multirow{2}{*}{534,4} & 1,6 & \multirow{2}{*}{1,6} & 22,9 & \multirow{2}{*}{22,9} \\
\hline $25-B$ & 162,2 & & 17,6 & & 17,1 & & 522,3 & & 1,6 & & 23,0 & \\
\hline $27-\mathrm{A}$ & 165,6 & \multirow{2}{*}{166,1} & 18,3 & \multirow{2}{*}{18,2} & 17,3 & \multirow{2}{*}{17,3} & 525,5 & \multirow{2}{*}{528,8} & 1,6 & 16 & 23,2 & \multirow{2}{*}{23,3} \\
\hline $27-B$ & 166,5 & & 18,1 & & 17,3 & & 532,0 & & 1,6 & 1,0 & 23,4 & \\
\hline $29-\mathrm{A}$ & 162,6 & $161 ?$ & 17,8 & 175 & 16,8 & 166 & 557,3 & 5550 & 1,7 & 18 & 23,5 & 234 \\
\hline $29-B$ & 159,8 & 101,2 & 17,2 & (1, & 16,5 & 10,0 & 552,7 & UJJ, & 1,8 & 1,0 & 23,4 & $2 \sqrt{3}, 4$ \\
\hline $31-\mathrm{A}$ & 164,5 & 1626 & 17,8 & 174 & 16,9 & 167 & 627,0 & 6165 & 1,9 & 18 & 23,6 & 232 \\
\hline $31-B$ & 160,6 & 102,0 & 17,0 & 1,4 & 16,4 & $10, r$ & 606,0 & & 1,8 & 1,0 & 22,9 & $2 J, L$ \\
\hline $33-\mathrm{A}$ & 172,8 & 1734 & 18,6 & 188 & 18,2 & 183 & 601,6 & 6103 & 1,9 & 10 & 24,5 & 244 \\
\hline $33-\mathrm{B}$ & 174,1 & $17 J, 4$ & 19,1 & 10,0 & 18,3 & 10,3 & 637,0 & 013,5 & 1,8 & 1,9 & 24,2 & 24,4 \\
\hline $35-\mathrm{A}$ & 176,8 & 1743 & 19,2 & 100 & 18,6 & 183 & 593,0 & 5831 & 1,8 & 18 & 24,7 & 246 \\
\hline $35-\mathrm{B}$ & 171,8 & & 18,8 & & 18,1 & & 573,2 & & 1,8 & & 24,6 & \\
\hline $37-A$ & 170,5 & 1676 & 18,1 & 178 & 18,0 & 177 & 707,7 & 6050 & 2,1 & 21 & 24,9 & 245 \\
\hline $37-\mathrm{B}$ & 164,7 & & 17,5 & & 17,4 & & 682,3 & & 2,0 & & 24,2 & \\
\hline $39-A$ & 162,9 & 1645 & 16,9 & 170 & 15,7 & 158 & 1367,7 & 13667 & 3,4 & 35 & 26,2 & 263 \\
\hline $39-\mathrm{B}$ & 166,1 & & 17,2 & 11,0 & 15,9 & & 1365,7 & & 3,5 & , & 26,4 & \\
\hline
\end{tabular}




\begin{tabular}{|c|c|c|c|c|c|c|c|c|c|c|c|c|}
\hline \multirow{2}{*}{$\begin{array}{l}\text { Profundidade } \\
\text { média }(\mathrm{cm}) / \\
\text { replicata }\end{array}$} & \multicolumn{12}{|c|}{ Concentração $\left(\mathrm{mg} \mathrm{kg}^{-1}\right)$} \\
\hline & cromo & média & níquel & média & cobre & média & zinco & média & cádmio & média & chumbo & média \\
\hline $41-\mathrm{A}$ & 151,3 & \multirow{2}{*}{150,4} & 15,4 & \multirow{2}{*}{15,3} & 14,3 & \multirow{2}{*}{14,1} & 1066,1 & \multirow{2}{*}{1077,5} & 3,1 & \multirow{2}{*}{3,1} & 24,3 & \multirow{2}{*}{24,1} \\
\hline $41-B$ & 149,6 & & 15,1 & & 13,9 & & 1088,9 & & 3,1 & & 23,9 & \\
\hline $43-\mathrm{A}$ & 150,4 & \multirow{2}{*}{149,7} & 15,2 & \multirow{2}{*}{15,2} & 13,7 & \multirow{2}{*}{13,6} & 909,6 & \multirow{2}{*}{920,1} & 2,9 & \multirow{2}{*}{2,9} & 24,3 & \multirow{2}{*}{24,2} \\
\hline $43-B$ & 149,1 & & 15,3 & & 13,5 & & 930,6 & & 2,9 & & 24,1 & \\
\hline $45-\mathrm{A}$ & 149,7 & \multirow{2}{*}{152,1} & 15,1 & \multirow{2}{*}{15,5} & 13,3 & \multirow{2}{*}{13,5} & 785,2 & \multirow{2}{*}{800,2} & 2,9 & \multirow{2}{*}{3,0} & 24,8 & \multirow{2}{*}{25,1} \\
\hline $45-B$ & 154,5 & & 15,9 & & 13,7 & & 815,1 & & 3,0 & & 25,3 & \\
\hline $47-\mathrm{A}$ & 134,4 & \multirow{2}{*}{132,9} & 13,3 & \multirow{2}{*}{13,2} & 10,5 & \multirow{2}{*}{10,4} & 512,8 & \multirow{2}{*}{517,0} & 2,1 & \multirow{2}{*}{2,1} & 21,7 & \multirow{2}{*}{21,6} \\
\hline $47-B$ & 131,4 & & 13,0 & & 10,3 & & 521,3 & & 2,0 & & 21,5 & \\
\hline $49-\mathrm{A}$ & 124,4 & \multirow{2}{*}{128,2} & 12,0 & \multirow{2}{*}{12,4} & 9,6 & \multirow{2}{*}{9,8} & 436,8 & \multirow{2}{*}{441,9} & 1,8 & \multirow{2}{*}{1,9} & 20,5 & 210 \\
\hline $49-B$ & 132,1 & & 12,7 & & 10,1 & & 447,0 & & 1,9 & & 21,4 & 21,0 \\
\hline $51-\mathrm{A}$ & 140,3 & 1400 & 14,1 & 141 & 10,7 & $10 \mathrm{e}$ & 494,6 & 5018 & 2,0 & 20 & 22,4 & 24 \\
\hline $51-B$ & 141,6 & 140,3 & 14,0 & 14,1 & 10,8 & 10,0 & 509,1 & 30,0 & 2,0 & 2,0 & 22,5 & 22,4 \\
\hline $53-\mathrm{A}$ & 137,0 & 1235 & 13,6 & 122 & 10,5 & 103 & 498,2 & 4831 & 2,1 & 20 & 22,1 & 217 \\
\hline $53-B$ & 130,1 & & 12,8 & 10,2 & 10,0 & 10,5 & 468,0 & 40,1 & 1,9 & 2,0 & 21,3 & $21, r$ \\
\hline $55-\mathrm{A}$ & 136,7 & 1325 & 13,5 & 132 & 10,4 & 101 & 459,7 & 1624 & 1,9 & 18 & 22,0 & 215 \\
\hline $55-\mathrm{B}$ & 130,4 & $1 \mathrm{IJ}, \mathrm{J}$ & 12,8 & 15,2 & 9,9 & 10,1 & 465,1 & 402,4 & 1,7 & 1,0 & 21,0 & $21, J$ \\
\hline $57-\mathrm{A}$ & 132,3 & 1318 & 12,9 & 120 & 9,6 & 06 & 410,3 & 4113 & 1,7 & 17 & 21,1 & 210 \\
\hline $57-B$ & 131,4 & 101,0 & 12,9 & 12,3 & 9,6 &,, 0 & 412,2 & 411,5 & 1,7 & $1, l$ & 20,9 & 21,0 \\
\hline $59-\mathrm{A}$ & 121,6 & 1212 & 11,7 & 116 & 8,5 & 85 & 329,1 & 3217 & 1,3 & 13 & 19,1 & 101 \\
\hline $59-\mathrm{B}$ & 120,8 & 121,2 & 11,5 & 11,0 & 8,5 & $0, J$ & 334,2 & (3) & 1,4 & $1, \mathrm{~J}$ & 19,1 & 17,1 \\
\hline $61-A$ & 116,7 & 1100 & 11,0 & 113 & 8,1 & 83 & 284,4 & 2004 & 1,2 & 13 & 18,6 & 100 \\
\hline $61-B$ & 121,2 & & 11,6 & 11,5 & 8,5 & , & 296,4 & & 1,3 & & 19,3 & \\
\hline
\end{tabular}




\begin{tabular}{|c|c|c|c|c|c|c|c|c|c|c|c|c|}
\hline \multirow{2}{*}{$\begin{array}{l}\text { Profundidade } \\
\text { média }(\mathrm{cm}) / \\
\text { replicata }\end{array}$} & \multicolumn{12}{|c|}{ Concentração $\left(\mathrm{mg} \mathrm{kg}^{-1}\right)$} \\
\hline & cromo & média & níquel & média & cobre & média & zinco & média & cádmio & média & chumbo & média \\
\hline $63-\mathrm{A}$ & 126,9 & \multirow{2}{*}{126,5} & 12,4 & \multirow{2}{*}{12,4} & 8,7 & \multirow{2}{*}{8,6} & 291,8 & \multirow{2}{*}{286,7} & 1,3 & \multirow{2}{*}{1,3} & 20,2 & \multirow{2}{*}{20,1} \\
\hline $63-\mathrm{B}$ & 126,0 & & 12,3 & & 8,6 & & 281,5 & & 1,2 & & 20,0 & \\
\hline $65-\mathrm{A}$ & 115,9 & \multirow{2}{*}{121,5} & 11,1 & \multirow{2}{*}{11,6} & 7,7 & \multirow{2}{*}{8,1} & 243,2 & \multirow{2}{*}{253,9} & 1,0 & \multirow{2}{*}{1,1} & 19,0 & \multirow{2}{*}{19,5} \\
\hline $65-\mathrm{B}$ & 127,1 & & 12,1 & & 8,4 & & 264,5 & & 1,2 & & 20,0 & \\
\hline
\end{tabular}


Tabela 60: Determinação de $\mathrm{Cr}, \mathrm{Ni}, \mathrm{Cu}, \mathrm{Zn}, \mathrm{Cd}$ e Pb em testemunho sedimentar, T-26.

\begin{tabular}{|c|c|c|c|c|c|c|c|c|c|c|c|c|}
\hline \multicolumn{13}{|c|}{ Testemunho T-26 } \\
\hline \multirow{2}{*}{$\begin{array}{l}\text { Profundidade } \\
\text { média }(\mathrm{cm}) / \\
\text { replicata }\end{array}$} & \multicolumn{12}{|c|}{ Concentração $\left(\mathrm{mg} \mathrm{kg}^{-1}\right)$} \\
\hline & cromo & média & níquel & média & cobre & média & zinco & média & cádmio & média & chumbo & média \\
\hline $1-\mathrm{A}$ & 163,7 & \multirow{2}{*}{161,3} & 18,4 & \multirow{2}{*}{18,0} & 18,1 & \multirow{2}{*}{17,8} & 555,5 & \multirow{2}{*}{556,1} & 1,8 & \multirow{2}{*}{1,8} & 22,6 & \multirow{2}{*}{22,3} \\
\hline $1-\mathrm{B}$ & 159,0 & & 17,7 & & 17,5 & & 556,6 & & 1,8 & & 22,0 & \\
\hline $3-\mathrm{A}$ & 168,3 & \multirow{2}{*}{166,4} & 18,6 & \multirow{2}{*}{18,4} & 18,3 & \multirow{2}{*}{18,1} & 628,3 & \multirow{2}{*}{620,5} & 2,0 & \multirow{2}{*}{2,0} & 23,2 & \multirow{2}{*}{23,1} \\
\hline $3-\mathrm{B}$ & 164,4 & & 18,2 & & 17,8 & & 612,8 & & 1,9 & & 22,9 & \\
\hline $5-\mathrm{A}$ & 172,3 & \multirow{2}{*}{169,5} & 19,2 & \multirow{2}{*}{18,8} & 19,0 & \multirow{2}{*}{18,6} & 630,8 & \multirow{2}{*}{604,8} & 2,1 & \multirow{2}{*}{2,1} & 24,0 & \multirow{2}{*}{23,5} \\
\hline $5-B$ & 166,7 & & 18,5 & & 18,1 & & 578,8 & & 2,1 & & 23,1 & \\
\hline $7-\mathrm{A}$ & 170,8 & \multirow{2}{*}{170,6} & 19,0 & \multirow{2}{*}{19,0} & 18,6 & \multirow{2}{*}{18,7} & 622,9 & \multirow{2}{*}{624,8} & 2,1 & \multirow{2}{*}{2,0} & 24,1 & \multirow{2}{*}{23,9} \\
\hline $7-B$ & 170,4 & & 19,0 & & 18,7 & & 626,6 & & 2,0 & & 23,6 & \\
\hline $9-\mathrm{A}$ & 174,6 & \multirow{2}{*}{170,6} & 19,7 & \multirow{2}{*}{19,3} & 19,3 & \multirow{2}{*}{18,9} & 686,3 & \multirow{2}{*}{696,0} & 2,3 & \multirow{2}{*}{2,3} & 24,5 & 240 \\
\hline $9-B$ & 166,7 & & 18,9 & & 18,6 & & 705,7 & & 2,2 & & 24,0 & 24,2 \\
\hline $11-\mathrm{A}$ & 157,5 & $150 ?$ & 17,5 & & 17,5 & 177 & 749,5 & 7508 & 2,3 & 23 & 23,3 & 235 \\
\hline $11-\mathrm{B}$ & 160,9 & 159,2 & 17,8 & $1 /, 6$ & 17,9 & $1 /, 1$ & 752,0 & 150,8 & 2,3 & 2,3 & 23,6 & 25,3 \\
\hline $13-\mathrm{A}$ & 169,1 & 1680 & 18,5 & 185 & 18,3 & 180 & 922,9 & 0035 & 3,0 & 20 & 25,2 & 250 \\
\hline $13-\mathrm{B}$ & 166,8 & 108,0 & 18,5 & 18,0 & 17,7 & 18,0 & 884,0 & 905,5 & 2,9 & 2,9 & 24,9 & 25,0 \\
\hline $15-\mathrm{A}$ & 169,0 & 1666 & 18,6 & 183 & 17,7 & 174 & 1147,8 & 11451 & 3,5 & 36 & 25,5 & 254 \\
\hline $15-\mathrm{B}$ & 164,2 & 166,6 & 18,0 & 18,3 & 17,2 & $1 /, 4$ & 1142,4 & 1145,1 & 3,6 & 3,6 & 25,3 & 25,4 \\
\hline $17-\mathrm{A}$ & 165,8 & 1664 & 18,2 & 184 & 17,6 & 176 & 1392,3 & 13600 & 4,1 & 41 & 25,6 & 257 \\
\hline $17-\mathrm{B}$ & 166,9 & 166,4 & 18,5 & 18,4 & 17,7 & $1 /, 0$ & 1347,5 & 1369,9 & 4,0 & 4,1 & 25,9 & 25,1 \\
\hline
\end{tabular}




\begin{tabular}{|c|c|c|c|c|c|c|c|c|c|c|c|c|}
\hline \multirow{2}{*}{$\begin{array}{l}\text { Profundidade } \\
\text { média }(\mathrm{cm}) / \\
\text { replicata }\end{array}$} & \multicolumn{12}{|c|}{ Concentração $\left(\mathrm{mg} \mathrm{kg}^{-1}\right)$} \\
\hline & cromo & média & níquel & média & cobre & média & zinco & média & cádmio & média & chumbo & média \\
\hline $19-A$ & 159,2 & \multirow{2}{*}{158,4} & 17,8 & \multirow{2}{*}{17,6} & 15,5 & \multirow{2}{*}{15,8} & 937,7 & \multirow{2}{*}{934,3} & 3,3 & \multirow{2}{*}{3,2} & 25,4 & \multirow{2}{*}{25,3} \\
\hline $19-\mathrm{B}$ & 157,6 & & 17,4 & & 16,0 & & 930,9 & & 3,1 & & 25,2 & \\
\hline $21-A$ & 174,9 & \multirow{2}{*}{171,8} & 20,0 & \multirow{2}{*}{19,7} & 15,0 & \multirow{2}{*}{14,7} & 616,7 & \multirow{2}{*}{616,2} & 3,0 & \multirow{2}{*}{2,9} & 27,3 & \multirow{2}{*}{26,9} \\
\hline $21-B$ & 168,7 & & 19,4 & & 14,4 & & 615,7 & & 2,8 & & 26,5 & \\
\hline $23-A$ & 168,7 & \multirow{2}{*}{168,4} & 18,9 & \multirow{2}{*}{19,0} & 13,4 & \multirow{2}{*}{13,2} & 408,8 & \multirow{2}{*}{413,0} & 2,1 & \multirow{2}{*}{2,1} & 25,1 & \multirow{2}{*}{25,1} \\
\hline $23-B$ & 168,2 & & 19,1 & & 12,9 & & 417,2 & & 2,1 & & 25,1 & \\
\hline $25-A$ & 163,5 & \multirow{2}{*}{161,3} & 18,6 & \multirow{2}{*}{18,2} & 12,2 & \multirow{2}{*}{12,1} & 348,4 & \multirow{2}{*}{339,5} & 1,8 & \multirow{2}{*}{1,8} & 24,0 & \multirow{2}{*}{23,8} \\
\hline $25-\mathrm{B}$ & 159,2 & & 17,8 & & 11,9 & & 330,5 & & 1,8 & & 23,6 & \\
\hline $27-A$ & 166,0 & \multirow{2}{*}{165,7} & 18,8 & \multirow{2}{*}{18,7} & 13,1 & \multirow{2}{*}{12,7} & 351,3 & \multirow{2}{*}{352,0} & 1,9 & \multirow{2}{*}{1,9} & 24,6 & 245 \\
\hline $27-B$ & 165,4 & & 18,6 & & 12,3 & & 352,6 & & 1,8 & & 24,5 & $24, J$ \\
\hline $29-\mathrm{A}$ & 165,3 & 1625 & 18,6 & 183 & 12,1 & 120 & 339,7 & 2406 & 1,8 & 18 & 24,5 & 243 \\
\hline $29-B$ & 159,6 & $102, J$ & 18,0 & 10,5 & 11,9 & 12,0 & 341,5 & $3+0,0$ & 1,8 & 1,0 & 24,0 & $24, J$ \\
\hline $31-A$ & 161,4 & 1615 & 18,1 & 181 & 11,7 & 118 & 314,6 & 3154 & 1,7 & 17 & 23,7 & 237 \\
\hline $31-\mathrm{B}$ & 161,7 & 101,3 & 18,1 & 10,1 & 11,9 & 11,0 & 316,2 & 310,4 & 1,7 & 1,1 & 23,8 & 25,1 \\
\hline $33-A$ & 165,3 & 1723 & 18,8 & 101 & 11,8 & 110 & 307,3 & 3035 & 1,6 & 16 & 23,7 & 242 \\
\hline $33-\mathrm{B}$ & 179,4 & 112,0 & 19,4 & 19,1 & 12,1 & 11,9 & 299,7 & $300, J$ & 1,7 & 1,0 & 24,7 & 24,2 \\
\hline $35-A$ & 170,6 & 1711 & 19,4 & 105 & 11,7 & 116 & 263,3 & 2666 & 1,4 & 14 & 23,1 & 232 \\
\hline $35-\mathrm{B}$ & 171,5 & 111,1 & 19,6 & 17,3 & 11,5 & 11,0 & 270,0 & 200,0 & 1,3 & 1,4 & 23,3 & $2 J, 2$ \\
\hline $37-A$ & 170,2 & 1601 & 19,7 & 196 & 11,3 & 112 & 252,5 & 2521 & 1,3 & 13 & 23,1 & 230 \\
\hline $37-\mathrm{B}$ & 168,1 & & 19,5 & & 11,1 & & 251,6 & & 1,3 & & 22,9 & \\
\hline $39-A$ & 174,1 & 1757 & 20,0 & 204 & 11,4 & 115 & 250,2 & 2486 & 1,3 & 13 & 23,2 & 234 \\
\hline $39-\mathrm{B}$ & 177,3 & & 20,8 & & 11,6 & & 247,0 & & 1,3 & & 23,6 & \\
\hline
\end{tabular}




\begin{tabular}{|c|c|c|c|c|c|c|c|c|c|c|c|c|}
\hline \multirow{2}{*}{$\begin{array}{l}\text { Profundidade } \\
\text { média }(\mathrm{cm}) / \\
\text { replicata }\end{array}$} & \multicolumn{12}{|c|}{ Concentração $\left(\mathrm{mg} \mathrm{kg}^{-1}\right)$} \\
\hline & cromo & média & níquel & média & cobre & média & zinco & média & cádmio & média & chumbo & média \\
\hline $41-\mathrm{A}$ & 169,1 & \multirow{2}{*}{169,6} & 19,6 & \multirow{2}{*}{19,7} & 10,9 & \multirow{2}{*}{10,9} & 225,0 & \multirow{2}{*}{230,0} & 1,1 & \multirow{2}{*}{1,2} & 22,4 & \multirow{2}{*}{22,5} \\
\hline $41-B$ & 170,0 & & 19,8 & & 10,9 & & 235,0 & & 1,2 & & 22,6 & \\
\hline $43-\mathrm{A}$ & 172,5 & \multirow{2}{*}{174,1} & 20,1 & \multirow{2}{*}{20,1} & 10,8 & \multirow{2}{*}{10,8} & 199,8 & \multirow{2}{*}{198,3} & 1,0 & \multirow{2}{*}{1,0} & 22,4 & \multirow{2}{*}{22,4} \\
\hline $43-B$ & 175,7 & & 20,1 & & 10,8 & & 196,8 & & 1,0 & & 22,3 & \\
\hline $45-\mathrm{A}$ & 168,1 & \multirow{2}{*}{169,8} & 19,5 & \multirow{2}{*}{19,6} & 10,6 & \multirow{2}{*}{10,7} & 179,5 & \multirow{2}{*}{179,9} & 0,9 & \multirow{2}{*}{0,9} & 21,8 & \multirow{2}{*}{21,9} \\
\hline $45-B$ & 171,5 & & 19,7 & & 10,8 & & 180,2 & & 0,9 & & 22,0 & \\
\hline $47-\mathrm{A}$ & 164,5 & \multirow{2}{*}{165,8} & 18,6 & \multirow{2}{*}{18,8} & 9,5 & \multirow{2}{*}{9,7} & 108,7 & \multirow{2}{*}{112,8} & 0,4 & \multirow{2}{*}{0,4} & 20,4 & \multirow{2}{*}{20,6} \\
\hline $47-B$ & 167,1 & & 18,9 & & 9,8 & & 116,9 & & 0,4 & & 20,8 & \\
\hline $49-\mathrm{A}$ & 169,0 & \multirow{2}{*}{168,0} & 19,2 & \multirow{2}{*}{18,8} & 9,6 & \multirow{2}{*}{9,6} & 99,0 & \multirow{2}{*}{98,8} & 0,2 & \multirow{2}{*}{0,2} & 20,2 & \multirow{2}{*}{20,2} \\
\hline $49-\mathrm{B}$ & 166,9 & & 18,5 & & 9,6 & & 98,6 & & 0,2 & & 20,2 & \\
\hline $51-\mathrm{A}$ & 165,3 & 1650 & 18,2 & 180 & 9,3 & 03 & 91,2 & 012 & 0,2 & ? & 19,4 & 105 \\
\hline $51-\mathrm{B}$ & 164,7 & 105,0 & 17,9 & 18,0 & 9,2 & 9,3 & 91,1 & 91,2 & 0,2 & 0,2 & 19,6 & 19,3 \\
\hline $53-\mathrm{A}$ & 163,9 & 1630 & 17,9 & 179 & 9,1 & 90 & 87,0 & $87 ?$ & 0,2 & 02 & 19,2 & 192 \\
\hline $53-\mathrm{B}$ & 162,1 & 105,0 & 17,9 & $1 /, 9$ & 9,0 & 9,0 & 87,5 & $8 /, 2$ & 0,2 & 0,2 & 19,1 & 19,2 \\
\hline $55-\mathrm{A}$ & 160,3 & 1618 & 17,2 & 176 & 8,8 & 89 & 79,6 & 813 & 0,1 & 01 & 18,7 & 188 \\
\hline $55-\mathrm{B}$ & 163,3 & 101,8 & 18,0 & $1 /, 0$ & 9,0 & 8,9 & 83,1 & 81,3 & 0,1 & 0,1 & 18,8 & 18,8 \\
\hline $57-\mathrm{A}$ & 162,7 & 1608 & 17,5 & 173 & 8,8 & 87 & 81,2 & 810 & 0,1 & 01 & 18,6 & 184 \\
\hline $57-\mathrm{B}$ & 158,9 & & 17,1 & & 8,6 & $\delta, I$ & 80,8 & $\delta 1,0$ & 0,1 & 0,1 & 18,3 & 18,4 \\
\hline $59-\mathrm{A}$ & 164,9 & 1625 & 17,5 & 175 & 8,6 & er & 77,8 & 781 & 0,1 & 01 & 18,4 & 184 \\
\hline $59-\mathrm{B}$ & 162,2 & 105,0 & 17,4 & 11,0 & 8,6 & $\delta, 0$ & 78,4 & 18,1 & 0,1 & 0,1 & 18,3 & 18,4 \\
\hline
\end{tabular}


Tabela 61: Determinação de $\mathrm{Cr}, \mathrm{Ni}, \mathrm{Cu}, \mathrm{Zn}, \mathrm{Cd}$ e Pb em testemunho sedimentar, T-28.

\begin{tabular}{|c|c|c|c|c|c|c|c|c|c|c|c|c|}
\hline \multicolumn{13}{|c|}{ Testemunho $\mathrm{T}-28$} \\
\hline \multirow{2}{*}{$\begin{array}{l}\text { Profundidade } \\
\text { média }(\mathrm{cm}) / \\
\text { replicata }\end{array}$} & \multicolumn{12}{|c|}{ Concentração $\left(\mathrm{mg} \mathrm{kg}^{-1}\right)$} \\
\hline & cromo & média & níquel & média & cobre & média & zinco & média & cádmio & média & chumbo & média \\
\hline $1-\mathrm{A}$ & 153,7 & \multirow{2}{*}{151,3} & 14,0 & \multirow{2}{*}{13,5} & 16,4 & \multirow{2}{*}{16,1} & 483,7 & \multirow{2}{*}{477,1} & 1,8 & \multirow{2}{*}{1,9} & 25,8 & \multirow{2}{*}{26,2} \\
\hline $1-\mathrm{B}$ & 148,9 & & 13,1 & & 15,7 & & 470,4 & & 1,9 & & 26,7 & \\
\hline $3-\mathrm{A}$ & 160,0 & \multirow{2}{*}{159,3} & 14,9 & \multirow{2}{*}{14,7} & 16,6 & \multirow{2}{*}{16,5} & 492,0 & \multirow{2}{*}{486,9} & 1,9 & \multirow{2}{*}{1,9} & 26,8 & \multirow{2}{*}{26,6} \\
\hline $3-\mathrm{B}$ & 158,5 & & 14,5 & & 16,5 & & 481,8 & & 1,9 & & 26,3 & \\
\hline $5-\mathrm{A}$ & 167,3 & \multirow{2}{*}{169,4} & 15,5 & \multirow{2}{*}{15,8} & 16,8 & \multirow{2}{*}{16,9} & 530,5 & \multirow{2}{*}{610,6} & 1,9 & \multirow{2}{*}{1,9} & 26,1 & \multirow{2}{*}{26,0} \\
\hline $5-B$ & 171,4 & & 16,2 & & 17,1 & & 690,6 & & 1,8 & & 26,0 & \\
\hline $7-\mathrm{A}$ & 161,3 & \multirow{2}{*}{158,9} & 14,7 & \multirow{2}{*}{14,4} & 17,5 & \multirow{2}{*}{17,2} & 549,7 & \multirow{2}{*}{544,6} & 2,1 & \multirow{2}{*}{2,1} & 28,1 & \multirow{2}{*}{28,1} \\
\hline $7-B$ & 156,5 & & 14,1 & & 16,8 & & 539,6 & & 2,1 & & 28,0 & \\
\hline $9-\mathrm{A}$ & 161,0 & \multirow{2}{*}{160,8} & 14,9 & \multirow{2}{*}{14,9} & 16,4 & \multirow{2}{*}{16,4} & 579,4 & \multirow{2}{*}{579,9} & 2,3 & \multirow{2}{*}{2,2} & 28,1 & ne 2 \\
\hline $9-\mathrm{B}$ & 160,6 & & 14,9 & & 16,4 & & 580,4 & & 2,2 & & 28,6 & 28,3 \\
\hline $11-\mathrm{A}$ & 155,9 & $161 ?$ & 14,8 & 151 & 15,9 & 163 & 578,8 & 5027 & 2,2 & 23 & 28,7 & 200 \\
\hline $11-\mathrm{B}$ & 166,6 & 101,2 & 15,3 & 15,1 & 16,7 & 10,3 & 606,6 & J92,1 & 2,3 & 2,3 & 29,4 & 29,0 \\
\hline $13-\mathrm{A}$ & 160,8 & $162 ?$ & 15,2 & 154 & 16,0 & 163 & 592,8 & 5084 & 2,1 & 21 & 26,4 & 263 \\
\hline $13-\mathrm{B}$ & 163,5 & 102,2 & 15,5 & 15,4 & 16,6 & 10,3 & 604,0 & J98,4 & 2,2 & 2,1 & 26,1 & 20,3 \\
\hline $15-\mathrm{A}$ & 162,3 & 1503 & 15,3 & 147 & 16,1 & 157 & 648,9 & 6371 & 2,4 & 24 & 27,9 & 281 \\
\hline $15-\mathrm{B}$ & 156,2 & 159,3 & 14,2 & 14,1 & 15,4 & 15,1 & 625,2 & $03 /, 1$ & 2,4 & 2,4 & 28,2 & 28,1 \\
\hline $17-\mathrm{A}$ & 147,9 & 1504 & 12,7 & 120 & 14,2 & 145 & 623,3 & 6317 & 2,4 & 25 & 28,4 & 285 \\
\hline $17-\mathrm{B}$ & 152,9 & 150,4 & 13,1 & 12,9 & 14,8 & 14,3 & 640,1 & 031,1 & 2,6 & 2,5 & 28,7 & 28,3 \\
\hline
\end{tabular}




\begin{tabular}{|c|c|c|c|c|c|c|c|c|c|c|c|c|}
\hline \multirow{2}{*}{$\begin{array}{l}\text { Profundidade } \\
\text { média }(\mathrm{cm}) / \\
\text { replicata }\end{array}$} & \multicolumn{12}{|c|}{ Concentração $\left(\mathrm{mg} \mathrm{kg}^{-1}\right)$} \\
\hline & cromo & média & níquel & média & cobre & média & zinco & média & cádmio & média & chumbo & média \\
\hline $19-\mathrm{A}$ & 153,4 & \multirow{2}{*}{153,0} & 13,9 & \multirow{2}{*}{13,9} & 15,7 & \multirow{2}{*}{15,6} & 664,1 & \multirow{2}{*}{659,7} & 2,7 & \multirow{2}{*}{2,7} & 30,0 & \multirow{2}{*}{29,7} \\
\hline $19-\mathrm{B}$ & 152,5 & & 13,9 & & 15,4 & & 655,3 & & 2,6 & & 29,5 & \\
\hline $21-\mathrm{A}$ & 152,2 & \multirow{2}{*}{152,2} & 13,0 & \multirow{2}{*}{13,4} & 15,6 & \multirow{2}{*}{15,6} & 668,9 & \multirow{2}{*}{676,2} & 2,6 & \multirow{2}{*}{2,6} & 28,0 & \multirow{2}{*}{28,3} \\
\hline $21-\mathrm{B}$ & 152,2 & & 13,8 & & 15,5 & & 683,5 & & 2,6 & & 28,6 & \\
\hline $23-\mathrm{A}$ & 150,0 & \multirow{2}{*}{152,3} & 12,9 & \multirow{2}{*}{13,4} & 13,7 & \multirow{2}{*}{14,0} & 771,5 & \multirow{2}{*}{786,9} & 2,6 & \multirow{2}{*}{2,7} & 29,2 & \multirow{2}{*}{29,1} \\
\hline $23-\mathrm{B}$ & 154,7 & & 13,8 & & 14,2 & & 802,3 & & 2,7 & & 29,0 & \\
\hline $25-\mathrm{A}$ & 152,7 & \multirow{2}{*}{157,7} & 13,2 & \multirow{2}{*}{14,2} & 13,5 & \multirow{2}{*}{14,1} & 807,3 & \multirow{2}{*}{838,5} & 3,3 & \multirow{2}{*}{3,2} & 30,3 & \multirow{2}{*}{29,9} \\
\hline $25-\mathrm{B}$ & 162,8 & & 15,2 & & 14,6 & & 869,6 & & 3,1 & & 29,5 & \\
\hline $27-\mathrm{A}$ & 152,9 & \multirow{2}{*}{158,6} & 13,6 & \multirow{2}{*}{14,2} & 13,5 & \multirow{2}{*}{14,0} & 807,8 & \multirow{2}{*}{832,7} & 3,2 & \multirow{2}{*}{3,2} & 30,6 & 305 \\
\hline $27-B$ & 164,3 & & 14,9 & & 14,5 & & 857,5 & & 3,1 & & 30,5 & (30,J \\
\hline $29-\mathrm{A}$ & 154,0 & $155 \mathrm{Q}$ & 13,4 & 126 & 13,6 & 127 & 834,8 & 8157 & 3,2 & 32 & 29,5 & 300 \\
\hline $29-\mathrm{B}$ & 157,6 & $15 J, 0$ & 13,7 & 15,0 & 13,8 & $15, i$ & 856,7 & $0+5, I$ & 3,3 & $J, 2$ & 30,5 & 30,0 \\
\hline $31-\mathrm{A}$ & 148,3 & 4400 & 12,1 & 122 & 12,4 & 124 & 802,4 & 7070 & 3,2 & 31 & 28,8 & 280 \\
\hline $31-B$ & 151,4 & 14,5 & 12,3 & 12,2 & 12,3 & 12,4 & 793,5 & מונד & 3,1 &,${ }_{1}$ & 29,0 & 20 \\
\hline $33-\mathrm{A}$ & 157,0 & 1557 & 13,7 & 137 & 11,7 & 116 & 676,4 & 6713 & 3,2 & 32 & 30,3 & 306 \\
\hline $33-\mathrm{B}$ & 154,3 & $13 J, I$ & 13,7 & $15, i$ & 11,5 & 11,0 & 666,2 & 071,0 & 3,2 & $J, 2$ & 31,0 & J \\
\hline $35-A$ & 156,8 & 1501 & 13,6 & 140 & 11,1 & 112 & 532,8 & 5361 & 2,8 & 27 & 30,1 & 300 \\
\hline $35-\mathrm{B}$ & 161,3 & $1 J 3,1$ & 14,4 & 14,0 & 11,2 & 11,2 & 539,4 & 300,1 & 2,7 & 2,1 & 30,0 & 30,0 \\
\hline $37-\mathrm{A}$ & 159,9 & 1591 & 14,5 & 144 & 11,0 & 111 & 513,8 & 5129 & 2,7 & 27 & 30,6 & 304 \\
\hline $37-\mathrm{B}$ & 158,4 & & 14,4 & & 11,2 & & 512,0 & & 2,6 & & 30,2 & \\
\hline $39-\mathrm{A}$ & 157,3 & 1576 & 14,1 & 140 & 10,9 & 110 & 487,0 & 4007 & 2,5 & 26 & 30,1 & 30.5 \\
\hline $39-\mathrm{B}$ & 157,9 & & 14,0 & 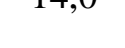 & 11,2 & & 494,5 & & 2,6 & & 30,8 & \\
\hline
\end{tabular}




\begin{tabular}{|c|c|c|c|c|c|c|c|c|c|c|c|c|}
\hline \multirow{2}{*}{$\begin{array}{l}\text { Profundidade } \\
\text { média }(\mathrm{cm}) / \\
\text { replicata }\end{array}$} & \multicolumn{12}{|c|}{ Concentração (mg kg-1) } \\
\hline & cromo & média & níquel & média & cobre & média & zinco & média & cádmio & média & chumbo & média \\
\hline $41-\mathrm{A}$ & 154,2 & \multirow{2}{*}{152,2} & 13,6 & \multirow{2}{*}{13,2} & 10,6 & \multirow{2}{*}{10,4} & 475,5 & \multirow{2}{*}{470,6} & 2,4 & \multirow{2}{*}{2,3} & 28,7 & \multirow{2}{*}{28,5} \\
\hline $41-B$ & 150,3 & & 12,7 & & 10,1 & & 465,6 & & 2,3 & & 28,2 & \\
\hline $43-\mathrm{A}$ & 152,9 & \multirow{2}{*}{155,2} & 13,5 & \multirow{2}{*}{13,7} & 10,6 & \multirow{2}{*}{10,7} & 485,7 & \multirow{2}{*}{486,9} & 2,5 & \multirow{2}{*}{2,5} & 29,3 & \multirow{2}{*}{29,5} \\
\hline $43-B$ & 157,6 & & 13,9 & & 10,8 & & 488,1 & & 2,5 & & 29,7 & \\
\hline $45-\mathrm{A}$ & 169,5 & \multirow{2}{*}{167,6} & 15,6 & \multirow{2}{*}{15,4} & 12,0 & \multirow{2}{*}{11,8} & 553,7 & \multirow{2}{*}{546,3} & 3,0 & \multirow{2}{*}{3,0} & 32,5 & \multirow{2}{*}{32,5} \\
\hline $45-B$ & 165,6 & & 15,1 & & 11,7 & & 538,8 & & 3,0 & & 32,5 & \\
\hline $47-\mathrm{A}$ & 168,1 & \multirow{2}{*}{169,0} & 15,7 & \multirow{2}{*}{15,9} & 12,1 & \multirow{2}{*}{12,1} & 535,2 & \multirow{2}{*}{540,9} & 3,0 & \multirow{2}{*}{3,0} & 33,2 & \multirow{2}{*}{33,2} \\
\hline $47-B$ & 169,9 & & 16,1 & & 12,2 & & 546,7 & & 3,1 & & 33,2 & \\
\hline $49-\mathrm{A}$ & 146,0 & \multirow{2}{*}{152,0} & 13,0 & \multirow{2}{*}{13,7} & 9,7 & \multirow{2}{*}{10,1} & 381,1 & \multirow{2}{*}{393,6} & 2,1 & \multirow{2}{*}{2,1} & 29,2 & 202 \\
\hline $49-B$ & 158,0 & & 14,4 & & 10,5 & & 406,0 & & 2,2 & & 29,1 & 29,2 \\
\hline $51-\mathrm{A}$ & 155,6 & 1547 & 14,1 & 120 & 9,7 & 06 & 342,6 & 3106 & 1,9 & 18 & 29,3 & 286 \\
\hline $51-B$ & 153,8 & $154, /$ & 13,7 & 15,9 & 9,5 & 9,0 & 338,7 & 340,6 & 1,8 & 1,8 & 27,9 & 28,0 \\
\hline $53-\mathrm{A}$ & 156,6 & $154 ?$ & 13,8 & 136 & 9,8 & 94 & 321,7 & 3154 & 1,6 & 16 & 27,2 & 275 \\
\hline $53-B$ & 151,8 & 154,2 & 13,4 & 15,0 & 9,0 & 9,4 & 309,0 & 315,4 & 1,7 & 1,0 & 27,7 & $27, \mathrm{~J}$ \\
\hline $55-\mathrm{A}$ & 144,2 & 1437 & 11,9 & 121 & 8,5 & 84 & 263,3 & 2622 & 1,3 & 13 & 25,3 & 254 \\
\hline $55-\mathrm{B}$ & 143,1 & $145, I$ & 12,3 & 12,1 & 8,3 & 0,4 & 261,1 & 202,2 & 1,3 & 1,3 & 25,5 & $2 J, 4$ \\
\hline $57-\mathrm{A}$ & 157,7 & 1491 & 14,1 & 128 & 9,3 & 85 & 260,5 & 2445 & 1,3 & 13 & 25,8 & 253 \\
\hline $57-B$ & 140,5 & & 11,5 & & 7,8 & & 228,6 & & 1,2 & & 24,8 & \\
\hline $59-\mathrm{A}$ & 142,5 & 1454 & 12,0 & 124 & 7,8 & 83 & 197,9 & 2045 & 0,9 & 09 & 24,3 & 241 \\
\hline $59-\mathrm{B}$ & 148,3 & & 12,8 & & 8,7 & & 211,0 & & 0,9 & & 23,8 & \\
\hline $61-A$ & 141,9 & 1432 & 12,1 & 121 & 7,7 & 76 & 160,1 & 1613 & 0,7 & 07 & 22,5 & 226 \\
\hline $61-B$ & 144,4 & $14 J, 2$ & 12,2 & 12,1 & 7,6 & 1,0 & 162,5 & 101,3 & 0,7 & 0,1 & 22,7 & 22,0 \\
\hline
\end{tabular}


Tabela 62: Determinação de $\mathrm{Cr}, \mathrm{Ni}, \mathrm{Cu}, \mathrm{Zn}, \mathrm{Cd}$ e Pb em testemunho sedimentar, $\mathrm{T}$-31.

\begin{tabular}{|c|c|c|c|c|c|c|c|c|c|c|c|c|}
\hline \multicolumn{13}{|c|}{ Testemunho $\mathbf{T}-31$} \\
\hline \multirow{2}{*}{$\begin{array}{l}\text { Profundidade } \\
\text { média }(\mathrm{cm}) / \\
\text { replicata }\end{array}$} & \multicolumn{12}{|c|}{ Concentração $\left(\mathrm{mg} \mathrm{kg}^{-1}\right)$} \\
\hline & cromo & média & níquel & média & cobre & média & zinco & média & cádmio & média & chumbo & média \\
\hline $1-\mathrm{A}$ & 150,0 & \multirow{2}{*}{150,9} & 18,6 & \multirow{2}{*}{18,8} & 17,3 & \multirow{2}{*}{17,4} & 563,5 & \multirow{2}{*}{556,2} & 1,5 & \multirow{2}{*}{1,5} & 21,6 & \multirow{2}{*}{21,7} \\
\hline $1-\mathrm{B}$ & 151,7 & & 18,9 & & 17,5 & & 548,9 & & 1,6 & & 21,7 & \\
\hline $3-\mathrm{A}$ & 167,7 & \multirow{2}{*}{168,8} & 21,3 & \multirow{2}{*}{21,1} & 19,5 & \multirow{2}{*}{19,5} & 504,7 & \multirow{2}{*}{503,9} & 1,8 & \multirow{2}{*}{1,8} & 24,2 & \multirow{2}{*}{24,1} \\
\hline $3-\mathrm{B}$ & 169,8 & & 21,0 & & 19,5 & & 503,0 & & 1,9 & & 24,0 & \\
\hline $5-\mathrm{A}$ & 168,0 & \multirow{2}{*}{165,4} & 21,3 & \multirow{2}{*}{20,8} & 19,4 & \multirow{2}{*}{19,3} & 581,0 & \multirow{2}{*}{568,4} & 1,8 & \multirow{2}{*}{1,7} & 24,0 & \multirow{2}{*}{23,7} \\
\hline $5-B$ & 162,8 & & 20,4 & & 19,1 & & 555,8 & & 1,7 & & 23,4 & \\
\hline $7-\mathrm{A}$ & 166,0 & \multirow{2}{*}{166,3} & 20,9 & \multirow{2}{*}{20,9} & 19,2 & \multirow{2}{*}{19,2} & 581,9 & \multirow{2}{*}{579,7} & 1,8 & \multirow{2}{*}{1,8} & 23,7 & \multirow{2}{*}{23,8} \\
\hline $7-B$ & 166,6 & & 20,8 & & 19,2 & & 577,5 & & 1,8 & & 23,9 & \\
\hline $9-\mathrm{A}$ & 153,6 & \multirow{2}{*}{150,5} & 19,4 & \multirow{2}{*}{19,0} & 18,0 & \multirow{2}{*}{17,5} & 572,3 & \multirow{2}{*}{568,8} & 1,6 & \multirow{2}{*}{1,6} & 21,9 & 21. \\
\hline $9-B$ & 147,4 & & 18,7 & & 16,9 & & 565,3 & & 1,5 & & 20,8 & 21,4 \\
\hline $11-\mathrm{A}$ & 165,7 & 1663 & 20,8 & & 19,4 & 105 & 566,4 & 5685 & 1,8 & 18 & 23,7 & 236 \\
\hline $11-\mathrm{B}$ & 167,0 & 166,3 & 21,0 & 20,9 & 19,6 & 19,3 & 570,6 & 568,5 & 1,8 & 1,8 & 23,6 & 25,6 \\
\hline $13-\mathrm{A}$ & 169,3 & 1606 & 21,2 & 212 & 20,0 & 100 & 581,6 & 5845 & 1,8 & 18 & 24,0 & 240 \\
\hline $13-\mathrm{B}$ & 170,0 & 109,0 & 21,2 & 21,2 & 19,9 & 19,9 & 587,5 & 584,5 & 1,8 & 1,8 & 24,0 & 24,0 \\
\hline $15-\mathrm{A}$ & 163,7 & 1648 & 20,8 & 210 & 19,3 & 105 & 571,8 & 5775 & 1,8 & 18 & 23,8 & 237 \\
\hline $15-\mathrm{B}$ & 165,8 & 104,0 & 21,1 & 21,0 & 19,6 & 19,3 & 583,3 & נו, & 1,9 & 1,0 & 23,6 & 25,1 \\
\hline $17-\mathrm{A}$ & 162,3 & 1624 & 20,5 & 206 & 19,5 & 103 & 704,5 & 7103 & 2,4 & 23 & 23,4 & 233 \\
\hline $17-\mathrm{B}$ & 162,4 & 162,4 & 20,6 & 20,6 & 19,0 & 19,3 & 716,0 & 710,3 & 2,3 & 2,3 & 23,3 & 25,3 \\
\hline
\end{tabular}




\begin{tabular}{|c|c|c|c|c|c|c|c|c|c|c|c|c|}
\hline \multirow{2}{*}{$\begin{array}{l}\text { Profundidade } \\
\text { média }(\mathrm{cm}) / \\
\text { replicata }\end{array}$} & \multicolumn{12}{|c|}{ Concentração $\left(\mathrm{mg} \mathrm{kg}^{-1}\right)$} \\
\hline & cromo & média & níquel & média & cobre & média & zinco & média & cádmio & média & chumbo & média \\
\hline $19-\mathrm{A}$ & 152,4 & \multirow{2}{*}{153,2} & 19,4 & \multirow{2}{*}{19,5} & 16,7 & \multirow{2}{*}{16,8} & 1001,1 & \multirow{2}{*}{1035,5} & 3,1 & \multirow{2}{*}{3,1} & 23,0 & \multirow{2}{*}{23,3} \\
\hline $19-\mathrm{B}$ & 154,0 & & 19,6 & & 16,8 & & 1069,9 & & 3,1 & & 23,6 & \\
\hline $21-\mathrm{A}$ & 173,3 & \multirow{2}{*}{171,8} & 22,4 & \multirow{2}{*}{21,9} & 19,7 & \multirow{2}{*}{19,2} & 1002,2 & \multirow{2}{*}{994,4} & 3,4 & \multirow{2}{*}{3,4} & 26,8 & \multirow{2}{*}{26,5} \\
\hline $21-\mathrm{B}$ & 170,4 & & 21,4 & & 18,6 & & 986,6 & & 3,4 & & 26,2 & \\
\hline $23-\mathrm{A}$ & 170,7 & \multirow{2}{*}{168,4} & 21,7 & \multirow{2}{*}{21,5} & 18,9 & \multirow{2}{*}{18,5} & 1025,4 & \multirow{2}{*}{1045,3} & 3,6 & \multirow{2}{*}{3,5} & 27,1 & \multirow{2}{*}{26,6} \\
\hline $23-\mathrm{B}$ & 166,2 & & 21,3 & & 18,1 & & 1065,2 & & 3,4 & & 26,0 & \\
\hline $25-\mathrm{A}$ & 171,2 & \multirow{2}{*}{169,7} & 21,8 & \multirow{2}{*}{21,7} & 17,8 & \multirow{2}{*}{17,7} & 1038,7 & \multirow{2}{*}{1051,7} & 4,0 & \multirow{2}{*}{4,0} & 27,4 & \multirow{2}{*}{27,5} \\
\hline $25-\mathrm{B}$ & 168,3 & & 21,6 & & 17,6 & & 1064,6 & & 4,0 & & 27,5 & \\
\hline $27-\mathrm{A}$ & 162,9 & \multirow{2}{*}{166,5} & 21,0 & \multirow{2}{*}{21,2} & 17,1 & \multirow{2}{*}{17,3} & 1033,4 & \multirow{2}{*}{1042,9} & 3,9 & \multirow{2}{*}{3,9} & 26,8 & \multirow{2}{*}{27,2} \\
\hline $27-\mathrm{B}$ & 170,1 & & 21,4 & & 17,6 & & 1052,3 & & 3,9 & & 27,6 & \\
\hline $29-\mathrm{A}$ & 168,1 & & 21,4 & & 17,6 & & 1089,4 & & 4,0 & & 27,6 & \\
\hline $29-\mathrm{B}$ & 166,2 & $16 /, 2$ & 21,2 & 21,3 & 17,4 & $1 /, 3$ & 1089,9 & 1089,7 & 3,9 & 4,0 & 27,4 & 27,5 \\
\hline $31-\mathrm{A}$ & 169,3 & & 21,7 & & 17,7 & & 1015,3 & & 4,0 & & 28,4 & \\
\hline $31-\mathrm{B}$ & 172,3 & $1 / 0,8$ & 21,8 & 21,8 & 17,8 & $1 /, 8$ & 1044,1 & 1029,1 & 4,0 & 4,0 & 28,5 & 28,5 \\
\hline $33-\mathrm{A}$ & 162,7 & & 20,9 & & 16,5 & & 954,5 & & 3,8 & & 27,4 & \\
\hline $33-\mathrm{B}$ & 168,8 & 165,8 & 21,6 & 21,3 & 17,0 & 16,1 & 954,2 & 954,4 & 4,0 & 3,9 & 28,6 & 28,0 \\
\hline $35-\mathrm{A}$ & 169,5 & & 21,5 & & 16,8 & & 913,5 & & 4,0 & & 29,7 & \\
\hline $35-\mathrm{B}$ & 169,2 & 169,3 & 21,5 & 21,5 & 16,7 & 16,8 & 924,6 & 919,1 & 3,9 & 3,9 & 29,5 & 29,6 \\
\hline $37-\mathrm{A}$ & 171,0 & 1708 & 22,0 & 218 & 16,8 & 166 & 911,3 & & 4,1 & & 29,4 & \\
\hline $37-\mathrm{B}$ & 170,5 & $1 / 0,0$ & 21,6 & 21,0 & 16,4 & 10,0 & 910,7 & 911,0 & 3,9 & 4,0 & 28,6 & 29,0 \\
\hline
\end{tabular}




\section{ANEXO F - Datação com ${ }^{210} \mathrm{~Pb}$}

\begin{tabular}{|c|c|c|c|c|c|c|c|}
\hline \multicolumn{8}{|c|}{ Testemunho T-13 / modelo CF:CR } \\
\hline $\begin{array}{l}\text { Profundidade } \\
\text { média }(\mathrm{cm})\end{array}$ & $\begin{array}{c}\text { Massa } \\
\text { Acumulada } \\
\left(\mathrm{g} \mathrm{cm}^{-2}\right)\end{array}$ & $\begin{array}{l}{ }^{210} \mathrm{~Pb}_{\text {total }} \\
\left(\mathrm{mBq} \mathrm{g}^{-1}\right)\end{array}$ & erro & $\begin{array}{c}{ }^{210} \mathrm{~Pb}_{\mathrm{exc}} \\
\left(\mathrm{mBq} \mathrm{g}^{-1}\right)\end{array}$ & erro & Idade & erro \\
\hline 1 & 0,19 & 77,23 & 1,67 & 61,86 & 2,01 & 2016,8 & --- \\
\hline 3 & 0,60 & 73,40 & 1,58 & 58,02 & 1,93 & 2015,0 & 0,1 \\
\hline 5 & 1,13 & 67,26 & 1,60 & 51,88 & 1,95 & 2013,5 & 0,2 \\
\hline 7 & 1,74 & 63,61 & 1,56 & 48,23 & 1,92 & 2011,7 & 0,3 \\
\hline 9 & 2,39 & 55,23 & 1,55 & 39,85 & 1,91 & 2009,8 & 0,5 \\
\hline 11 & 3,09 & 55,23 & 1,51 & 39,85 & 1,88 & 2007,7 & 0,6 \\
\hline 13 & 3,91 & 54,67 & 1,45 & 39,29 & 1,83 & 2005,3 & 0,7 \\
\hline 15 & 4,73 & 50,97 & 1,55 & 35,59 & 1,91 & 2002,8 & 0,9 \\
\hline 17 & 5,57 & 48,16 & 1,45 & 32,78 & 1,83 & 2000,3 & 1,0 \\
\hline 19 & 6,44 & 47,23 & 1,41 & 31,85 & 1,80 & 1997,8 & 1,1 \\
\hline 21 & 7,30 & 45,88 & 1,35 & 30,50 & 1,75 & 1995,2 & 1,2 \\
\hline 23 & 8,19 & 43,72 & 1,35 & 28,34 & 1,76 & 1992,6 & 1,4 \\
\hline 25 & 9,13 & 31,23 & 1,26 & 15,85 & 1,68 & 1989,8 & 1,4 \\
\hline 27 & 10,17 & 32,57 & 5,13 & 17,19 & 5,25 & 1986,8 & 6,4 \\
\hline 29 & 11,22 & 40,40 & 5,36 & 25,02 & 5,48 & 1983,7 & 7,3 \\
\hline 31 & 12,31 & 31,44 & 1,33 & 16,06 & 1,73 & 1980,4 & 2,0 \\
\hline 33 & 13,58 & 32,65 & 1,40 & 17,27 & 1,79 & 1976,7 & 2,3 \\
\hline 35 & 14,94 & 29,88 & 1,27 & 14,50 & 1,69 & 1972,7 & 2,3 \\
\hline 37 & 16,36 & 29,82 & 1,29 & 14,44 & 1,71 & 1968,5 & 2,6 \\
\hline 39 & 18,03 & 20,98 & 1,12 & 5,60 & 1,58 & 1963,5 & 2,5 \\
\hline 41 & 19,69 & 15,38 & 1,12 & & & & \\
\hline
\end{tabular}




\begin{tabular}{|c|c|c|c|c|c|c|c|}
\hline \multicolumn{8}{|c|}{ Testemunho T-18 / modelo CF:CR } \\
\hline $\begin{array}{l}\text { Profundidade } \\
\text { média }(\mathrm{cm})\end{array}$ & $\begin{array}{c}\text { Massa } \\
\text { Acumulada } \\
\left(\mathrm{g} \mathrm{cm}^{-2}\right)\end{array}$ & $\begin{array}{l}{ }^{210} \mathrm{~Pb}_{\text {total }} \\
\left(\mathrm{mBq} \mathrm{g}^{-1}\right)\end{array}$ & erro & $\begin{array}{l}{ }^{210} \mathrm{~Pb}_{\mathrm{exc}} \\
\left(\mathrm{mBq} \mathrm{g}^{-1}\right)\end{array}$ & erro & Idade & erro \\
\hline 1 & 0,16 & 79,37 & 1,80 & 63,67 & 2,16 & 2016,8 & --- \\
\hline 3 & 0,59 & 79,14 & 1,70 & 63,44 & 2,08 & 2014,6 & 0,4 \\
\hline 5 & 1,15 & 73,14 & 1,68 & 57,44 & 2,06 & 2012,4 & 0,6 \\
\hline 7 & 1,87 & 65,13 & 1,61 & 49,43 & 2,00 & 2009,6 & 0,7 \\
\hline 9 & 2,73 & 57,13 & 1,78 & 41,43 & 2,15 & 2006,3 & 0,9 \\
\hline 11 & 3,61 & 58,23 & 1,75 & 42,54 & 2,12 & 2003,0 & 0,9 \\
\hline 13 & 4,44 & 56,44 & 1,59 & 40,74 & 1,99 & 1999,8 & 0,8 \\
\hline 15 & 5,31 & 44,71 & 1,52 & 29,02 & 1,93 & 1996,5 & 0,8 \\
\hline 17 & 6,26 & 42,30 & 1,39 & 26,60 & 1,83 & 1992,8 & 0,9 \\
\hline 19 & 7,27 & 33,82 & 1,32 & 18,12 & 1,78 & 1989,0 & 0,9 \\
\hline 21 & 8,32 & 35,81 & 1,36 & 20,11 & 1,81 & 1984,9 & 0,9 \\
\hline 23 & 9,45 & 30,72 & 1,29 & 15,02 & 1,76 & 1980,6 & 1,0 \\
\hline 25 & 10,70 & 28,45 & 1,29 & 12,75 & 1,76 & 1975,9 & 1,1 \\
\hline 27 & 11,91 & 29,45 & 5,13 & 13,75 & 5,27 & 1971,2 & 3,1 \\
\hline 29 & 13,13 & 32,34 & 5,36 & 16,64 & 5,49 & 1966,6 & 3,3 \\
\hline 31 & 14,40 & 31,38 & 1,26 & 15,68 & 1,74 & 1961,7 & 1,1 \\
\hline 33 & 15,76 & 23,58 & 1,26 & 7,88 & 1,74 & 1956,5 & 1,2 \\
\hline 35 & 17,26 & 23,47 & 1,24 & 7,77 & 1,73 & 1950,8 & 1,3 \\
\hline 37 & 18,98 & 19,54 & 1,16 & 3,84 & 1,67 & 1944,2 & 1,4 \\
\hline 39 & 20,76 & 27,02 & 1,19 & 11,32 & 1,69 & 1937,4 & 1,5 \\
\hline 41 & 22,55 & 22,03 & 1,18 & 6,33 & 1,68 & 1930,5 & 1,5 \\
\hline 43 & 24,42 & 23,49 & 1,18 & 7,79 & 1,68 & 1923,4 & 1,5 \\
\hline 45 & 26,31 & 22,09 & 1,32 & 6,39 & 1,78 & 1916,1 & 1,7 \\
\hline 47 & 28,27 & 22,82 & 1,29 & 7,12 & 1,76 & 1908,6 & 1,7 \\
\hline 49 & 30,29 & 23,35 & 1,18 & 7,65 & 1,68 & 1900,9 & 1,7 \\
\hline 51 & 32,21 & 18,17 & 1,22 & 2,48 & 1,71 & 1893,5 & 1,6 \\
\hline 53 & 33,76 & 15,70 & 1,20 & & & & \\
\hline
\end{tabular}




\begin{tabular}{|c|c|c|c|c|c|c|c|}
\hline \multicolumn{8}{|c|}{ Testemunho T-19 / modelo CF:CR } \\
\hline $\begin{array}{l}\text { Profundidade } \\
\text { média }(\mathrm{cm})\end{array}$ & $\begin{array}{c}\text { Massa } \\
\text { Acumulada } \\
\left(\mathrm{g} \mathrm{cm}^{-2}\right)\end{array}$ & $\begin{array}{l}{ }^{210} \mathrm{~Pb}_{\text {total }} \\
\left(\mathrm{mBq} \mathrm{g}^{-1}\right)\end{array}$ & erro & $\begin{array}{l}{ }^{210} \mathrm{~Pb}_{\mathrm{exc}} \\
\left(\mathrm{mBq} \mathrm{g}^{-1}\right)\end{array}$ & erro & Idade & erro \\
\hline 1 & 0,16 & 90,88 & 1,80 & 75,68 & 2,16 & 2016,8 & --- \\
\hline 3 & 0,53 & 91,12 & 1,77 & 75,92 & 2,13 & 2015,1 & 0,1 \\
\hline 5 & 0,96 & 87,81 & 1,77 & 72,61 & 2,14 & 2013,7 & 0,4 \\
\hline 7 & 1,43 & 81,77 & 1,71 & 66,57 & 2,09 & 2012,2 & 0,6 \\
\hline 9 & 1,97 & 78,92 & 1,74 & 63,72 & 2,11 & 2010,5 & 0,8 \\
\hline 11 & 2,54 & 81,00 & 1,78 & 65,80 & 2,15 & 2008,6 & 1,0 \\
\hline 13 & 3,11 & 89,84 & 1,76 & 74,64 & 2,13 & 2006,8 & 1,2 \\
\hline 15 & 3,68 & 78,29 & 1,73 & 63,09 & 2,11 & 2005,0 & 1,4 \\
\hline 17 & 4,27 & 76,40 & 1,67 & 61,20 & 2,06 & 2003,1 & 1,7 \\
\hline 19 & 4,86 & 81,61 & 1,72 & 66,41 & 2,10 & 2001,2 & 1,9 \\
\hline 21 & 5,44 & 93,89 & 1,72 & --- & 2,10 & 1999,3 & 2,1 \\
\hline 23 & 6,05 & 69,82 & 1,60 & 54,62 & 2,00 & 1997,3 & 2,4 \\
\hline 25 & 6,67 & 72,89 & 1,71 & 57,69 & 2,09 & 1995,4 & 2,6 \\
\hline 27 & 7,26 & 62,12 & 5,13 & 46,92 & 5,27 & 1993,4 & 2,8 \\
\hline 29 & 7,86 & 54,74 & 5,36 & 39,54 & 5,49 & 1991,5 & 3,1 \\
\hline 31 & 8,49 & 50,39 & 1,47 & 35,19 & 1,90 & 1989,5 & 3,3 \\
\hline 33 & 9,18 & 40,75 & 1,48 & 25,55 & 1,90 & 1987,3 & 3,6 \\
\hline 35 & 9,98 & 37,98 & 1,43 & 22,78 & 1,86 & 1984,7 & 3,9 \\
\hline 37 & 10,91 & 29,68 & 1,26 & 14,48 & 1,74 & 1981,7 & 4,3 \\
\hline 39 & 11,92 & 47,33 & 1,39 & 32,13 & 1,84 & 1978,5 & 4,6 \\
\hline 41 & 12,96 & 43,44 & 1,59 & 28,24 & 1,99 & 1975,1 & 5,0 \\
\hline 43 & 13,99 & 38,90 & 1,47 & 23,70 & 1,90 & 1971,8 & 5,4 \\
\hline 45 & 14,99 & 35,07 & 1,50 & 19,87 & 1,92 & 1968,6 & 5,8 \\
\hline 47 & 16,05 & 36,91 & 1,62 & 21,71 & 2,02 & 1965,2 & 6,3 \\
\hline 49 & 17,14 & 36,08 & 1,45 & 20,88 & 1,88 & 1961,7 & 6,7 \\
\hline 51 & 18,31 & 20,06 & 1,22 & 4,86 & 1,71 & 1957,9 & 7,1 \\
\hline 53 & 19,54 & 27,54 & 1,30 & 12,34 & 1,77 & 1953,9 & 7,6 \\
\hline 55 & 20,88 & 23,69 & 1,34 & 8,49 & 1,80 & 1949,6 & 8,1 \\
\hline 57 & 22,28 & --- & --- & --- & --- & 1945,1 & 8,7 \\
\hline 59 & 23,51 & 28,67 & 1,28 & 13,47 & 1,75 & 1941,2 & 9,2 \\
\hline
\end{tabular}




\begin{tabular}{|c|c|c|c|c|c|c|c|}
\hline \multicolumn{8}{|c|}{ Testemunho T-28 / modelo CF:CR } \\
\hline $\begin{array}{l}\text { Profundidade } \\
\text { média }(\mathrm{cm})\end{array}$ & $\begin{array}{c}\text { Massa } \\
\text { Acumulada } \\
\left(\mathrm{g} \mathrm{cm}^{-2}\right)\end{array}$ & $\begin{array}{l}{ }^{210} \mathrm{~Pb}_{\text {total }} \\
\left(\mathrm{mBq} \mathrm{g}^{-1}\right)\end{array}$ & erro & $\begin{array}{l}{ }^{210} \mathrm{~Pb}_{\text {exc }} \\
\left(\mathrm{mBq} \mathrm{g}^{-1}\right)\end{array}$ & erro & Idade & erro \\
\hline 1 & 0,15 & 90,31 & 1,83 & 74,91 & 2,15 & 2016,8 & --- \\
\hline 3 & 0,45 & 92,21 & 1,85 & 76,81 & 2,16 & 2015,2 & 0,3 \\
\hline 5 & 0,79 & 91,71 & 1,84 & 76,31 & 2,15 & 2013,9 & 0,4 \\
\hline 7 & 1,17 & 79,07 & 1,69 & 63,67 & 2,03 & 2012,5 & 0,4 \\
\hline 9 & 1,59 & 82,08 & 1,82 & 66,68 & 2,14 & 2011,0 & 0,5 \\
\hline 11 & 2,05 & 89,06 & 1,87 & 73,66 & 2,18 & 2009,3 & 0,5 \\
\hline 13 & 2,55 & 80,40 & 1,71 & 65,00 & 2,04 & 2007,4 & 0,5 \\
\hline 15 & 3,06 & 68,31 & 1,56 & 52,91 & 1,92 & 2005,6 & 0,5 \\
\hline 17 & 3,58 & 79,24 & 1,81 & 63,84 & 2,13 & 2003,7 & 0,6 \\
\hline 19 & 4,11 & 72,25 & 1,72 & 56,85 & 2,06 & 2001,7 & 0,5 \\
\hline 21 & 4,64 & 64,24 & 1,65 & 48,84 & 2,00 & 1999,8 & 0,5 \\
\hline 23 & 5,19 & 53,46 & 1,43 & 38,06 & 1,82 & 1997,8 & 0,5 \\
\hline 25 & 5,75 & 43,04 & 1,42 & 27,64 & 1,81 & 1995,7 & 0,5 \\
\hline 27 & 6,35 & 54,64 & 1,54 & 39,24 & 1,91 & 1993,6 & 0,6 \\
\hline 29 & 6,96 & 45,45 & 1,38 & 30,05 & 1,78 & 1991,3 & 0,5 \\
\hline 31 & 7,57 & 50,99 & 1,54 & 35,59 & 1,90 & 1989,1 & 0,6 \\
\hline 33 & 8,22 & 42,23 & 1,53 & 26,83 & 1,90 & 1986,7 & 0,6 \\
\hline 35 & 8,98 & 41,39 & 1,37 & 25,99 & 1,77 & 1983,9 & 0,7 \\
\hline 37 & 9,75 & 33,55 & 1,28 & 18,15 & 1,70 & 1981,1 & 0,7 \\
\hline 39 & 10,51 & 36,29 & 1,42 & 20,89 & 1,81 & 1978,3 & 0,7 \\
\hline 41 & 11,30 & 29,72 & 1,39 & 14,32 & 1,79 & 1975,4 & 0,7 \\
\hline 43 & 12,08 & 35,02 & 1,29 & 19,62 & 1,72 & 1972,5 & 0,7 \\
\hline 45 & 12,87 & 35,45 & 1,36 & 20,05 & 1,77 & 1969,6 & 0,7 \\
\hline 47 & 13,64 & 36,89 & 1,40 & 21,49 & 1,79 & 1966,8 & 0,7 \\
\hline 49 & 14,40 & 33,35 & 1,34 & 17,95 & 1,75 & 1964,0 & 0,7 \\
\hline 51 & 15,23 & 28,33 & 1,21 & 12,93 & 1,65 & 1961,0 & 0,7 \\
\hline 53 & 16,11 & 27,12 & 1,32 & 11,72 & 1,73 & 1957,8 & 0,8 \\
\hline 55 & 17,11 & 31,77 & 1,48 & 16,37 & 1,86 & 1954,1 & 0,9 \\
\hline 57 & 18,19 & 25,07 & 1,25 & 9,67 & 1,69 & 1950,2 & 0,9 \\
\hline 59 & 19,26 & 23,17 & 1,28 & 7,77 & 1,71 & 1946,2 & 0,9 \\
\hline 61 & 20,39 & 23,08 & 1,25 & 7,68 & 1,68 & 1942,1 & 1,0 \\
\hline
\end{tabular}




\begin{tabular}{|c|c|c|c|c|c|c|c|c|c|c|}
\hline \multicolumn{11}{|c|}{ Testemunho T-26 / modelo CRS } \\
\hline $\begin{array}{l}\text { Profundidade } \\
\text { média }(\mathrm{cm})\end{array}$ & $\begin{array}{l}\text { Massa } \\
\left(\mathrm{g} \mathrm{cm}^{-2}\right)\end{array}$ & $\begin{array}{l}{ }^{210} \mathrm{~Pb}_{\text {total }} \\
\left(\mathrm{mBq} \mathrm{g}^{-1}\right)\end{array}$ & erro & $\begin{array}{l}{ }^{210} \mathrm{~Pb}_{\mathrm{exc}} \\
\left(\mathrm{mBq} \mathrm{g}^{-1}\right)\end{array}$ & erro & $\begin{array}{c}\text { Fluxo }{ }^{210} \mathrm{~Pb} \\
\left(\mathrm{mBq} \mathrm{cm}{ }^{-2} \mathrm{ano}^{-1}\right)\end{array}$ & $\begin{array}{l}\text { Inventário } \\
{ }^{210} \mathrm{~Pb} \\
\left(\mathrm{mBq} \mathrm{g}^{-1}\right)\end{array}$ & $\begin{array}{l}\text { Idade } \\
\text { (ano) }\end{array}$ & Data & erro \\
\hline 1 & 0,29 & 78,86 & 2,76 & 63,16 & 3,01 & 18,48 & 528,25 & 0,00 & 2016,8 & --- \\
\hline 3 & 0,33 & 83,10 & 1,87 & 67,40 & 2,22 & 22,27 & 509,76 & $-1,15$ & 2015,7 & 2,1 \\
\hline 5 & 0,43 & 83,03 & 1,67 & 67,33 & 2,05 & 28,72 & 487,49 & $-2,58$ & 2014,2 & 2,0 \\
\hline 7 & 0,39 & 77,15 & 1,68 & 61,45 & 2,06 & 23,91 & 458,77 & $-4,53$ & 2012,3 & 1,6 \\
\hline 9 & 0,44 & 74,08 & 1,71 & 58,38 & 2,09 & 25,67 & 434,86 & $-6,26$ & 2010,5 & 1,7 \\
\hline 11 & 0,51 & 78,72 & 1,69 & 63,02 & 2,08 & 31,96 & 409,19 & $-8,21$ & 2008,6 & 1,8 \\
\hline 13 & 0,54 & 66,54 & 1,53 & 50,84 & 1,95 & 27,29 & 377,23 & $-10,83$ & 2006,0 & 1,8 \\
\hline 15 & 0,42 & 63,38 & 1,50 & 47,68 & 1,92 & 20,10 & 349,94 & $-13,24$ & 2003,6 & 1,6 \\
\hline 17 & 0,54 & 67,17 & 1,52 & 51,47 & 1,94 & 27,87 & 329,84 & $-15,14$ & 2001,7 & 1,6 \\
\hline 19 & 0,54 & 59,71 & 1,49 & 44,01 & 1,91 & 23,63 & 301,97 & $-17,98$ & 1998,8 & 1,6 \\
\hline 21 & 0,72 & 40,88 & 1,30 & 25,18 & 1,77 & 18,15 & 278,34 & $-20,60$ & 1996,2 & 1,4 \\
\hline 23 & 0,65 & 34,26 & 1,32 & 18,56 & 1,78 & 12,12 & 260,20 & $-22,77$ & 1994,0 & 1,4 \\
\hline 25 & 0,74 & 35,53 & 1,33 & 19,83 & 1,79 & 14,68 & 248,08 & $-24,30$ & 1992,5 & 1,6 \\
\hline 27 & 0,69 & 36,12 & 5,13 & 20,42 & 5,27 & 14,00 & 233,40 & $-26,26$ & 1990,5 & 5,0 \\
\hline 29 & 0,72 & 31,27 & 5,36 & 15,57 & 5,49 & 11,22 & 219,40 & $-28,25$ & 1988,5 & 5,3 \\
\hline 31 & 0,70 & 33,41 & 1,32 & 17,71 & 1,78 & 12,31 & 208,18 & $-29,94$ & 1986,9 & 1,5 \\
\hline 33 & 0,70 & 44,39 & 1,47 & 28,69 & 1,90 & 20,18 & 195,86 & $-31,90$ & 1984,9 & 1,5 \\
\hline 35 & 0,86 & 57,15 & 1,53 & 41,50 & 1,94 & 35,56 & 175,69 & $-35,40$ & 1981,4 & 1,6 \\
\hline 37 & 0,95 & 33,92 & 1,31 & 18,22 & 1,77 & 17,25 & 140,12 & $-42,67$ & 1974,1 & 1,4 \\
\hline 39 & 0,98 & 43,33 & 1,43 & 27,63 & 1,87 & 27,18 & 122,88 & $-46,89$ & 1969,9 & 1,6 \\
\hline 41 & 1,07 & 40,23 & 1,41 & 24,53 & 1,85 & 26,23 & 95,69 & $-54,93$ & 1961,9 & 1,6 \\
\hline
\end{tabular}




\begin{tabular}{|c|c|c|c|c|c|c|c|c|c|c|}
\hline \multicolumn{11}{|c|}{ Testemunho T-26 / modelo CRS } \\
\hline $\begin{array}{l}\text { Profundidade } \\
\text { média }(\mathrm{cm})\end{array}$ & $\begin{array}{l}\text { Massa } \\
\left(\mathrm{g} \mathrm{cm}^{-2}\right)\end{array}$ & $\begin{array}{l}{ }^{210} \mathrm{~Pb}_{\text {total }} \\
\left(\mathrm{mBq} \mathrm{g}^{-1}\right)\end{array}$ & erro & $\begin{array}{l}{ }^{210} \mathrm{~Pb}_{\text {exc }} \\
\left(\mathrm{mBq} \mathrm{g}^{-1}\right)\end{array}$ & erro & $\begin{array}{c}\text { Fluxo }{ }^{210} \mathrm{~Pb} \\
\left(\mathrm{mBq} \mathrm{cm}{ }^{-2} \mathrm{ano}^{-1}\right)\end{array}$ & $\begin{array}{l}\text { Inventário } \\
{ }^{210} \mathrm{~Pb} \\
\left(\mathrm{mBq} \mathrm{g}^{-1}\right)\end{array}$ & $\begin{array}{l}\text { Idade } \\
\text { (ano) }\end{array}$ & Data & erro \\
\hline 43 & 0,90 & 31,26 & 1,30 & 15,56 & 1,77 & 14,05 & 69,47 & $-65,23$ & 1951,6 & 1,3 \\
\hline 45 & 1,02 & 26,19 & 1,64 & 10,49 & 2,03 & 10,72 & 55,41 & $-72,50$ & 1944,3 & 1,7 \\
\hline 47 & 1,01 & 21,12 & 1,23 & 5,42 & 1,72 & 5,46 & 44,69 & $-79,41$ & 1937,4 & 1,3 \\
\hline 49 & 1,07 & 22,05 & 1,33 & 6,35 & 1,72 & 6,79 & 39,23 & $-83,60$ & 1933,2 & 0,8 \\
\hline 51 & 0,95 & 22,98 & 1,20 & 7,28 & 1,70 & 6,93 & 32,44 & $-89,71$ & 1927,1 & 1,6 \\
\hline 53 & 1,05 & 23,02 & 1,21 & 7,32 & 1,76 & 7,68 & 25,51 & $-97,44$ & 1919,4 & 0,9 \\
\hline 55 & 1,20 & 23,06 & 1,24 & 7,36 & 1,72 & 8,83 & 17,84 & $-108,95$ & 1907,8 & 1,3 \\
\hline
\end{tabular}




\section{ANEXO G - Perfis Sedimentares}
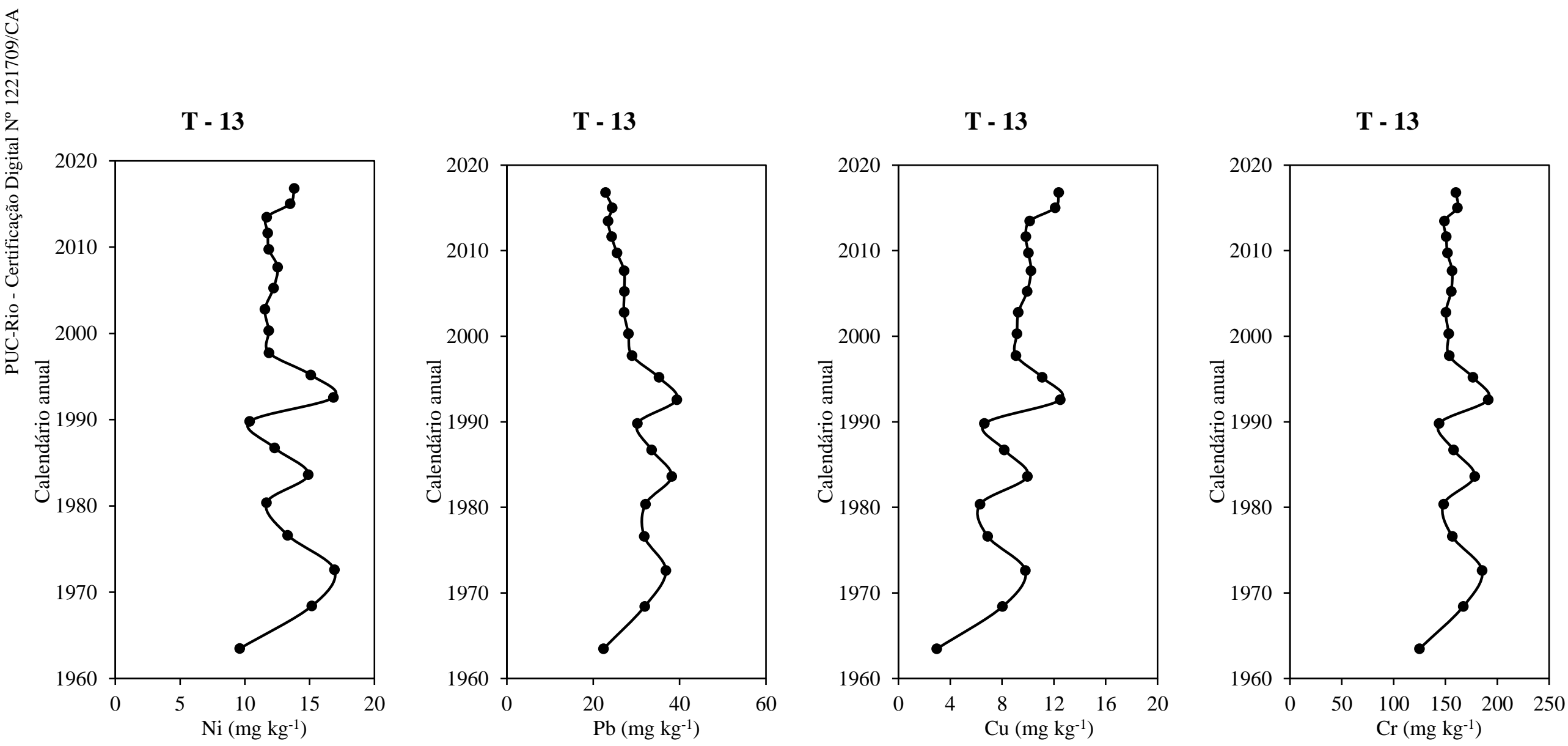

Figura 48: Idade versus concentração de níquel, chumbo, cobre e cromo, testemunho T-13 

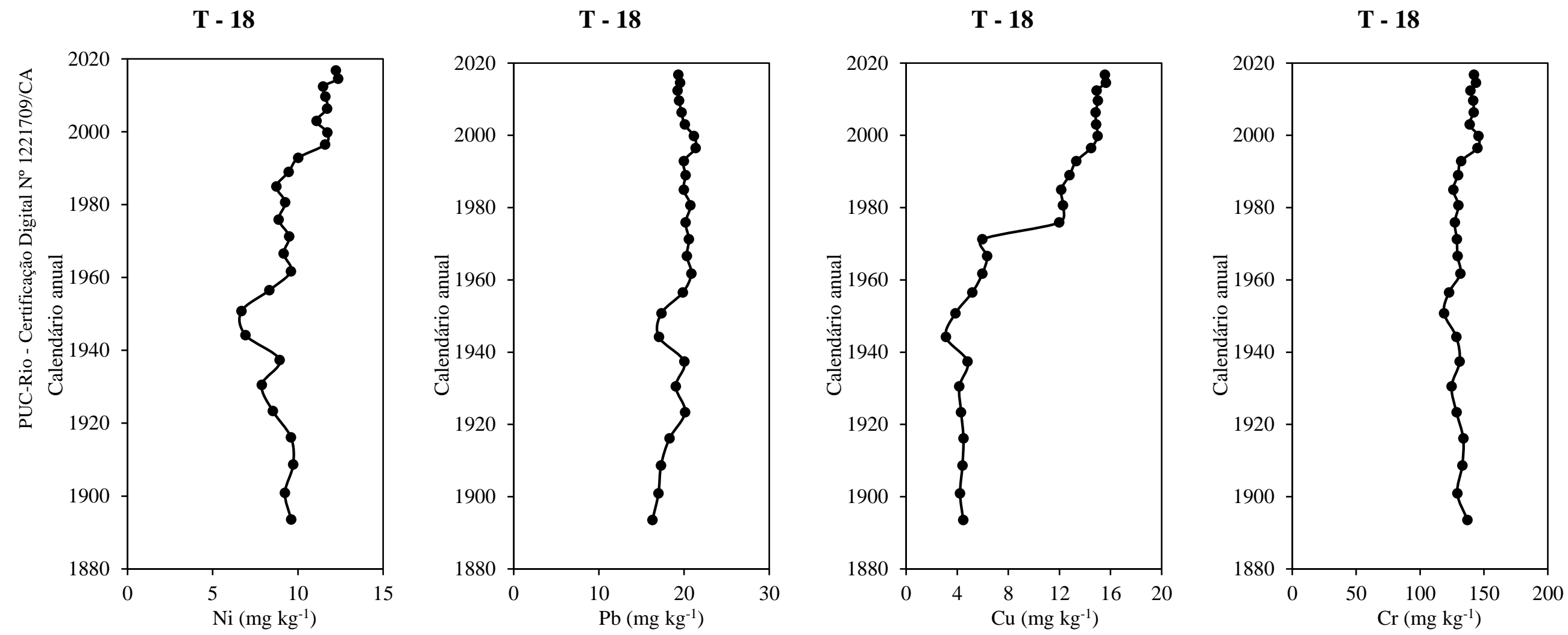

Figura 49: Idade versus concentração de níquel, chumbo, cobre e cromo, testemunho T-18 

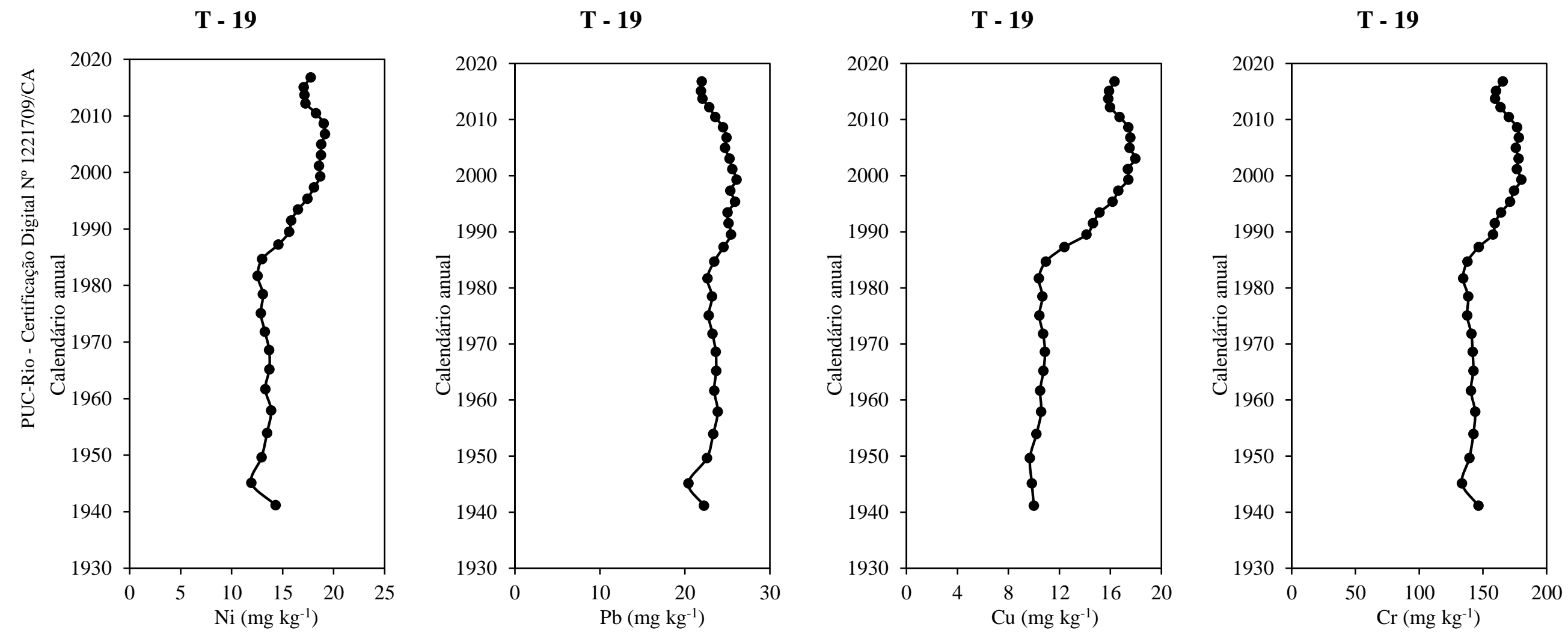

Figura 50: Idade versus concentração de níquel, chumbo, cobre e cromo, testemunho T-19 

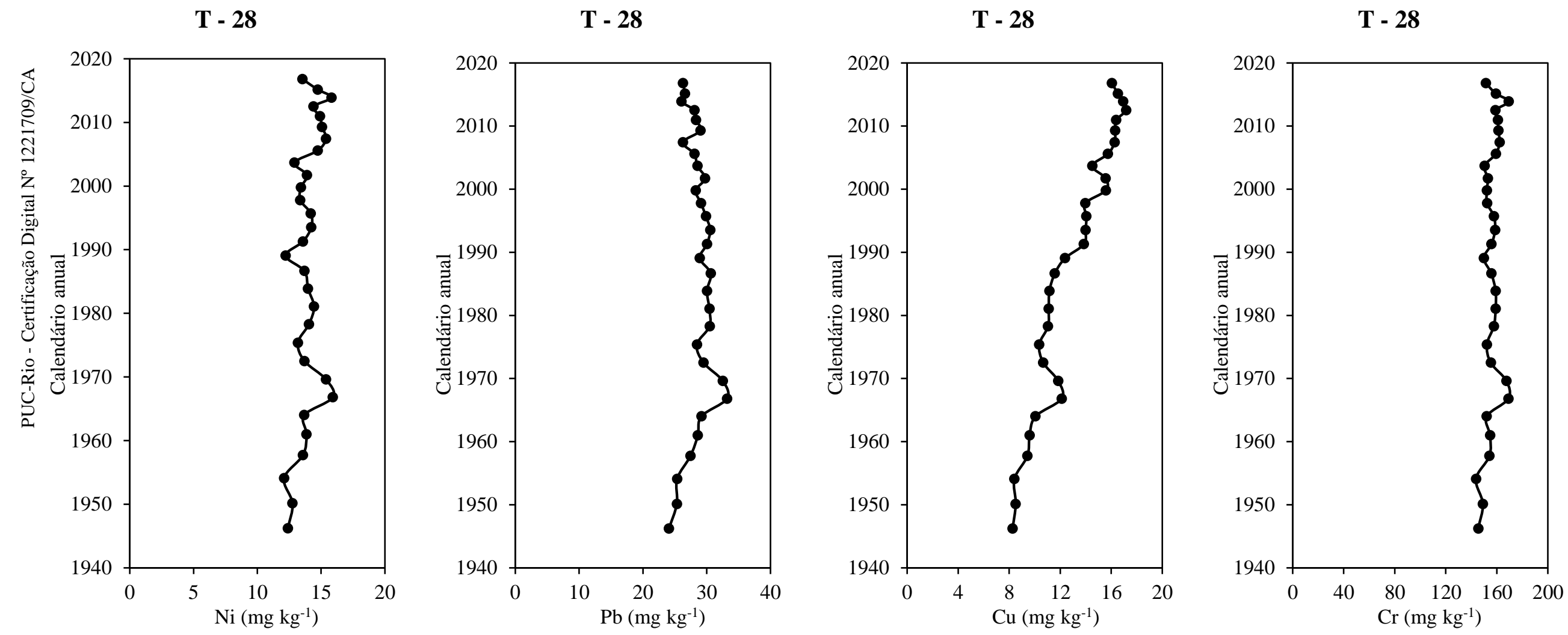

Figura 51 Idade versus concentração de níquel, chumbo, cobre e cromo, testemunho T-28 

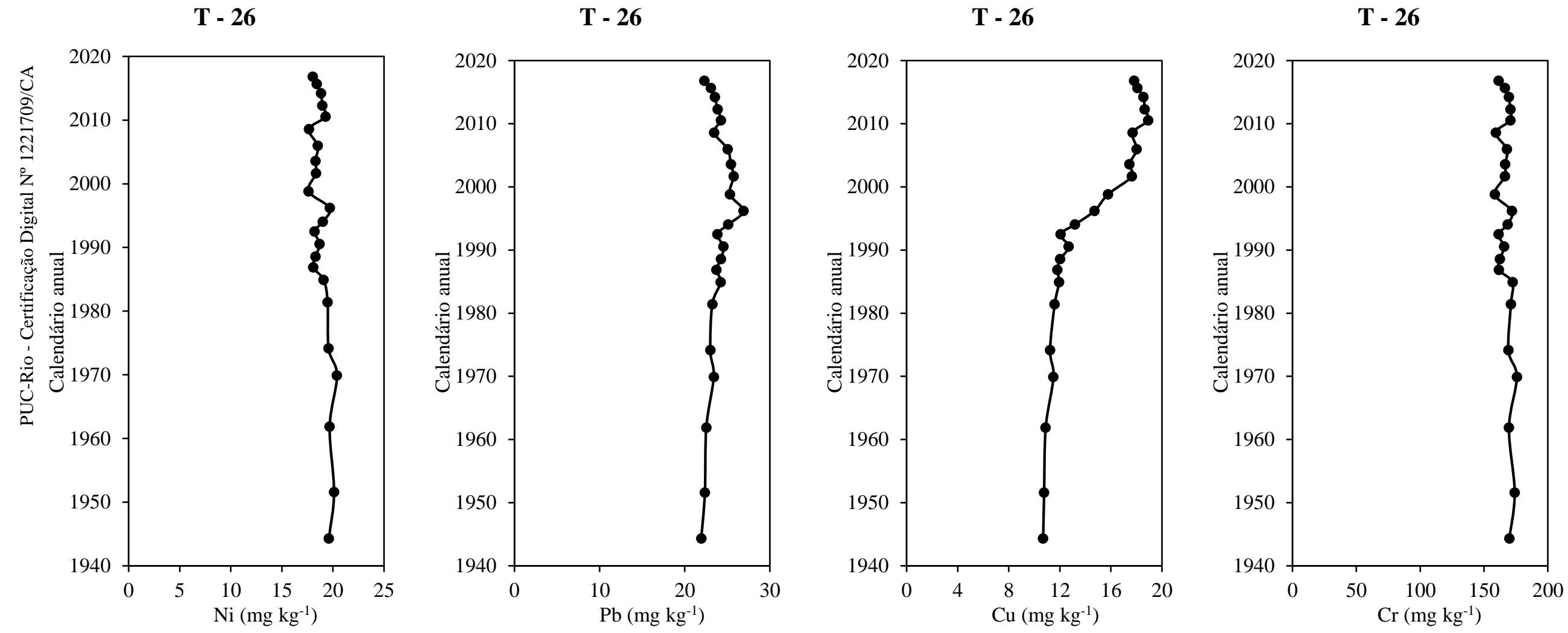

Figura 52: Idade versus concentração de níquel, chumbo e cromo, testemunho T-26 